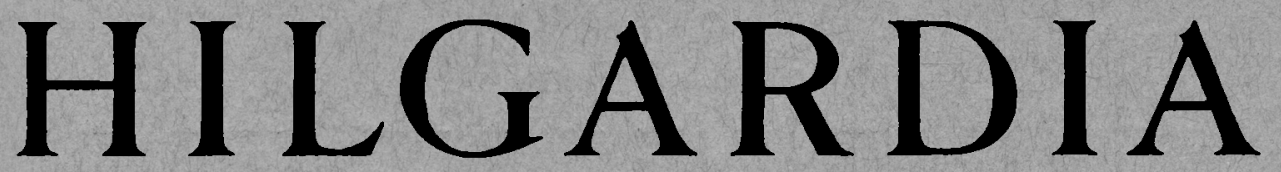

A Journal of Agricultural Science Published by the California Agricultural Experiment Station

\title{
ECONOMIC EFFICIENCY IN PLANT OPERATIONS WITH SPECIAL REFERENCE TO THE MARKETING OF CALIFORNIA PEARS
}

\author{
B. C. FRENCH, L. L. SAMMET, \\ and R. G. BRESSLER
}

UNIVERSITY OF CALIFORNIA - BERKELEY, CALIFORNIA 


\section{CONTENTS}

Foreword

I. Introduction

II. Theoretical framework

The nature of plant operations.

Needed modifications 548

The theory of the individual firm-reformulated 557

III. A methodological approach to cost measurement 579

Labor 580

Materials 588

Other operating inputs 589

Durable goods 591

Aggregation and integration. 591

IV. Production efficiency in pear packing. 592

The sample of packing plants. 593

Pear packing operations 594

Performance and cost standards. 599

Stage technologies and component cost standards. 602

The long-run cost function. 660

V. Summary and conclusions. 704

Major findings with respect to pear packing 705

Theoretical and methodological approach ................. 707

Acknowledgments 709

Bibliography 710

Appendix A 713 


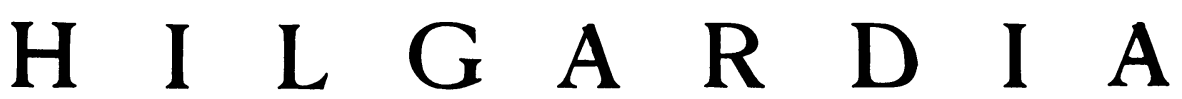 \\ A Journal of Agricultural Science Published by \\ the California Agricultural Experiment Station
}

VOL. 24

JULY, 1956

No. 19

\section{ECONOMIC EFFICIENCY IN PLANT OPERATIONS WITH SPECIAL REFERENCE TO THE MARKETING OF CALIFORNIA PEARS}

\author{
B. C. FRENCH, ${ }^{2}$ L. L. SAMMET, ${ }^{3}$ and R. G. BRESSLER ${ }^{4}$
}

\section{FOREWORD}

For some years the California Agricultural Experiment Station and the United States Department of Agriculture have been coöperating on a series of studies of marketing cost and efficiency for deciduous fruits. These studies have had two major objectives: (1) the development of appropriate and effective research approaches to problems of plant operation and organization, making use of a combination of techniques from the fields of economics, accounting, and engineering; and (2) the application of these techniques to specific problems in the handling and marketing of deciduous fruits in California.

The present publication is the first comprehensive technical research report on this work. It is concerned with the development of the appropriate theoretical framework for studies of plant costs and efficiency and with the research methods used in the empirical approach to these theoretical relationships. It then applies these methods to an analysis of the major functions or stages in fresh pear packing houses. Finally, stage relationships are synthesized into descriptions of short- and long-run cost functions under efficient operating conditions. Much of the material on stage relationships has been published as a series of Giannini Foundation mimeograph reports and as popularized research digests in California Agriculture. These functions were used to determine optimum combinations of plant technologies and to synthesize plant cost and economies of scale functions in a thesis entitled "Economic Efficiency in California Pear Packing Plants," submitted by the senior author to the Graduate Division, University of California, in 1953. This thesis also brought together and developed the appropriate theoretical and empirical methodology. The present publication is largely a revision and elaboration of the thesis study.

\footnotetext{
${ }^{1}$ Received for publication June 10, 1955.

${ }^{2}$ Formerly Coöperative Agent of the Agricultural Marketing Service, U. S. Department of Agriculture, and the Experiment Station, University of California, Berkeley, now Assistant Professor of Agricultural Economies, Michigan State University.

${ }^{3}$ Coöperative Agent of the Agricultural Marketing Service, U. S. Department of Agriculture and the Experiment Station, and Specialist in the Experiment Station, University of California, Berkeley.

4 Professor of Agricultural Economics and Director of the Giannini Foundation of Agricultural Economics.
} 


\section{INTRODUCTION}

A casual survey of plants producing almost any type of marketing service is likely to reveal a wide variation in both the scale and methods of operation. California pear packing plants, for example, presently use at least five different methods to dump orchard-run fruit on conveyors to the graders and packers, several types and sizes of grading tables, at least three types of packing equipment, four or five methods of transporting fruit within the packing house, and so on. The hourly capacities of the largest pear plants are approximately five times as great as for the smallest plants. Similar variations in technologies and size may be observed in other fruit packing plants and in plants performing other types of marketing services as well.

Many of these plants are using technologies and are of a size quite efficient for the particular conditions under which the firm must operate. Others are operating with considerably less than the efficiency that would be possible. This is due in part to unforeseen changes and innovations. Unless radical cost reductions are involved, new technologies tend to be adopted slowly as old equipment wears out since the investment cost has already been incurred. Perhaps equally or even more important in accounting for variations in efficiency, however, is lack of information. Individual plant managers normally cannot be aware of the cost relations for each alternative technology that might be used to perform a given operation or of the costs associated with plants of many different sizes. In fact, some managers may not know about some of the more newly available technologies.

This paper is concerned primarily with theoretical-analytical aspects of studies aimed at supplying managers with more complete information of this type. The specific objectives are: (1) to examine and to develop further a general theoretical framework for cost and efficiency research; (2) to describe a methodological approach to these studies; and (3) to illustrate the application of this theory and methodology in an investigation of the operations of. California pear packing plants. On a fundamental level, the analysis should contribute to the general body of economic theory of production and so be of value in future research in cost and efficiency. On an applied level, the study of pear packing operations provides material that should be useful to plant managers in formulating decisions on technologies and scale of operations that may be most efficient for the specific operating conditions with which they are faced.

\section{THEORETICAL FRAMEWORK}

The theoretical framework for studies of cost and efficiency is based on elaborations and modifications of the conventional economic theory of production. ${ }^{5}$ The kinds of elaborations that may be needed are suggested by an examination of the way plants-particularly plants producing marketing

${ }^{5}$ By conventional theory we mean the treatment found in such books as Sune Carlson, A Study on the Pure Theory of Production (London: P. S. King and Son, Ltd., 1939); P. A. Samuelson, Foundations of Economic Analysis (Cambridge: Harvard University Press, 1947) ; K. E. Boulding, Economic Analysis (New York: Harper and Bros., 1948); and E. Schneider, Pricing and Equilibrium (New York: The Macmillan Company, 1951). 
services-actually operate. Incorporation of modifications in the conventional theory then provides a more workable base for studies of cost and efficiency.

\section{The Nature of Plant Operations}

Activity within plants usually consists of an integration and aggregation of many different operating stages. The technical definition of a stage is a matter of both convenience and logic, depending on the importance of the elemental operations and the way in which they fit in with the flow of products and materials. Brems ${ }^{6}$ defines a stage as the aggregate of all units of a single durable factor employed by a plant (with or without nondurable factors coöperating with it). A somewhat broader definition might include several different but closely coöperating types of durable factors within a single stage and would also take account of the fact that some stages might consist entirely of variable factors. Thus, a stage consists of all productive services-durable or nondurable-that coöperate in performing a single operation or a group of minor but closely related operations.

The meaning of the term "stage" may be made clear by the accompanying hypothetical and highly simplified plant process flow diagram (fig. 1). The diagram indicates that the production process begins with the receipt of some basic material, either in raw or partially processed form. This is the first stage in the plant operations. The material is then transported to a second stage where its form is in some way transformed. It then moves to another stage where another transformation occurs. In the example, a byproduct is removed at this point and flows in another direction where it may also receive additional treatment at successive stages. At various points other materials are received, then transformed in various stages, and finally are fed into the main line of flow, where they are combined with other partially completed products. Various of the partially completed products may be "split off" at different stages and given different treatments through a new series of stages so that finally several types of completed products emerge from the production lines. The specific patterns of flow will, of course, vary with different products and different plants but figure 1 is indicative of their general nature.

Note that the various stages are connected by transportation links. Transportation may be conveniently classified into two types-within stage and between stage transportation. Within-stage transportation may be considered as part of the operations of the stage itself. Between-stage transportation is, in a sense, a stage itself in which the only operations performed are to move the product from one place to another.

The diagram also shows a frequent occurrence of temporary storage between the various stages. These operations play an important part in coordinating and leveling out the flow of materials and products through the plant. For example, materials may be received at irregular intervals, but a fairly continuous flow through the plant is maintained by feeding

"Hans Brems, "A Discontinuous Cost Function," American Economic Review, vol. 42, September, 1952, p. 577. Material for this article is drawn in large part from the work of Ivar Jantzen, "Voxende Udbytte i Industrien," Nationalokonomisk Tidsskrift (1924). An English translation appeared in Principles of Business Planning and National Calculations, published by Jantzen in 1939. 


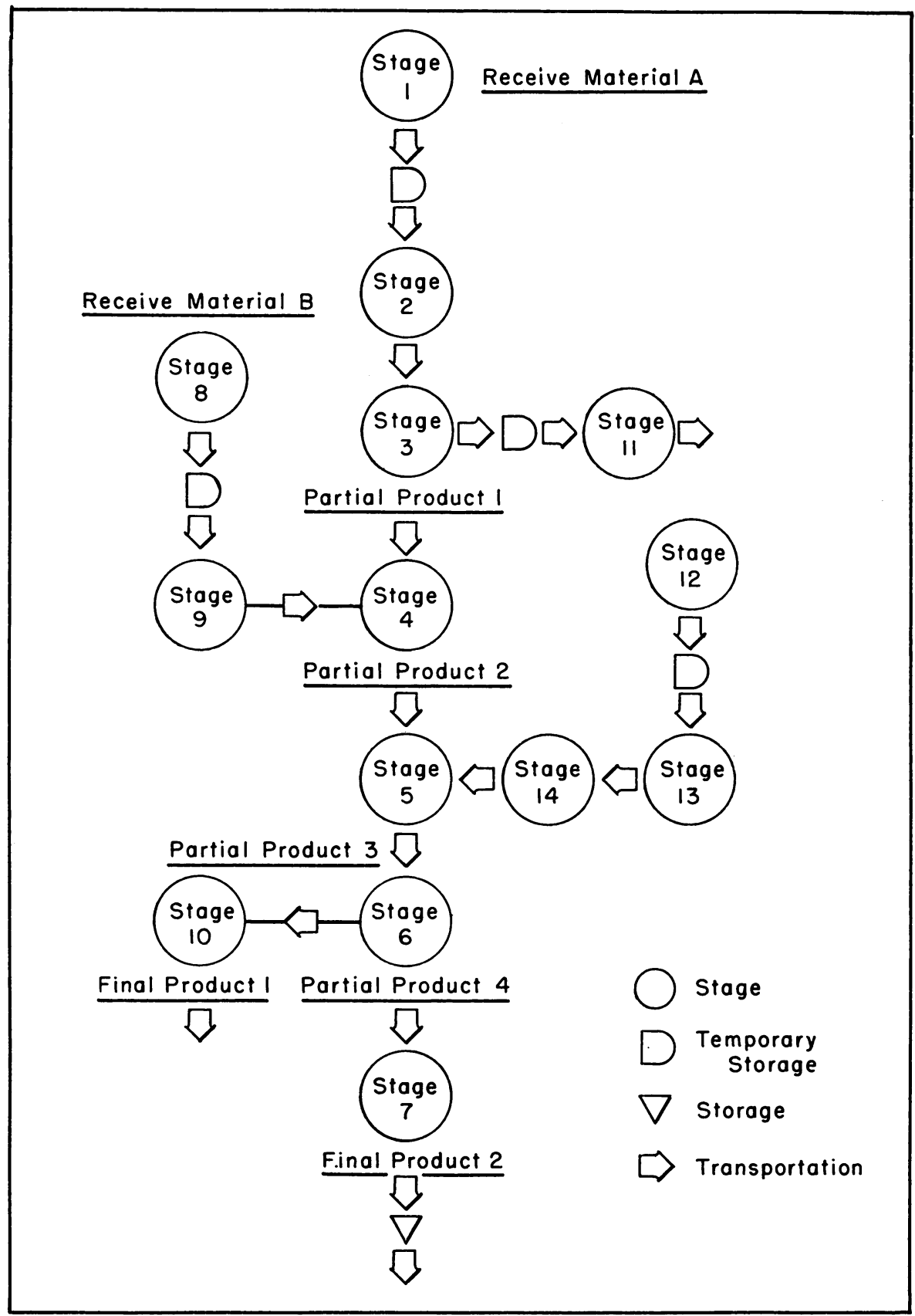

Fig. 1. Hypothetical plant process flow diagram. 
into and withdrawing from temporary storage. Storage plays a similar role in other parts of the plant. It compensates in large measure for irregularities in rates of worker activity and is a key factor in permitting workers to perform two or more different operations. And with discontinuous or batch-type production, storage underlies the entire process from the beginning to the end of the "production period."

In most instances the inputs at each stage are related to the flow of a single physical volume variable. Inputs at stages 1 and 2 , for example, would be related to the volume of material $\mathrm{A}$, or at stage 4 to the volume of partial product 1 , and so on. As the various stages become more directly connected, i.e., as between-stage transportation and the opportunities for temporary storage are reduced, the flow of these materials and partial products becomes highly integrated. Unless rates of output at all stages can be varied simultaneously the impact of such integration is to lessen the possible range of rate variation at any particular stage. In the extreme, this may reduce to virtually a single rate or perhaps several discrete rates.

The technical requirements of certain processes further limit rate variation in given plants. For example, technical and legal requirements set very narrow limits to rates for such operations as sterilizing, pasteurizing, cooking, canning, baking, et cetera. Some operations require bacteriological action and again involve technical limits on production periods and rates.

These limitations are commonly offset by organizing plants in multiple units-in effect, several plants within a plant. A four-unit plant, for example, might operate at relative rates of one fourth, one half, three fourths, and one. Rate variation, of course, is not necessarily restricted in all plants. Many production processes permit continuous variation in rates of output over fairly wide ranges. On the other hand, there are countless examples of plants and processes where the opportunities for rate changes are quite limited.

In addition to variations in the rate dimension, total plant output may also be varied by changing the hours of plant operation within any demand or sale period. For example, the total daily output of a fruit packing house is commonly produced with various combinations of rates of output and hours of operation. Similarly, the automobile industry may produce the year's supply of cars in considerably less than a year and then shut down to "retool." New automobiles may be sold out of storage and, as the demand situation warrants, the retooling period may be shortened or extended.

For some types of plants, the possibilities of storage are quite limited, and the product is consumed almost as soon as it is produced. In this case the period of consumption corresponds very closely to the period of production, as is assumed by conventional theory. An electric power plant is a good example. There is virtually no storage of the electricity, so it must be produced as used. But for the vast majority of plants, the output required to satisfy a given demand may commonly be produced over a fairly wide time period.

One additional point on the nature of plant operations should be stressedthe limited degree of factor substitution (in the short run) that is possible with most types of production processes. This can be made clear by a listing 
of the major types of inputs: labor, equipment, buildings, raw materials, and operating inputs such as power, heat, and the like. Labor is not a substitute for mechanical power to any great extent in mechanized plants, and certainly not for fuel or steam. In most cases raw materials are very limited substitutes for other inputs and frequently enter into the final product in rigidly prescribed proportions. Some variation in raw materials is possible, but if the final product is defined precisely this possibility becomes quite restricted. The major substitution possibilities appear to be between labor and equipment. But in the short run in which the plant-a given set of building and equipment units-remains fixed, such substitutions are not possible. Changes in equipment define a new plant (as viewed here) and this involves long-run considerations.

\section{Needed Modifications}

The discussion of the nature of plant operations suggests a need for four important modifications or elaborations to the conventional marginalist economic theory of production. These modifications stress the time dimension for output variation, plant segmentation involving the use of many identical machines, discontinuous variation in rates of output, and multiple rather than single stage plants. Additional modifications may be needed in the treatment of durable inputs.

We need also to distinguish between the use of economic theory of production to explain how plant managers should act if the objective is to maximize profits and its use to describe how they actually do or will act in any given situation. These views are frequently confused in economic discussions, and this has led to some misunderstanding. In this paper we are interested in theory as a tool for analysis rather than as a descriptive explanation of this sector of the economy.

\section{The Time Dimension}

If rates of plant output are held constant and total output varied by varying the number of hours worked per day or week, the uniform level of intensification in the rate sense can be expected to produce constant marginal eost. This will be true even though the cost function may be curvilinear in the rate dimension. The linear total cost functions obtained in a number of empirical studies apparently have resulted largely from variation of this type, although this has not always been made clear in the reports. Failure to distinguish clearly between the rate and time dimensions leads to confusion and appears to be a source of some controversy concerning the nature of cost curves.

A good example of cost curves that are almost perfect reflections of variations in output through hours of operation can be found in the study of ginning operations in Texas by Paulson (1942).? These curves show the total cost of ginning per season in relation to the total number of bales ginned. For technical reasons, gins normally operate at constant rates, and vary the number of hours of operation per season as required to handle the total available volume. Variation in total volume and total cost then results almost

\footnotetext{
"See "Literature Cited" for citations, referred to in the text by author and date.
} 
entirely from variations in the total hours of operation per season. Since cost and volume are both linear functions of hours, they are also linear functions of each other.

The importance of the distinction between the rate and the time dimensions is again brought out in a study of fuel consumption and costs in air transportation by Ferguson (1950). Using engineering determinants of physical inputs relative to physical outputs, he develops a cost function for fuel in terms of several variables such as velocity, distance, gross weight, and wing area. Output is measured in foot-pounds, which is similar to measuring plant output in terms of rate of output per hour times hours worked. When factors such as wing area are held fixed at specified levels-i.e., the given plant-total cost becomes a function of the gross weight transported, velocity, and distance. With velocity held fixed at average rates, costs are expressed as a function of only two variables, weight and time. After deriving marginal costs from this function with respect to both time and weight, Ferguson notes that:

The marginal cost, i.e., the marginal real cost of fuel, is linear in the case of changes in hours, but in the second case (changes in weight) it is curvilinear, cost increasing as the square of the weight. Here is an empirically derived marginal cost curve with the upward concavity of the elementary texts! (Ferguson, 1950 ; p. 230.)

The exclamation point suggests that the author was either surprised or excited at his findings, but they certainly should not be surprising if the time and rate dimensions are kept separate as Ferguson has correctly done. In this case the change in weight represents intensification in the traditional sense and so may be expected to result in diminishing marginal returns.

Cost studies involving transportation have tended to distinguish more clearly between rate and distance or time dimensions. ${ }^{8}$ This may be because these studies commonly involve several variables, such as route density and volume per stop in addition to distance and velocity. Under these circumstances, the time or distance dimension may be somewhat more obvious, although no more important than in the previous cases.

The cost functions in many studies of the type described above are based on statistical analyses of accounting cost and output data for a series of accounting periods. In many cases, variation in output per accounting period results from changes in hours of operation as well as from changes in instantaneous output rates. This means that the resulting cost functions will tend to be linear or curvilinear, depending on whether the variation in output per accounting period is predominantly the result of variation in hours of operation or of change in output rates per hour. This, along with certain basic difficulties in methods and techniques, makes it impossible to preclude total cost curvature in these studies. ${ }^{\circ}$

${ }^{8}$ See, for example, R. G. Bressler, Jr., and D. O. Hammerberg, Efficiency of Milk Marketing in Connecticut: 3. Economics of the 'Assembly of Milk, Bulletin 239, February, 1942 ; G. G. Judge and R. L. Baker, Time and Cost Functions for Egg Routes, Poultry Science, vol. 31, July, 1952; R. G. Bressler, Jr., City Milk Distribution (Cambridge: Harvard University Press, 1952), especially chapters 9 and 10.

${ }^{9}$ For further discussion, see Caleb A. Smith. "The Cost-Output Relation for the United States Steel Corporation," The Review of Economic Statistics, November, 1942; and Richard Ruggles, "The Concept of Linear Total Cost-Output Regression," American Economic Review, vol. 31, June, 1941. 


\section{Optimum Factor Combinations}

Where cost functions are linear in a rate sense, the theoretical conditions for optimum combinations of factors may not be appropriate or attainable. For example, with pure competition in the purchase of productive services, the condition that the service price productivity ratios must be equal no longer holds. Marginal physical productivities are constant and so are the service prices. Only by chance would all cost-productivity ratios be the same. If the production function is linear and independent-i.e., of the Form $Q=$

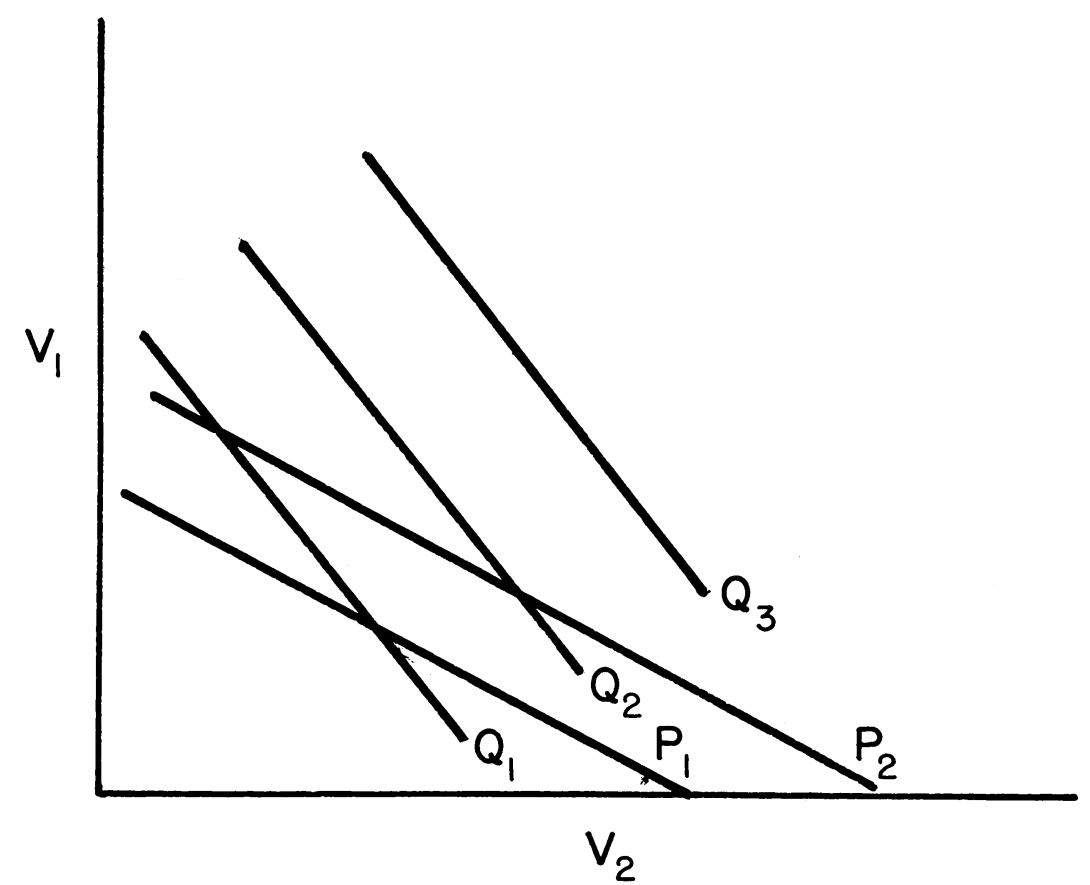

Fig. 2. Linear and independent production map and purely competitive factor price relations.

$a+b V_{1}+c V_{2}$-either all combinations of factors give minimum costs or only one of the services will be used, depending on the relative prices of the services.

This is illustrated in figure 2 , where $Q_{1}, Q_{2}, Q_{3}$ are isoquants for a linear and independent production function, assumed continuous for simplicity. $P_{1}$ and $P_{2}$ are isocosts, the slope of each line representing the relative prices of the services with pure competition. It is clear that with these price relations only $V_{2}$ would be used, for this would give the maximum output for a given outlay. If the price lines have the same slope as the isoquants, all service combinations along a given isocost yield the same output, and the particular combination is a matter of indifference. If the slopes of $P_{1}$ and $P_{2}$ were greater than that of the isoquants, only $V_{1}$ would be used. Where the services are used in fixed proportions, as seems frequently to be the case, 
the factor combinations are determined by the technical considerations of production and cannot be influenced by prices. ${ }^{10}$

Where prices of the services vary with the quantities used and the production function is linear, it may still be possible to combine these services so as to obtain equal cost-productivity ratios, but this is achieved through price changes rather than diminishing productivity. In short, isocosts will then be concave to the origin with the result that tangency positions representing cost minimizing combinations of factors will occur.

Figure 3 illustrates the determination of the optimum use of two identical machines to produce any given output where inputs for each machine vary in the continuous manner assumed by conventional theory. At low levels of output, these isocosts are convex to the origin, an effect that stems from the decreasing marginal costs sector of the conventional total cost curve as applied to an individual machine. As output rate increases, the isocost curvature decreases, eventually reverses, and then becomes increasingly more concave to the origin as output expands further. The reversal in isocost curvature occurs at the point of inflection in the total cost curve, and the concave isocost curvature reflects the increasing marginal cost sector of the total cost curve. The solid lines in the chart are isocosts for producing with two identical machines. The dashed lines are isoquants. Points of tangency of isocosts and isoquants occur along a line at a 45-degree angle through the origin, which represents equal utilization of the two machines. In the range of output up to $A B$, these points of tangency define the maximum total cost for producing any output, and costs will be minimized by using only one machine or the other. When total output reaches $A B$, equal output with both machines or production with only one machine gives the same total cost. For outputs greater than $A B$, costs are minimized at points of tangency of the isocosts with the highest possible isoquiant. These tangencies occur only at points where both machines are used equally-i.e., where marginal costs are equal.

The minimum total cost curve derived from figure 3 is illustrated in the top part of figure 4. Only one machine is used to produce outputs up to $O X_{1}$ (corresponding to output $A B$ in figure 3). A "kink" or discontinuity occurs at $O X_{1}$ where the second machine comes into use. But to obtain minimum costs, the two machines are used equally. If a third machine is added, all three will be used at the same rate (total output will be the sum of the output with each machine) and another discontinuity will occur at $O X_{2}$ where this machine is brought into use. Thus, when output is varied by varying the use of identical machines, the variable cost function for the plant will be discontinuous even though continuous variation is possible for each machine. However, as the number of equipment units is increased, the total cost function approaches linearity.

In many instances the variable inputs tend to be associated with each machine in fixed proportions. For example, each lidding or sealing machine in a food processing plant may always require one worker, regardless of the rate at which material flows through it. And other types of machines may

${ }^{10}$ For a mathematical treatment of this problem, see John S. Henderson, "Marginal Productivity Analysis-A Defect and a Remedy," Econometrica, January, 1953. 
operate at constant rates per hour so that operating costs in addition to labor costs vary discontinuously with the use of successive units of equipment. With these fixed proportions the discontinuities are much more marked as suggested by the "step" function for labor in part $B$ of figure 4 . The steps occur as output is varied up to the capacity of each unit, and an additional machine is brought into use. The function represents "economic" rather than physical inputs-i.e., man-hours for which the plant must pay.

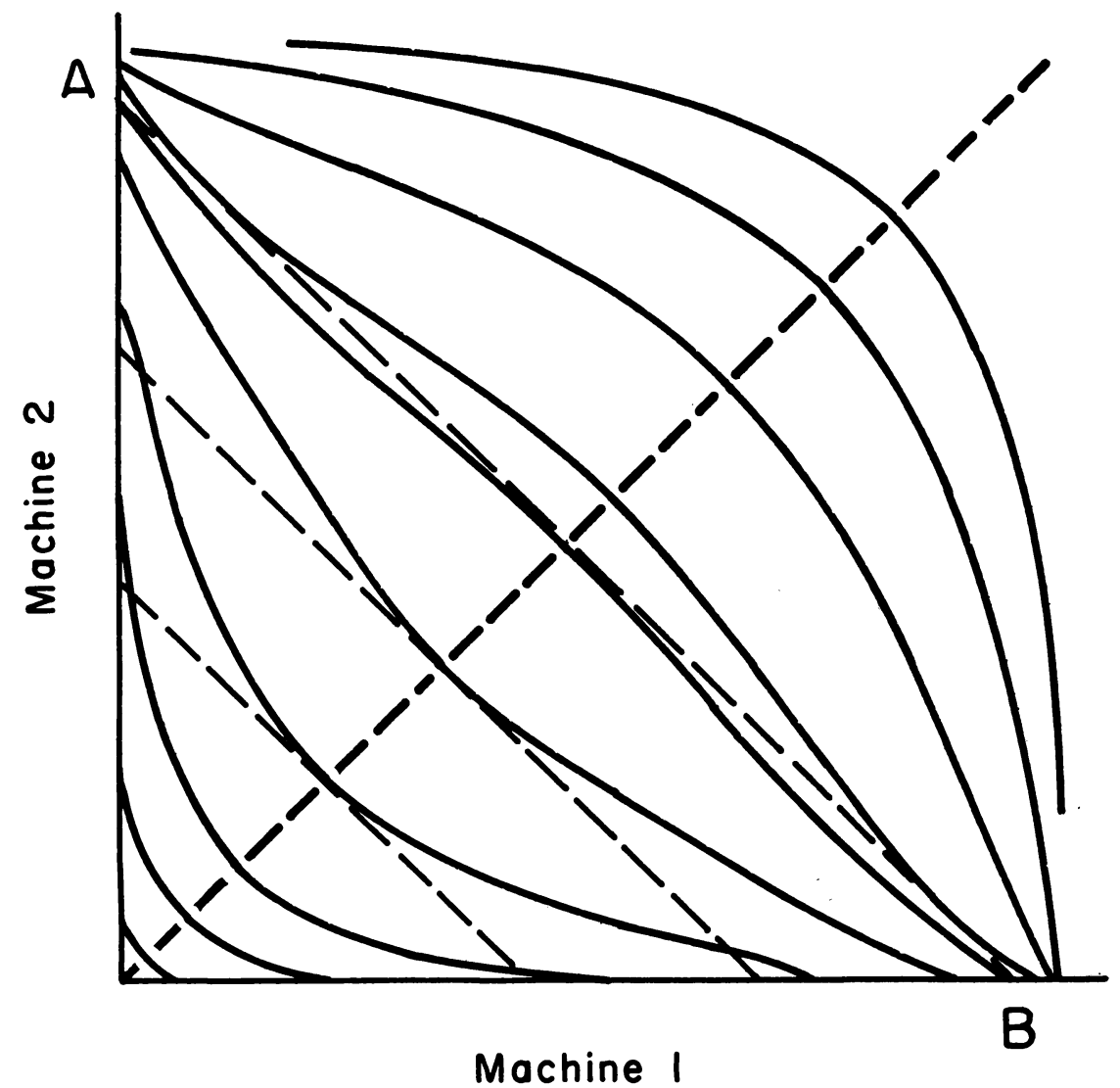

Fig. 3. Isocost-isoquant map for production with two identical machines.

Physical inputs in terms of energy and exertion may vary continuousiy and idleness will be noted at all but the lower corner positions on the curve.

When the cost function is discontinuous, the condition that profits are maximized where marginal cost equals marginal revenue may no longer apply. Brems (1952; p. 583) shows that with discontinuous functions there may be points of marginal revenue and marginal cost equality, but the profit maximizing point may be a "corner" where $M C \neq M R$. Figure 5 shows a discontinuous long-run total cost curve and a continuous total revenue 

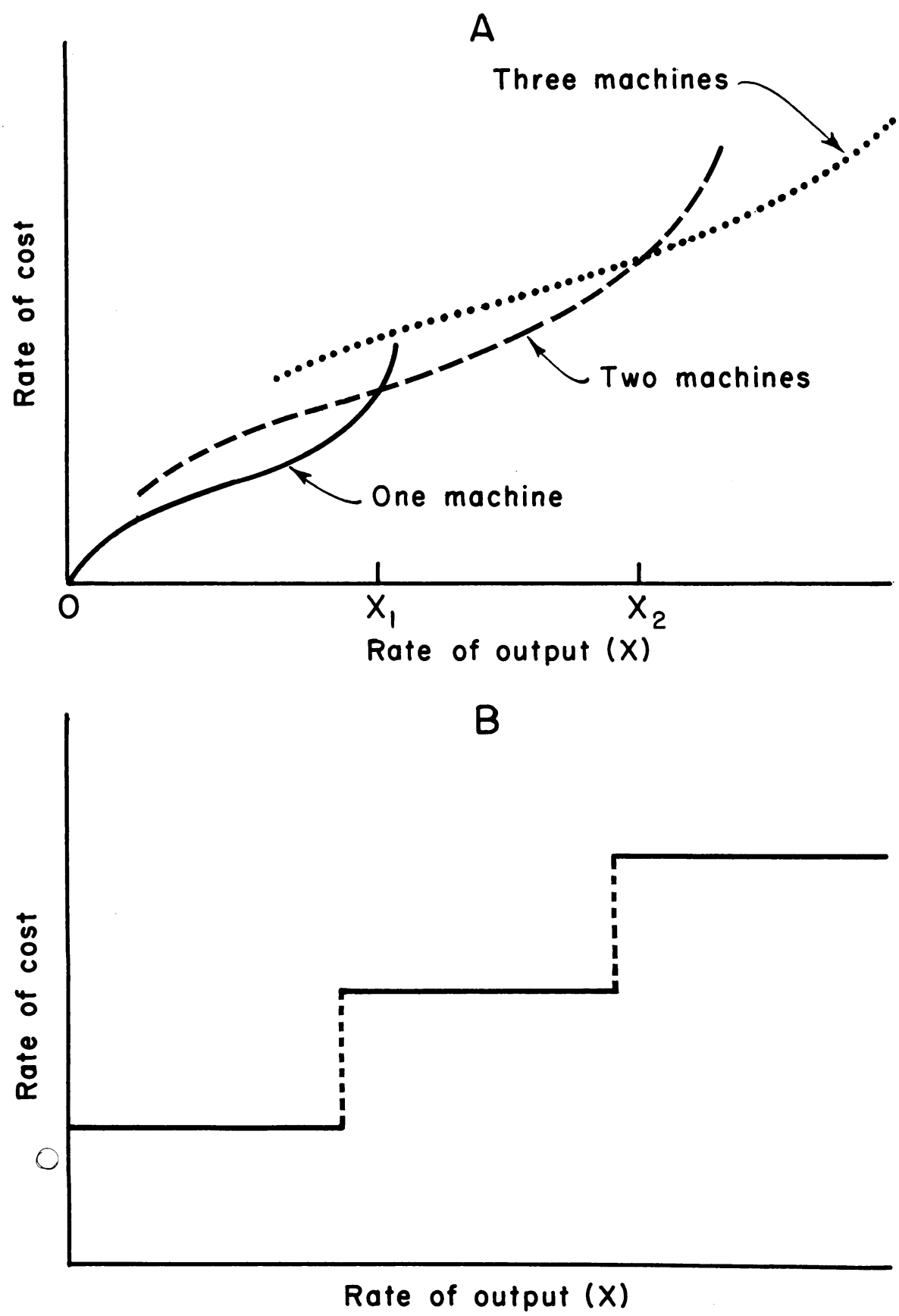

Fig. 4. Total variable cost functions involving the use of three identical machines in given plants. A-costs vary continuously for each machine; B-labor fixed per machine. 
curve. ${ }^{11}$ Marginal cost equals marginal revenue at output $O X_{2}$, but examination of the figure reveals that profits are actually maximized (distance between total revenue and total cost is greatest) at output $O X_{1}$-a corner position where marginal cost is not equal to marginal revenue. This situation would be equally possible with discontinuous short-run curves. In either

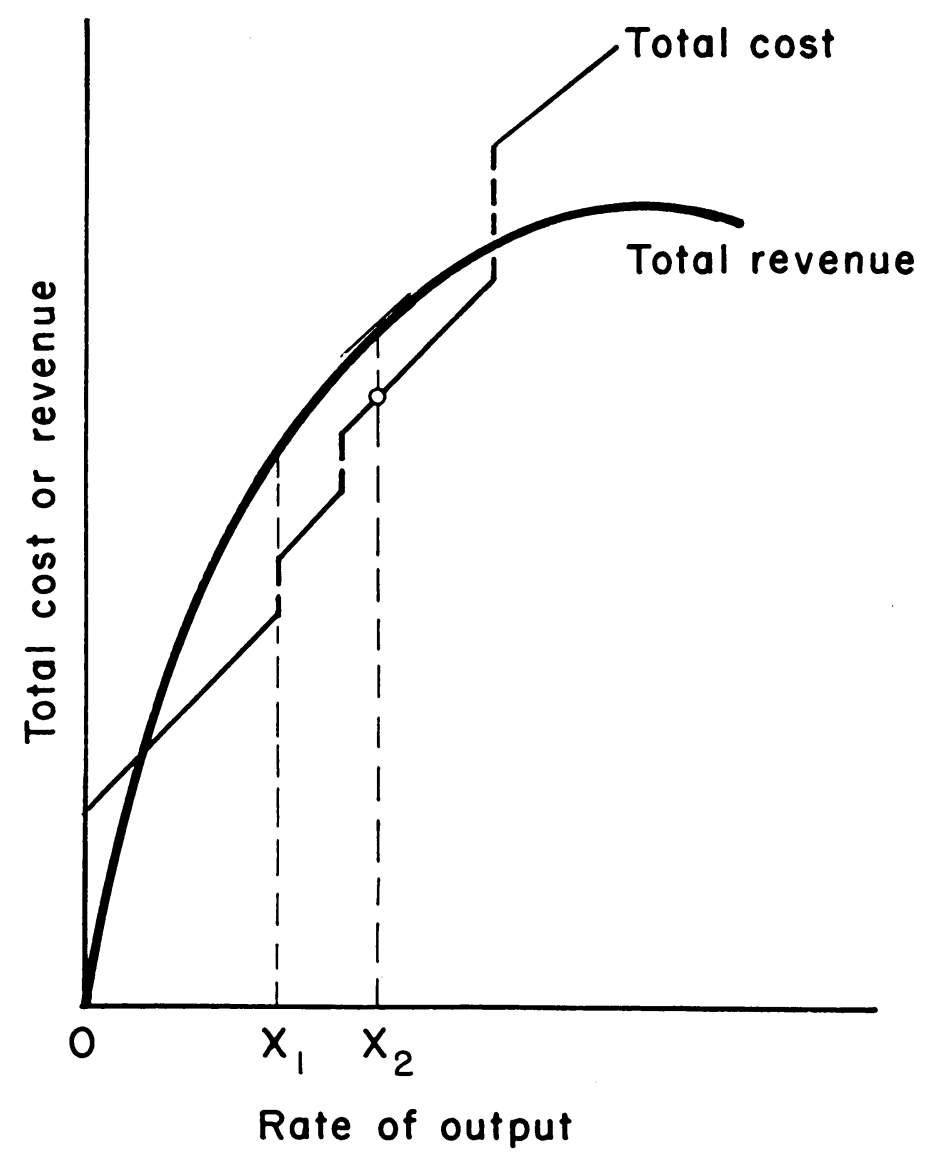

Fig. 5. A discontinuous cost function illustrating a situation in which profits are maximized at a corner position where $\mathrm{MC} \neq \mathrm{MR}$ rather than at a point where $\mathrm{MC}=\mathrm{MR}$.

case, the profit maximizing position cannot be determined by simple calculus. The cost function must be examined over its entire range and the maximum profits calculated for each continuous section of the curve. The maxima are compared and the maxima maximorum selected from these to determine the optimum rate of output.

${ }^{11}$ The diagram is reproduced from Brems, op. cit., p. 583. Presumably, this is a longrun function since the cost of the durable factors contributes to the discontinuities. The problem of durable costs and the procedures for incorporating them into the analysis are considered in this and in the next section. 


\section{Segmentation and Discontinuities}

In explaining the results of a statistical analysis of cost and output for a leather belt shop, Joel Dean (1941a; p. 51) notes that:

Segmentation of this plant into a number of similar operating units, each of which can be withdrawn from operation without influencing the efficiency of the others, tends to result in constant marginal cost up to the point where all units are fully utilized.

In other words, when increases in rates of output and input are associated with successive use of identical machines and the successive addition of workers to perform identical jobs with no real intensification on a fixed factor or changes in the proportions of inputs, the resulting total cost function will tend to be linear, although discontinuous. ${ }^{12}$ Segmentation may occur both within stages and by dividing the entire plant into a number of identical operating units. This possibility is neglected in much of the usual theory where it is assumed that fixed factors are indivisible in the short run and that all enter simultaneously into the production process. Segmentation appears to be another factor, along with variations in the time dimension, which may account for some of the linear functions obtained in empirical studies. ${ }^{13}$

The cost functions of the usual theory are assumed to be continuous, but where output is varied by successively employing identical machines, the curves may be discontinuous. In the short run, only variable inputs and costs enter into the production decisions and the plant-a given set of building and equipment units-remains fixed. Discontinuities in the cost function for this given plant result only from the changes in variable costs as successive units of equipment are brought into use.

\section{Plant Stages}

Each of the many stages which in the aggregate form a plant is represented by a cost function much as if it were a plant itself. The total of the stage cost curves, along with certain over-all cost components not associated with specific stages, form the total cost function for the entire plant. The usual theory of production has its most direct application to the individual stage and not the entire plant or firm, except in the rare situations of a firm with a single plant and a plant with a single stage. The integration and aggregation of these stages into total plant operations lead to additional problems. The first of these is the problem of finding "harmonious" combinations of capacities for the units of fixed (but discretely divisible) equipment used at each plant stage (Brems, $1952 ;$ p. 580). With technology constant, this amounts to finding a common denominator of the capacities of all the

12 The possibilities of this type of linear function resulting from "segmentation" are also suggested by George Stigler, "Production and Distribution in the Short-Run," Journal of Political Economy, vol. 47, June, 1939.

${ }^{13}$ For example, see United States Steel Corporation, T.N.E.C. Papers (New York: United States Steel Corporation, 1940, pamphlet 6); K. H. Wylie and M. Ezekiel, "The Cost Curve for Steel Production," Journal of Political Economy, vol. 48, December, 1940; Joel Dean, Statistical Cost Functions of a Hosiery Mill. (Chicago: University of Chicago Press, 1941.) 
durable factors that may be employed at the various stages-this common denominator representing the rate of output that minimizes the average total unit cost of operation.

A second problem, which is certainly recognized in the usual theory but in a somewhat different manner, is the choice of appropriate types of equipment at each plant stage. Modern technology offers many methods and kinds of machines for performing given operations. The economy of a given machine may depend on the rates of plant output, and the choice of machine must be considered simultaneously with the problem of harmony. The aggregation of the various plant stages also adds to the discontinuities noted previously since "kinks" or "breaks" in the cost functions usually will not occur at the same output rate for all stages. These problems are considered in more detail in the following section.

\section{The Problem of Durables}

In the usual treatment of production theory, no assumptions are made concerning the nature of the factors "held fixed" in defining a plant. Presumably, these inputs, like any others, can be purchased as needed, although applied to the productive process at fixed rates. There is no problem in defining either the long-run or the short-run cost curve.

But some difficulty is encountered when it is noted that in a plant these fixed factors are durable capital goods such as buildings and equipment. Like any other input, the inputs of capital goods must be considered as rates or flows where the real input is the use or service of the capital good. For example, inputs may be in terms of so many laborers, so much power, and the use of so much equipment per hour of plant operation. "This creates real difficulty in defining the 'prices' for the services of the capital goods, for they are not completely consumed during the production process or the production period." (Bressler, 1950; p. 14.)

It seems reasonable also

...that over the useful life of the capital good these prices multiplied by the inputs or use must aggregate enough to repay the original investment, pay interest on the capital including a return for risk, and keep the equipment in a useful state of repair. In addition, government services are financed in part by property taxes levied on the basis of some valuation of these investments, and these are costs that also must be covered. Thus capital goods give rise to certain 'fixed' costs, including depreciation, interest, insurance (part of risk payment) repairs, and taxes. (Bressler, 1950 ; p. 14.)

To complicate matters further, depreciation consists of both a time component-exposure to elements, et cetera-and a use component-wear and tear associated with actual use. Moreover, there is an interaction between repair costs and the magnitude of the time and use depreciation.

The net result is that

...there is in most instances no way of linking particular units of input with particular units of output in the sense that we can say that $a$ units of input produce the output of period I, $b$ units of input the output of period II, and so on. All that we can say is that all the inputs embodied in the durable good are jointly responsible for the whole stream of output. (Lutz, 1951 ; pp. 6-7.)

And, as a consequence, 
...the usual diagrammatic representation of the average fixed cost curve (and consequently also the average total cost curve) is inadequate as a means of dealing with durable goods costs. (Lutz, 1951; p. 11.)

Thus, costs of durable goods have no meaning in the short run; from the viewpoint of the firm they are replaced by "quasi-rents" based on the earning capacity of the investment.

\section{The Theory of the Individual Firm-Reformulated}

The critical discussions of the modifications needed for the existing body of economic theory of the individual firm provide a basis for reformulating this theory into a more useful analytical tool and, at the same time, a more realistic description of plant operations. The reformulation requires adding the dimension of variation in output through variation in hours of operation; it must take account of plant segmentation and the discontinuous nature of cost functions; it must recognize that a plant is an integration and aggregation of many operating stages with a resulting compounding of the usual theory; and, finally, it must recognize and take account of the problems that are encountered in pricing the services rendered by inputs of durable factors.

\section{The Firm in the Short Run}

It was pointed out in the previous discussion of durables that there is no clear way to associate the costs of durable inputs with specific outputs of specific time periods. These costs were noted to be functions of both time and use. Costs associated with wear-Keynes' "user costs" (Keynes, 1935; pp. 66-73) - would, of course, be included in variable costs, but costs associated entirely with the elapse of time- "fixed costs"- cannot enter in any meaningful sense into the short-run cost function. Thus, only variable costs need be considered in determining profit-maximizing adjustments for any specific plant. ${ }^{14}$

A plant consists of a given set of buildings, equipment, and layout. Operations within the plant are composed of a number of stages and transportation links, in each of which specified transformations or transportations take place. ${ }^{15}$ Associated with each stage are certain units of equipment. Given these equipment units, the operating cost functions and the user cost functions are defined. Raw materials costs are defined by the nature of the product. Labor cost functions are defined by the types of equipment used and the nature of the transformations that occur at each stage and by the equipment and layout with regard to transportation links. Thus, when the plant is specified, the combinations of services to be used are also largely specified and there is little opportunity for substitution among these factors. The problem of combination of factors then is solved by the "fixed" technological coefficients, and cost minimization reduces to avoiding the use of excessive or unnecessary quantities of productive services.

\footnotetext{
${ }^{14}$ User costs may, of course, be influenced by past rates of output and the age of the capital goods, but at any point in time they are independent of long-run considerations.

${ }^{15}$ Most of the discussion that follows is oriented toward continuous process plants as these are the primary concern in this report, but with minor modifications the developments are generally applicable to discontinuous or batch-type operations as well.
} 
The total variable plant cost function is obtained by a simple addition of the individual stage functions, the transportation functions, and the general cost functions for items not associated with specific stages-e.g., accountants, janitors, and many materials. Consistency is maintained among the various stage functions by the flow of materials and products through the plant coupled with a certain amount of temporary storage (see previous flow diagram, fig. 1). Inputs are generally controlled by the flow of materials and products rather than the reverse, although in some stages they are determined simultaneously.

Assuming that the firm knows the conditions of demand, the total variable cost function may be used to determine the rates of short-run output that maximize total profits. As has been stressed throughout the previous discussion, the output required to meet a given demand commonly can be produced at various combinations of rates of output and hours of operation since the time rates for production and demand usually are not identical. The problem then is to determine which of these alternative combinations will result in maximum profits.

In solving this problem, one additional consideration must be introduced. As rates of output are increased, the hours of operation required to produce any total quantity of product are decreased, and this increases the period that the products must be stored. Thus, costs of storage must be considered in deciding on the rates and hours of operation. Storage cost is a function of both rate and time and can be introduced directly into the total cost function. However, the presentation will be simplified somewhat by first omitting storage costs from consideration.

For purposes of illustration it will be convenient at first to assume that the plant cost function is fully and continuously variable in terms of rates of output and that there are no institutional barriers to variations in the time period of production. These assumptions will be dropped later.

No Storage Costs. Where storage costs are zero, the total plant variable cost function is defined as:

$$
T V C=f\left(X_{1}, \cdots, X_{m}\right) t, \quad t \leqq k
$$

where $f\left(X_{1}, \ldots, X_{m}\right)$ is a variable cost function of rates of output of products $X_{1} \ldots X_{m}$ with optimum (least cost) combinations of productive services, and $t$ represents units of time. The constant, $k$, represents the total units of time available in the period. For convenience, factor prices are here assumed given and constant and thus are omitted as variables in equation (1). Figure 6 shows such a function as a cost surface in terms of the rate of output for a single product and time. The surface is shaped as the conventional inverted $S$ in the rate $(X)$ direction and is linear in the time dimension for any value of $X$, ending discontinuously at $k$.

Total revenue is defined as some function of the total quantity of each product sold in a particular time period of $k$ time units.

$$
T R=f_{1}\left(Q_{1}, \cdots, Q_{m}\right)
$$

Assuming that the demand or sale period is defined so that the total production of the period is sold within the period, $Q_{i}=X_{i} t$ where $Q_{i}$ is the total 
quantity of product $i$ sold during the time period and $X_{i}$ is the rate of production of product $i$. Expression (2) may be written

$$
T R=f_{1}\left(X_{1}, \cdots, X_{m} ; t\right)
$$

Total revenue is jointly related to rates and time of operation. Thus, time $(t)$ is included within the function rather than as an independent multiplier as in the case of the cost function-equation (1) above.

Short-run profits-i.e., returns over variable costs-are defined as

$$
\pi=T R-T V C=f_{1}\left(X_{1}, \cdots, X_{m} ; t\right)-f\left(X_{1}, \cdots, X_{m}\right) t
$$

Because of the restrictions on the total units of time within any period, the profit function is discontinuous, variations in $t$ being limited to the range represented by $k$. This leads to difficulties in defining the profit-maximizing conditions. In some cases, a maximum value may be obtained within the range of the discontinuity and in other cases no maximum is possible for values of $t<k$-that is, maximum profits may occur at $t=k$.

Consider first the situation under pure competition. The total revenue function is linear and may be written

$$
T R=\sum_{i=1}^{m} p_{i} Q_{i}
$$

or

$$
T R=\sum_{i=1}^{m} p_{i} X_{i} t
$$

where $p_{i}$ 's are prices of the products. The profit function (4) then is completely linear in the time dimension. If price $\left(p_{i}\right)$ is greater than or equal to the minimum average variable cost of the plant, it would obviously pay to operate at the minimum average variable cost rate of output for the full amount of time $(k)$ that is available. This is illustrated in figure 7 which shows a cross section of the cost surface in figure 6 , holding the rate of output at the minimum average cost level. Line $O A$ shows the resulting total variable cost in relation to time of operation and corresponds to line $A B$ in figure 6. Line $O B$ is a corresponding trace on a revenue plane with time and rates as the independent variables. Profits increase continuously up to $k$, the full time period.

Further increases in profits are possible, however, through rate adjustments. This is illustrated in figure 8 which shows the traces of the total cost and revenue surfaces with time held at $k$. Average variable costs are minimized at a rate of output $O X_{1}$, corresponding to the distance $O A$ in figure 6 . The distance $A X_{1}$ in figure 8 is the same as $A k$ in figure 7. Line $O D$ is a corresponding trace on the revenue plane, and $B X_{1}$ corresponds to $B k$ in figure 7. It is clear that "profits" will be increased and maximized by increasing the rate of output to $O X_{2}$ where marginal cost equals marginal revenue. In terms of equation (4)-the profit function- $t$ becomes a constant $(k)$ and the function is expressed entirely in terms of rates as specified in the conventional theory of the firm. In other words, the introduction of time into the analysis involves no change in the profit-maximizing conditions 
under pure competition but requires operation continuously throughout the time period $k$.

With imperfect competition, however, the situation may be somewhat different, for now the revenue function will be curvilinear in both the rate and time dimensions. Whether or not a maximum profit position occurs at some time $(t)$ less than $k$ can be determined only by solving the profit function (equation 4 ) for the maximizing values of the rates of output and time. If the $t$ resulting from this calculation turns out to be equal to or greater

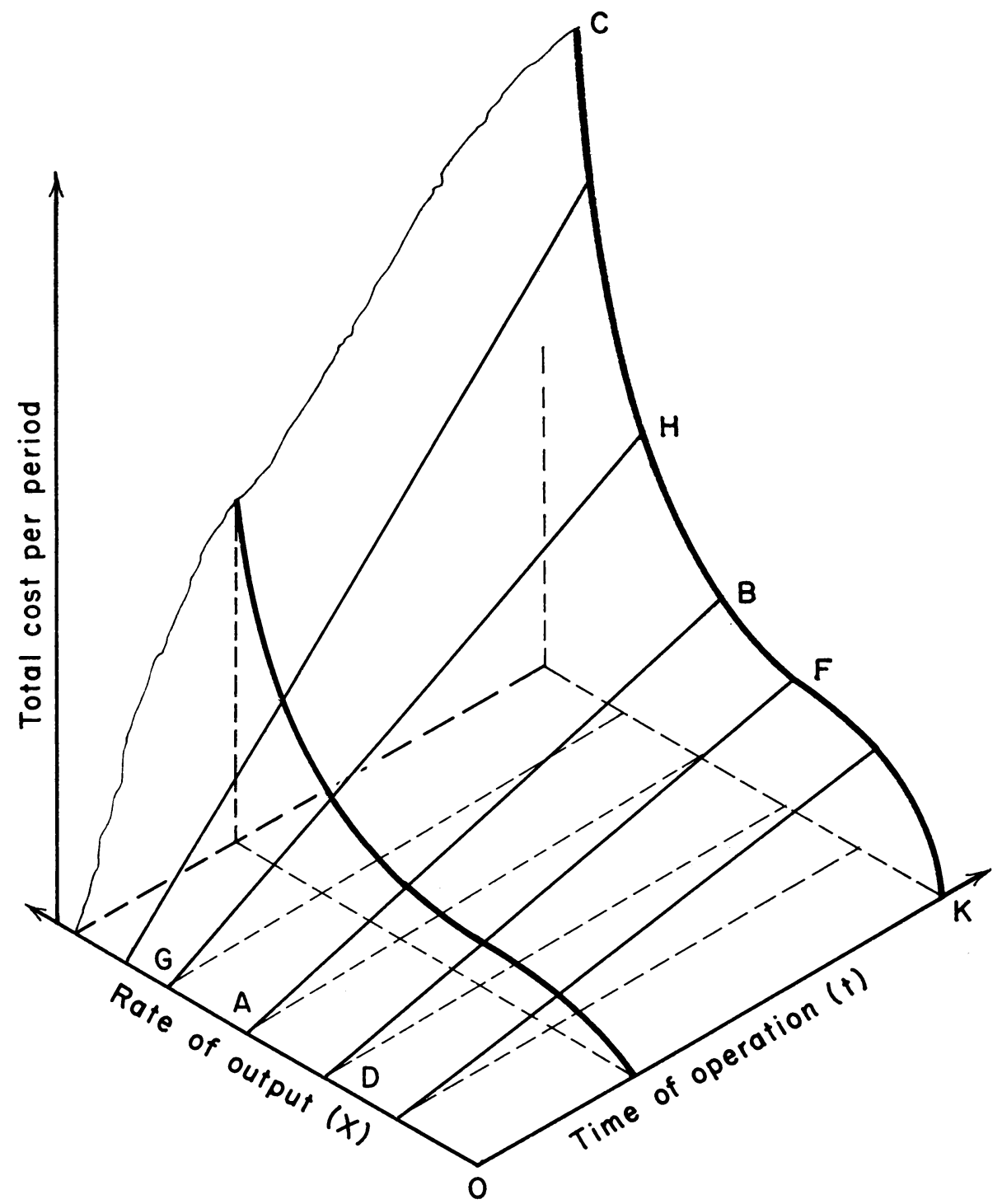

Fig. 6. A cost surface for producing a single product by varying both rate and time of operation. Storage costs are assumed zero. 
than $k$, it again becomes a constant since $k$ is its limiting value. The solution then is as indicated in the conventional theory, i.e., take partial derivatives with respect to rates of output of each product, set equal to zero, and solve. The optimum conditions are that the marginal cost of each product is equal to its marginal revenue-all in a rate sense.

The conditions for maximum profits for the case where a maximum occurs at $t \leqq k$ are determined by taking partial derivatives of the net revenue func-

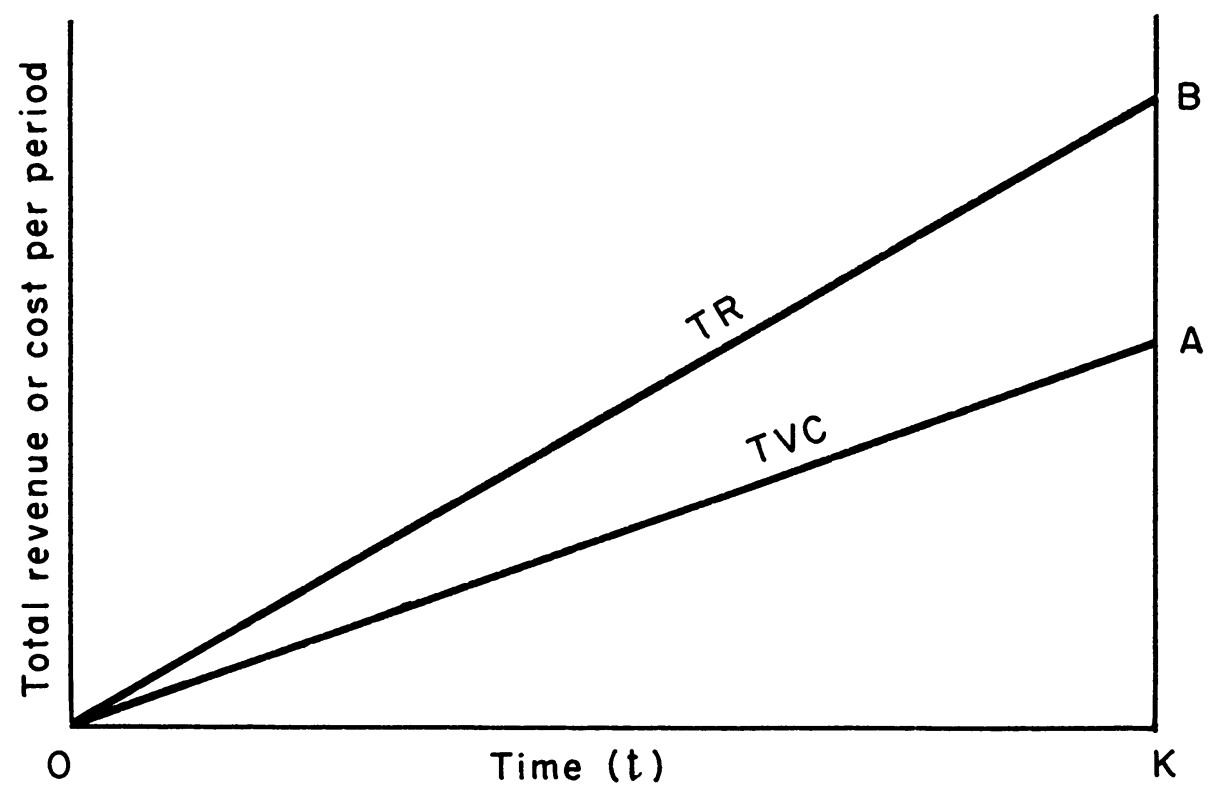

Fig. 7. Cost and revenue traces with rate of output (X) held at the minimum average cost rate.

tion with respect to all output variables and $t$, the time of operation. Profits are maximized when all partials are equal to zero, or

$$
\begin{gathered}
\frac{\partial \pi}{\partial X_{i}}=\frac{\partial f_{1}\left(X_{1}, \cdots, X_{m} ; t\right)}{\partial X_{i}}-\frac{\partial f\left(X_{1}, \cdots, X_{m}\right) t}{\partial X_{i}}=0 \\
\frac{\partial \pi}{\partial t}=\frac{\partial f_{1}\left(X_{1}, \cdots, X_{m} ; t\right)}{\partial t}-f\left(X_{1}, \cdots, X_{m}\right)=0
\end{gathered}
$$

and from (7) and (8)

$$
M R_{i}=M C_{i} t
$$

and

$$
M R_{t}=C_{x}
$$

where $M R_{i}$ is the marginal revenue for product $X_{i}, M R_{t}$ is the marginal revenue with respect to $t, M C_{i}$ is the marginal cost of the rate of output per unit of $t$, and $C_{x}$ is the total variable cost per unit of $t$ with rates of output 
held at specified levels. The conditions indicated by equations (9) and (10) hold only where $t \leqq k$. An interesting and significant secondary condition may also be derived from these functions. Where the total revenue curve passes through the origin as illustrated in figure 9 -i.e., there are no constant terms-and with $Q_{i}$ equal to $X t$, then $X t$ must occur in every term of the total revenue function. In that case

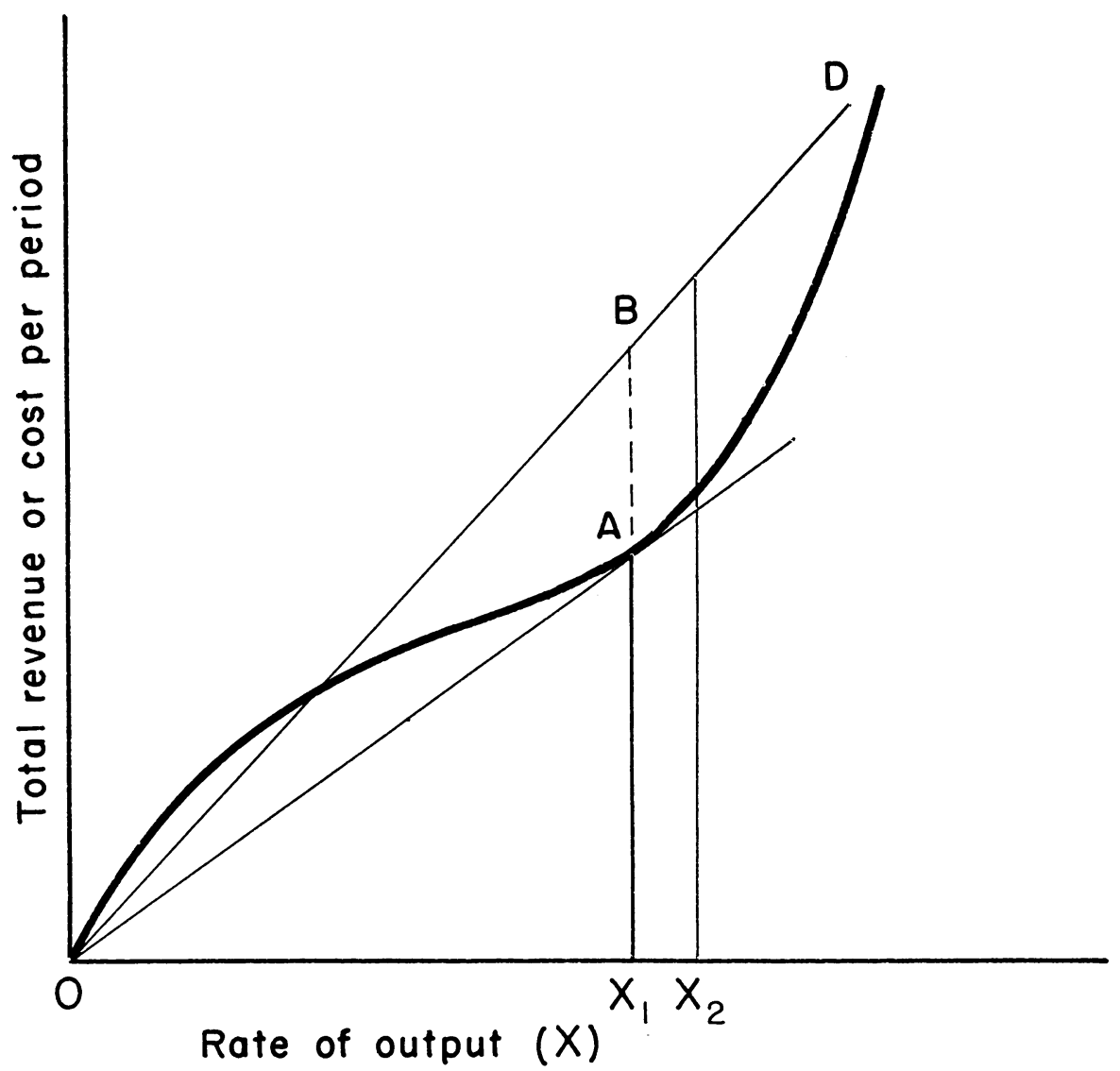

Fig. 8. Cost and revenue traces with operating time ( $t$ ) held at $k$, the total amount of time available.

$$
\begin{aligned}
& \frac{\partial T R}{\partial t}=\frac{T R}{t}=M R_{t} \\
& \frac{\partial T R}{\partial X_{i}}=\frac{T R}{X_{i}}=M R_{i}
\end{aligned}
$$

and

$$
M R_{t} t=M R_{i} X_{i}
$$

Substituting from equations (9) and (10)

$$
\frac{C_{x}}{X_{i}}=M C_{i}
$$


that is, average variable cost equals marginal cost. But this holds only where average variable cost is a minimum. Thus, the condition specifies that to maximize profits the plant will operate at a rate which minimizes average variable costs or at rates corresponding to minimum average cost rates in the case of multiple products.

The maximum profit solution might be illustrated graphically by superimposing the revenue curve in figure 9 (which can be expressed in terms of

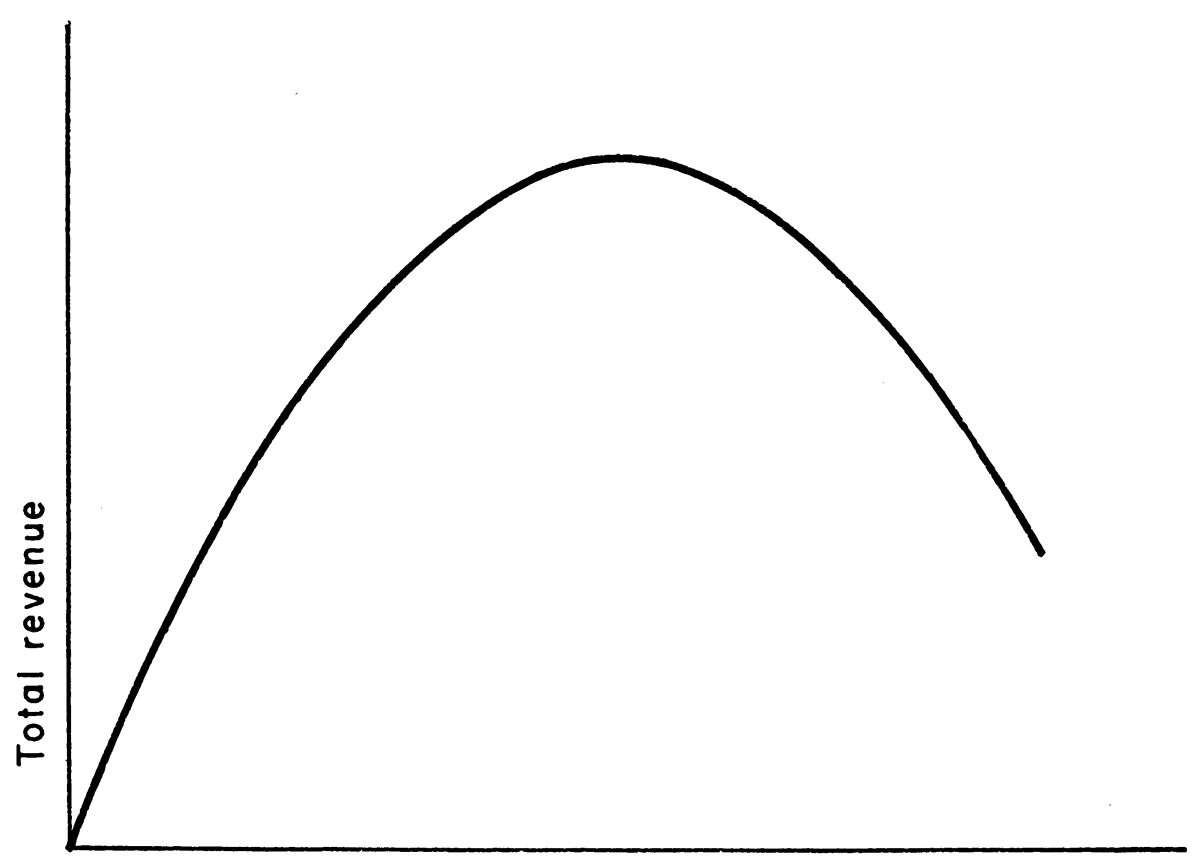

Total sales $(t x)$

Fig. 9. A total revenue function.

$X$ and $t$ as well as $Q$ ) as a revenue surface on figure 6 . The point of maximum distance between the two surfaces indicates the optimum combination of rates of output and time of operation. If the demand were quite large, the plant might find it profitable to operate for the full amount of time available and would equate marginal costs and marginal revenue along the trace $K B C$ in figure 6 . But with lower demand, the maximum profit point might occur at a point where $t<k$.

This situation is illustrated in figure 10 . Line $O A$ repeats the variable cost function of figure 7 ( $X$ held at the minimum average cost rate) and the solid line OB is the revenue function expressed in relation to time $(t)$ with output $(X)$ at the minimum average cost rate. Profits are maximized by operating for time $\mathrm{Ot}_{2}$. If rates of output are decreased or increased, the traces of the cost surface are lowered or raised as illustrated by $O A^{\prime}$ and $O A^{\prime \prime}$ in the diagram. They correspond to lines $D F$ and $G H$ in figure 6. Each cost 
trace is opposite (exactly beneath) a different trace on the revenue surface. Thus, for each shift in rates of output, and so in the cost trace, there is a corresponding shift to a different revenue trace. Relative profit maxima occur for every pair of traces, as indicated at points $O t_{1}$ and $O t_{3}$, but none of these points yields as great a quantity of profits as the combination of the minimum average cost rate and the time $O t_{2}$. This follows from expression (14) which indicates that when $t$ is less than $k$, a condition for maximum profits is that the firm operates at the minimum average variable cost rate of output.

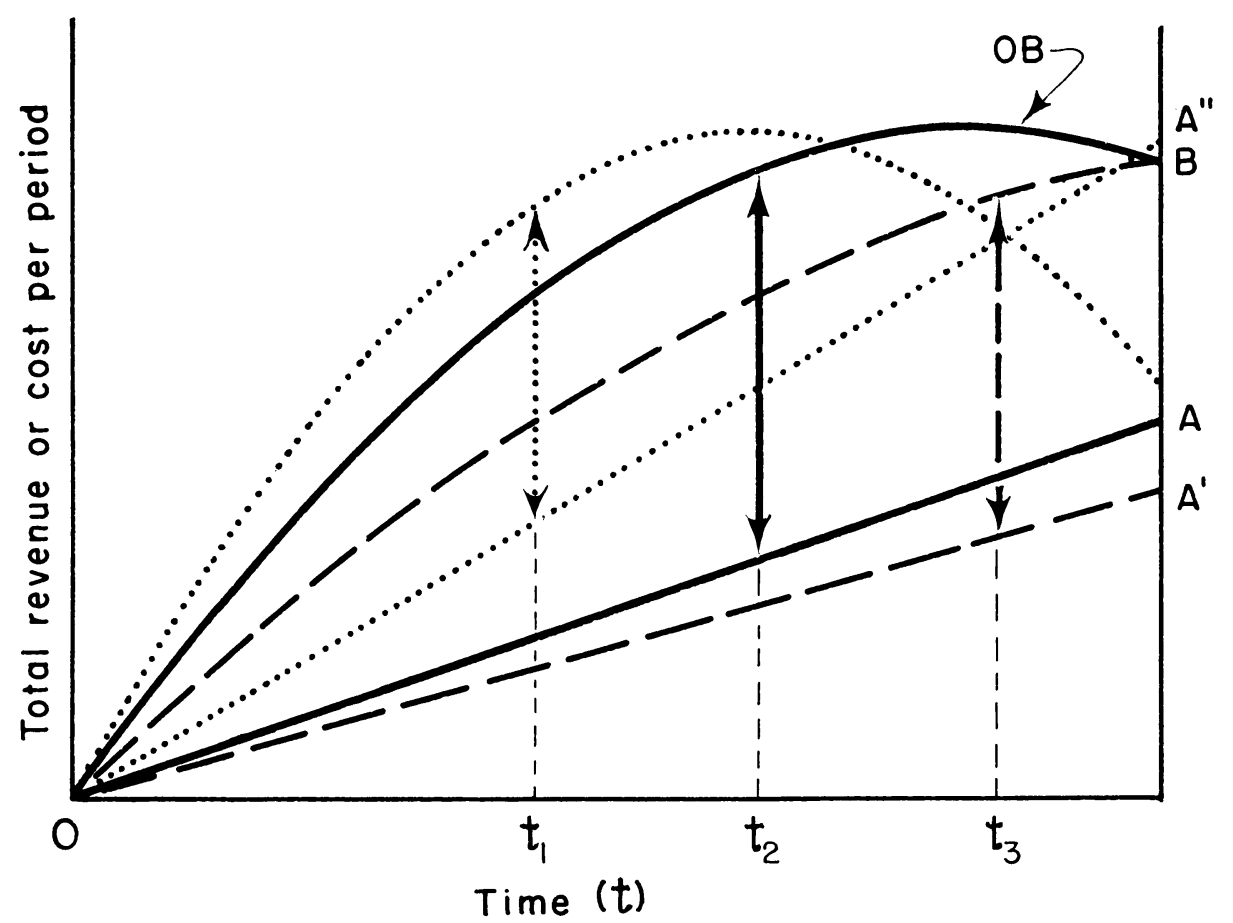

Fig. 10. Cost and revenue traces with rates of output held at OD, OA, and OG in figure 6 . $\mathrm{OA}^{\prime}$ corresponds to line $\mathrm{DF}$ in figure $6, \mathrm{OA}$ to $\mathrm{AB}$, and $\mathrm{OA}^{\prime \prime}$ to $\mathrm{GH}$.

Storage Costs. For any demand or sale period, storage requirements may vary widely depending on the rates of consumption and production and the hours and distribution of production through the demand period. Several of a great many such relationships are illustrated in figure 11. In part $A$ of this diagram, total quantity of production or consumption, $Q$, is shown in relation to elapsed time, $t$, during a demand period of total length $k$. The consumption rate, $r$, is assumed uniform throughout the period and the total quantity consumed at any time within the demand period is $q=r t$, or a total $O A$ for the full demand period $k$.

With demand assumed uniform throughout the period, production must start at the beginning of the period (assuming no carry-over from previous periods) and continue at a rate at least equal to the demand rate. In the 
simplest case, consumption and production rates would be identical, the production and consumption curves would coincide, and there would be no storage. Two other possible production patterns are shown in figure 11A. In one, production is at a uniform and continuous rate greater than the consumption rate. Production continues along the line $O B$ until the total quantity $O A$ for the demand period $k$ is produced. Storage stocks are accumulated at a rate equal to the difference between the consumption and production rates and reach a maximum $B b$ at time $t_{1}$. Thereafter, there is no production, and demand is supplied by drawing on storage stocks. At a lower rate of output, with continuous operation throughout the production period, the quantity produced might follow the path $O B^{\prime}$, with the total supply for the demand period produced in the time $t_{2}$ and maximum storage stocks $B^{\prime} b^{\prime}$. Many similar linear relationships between total consumption, production, and storage stocks are possible through varying rate of output and hours of plant operation.

Another type of production plan is illustrated by the step function in figure $11 \mathrm{~A}$. Here production occurs in a series of discontinuous periods and at rates higher than the consumption rate. Storage stocks accumulate during the production periods and are drawn on to meet demand during the idle periods. Storage requirements in this situation evidently depend on the relative rates of production and consumption and on the lengths of the individual production periods.

The interrelation among rates and time of production, consumption rates, and storage requirements is clear from figure 11A. For example, with both production and consumption rates uniform and continuous and a fixed demand period, storage requirements increase both in quantity and average length of storage as rate of production rises and production time decreases (compare $B^{\prime} b^{\prime}$, figure $11 \mathrm{~A}$, with $B b$ ). With discontinuous production during the demand period, storage requirements will be small if the production and consumption rates are close together or if the production periods are short. Storage requirements are increased as these factors vary in the opposite direction.

The possibility of variations in the consumption pattern during the demand period also is recognized, and the effects on storage requirements would be similar to that described above.

In converting storage requirements into costs, three categories need to be considered. These are the costs of handling materials into and out of storage, the variable costs of storage operation, and the fixed costs of storage buildings and equipment. Handling costs would be largely a function of the nature and total volume of products stored during the demand period, the variable costs of storage operation would be a function of the timeweighted average quantity of products in storage, and the fixed costs would be a function of the maximum storage holdings during the period-for example, the quantity $B b$ in the first case of continuous production at uniform rates illustrated in figure 11A.

From the above, it appears that storage costs can be expressed as:

$$
T S C=f_{s}\left(X_{1}, \cdots, X_{m} ; r_{1} \cdots r_{m} ; t\right) \quad t \leqq k
$$



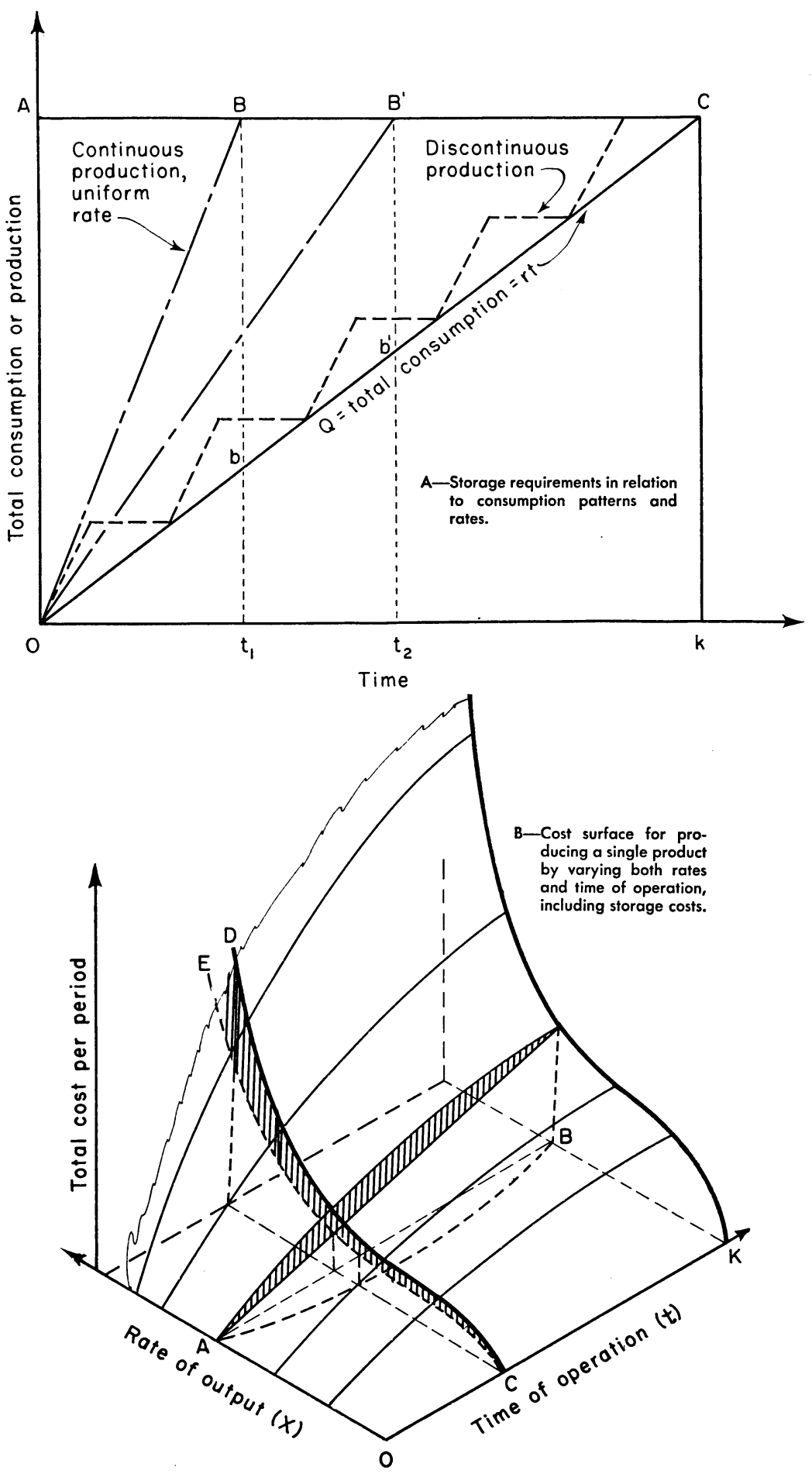

Fig. 11. Storage requirements and total costs (including storage) in relation to production and consumption pattern and rates. 
in which $X_{1}, \ldots, X_{m}$ represent output rates of different products, $r_{1} \ldots r_{m}$ the consumption rates of different products, $t$ the length and pattern of the production periods, and $k$ the total available time in the demand or sale period.

Equation 15 is a general expression relating total storage costs to a wide variety of possible patterns of consumption and production during the demand period. If the particular consumption and production pattern represented by the lines $O C$ and $O B$ or $O B^{\prime}$ in figure $11 \mathrm{~A}$ is specified-that is, continuous production and consumption at uniform rates, but with the production rate higher than the consumption rate-costs relative to the case with no storage can be represented as in figure 11B. Costs in this diagram are shown in relation to rate of output and production time and indirectly in relation to total output since total output is a function of the production rate and time variables. However, traces could be developed in the cost surface which represent costs at given levels of total output as different combinations of output rates and time are used. Following such constant output cost traces would show an increasingly steep cost surface as the time dimension is reduced. This reflects the increasing storage requirements indicated in figure $11 \mathrm{~A}$ as operating time is reduced and output rate increased in producing a given total output (assuming a continuous and uniform consumption rate).

If the assumption of continuous consumption at a uniform rate is retained but a production pattern similar to that represented by the step function in figure $11 \mathrm{~A}$ is considered, the cost surface with storage may be considerably altered. As noted previously, the storage requirements under these assumptions depend on both the rate of production and the length of the individual production periods. With output rates very near the consumption rate or with very short production periods, storage requirements and costs may become quite small.

Figure $11 \mathrm{~B}$ is similar to figure 6 except that it includes the costs of storage. Where the cost surface in figure 6 is linear in the time dimension, the modified surface-including storage costs-is now curved. In the rate dimension, the surface is again shaped as an inverted $S$. At the limits of the time period, $t=0$ and $t=k$, there is no storage and the cost traces in the rate dimension are identical with figure 6 . That is, with $t=k$ (assuming uniform rates of production and consumption throughout the demand period) production and consumption are simultaneous and there is no storage; and with $t=0$, there is no production, hence no storage. While storage costs fall in absolute value as $t$ approaches 0 , they become a relatively greater part of the total cost, including storage. At intermediate points in the demand period, the cost surface rises more steeply in figure 11B than in figure 6 due to the addition of storage costs.

Many production and consumption patterns other than those illustrated in figure $11 \mathrm{~A}$ are possible, and each would involve different requirements and costs for storage and would result in a different total cost surface. The variations illustrated in figure 11, however, should adequately illustrate how the addition of storage costs may affect the total cost surface.

The procedures for determining the rates of output and hours of opera- 
tion that give maximum profits are as before and need not be repeated. The leading result of introducing storage costs is that for $t<k$ the plant will operate at lower rates of output than in the case of no storage costs. This is illustrated, for the particular consumption and production patterns assumed, in figure $11 \mathrm{~B}$. Line $C D$ represents a trace on the cost surface, includ-

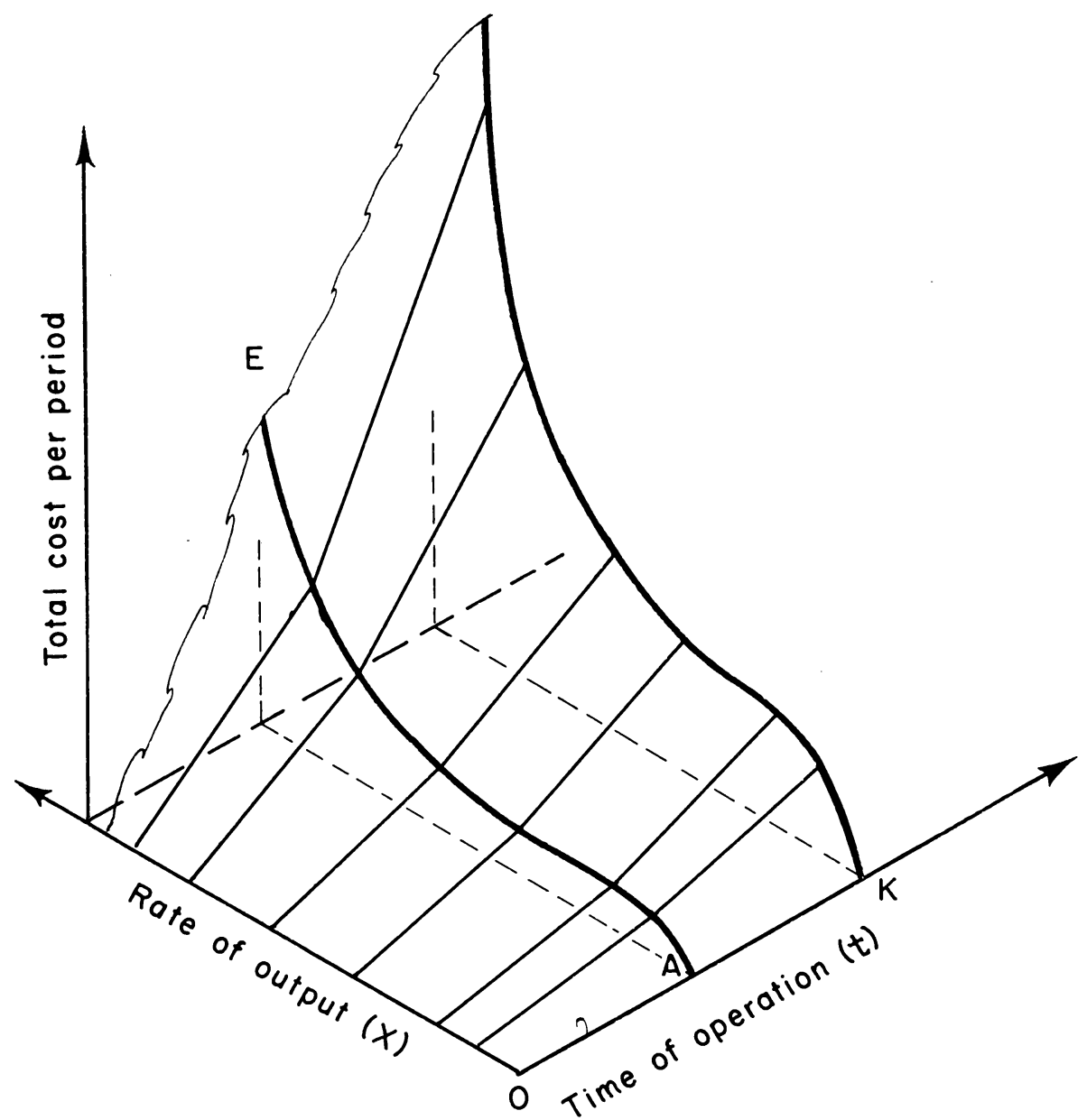

Fig. 12. Cost surface for producing a single product with both rate and time variation and with a discontinuity due to increased pay rates for overtime.

ing storage costs. The dotted line CE below CD is a trace on the cost surface without storage as represented in figure 6 . The straight line $A B$ projected on the base represents the "expansion path" or the minimum average cost rate of output in the absence of storage costs. Now, as storage costs are added, the surface becomes somewhat steeper and the minimum average cost point-the point of tangency of a straight line from $C$ with the lowest 
point on the curve $C D$ or $C E$-shifts toward the time axis. Allowing time to vary, the expansion path now describes a curve as suggested by the dotted line $A B$ projected on the base. The deviations of the dotted expansion path from the straight line path with no storage cost will vary with the nature of the plant and storage costs.

As in the case of no storage, if the calculated $t$ turns out to be greater than the available time within the demand period, the profit maximizing position would be determined in the manner indicated by conventional marginalist theory. Storage costs, other than required to adjust to irregularities in consumption would drop out of the function.

Discontinuities in the Time Dimension. The analysis has so far assumed that plants are free to vary hours of plant operation with no change in cost rates. Normally, however, this is not likely to be the case. Union regulations may require overtime rates of pay after some specified number of hours, or they may require that workers be paid for a minimum number of hours regardless of the time actually worked. The maintenance of satisfactory labor relations and labor supplies may also require that workers be guaranteed steady employment for some minimum amount of time per week or month. The existence of these institutional factors means that, even though the plant operates at a constant rate, cost may vary discontinuously with variations in the hours of plant operations.

A discontinuity of this type resulting from increased wage rates with overtime pay is suggested by figure 12 , omitting storage costs. When the time of operation reaches the level $O A$ (say 8 hours per day) all wage rates are increased by some constant proportion and there is a "kink" in the surface. As a consequence of this discontinuity, to operate for more than time $O A$ may be "unprofitable." This is suggested in figure 13 where total costs and total revenue are shown in relation to total output $(t X)$, with rate of output held at the minimum average cost level. Relative to these functions, profits are maximized at the corner position $O A$. With a continuous surface in the rate direction as in figure 12, however, marginal costs could be equated with marginal revenue to maximize profits by varying rates of output along line $A E$, but the rate of output would be above the minimum average cost level. This, of course, does not mean that the profit maximizing position would never occur in the overtime range of hours of operation. The situation described above is one of many alternatives. Other "time" discontinuities can be incorporated into the model and the optimum position calculated in a similar manner. But with these discontinuities, the calculations are necessarily somewhat more complex than in the continuous case.

Discontinuities in the Rate Dimension. In order to indicate more clearly the underlying relations, the formulation above has been based on the assumption that plant cost functions are continuous in the rate dimension. However, previous discussions suggested that this is likely to be a highly unrealistic assumption with modern industrial type plants. Therefore this assumption will now be dropped and the conclusions above modified to allow for discontinuities in both the rate and time dimensions. Figure 14 suggests the general nature of a cost surface with discontinuities in both 
the rate and time dimensions. The surface increases in a series of "steps" in the rate direction and shows a "kink" in the time direction. Many other alternative types of discontinuous surfaces are possible, of course.

It is clear that in this case the profit maximizing rate and time of output cannot be defined in terms of "marginal calculus" since this holds only for continuous functions. To determine the optimum position then requires that total cost and revenue be compared over the entire area of the surface.

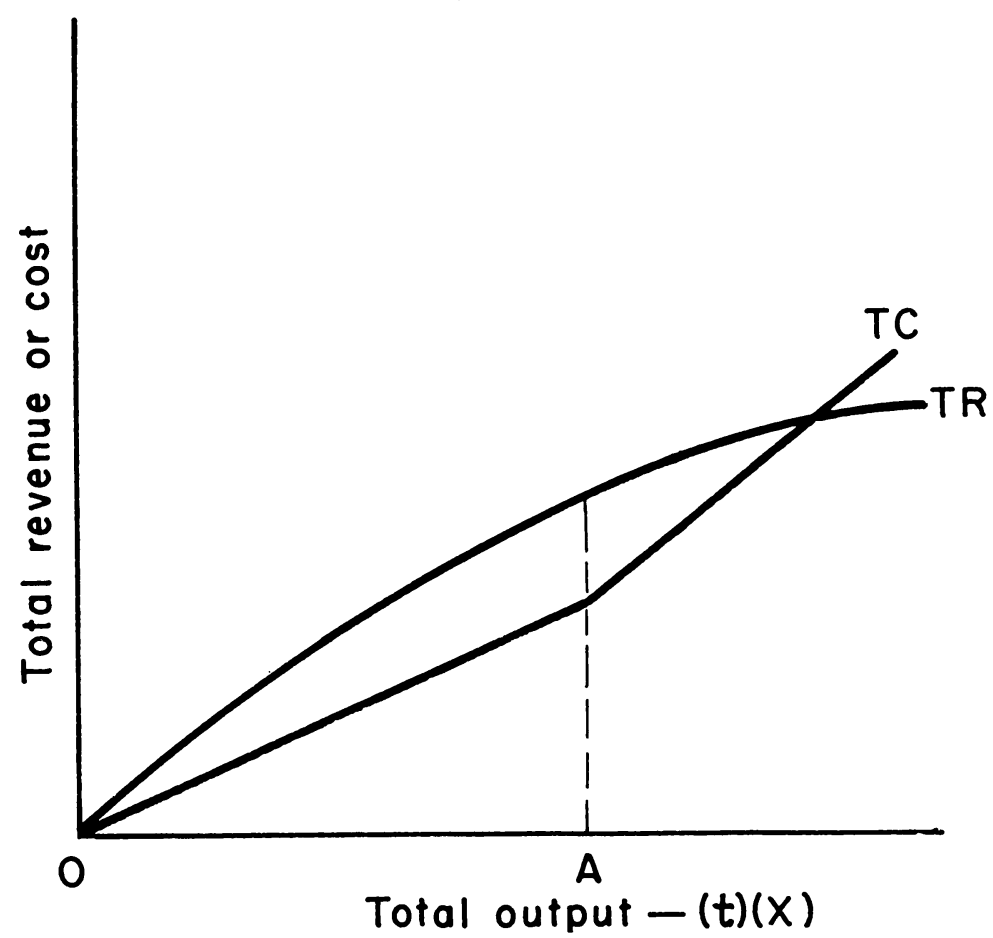

Fig. 13. A "kinked" cost curve due to overtime pay rates, showing where "overtime" operations would be unprofitable.

Maximum profit positions must be calculated for each of the continuous areas of the surface and these areas compared in absolute yield of profits, the maximum of these being selected.

Earlier discussions indicated that, with the possibility of a corner point yielding maximum profits, marginal cost need not equal marginal revenue. In fact, there could be points where marginal revenue and marginal cost were equal that yield a smaller total profit than other points where they are not equal (Brems, $1952 ;$ p. 583).

For plants with limited opportunities to vary rates of output (see section on nature of plant operations) the determination of the maximum profit position need not be difficult (assuming that the conditions of demand are known). But it is clear that where rates can be varied (discontinuously) and with several products and various institutional limitations to time variation, the problem of calculating the true optimum profit position becomes extremely complex. 


\section{The Firm in the Long Run}

The problems facing the firm in the long run are essentially the same as those in the short run-how much to produce and at what rates. Both involve the comparison of cost and revenue functions to determine the optimum rates of production. But the long-run cost function cannot be

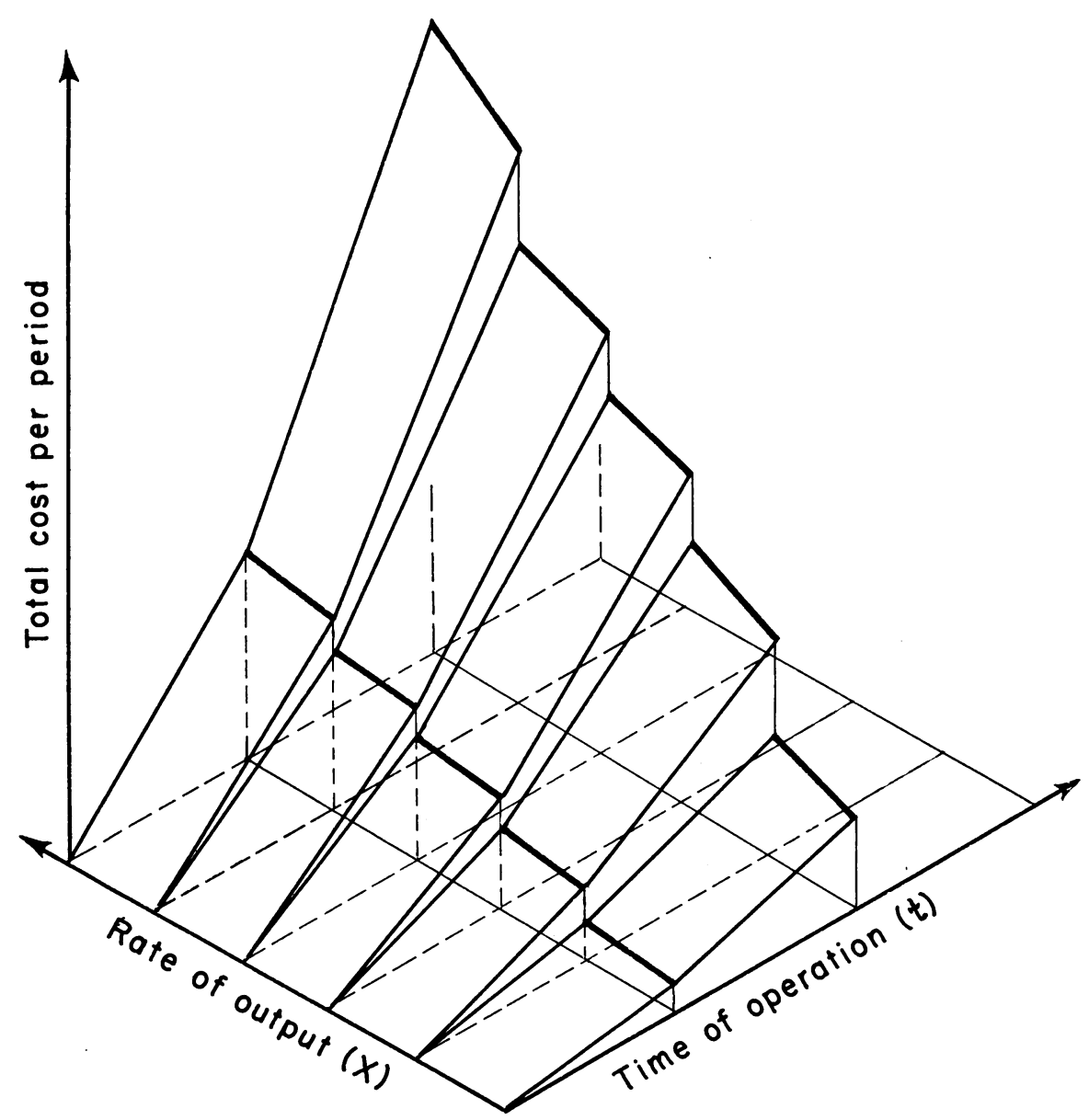

Fig. 14. A discontinuous rate-time cost surface.

determined directly. It must be approached through the short run by comparing costs of plants of many sizes and technologies and combining these into a function representing the least cost of producing at any rate of output for any number of hours per demand or sale period. ${ }^{16}$ In developing this function, several factors must be considered that were not encountered in the analysis of the short run. These are: (1) the fixed cost of dura-

${ }^{16}$ It will be recalled that every alternative combination of units of equipment, buildings, and layout has been defined here as consisting of a different plant. 
ble factors; (2) the problem of the selection of alternative production techniques and their integration; and (3) uncertainty and the needs for flexibility. ${ }^{17}$

Cost of Durables. In the long run, durable capital goods must be included in the cost considerations just as any other factor. It will be recalled that capital goods give rise to certain "fixed" costs, including depreciation, interest, insurance (part of risk payment), repairs, and taxes. Depreciation consists of a time component-exposure to elements, for example-and a use component-wear and tear associated with actual use. ${ }^{18}$ There is also an interaction between repair costs and depreciation costs associated with both wear and time. By continually incurring repair costs-probably at an increasing rate through time-the life of a durable item can be extended almost indefinitely (disregarding obsolescence).

In addition to deterioration, parts of the other costs associated with capital goods are functions of time, and independent of use. Interest, taxes, and insurance are related to time periods, although it might be argued that part of this is due to imperfections of the marketing system (Bressler, $1950 ;$ p. 14). But the prices or costs that are required in the analysis are for services of the durable goods. "Since use may vary from completely idle to 24 hours per day, it must be recognized that prices for the use of capital goods cannot be defined uniquely but are themselves a function of the amount of use." (Bressler, 1950; p. 15.)

It is not difficult to introduce the costs for capital goods into the concept of plant costs formulated in the previous section. Figure 15 repeats the diagram shown in figure 6 with the addition of a fixed base. This base-the distance $O A$-represents the time costs associated with the capital goods, expressed as a constant for the sale or demand period. ${ }^{10}$ Or more properly, the fixed base represents the long-run average rate of returns above variable costs that are required to maintain and replace the capital goods. Returns in any particular short-run period need not cover these costs, but over the long run they must average this amount if the firm is to continue in business. This is a long-run equilibrium concept. The long-run cost function will then consist of an envelope to many individual plant functions, such as illustrated in figure 15, including as above, the estimated returns above variable costs required to maintain and replace the capital goods. And, of course, just as the short-run function contains an "operating time" element, so also will the long-run function.

Selection of Alternative Production Techniques. The development of the long-run cost function is a problem of selecting and integrating the most efficient of alternative production techniques for plants of all sizes and for specified operating conditions. The analytical process must begin

\footnotetext{
${ }^{17}$ A degree of uncertainty and a need for flexibility exist in the short run, of course. The point is that uncertainty is magnified many times in the long run and the needs for flexibility are adjusted to this uncertainty. The given short-run plant either is or is not flexible in varying degree.

${ }^{18}$ Obsolescence, commonly regarded as a component of depreciation, is considered here as an element of uncertainty.

${ }^{19}$ Elements of "user costs" associated with the durable goods, of course, are included with variable costs.
} 


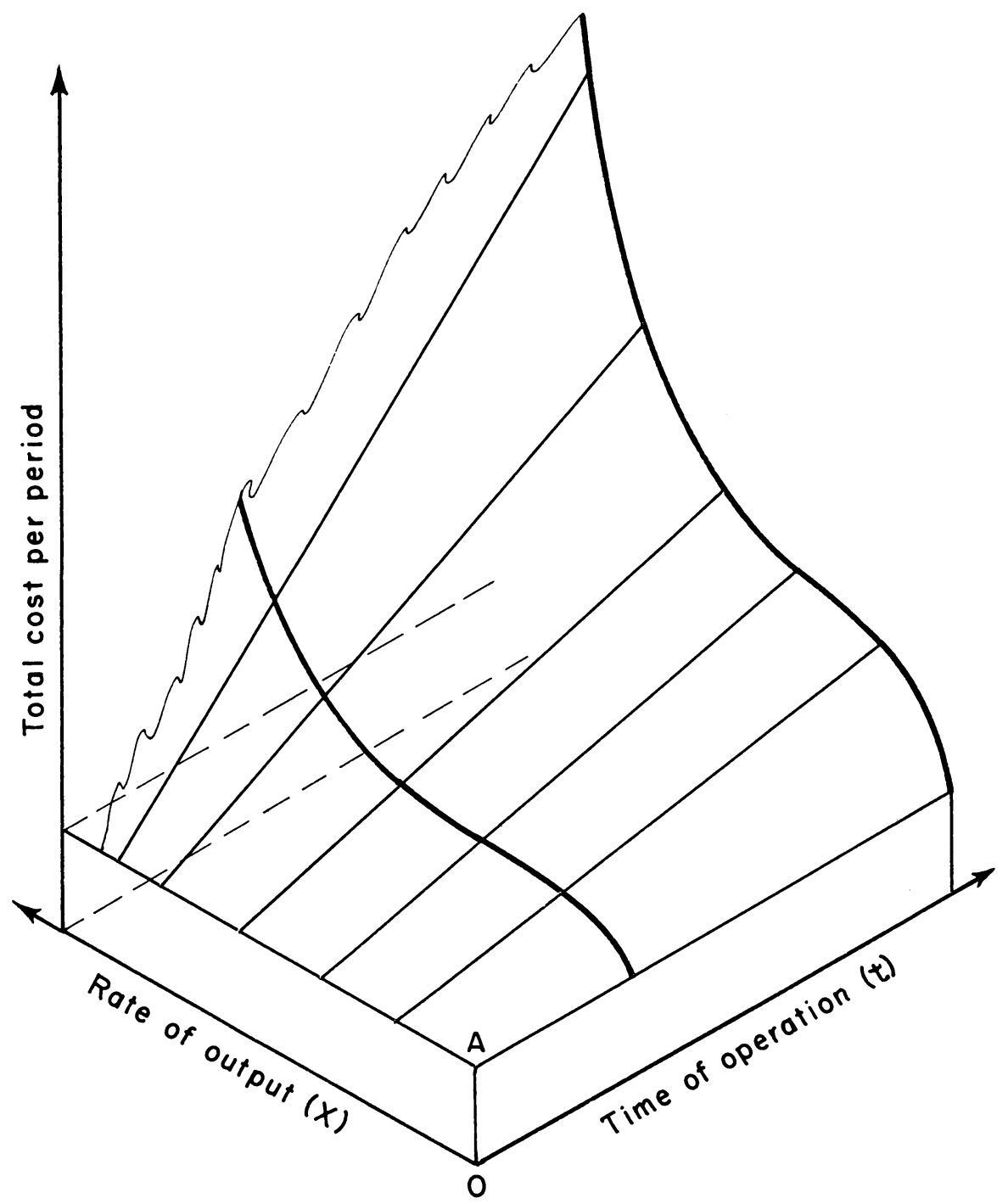

Fig. 15. Rate-time cost surface for a given plant, including "fixed costs" for durable capital goods.

with the individual stage, for alternative methods and equipment-technologies-are substituted stage by stage rather than on an over-all basis. Let $a_{1}$ be the number of alternative technologies available at stage $1, a_{2}$ the number of technologies that can be used at stage 2, and so on for $s$ stages. The total number of possible complexes or combinations of technologies $(T)$ is given by the expression ${ }^{20}$

$$
a_{1} a_{2} a_{3} \ldots a_{s}=T
$$

${ }^{20}$ If any stages are technically interdependent, the total number of feasible combinations would be less than indicated by this equation. 
The long-run total cost or planning function representing the least cost for any rate of output can be determined as an envelope to the long-run cost curves for each of the many different complexes of stage technologies. This is essentially the procedure outlined in conventional theory but with added dimensions.

It is clear that, even with only a few stages and a few alternative technologies available at each stage, the total number of combinations may be quite large. To compute total cost functions for all of the possible combinations of technologies would be an extremely difficult task. An alternative and somewhat simpler approach would be to determine the efficient technologies for each rate of output stage by stage. Stage cost functions representing only efficient technologies can then be aggregated into a long-run total cost function that would be the same as the envelope described above. Computations of total cost functions for many inefficient combinations of technologies would be eliminated.

To carry out this procedure, it will be helpful to distinguish between what might be called an economic stage and the technical stages that have been described previously. An economic stage may be composed of several technical stages wherein, given the rate of plant output, the use of a certain technology at one of these stages may limit or modify the use of some other technology at another of these stages. The minimum cost technologies can be determined only by joint consideration of all stages that are so related. In effect, for purposes of cost comparison, the joint stages must be redefined into a single stage which will be called an economic stage.

For some technical stages, the operations and equipment that can be used may be of such a nature that, given the rate of plant output, the particular technology employed has no influence on the technologies that can be used at other stages or on the costs of those technologies. This is true, for example, of the lidding stage in most fresh fruit packing houses. Given the rate of plant output, the type of lidding machine used has no effect on the costs of technologies at other stages, nor does it modify or limit the use of any of the other technologies. Thus, the type of lidding machine that is most efficient for any rate of output may be determined independently of considerations with regard to costs or technologies used at other stages. This type of stage might therefore be called independent, although the independence exists only in the strict sense indicated above. The technical stage in this case is exactly the same as the economic stage.

Conceivably, all stage cost functions for a particular type of process might consist of a jointly related chain, making the separate consideration of any technical stage or group of technical stages impossible. The entire process would then consist of a single economic stage and to determine the least-cost, long-run cost function would require that the original procedure outlined above be followed, i.e., to consider all possible combinations of stage technologies. On the other hand, where the nature of the plant process is such that several economic stages may be distinguished, the second procedure might be followed more conveniently. That is, technologies or combinations of technologies that are most efficient for any rate of output or hours of operation per demand or sale period can be determined separately for each economic stage. 
The general nature of the selection and integration process is illustrated by the hypothetical stage cost functions shown in figure 16. These curves represent several alternative technologies for two of the economic stages. Each curve shows the total stage cost per demand or sale period-including operating costs and returns above variable costs required to maintain and replace the durable factors-expressed in relation to the rate of output. The time of operation per period is held fixed at some given level and technology is constant for each function. ${ }^{21}$ The curve representing each technology may be viewed as an "envelope" to the cost curves of plants of different size and employing different quantities of the same type of equipment.

Another "envelope" may be drawn to the curves representing the different technologies to obtain the long-run cost function for each economic stage. In the example, technology II in stage 1 is least costly if hourly volume is less than $O X_{1}$. Technology III provides the least cost if output is between $O X_{1}$ and $O X_{2}$; IV gives the lowest cost for rates of output between $O X_{2}$ and $O X_{3}$; and beyond $O X_{3}$ technology $\mathrm{V}$ shows the lowest cost. Note that technology I fails to be most economical for any output and so is eliminated in determining the "envelope."

A similar envelope is obtained for stage 2 and for each of the other plant stages. These functions may then be aggregated (including costs of a general nature) to determine the total long-run cost or planning curve. If hours of operation per sale period are held at a different level, a different set of stage functions is obtained and thus a different long-run cost curve. In fact, there will be a whole family of planning functions, one for each time of operation, which means that time of operation is itself a variable in the cost function. ${ }^{22}$

The cost functions shown in figure 16 illustrate a situation where, as the number of alternative technologies available at each stage increases, the magnitude of the discontinuities in the long-run cost function tends to decrease, although their total number may increase. There is a further relative decrease in the magnitude of the discontinuities (and again a further increase in their number) as the stage cost functions are aggregated into an over-all cost curve. The long-run cost curve with variable techniques thus approaches a continuous function and in the purely theoretical extreme would be continuous, although the latter is quite unlikely for most types of plants.

The long-run cost function is used to determine optimum rates of output just as in the short run, with the long-run rates defining the size of the plant. It was noted previously that, under pure competition, each firm would operate for the full amount of time available during the sale period. Optimum rates of output can be calculated in the manner indicated by the conventional theory (Carlson, 1939; Samuelson, 1947; Boulding, 1948; Schneider, 1951). Under these circumstances, the long-run equilibrium adjustment would find each firm at the minimum point on its long-run cost function.

\footnotetext{
${ }^{21-} \mathrm{A}$ change in equipment size is viewed here as a change in technology.

${ }^{22}$ This discussion encompasses much of the material developed by Ivar Jantzen and further elaborated by Hans Brems. Brems, op. cit.
} 

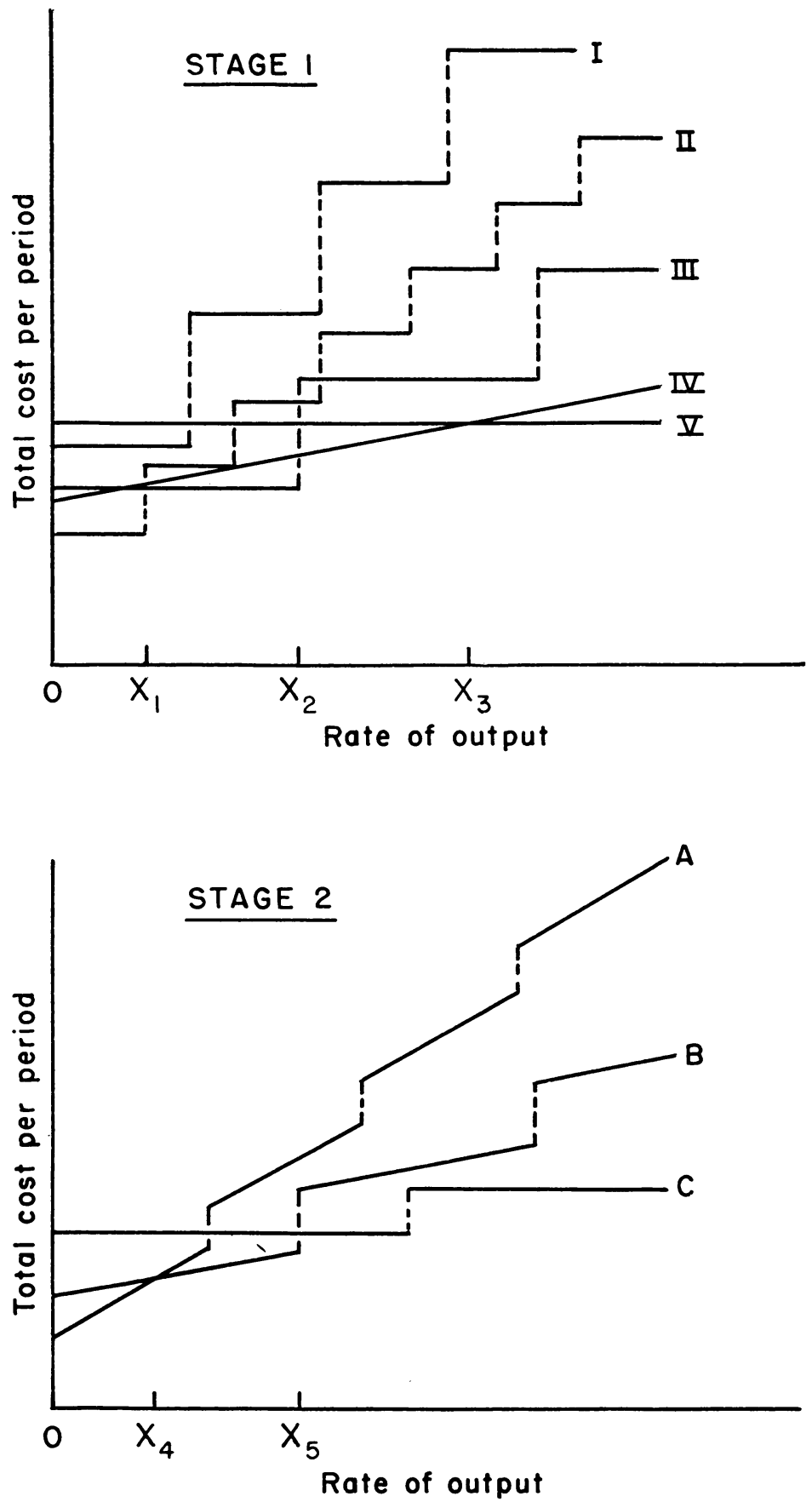

Fig. 16. Cost functions for alternative technologies at two plant stages, with operating time per demand or sale period held at a specific figure. 
With imperfect competition, however, there is no reason to suppose that a firm would necessarily operate either for the full amount of time available in the sale period or at the minimum point on the long-run average cost function. The latter is reached only by operating for the full amount of time available during the sale period (due to a spreading of "time" costs). But operation at the minimum point on this curve might involve a total amount of production per sale period greater than required to maximize profits. If profits were to be maximized, total output would have to be reduced, either by reducing operating time per period or by reducing the scale of plant or both. The most economical procedure in the long run would be, first, to reduce the scale to the point where long-run average variable costs were a minimum and, thereafter, to reduce total output by reducing operating time, until the profit maximizing quantity of production was reached-all this, of course, assuming no institutional barriers to such adjustments. If the demand were great enough, the firm might operate (by chance) at the minimum point of the long-run total cost function, or even beyond this point.

Uncertainty and Flexibility. In reaching decisions on the size of plant and methods of operation that will prove most profitable, the business manager is faced with two kinds of uncertainty: (1) as to the future course of product and factor prices; and (2) as to the estimates of the amount of return above variable costs required to replace and maintain the durable items of the plant. The latter is a consequence of an inability to evaluate correctly the rates at which the durable items deteriorate (partly a result of the first uncertainty) and to predict future dates at which new technological developments may render the equipment obsolete. In his decision-making process the business manager must consider two factorswhat are the probabilities that prices or conditions will change by various amounts, and what are the consequences of errors in expectations of net returns. ${ }^{23}$ The evaluation of the first of these factors is extremely difficult and certainly will not be evaluated in the same way by all businessmen. Answers to the second question can be suggested by assuming alternative prices or conditions and calculating the potential returns under these circumstances. Willingness to invest or produce in the face of a given risk or uncertainty depends largely on the magnitude of possible gains or losses and the individual's ability and willingness to withstand adverse fortune as well as to make profits (Hicks, 1946; p. 126).

To incorporate these concepts directly into the theory developed in the preceding pages would require the consideration of many special casesdifferent models for different individuals and circumstances plus an overall consideration of the combined effects of the expectations and reactions of all businessmen together. No attempt will be made to do this here. The fundamental theoretical relationships underlying cost and production which have been emphasized here should remain basically valid regardless of the uncertainties involved, although some minor modifications might be re-

\footnotetext{
${ }^{23}$ The matter of expectations as probabilities is treated at some length by A. G. Hart, "Risk, Uncertainty, and the Unprofitability of Compounding Probabilities," Studies in Mathematical Economics and Econometrics (Chicago: University of Chicago Press, 1942).
} 
quired to fit special cases. It may be well, however, to include a brief discussion of a form of insurance against some of these uncertainties-insurance obtained through flexibility in the plant operations.

The entrepreneur is interested in at least four types of flexibility. ${ }^{24}$ The first consists of flexibility to adjust to seasonal changes in output. Such changes are common, for example, in agriculture, in retail store sales, and in passenger transportation, to mention only a few. Variation of this sort may be reasonably certain and may be anticipated, in part, from historical patterns. For plants where the period of production need not correspond exactly to the period of consumption, the most efficient (least costly) means of obtaining this kind of flexibility may be through variations in hours of plant operation. As was pointed out previously, this permits the plant to operate always at or near its most efficient rates of output, but requires storage.

In many instances, however, there are institutional barriers which render continuous variation in hours of operation relatively uneconomical-at least in some ranges. Under these circumstances flexibility must be "built in" by using technologies which permit the maintenance of fairly uniform variable unit costs for a considerable range in rates of output (Stigler, 1939; pp. 305-27). But flexibility itself entails a cost, for more efficient technologies might be used if the plant operated at stable rates of output. "The most common way of obtaining this type of flexibility is by the use of many small identical machines rather than larger units which would be more efficient if regularly fully utilized. ${ }^{25}$ This also provides a form of insurance against large losses. For example, if a refrigerator plant has only a single compressor and it fails, everything spoils.

The profitability of building in various amounts of flexibility must be judged in the light of expectations-however vague-concerning the future variations in total output and the opportunities to adjust to these variations by varying hours of operation. Given the expected variations-i.e., the number of hours of operation that may be required at different ratesthe technologies giving lowest costs for these circumstances may be determined. Total variable costs are estimated for the anticipated number of hours of operation at each rate for each technology. ${ }^{28}$ To the sum of the variable costs are added'the charges to cover the replacement of the durable items associated with each technology. The total costs of the technologies are then compared, and the lowest cost method is selected as indicated in the previous section. This procedure can be carried out for plants of any size, but due to the infinite number of alternative situations, a general planning or "economies of scale" curve for flexible plants is difficult to develop.

A second type of flexibility, which is closely related to the first, permits a more economical adjustment to the changing factor prices and to inno-

${ }^{24}$ Three of these types are suggested in Cost Behavior and Price Policy, National Bureau of Economic Research, New York, 1943, pp. 223-25.

${ }^{25}$ Cost Behavior and Price Policy, p. 224. For a further discussion of this problem, see J. M. Clark, The Economics of Overhead Costs (Chicago: University of Chicago Press, 1923).

${ }^{28}$ Recall that a change in the size of equipment units is defined here as a change in technology. 
vations. It is obtained by substituting variable services for fixed servicesfor example, by employing technologies that require large amounts of labor relative to equipment. As rates of output fall, labor can be "laid off" but fixed items are committed before production ever begins. And with this flexibility, innovations can now be incorporated into the plant process with reduced losses from obsolescence. Again, the decision must be made in terms of the rate-time-of-operation complex and in terms of expectations as to future changes.

A third type of flexibility "permits economical change to a somewhat different product or an alteration in the proportions of joint or allied products. It is obtained by the use of general purpose rather than entirely specialized machinery." ${ }^{27}$ The nonspecialized equipment may be less efficient for specific combinations of outputs, yet may prove more economical if there is a considerable variation in proportions of products.

A fourth type of plant flexibility "permits rapid adaptation to long-term change in quantity of output demanded. Businessmen are particularly concerned that their plant be easily expanded. It seems obvious that the firm which can most economically revise its scale has a competitive advantage; for instance, there is much to be gained from reducing scale in periods of prolonged depression or in secularly declining industries. The efficiency of a plant depends not only on the level of technology prevailing at the time it was built, but on the changes of scale then contemplated.,"28

Before leaving this problem, a few words should be added concerning an aspect of flexibility that is difficult to quantify-timeliness of operation. Plant managers may at times find themselves faced with a peculiar market situation where very rapid production and handling for a short period may yield high profits or prevent large losses. Or a firm processing perishables may suddenly become swamped with fruit to be processed. Immediate handling may save many dollars. Plants using large amounts of machinery may be best able to adjust to these situations. Thus, what appears to be a more costly technology may in the long run yield the greater total returns. ${ }^{20}$

\section{A METHODOLOGICAL APPROACH TO COST MEASUREMENT}

The problem of measuring and comparing costs may be approached in a number of different ways, the most efficient method depending on the specific objectives of the study and the resources available for carrying out the research. For example, if the objectives are broad and the resources limited, careful analysis of average costs based on accounting records may give a rough, but useful, approximation to economies of scale or variations in relative efficiency among plants. On the other hand, the development of improved methods of performing particular operations may require very

${ }^{27}$ Cost Behavior and Price Policy, op. cit., p. 225.

${ }^{28}$ Ibid., pp. 224-25.

${ }^{29}$ For an interesting discussion of this problem with respect to farming operations, see Martin R. Cooper, "That Extra Machine May Pay in the Long-Run," The Agricultural Situation, Bureau of Agricultural Economics, U. S. Department of Agriculture, April, 1953. 
detailed industrial analysis or time and motion study. The economic-engineering approach that is outlined here is designed for studies concerned with comparing the relative efficiency of alternative technologies and with deriving specific cost functions for individual plants and long-run functions involving plants of different size. However, the general methodology would also be appropriate for studies with slightly different objectives.

The previous theoretical considerations suggest that, for these purposes, cost measurement should begin at the stage level or, in some cases, with even more elemental operations. In this way, the measurements yield inputoutput functions that provide a fundamental basis for comparing the costs of alternative technologies and for developing total plant cost curves. The material in this section is concerned with the sources of data required for these measurements and with the general analytical procedures used to develop estimates of the cost-output relations at each stage and the combination of these into total cost functions. The measurement problems differ somewhat among the major types of inputs and will be discussed under four headings: labor, materials, other operating inputs, and durables.

\section{Labor}

Two main sources of data can be used to estimate basic physical and costoutput relationships for labor: (1) plant payroll and output records and (2) engineering studies of actual operations.

\section{Plant Records}

Plant payroll records usually show the hours of labor per day or week and the pay rates for each worker in the plant. Where these records indicate, or can be made to indicate, the nature of each worker's job, they may be related to the corresponding volumes of products to develop labor inputoutput functions for most of the plant stages. ${ }^{30}$ It must be recognized, of course, that the changes in output and input from period to period may result from both changes in rates and changes in hours of operation. Time must be introduced into the function, either directly or as a "deflator," to reduce each period observation to an average rate basis. From the standpoint of developing a function that is the closest possible approximation to "instantaneous" rates, the data should apply to short time periods with nearly constant rates of input and output within each period. As the length of the observation period is reduced, the rates become more uniform within the period. The functions derived from these data then will more closely approximate instantaneous rates of input and output. Data on a daily basis may come closest to meeting these conditions. The observations over periods, in a rate sense, should cover a wide range, of course, if the function is to be stable and valid for many rates of output.

The disadvantage of payroll records is that they usually reveal little of the specific details of many of the plant jobs. For example, they may con-

\footnotetext{
${ }^{30}$ Some jobs may not be related to specific stages but to the over-all operation-for example, plant foremen. Other jobs, such as bookkeeping, may be related mainly to the size of plant rather than to volume in a given plant, although the number of payroll clerks and the like may be varied with the total number of workers employed in the plant.
} 
ceal the fact that a considerable portion of the man-hours involved in performing a particular job may consist of idle time and that a higher rate of performance or output could be attained under other circumstances. Another difficulty is that the records may contain errors or be incomplete in classifying workers as to the type of work performed. Moreover, since accounting procedures are far from standardized, it will often be difficult to obtain strictly comparable records from a number of plants.

\section{Engineering Studies}

Engineering studies provide a means of obtaining basic labor data that are not readily available from accounting records. Four specific types of studies are important in this regard: (1) detailed descriptions of plant operations; (2) time studies; (3) work sampling studies; and (4) analysis of standard work data.

Description. This type of study is useful mainly to provide a general picture of the plant organization - the crew setup, kinds of operations performed, and the like. It consists of detailed descriptions of each plant job, number of workers employed on each job and stage for the observed rates of output, and the flow of materials through the plant. It is intended as a supplement rather than a substitute for other types of studies but in some cases may provide all the needed information.

Time Studies. Time studies usually involve stop-watch measurement of unit time requirements over a short period of production-say, 20 to 60 minutes. Prior to actual measurement, the job is described or analyzed and the production units defined. Individual measurement is then made of the elapsed time between the beginning and end of work on each production unit. In some cases, the time per production unit may be divided into several elements and separate time measurements obtained for each element. The level of performance may be judged relative to some concept of a "normal" rate of activity, and all time observations are adjusted to this standard. Through this procedure, it is expected that the time measurements of different workers will reflect a more uniform level of skill and rate of activity. ${ }^{31}$

The disadvantages of this type of study are in the rating procedure and in the fact that only a few workers are observed, and they are observed over short periods of time. The concept of a normal rate of activity is rather vague and the ability of time study men consistently to rate different jobs and workers accurately to the same norm is open to some question, although it is claimed that trained industrial engineers are consistent within limits of 5 per cent. Where only a few workers are studied for short periods, the observations may not be fully representative of the usual activity associated with the job, particularly if there is worker reaction to the time study. This disadvantage is reduced, however, if the rating procedure achieves its objective. In spite of these limitations, the rating procedures will usually result in a "tightening" of the seatter of observations and thus reduce the possible range of error.

\footnotetext{
${ }^{31}$ For a more detailed treatment see R. M. Barnes, Motion and Time Study (New York: John Wiley and Sons, 1949); or R. L. Morrow, Time Study and Motion Economy (New York: Ronald Press, 1946).
} 
Work Sampling Studies. The work sampling technique, commonly called ratio delay, is essentially a procedure of sampling workers' activities through time. ${ }^{32}$ It provides estimates of the proportions of time spent by various workers on various operations. When related to the total man-hour inputs and corresponding outputs, it yields estimates of the unit time requirements for the detailed elements of each job.

One of the limitations of time studies-all workers not working at the same rate-is still not overcome by the use of the work sampling method. However, this problem may be reduced, at least, in that the studies cover a longer period of time and more workers and, therefore, may provide a better representation of "normal" performance. Other advantages are: it can be applied to some jobs where time study is quite ineffective; the studies reveal where delays and idleness occur, which disclosures may lead to the development of means of minimizing them; the work sampling studies may require less field time to obtain a given amount of data or to cover a given number of operations; and finally, the sampling procedure involved in this method provides an objective measure of the reliability of the time measurements. ${ }^{33}$

Standard Work Data. This is a micromotion technique based on the use of standard work data developed by industrial engineers. It can be used to estimate approximate standard labor requirements without direct measurement. It requires a detailed description of each operation and manipulation involved in the job. This includes specifying each arm and hand motion, type of grasp, weights and dimensions of objects moved, body turns, and so on. If each micromotion is adequately described, standard time requirements can be taken from motion and time tables. The sum of the time requirements for all microelements in a job represents an estimate of the basic unit time requirements.

It would appear that this method might be a great timesaver as it eliminates actual direct measurement. Unfortunately, in some cases, the element descriptions and computations involved are themselves so time consuming that they may offset much of the gain from eliminating actual measurement. Other difficulties with this method are that it requires a somewhat specialized skill, and there is some question as to the reliability of the standard data themselves. ${ }^{34}$ On the whole, this method may be useful to supplement or check against direct measurement, but probably it cannot yet be considered an adequate substitute.

\footnotetext{
${ }^{32}$ For a detailed discussion of this method and of the problem of testing the statistical significance of the ratio-delay estimates, see L. L. Sammet and J. B. Hassler, "Use of the Ratio-Delay Method in Processing Plant Operations," Agricultural Economics Research, October, 1951; D. G. Malcolm and L. L. Sammet, "Work Sampling Applications," Journal of Industrial Engineєring, May, 1954 ; L. L. Sammet and D. G. Malcolm, "Work Sampling Studies: Guides to Analysis and Accuracy Criteria," Journal of Industrial Engineering, July, 1954.

${ }^{33}$ The latter also ean be true of time study, but limited numbers of observations usually mean low "reliability"-this in part offset by the "rating" procedure.

${ }^{34}$ For example, see Adam Abruzzi, "Developing Standard Data for Predictive Purposes," Proceedings, Fourth Annual Industrial Engineering Institute. University of California, Berkeley and Los Angeles, 1952.
} 


\section{Analytical Procedures}

The data collected from the sources described above provide a quantity of material that can be used to estimate the physical input-output and cost relations for the labor associated with each alternative technology at each plant stage. The analytical process may be viewed as consisting of three steps: (1) development of the physical standards of performance; (2) verification of these standards; and (3) development of cost standards.

Physical Standards. Implicit in the formulation of the theory of production is the assumption that inputs and their corresponding outputs are representative of "efficient" levels of performance-i.e., performance that can be maintained under good management with usual operating conditions. But actual measured labor performance commonly shows a wide variation, and this creates a problem in defining the levels that appear most "reasonable" as practical approximations to theoretical performance. Certainly a standard corresponding to peak performance would not be "reasonable." On the other hand, it might be expected that a level of performance that could be maintained under good management and "normal" operating conditions would be somewhat above average for actual performance in many plants since the average reflects inefficient as well as efficient operation. In this analysis, standards of "reasonably efficient" performance have been expressed in terms of output rates for average workers when the plant operations are organized to result in minimum unavoidable delay. These standards tend to fall about halfway between peak and average plant performance. These are standards which can be attained and exceeded but which are still better than average. This definition, which is somewhat indefinite and admittedly arbitrary, is reflected in the quantitative material of the following sections.

To determine standard input-output functions may require any of a wide variety of analytical procedures, including mathematical and graphic statistical techniques. For some operations, plant records may prove the most productive source of data; for other cases, engineering studies may be most useful. In many instances, two or more sources may yield data that reinforce and supplement each other. It should be stressed, however, that, regardless of the specific procedures and kinds of data that seem most appropriate for a particular operation, the analysis should yield functions representing rates of input and output. The rate functions may then be converted to appropriate functions where volume is increased by increasing hours at more or less constant rates of output. Failure to separate the effects of variations in rates and variations in time may give completely unrealistic descriptions of the true nature of the production function. ${ }^{35}$

The standard input-output relations may be discontinuous, taking account of the fact that workers must be hired in whole units. For standards based on engineering studies, the measurement process gives results initially in terms of "basic" labor time requirements-"instantaneous" functions. Allowances for rest periods and necessary delays are added and the standards expressed

\footnotetext{
${ }^{35}$ The fatigue factor-decreased productivity with increased hours of work-in some
} cases may complicate this separation. 


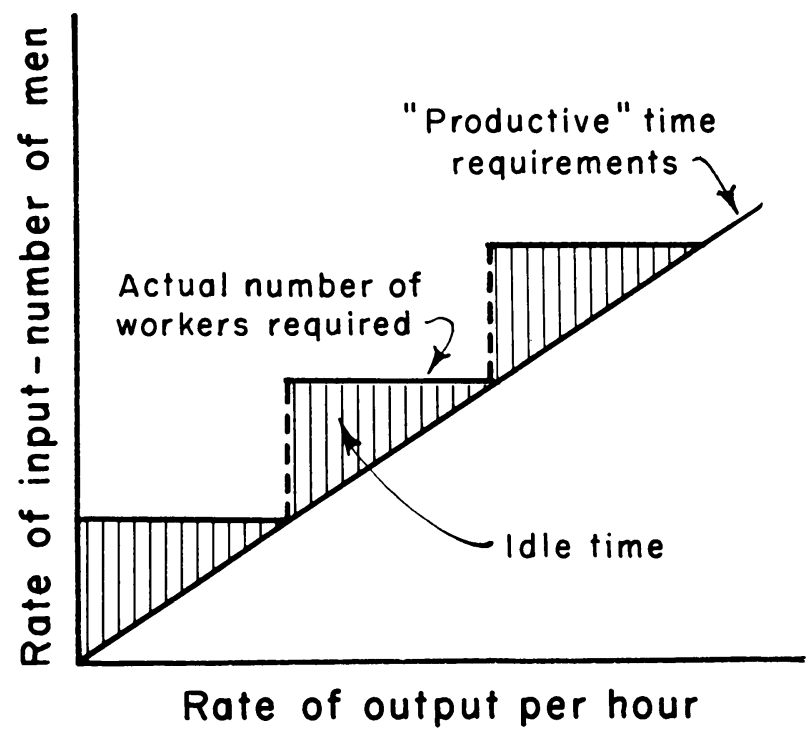

Fig. 17. Labor performance standard based on engineering studies.

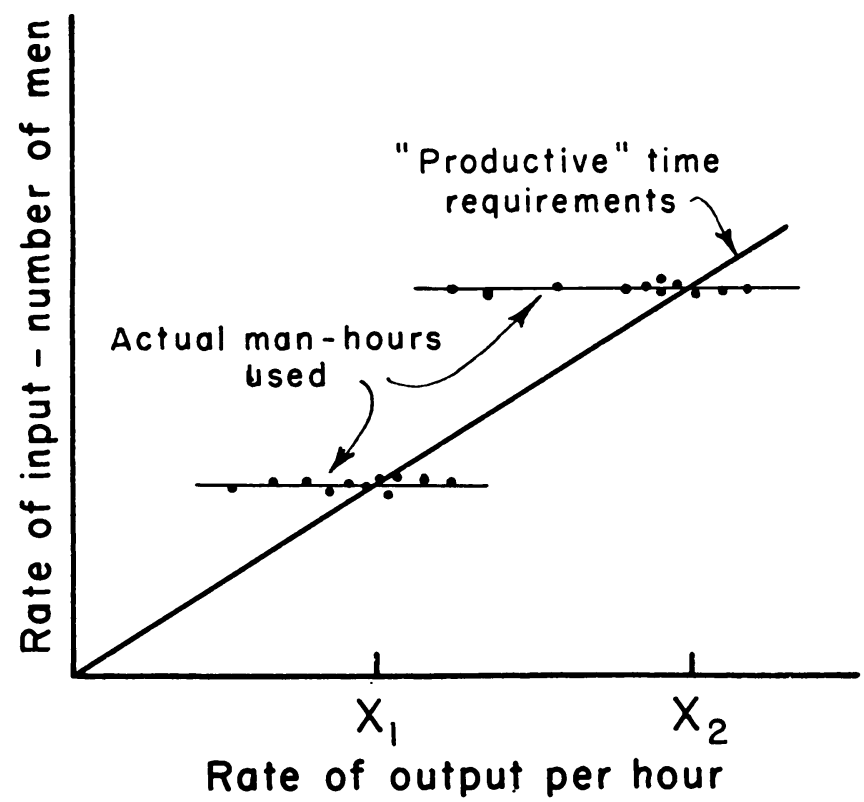

Fig. 18. Labor performance standard based on accounting record data. 
more conveniently as average rates over time. The continuous sloping line in figure 17 illustrates such a standard, with the "steps" indicating the actual number of workers that must be hired. The shaded area represents "idle" time-i.e., time that is idle other than for rest periods and necessary delays.

Where the standards are based on accounting record data, the measurement process may yield input-ouput relations directly in terms of a "step" function as suggested in figure 18. In this case, the productive time requirements are estimated by the continuous function passing through the upper range of observations. Presumably, if outputs $O X_{1}$ and $O X_{2}$ could be reached and exceeded in a number of instances, the observations for rates of output below $O X_{1}$ and $O X_{2}$ were accompanied by idle time or reduced rates of performance.

Verification of the Standards. Having developed physical production functions in the form of performance standards, the next step is to ascertain whether or not the standards do, in fact, appear to represent reasonably efficient performance. Where the standard is based entirely on accounting data, its verification is implicit in the analytical process since the data used to develop the standard represent actual performance over a fairly long period. As soon as any standard is calculated, its relation to actual performance is known.

On the other hand, standards based on engineering studies may cover only a short period of time and perhaps only a limited number of workers. Adjustment or "leveling" of the time values to some norm may reduce the variation in the estimates but, as was indicated previously, the norm itself may not be well established. Thus, it is desirable to compare these standards with actual rates of performance to see if they appear to represent "reasonably efficient" levels of performance.

A comparison of this type is illustrated in figure 19 (French, 1952). The diagram shows the average hourly rate of output of packed fruit in nine California pear packing plants in relation to the average number of packers employed on particular days. The solid line represents the standard rate of output for any number of packers (holding fruit size at the average level for all plants). The standard is based on time and work sampling studies. Each dot represents, for one of the nine plants, the number of packers and their actual total average hourly rate of output for a particular day of the season.

A part of the variation in the scatter of daily observations is due to variations in fruit size-a factor which is largely beyond the control of management and which is a variable in the standard itself. For a proper comparison of actual and standard performance, both the observed and standard rates of output should reflect the same average fruit size. However, the specific sizes represented by each daily observation were not known in all cases and, therefore, actual performance was compared with the standard rates of output corresponding to the average of all sizes packed among all plants for the season, the latter being known. Adjustment for the size factor would probably bring some of the lower observations closer to the standard, although available evidence suggests that daily variations in the average size of fruit were not especially large. 
Studies in the sample plants revealed that, aside from variations in average fruit size, the major factors contributing to low rates of performance on some days were delays in the plant operations and imperfect adjustment of the packing crew size to rates of fruit flow. The standards represent operating conditions where these delays and imperfect adjustments are reduced to a reasonable minimum. The degree of "reasonableness" is suggested by the fact that hourly rates of output in nearly all of the sample plants equalled or exceeded the standard on some days during the seasons studied. Of the

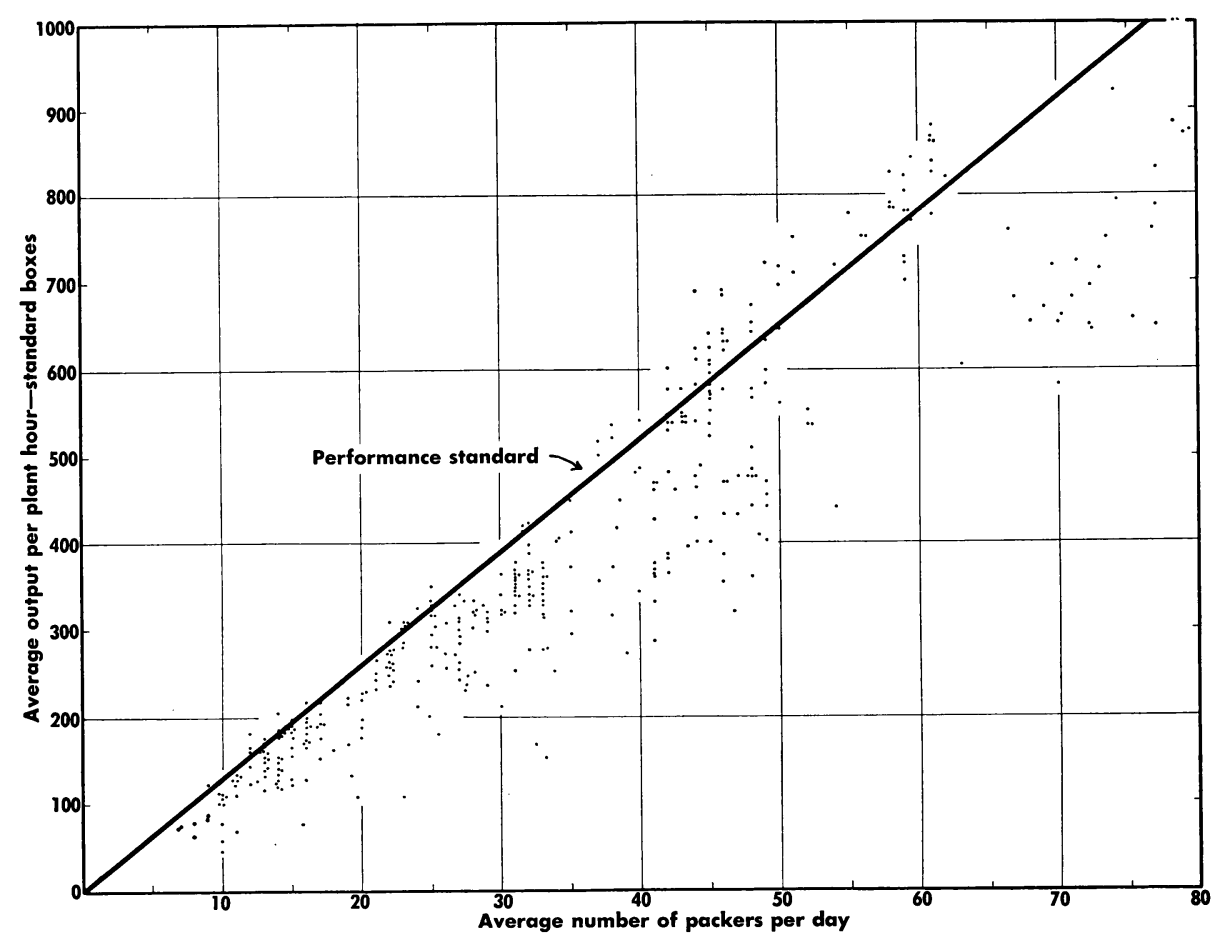

Fig. 19. Relation of standard to actual rates of packer performance in nine California pear packing plants.

total observations in figure 19 , about 20 per cent were on or above the standard. In other words, these standards are well within the range of actual performance, but they do represent better than average efficiency.

Cost Standards. To be of use in the decision-making process, the physical performance standards must be transformed into estimates of cost as functions of the rate of output. This is a fairly simple problem in theory but, in actual measurement, it is complicated by the fact that wage rates may be on an hourly or a piece-rate basis. A specific example will be used to illustrate the procedures involved in transforming physical functions to cost functions. Labor performance standards for lidding boxes on three types of machines in California pear, apple, and grape packing plants are given in table 1 (French, 1953). The standards indicate, for example, that a stitcher operator who places the top pad on the box himself can lid up to 
280 boxes per hour. ${ }^{38}$ If the rate of plant output is less than 280 boxes per hour, the operator will be unavoidably idle for a portion of his time, but he must be paid for the entire hour. He has a fixed working station and must remain there at all times, although there is some flexibility due to "on line storage" on the conveyors carrying the boxes to the lidding machine. When rates of output exceed 280 boxes per hour, another operator and machine must be employed. Beyond 560 boxes, a third operator and machine are required, and so on. There would be, of course, minor variations in these breaking points with different operators.

TABLE 1

PERFORMANCE STANDARDS FOR LIDDING PEAR, APPLE, AND GRAPE BOXES

\begin{tabular}{|c|c|c|c|}
\hline Item & $\begin{array}{l}\text { Stitcher type } \\
\text { lidder* }\end{array}$ & $\begin{array}{l}\text { Low-speed } \\
\text { lidder }\end{array}$ & $\begin{array}{l}\text { High-speed } \\
\text { lidder }\end{array}$ \\
\hline & \multicolumn{3}{|c|}{ boxes per hour } \\
\hline Maximum machine capacity.. & 500 & 720 & 1,600 \\
\hline \multirow{4}{*}{ 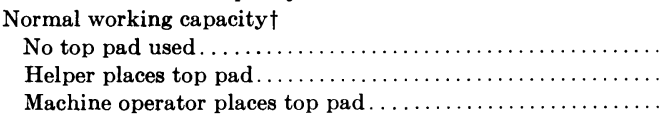 } & & & \\
\hline & 370 & 460 & 1,010 \\
\hline & 370 & 460 & 1,010 \\
\hline & 280 & 330 & 540 \\
\hline
\end{tabular}

* Standards are based on an a verage of 3 nails per side.

$\dagger$ Includes allowances of 4.2 per cent for rest periods, 4 per cent for personal time, and 10 per cent for getting lid, , oiling machine, and miscellaneous.

The physical performance standards do not directly determine labor costs. They determine the number of workers that must be employed to achieve a given rate of output. The labor cost is then estimated by multiplying the required number of workers by the appropriate wage rates. ${ }^{37}$ These calculations are illustrated for the lidding operation in table 2.

When labor is paid on a piece-rate basis-not all jobs are adapted to this method of payment-the problem of transforming physical inputs to a cost basis is simplified in one respect and complicated in others. Direct labor costs are determined, not by units of input, but by units of output. In this respect, the labor cost function is simply a linear function of the rate of output with the slope of the function equal to the level of the piece rate.

However, the established piece rate must bear some direct relation to the typical levels of physical performance. Over the long run, earnings of these workers might be expected to exceed those of hourly pay workers of the same skill only by an amount corresponding to the higher levels of exertion in response to the piece-rate incentives. Industrial engineering experience has suggested that performance standards for workers paid on a unit basis would normally be about 25 per cent higher than for hourly rates (Barnes, 1949 ; p. 330 ), although in some cases the response might be considerably

${ }^{36}$ These standards are appropriate for hourly pay rates. On an incentive basis-i.e., piece-rates or variable hourly rates that give increased earnings with increased outputthe rate output could reasonably be expected to be 25 per cent higher.

${ }_{37}$ These prices may be constant or a function of the quantity of inputs. For simplicity, they are assumed constant in the discussion that follows-i.e., competitive conditions. 
higher (French and Sammet, 1954). There are, of course, many types of wage incentive plans involving varying combinations of hourly and piecework wages and thus varying degrees of incentive. The straight piece rate appears to provide the maximum incentive with somewhat lower responses from the other plans.

TABLE 2

LABOR REQUIREMENTS AND COSTS OF LIDDING PEAR, APPLE, AND GRAPE BOXES

\begin{tabular}{|c|c|c|c|c|c|c|c|c|c|}
\hline \multirow{3}{*}{ Average rate of plant output } & \multicolumn{6}{|c|}{ Estimated lidding crew } & \multicolumn{3}{|c|}{ Labor cost per hour } \\
\hline & \multicolumn{2}{|c|}{ Stitcher } & \multicolumn{2}{|c|}{ Low speed } & \multicolumn{2}{|c|}{ High speed* } & \multirow{2}{*}{ Stitcher } & \multirow{2}{*}{ Low speed } & \multirow{2}{*}{ High speed } \\
\hline & $\mathrm{L}$ & $\mathbf{H}$ & $\mathrm{L}$ & $\mathbf{H}$ & $\mathbf{L}$ & $\mathrm{H}$ & & & \\
\hline boxes per plant hour & \multicolumn{6}{|c|}{ Top pad used } & & & \\
\hline $0-280$. & 1 & .. & 1 & .. & 1 & .. & $\$ 1.40$ & $\$ 1.40$ & $\$ 1.10$ \\
\hline $281-330$. & 1 & 1 & 1 & .. & 1 & $\because$ & 2.45 & 1.40 & 1.10 \\
\hline $331-370 \ldots$ & 1 & 1 & 1 & 1 & 1 & .. & 2.45 & 2.45 & 1.10 \\
\hline $371-460 \ldots$ & 2 & . & 1 & 1 & 1 & .. & 2.80 & 2.45 & 1.10 \\
\hline $461-540 \ldots \ldots \ldots \ldots$ & 2 & .. & 2 & .. & 1 & .. & 2.80 & 2.80 & 1.10 \\
\hline $541-560 \ldots$ & 2 & $\cdots$ & 2 & $\cdots$ & 1 & 1 & 2.80 & 2.80 & 2.15 \\
\hline $561-660 \ldots \ldots \ldots \ldots \ldots \ldots$ & 2 & 1 & 2 & .. & 1 & 1 & 3.85 & 2.80 & 2.15 \\
\hline $661-790 \ldots \ldots \ldots \ldots \ldots \ldots$ & 3 & $\ldots \ddagger$ & 2 & 1 & 1 & 1 & 4.20 & 3.85 & 2.15 \\
\hline $791-840 \ldots \ldots \ldots \ldots \ldots \ldots \ldots$ & 3 & $\cdots$ & 3 & $\ldots \ddagger$ & 1 & 1 & 4.20 & 4.20 & 2.15 \\
\hline $841-930 \ldots \ldots \ldots \ldots \ldots \ldots \ldots$ & 3 & 1 & 3 & . & 1 & 1 & 5.25 & 4.20 & 2.15 \\
\hline \multirow[t]{2}{*}{$931-1,000 \ldots \ldots \ldots \ldots \ldots \ldots \ldots \ldots$} & 4 & $\ldots \S$ & 3 & .. & 1 & 1 & 5.60 & 4.20 & 2.15 \\
\hline & \multicolumn{6}{|c|}{ No top pad } & & & \\
\hline $0-370 \ldots$ & 1 & . & 1 & .. & 1 & .. & 1.40 & 1.40 & 1.10 \\
\hline $371-460 \ldots \ldots$ & 2 & . & 1 & .. & 1 & .. & 2.80 & 1.40 & 1.10 \\
\hline $461-740 \ldots \ldots$ & 2 & . & 2 & .. & 1 & .. & 2.80 & 2.80 & 1.10 \\
\hline $741-920 \ldots \ldots \ldots \ldots \ldots$ & 3 & .. & 2 & .. & 1 & .. & 4.20 & 2.80 & 1.10 \\
\hline $921-1,000 \ldots \ldots \ldots \ldots \ldots \ldots$ & 3 & .. & 3 & .. & 1 & .. & 4.20 & 4.20 & 1.10 \\
\hline
\end{tabular}

${ }^{*} \mathrm{~L}$-lidder; H-helper; number of lidders corresponds to number of machines. Crew is set up to give minimum labor cost for any output.

$\dagger$ Wage rates used: Lidder-Low speed or Stitcher, $\$ 1.40$ per hour; high-speed, $\$ 1.10$ (less skill required with high-speed machine); helper, $\$ 1.05$ per hour.

t An additional helper could be added, rather than another lidder, up to 740 boxes per hour. Labor costs would be $\$ 4.90$ per hour instead of the $\$ 4.20$ indicated, but equipment costs would be reduced. The economical decision depends on the length of season and the cost of the machine.

$\S$ As above, additional helpers could be added rather than an additional machine.

Indirectly, the rate of output of key piece-rate workers has a substantial influence on the efficient utilization of labor and equipment throughout the plant. Greater rates of output on the part of piece-rate labor may, in many instances, permit a more harmonious adjustment among the plant stages. Thus, although the labor costs are not directly related to units of input, the efficiency of these units may have an important effect on plant costs.

Moreover, improvements in the productivity of these workers could, in the long run, be expected to result in a reduction in piece rates.

\section{Materials}

Materials might be classed in two groups-those which are contained within the final product in some definable form and those which are consumed in the 
production process and do not enter directly into the product. The latter usually consist of chemicals of one type or another and are discussed under that heading in the following section. The costs of materials contained within the final product are probably the easiest of the inputs to measure for they commonly enter in rigidly fixed proportions. The physical inputs may be measured quite effectively by the simplest of engineering studies. A fruit packing box, for example, consists of so many nails, various pieces of wood, glue, and labels. More complex items such as automobiles or typewriters differ only in degree. Given these specifications, the costs of the materials are obtained by simply multiplying the physical quantities by their prices which may be constant or some function of the quantity purchased. Price data usually may be obtained from catalogs and listings of the manufacturers of the basic materials.

An alternative source of materials cost data is the plant accounting records. Operating statements commonly contain materials cost information on a per unit of product basis. If not, it can be calculated from the inventory records. An advantage of record data is that they usually reflect any loss due to breakage or damage that should properly be considered a cost of materials. And the materials price data reported by plants may be somewhat more realistic than figures listed by manufacturers since the actual sales may involve discounts and various "special deals." A disadvantage of the record data is that inventory records may carry materials costs on the basis of past purchase prices for particular "batches" rather than reflecting current costs.

\section{Other Operating Inputs}

Other operating inputs, in addition to labor and materials, consist of items such as power, fuel, water, and chemicals, miscellaneous supplies and general expense, and administrative costs.

\section{Power, Fuel, Water, and Chemicals}

Power and fuel costs may be estimated either from accounting records or by engineering studies of chemical processes and various machine requirements. Data from accounting records usually consist of monthly figures based on bills from power or water companies or a total figure for the accounting period for various chemicals and fuels used. Such figures provide average costs for broad periods but may be of limited value in developing basic input-output relations. In some plants, the amounts of these items are so small that the average figures may be used with little absolute error even though logically poor. In fresh fruit packing houses, for example, power and fuel costs commonly amount to less than 1 per cent of the total cost. On the other hand, in some types of plants, these costs account for a fairly large proportion of the cost, and a functional relation between costs and output may be very desirable.

Cost estimates in a functional form can be obtained through engineering estimates based on data concerning chemical process and machine requirements and to a lesser extent from regression analysis of record data. ${ }^{38}$ For

\footnotetext{
${ }^{38}$ For a more detailed discussion of engineering estimates of production and cost func-
} 
example, a power curve may be calculated for each electric motor, showing the relationship between kilowatt hours used and motor load. Fuel and water requirements in relation to rates of electric power output may be determined by engineering calculation in steam generating plants, and in this particular case, analysis of accounting records might also yield some good results in a functional form. Chemicals, other than basic materials, are consumed in fixed and varying proportions in many processes-textile manufacture, steel production, agriculture (weed killers, insecticides, et cetera), to name a few. Technical data concerning chemical requirements and the effects of varying quantities of chemicals on rates of final output are commonly available through plant engineers and chemists. The physical functions can be converted to cost functions, as in the case of materials and labor, by applying the appropriate prices obtained either from the plant or the suppliers of the power and chemicals.

\section{Miscellaneous Supplies and General Expense}

Miscellaneous supplies consist of items such as paper, pencils, janitorial materials, and the like. The quantities required of these items may be some function of the size of plant but may bear little relation to the variations in rates of output within the plant. Estimates of these costs must be obtained primarily from plant operating statements giving the aggregate cost of these items for the accounting period. Since "technologies" are fairly uniform (or difficult to distinguish) with regard to miscellaneous supplies and since their costs are small in total, accounting records may provide a good practical basis for estimating the cost-size-of-plant relationship.

General expenses consist of such items as dues, donations, licenses, et cetera. They are usually quite minor in total and can be determined only from plant records. The costs of these items may show considerable variation according to the location of the plant. Perhaps the best that can be done in analyzing these costs is to relate the average miscellaneous costs per plant to plant size to determine, if possible, any cost-size-of-plant relationship. This may be done separately for different areas if location has an important effect and if data are available for enough plants in each area.

\section{Administrative Costs}

Administrative costs consist of the salaries of managers and executives. They are probably the most difficult to estimate of any of the various inputs. Accounting records are the chief source of these data, but frequently the needed information is carried in an inaccessible "confidential" account. And even where the records are freely available, salaries may be difficult to separate from profits. Moreover, the salary scale is often related to net returns which means that the payment in a given year may not be indicative of long-run salary levels. About the best that can be done is to obtain such data as are available from accounting records, to separate profits from salaries to the extent that it is possible, and then to calculate an average for

tions for energy requirements, see Hollis B. Chenery, "Process and Production Functions from Engineering Data," Studies in the Structure of the American Economy by W. Leonteif and others (New York: Oxford University Press, 1953), chapter 8. 
each plant for a period of years-deflated by some price index. These averages might then be related to plant size to bring out, if possible, any administrative cost-size-of-plant relationship. The nonhomogeneous nature of managerial inputs, however, makes this an extremely arbitrary procedure.

\section{Durable Goods}

Three main sources of data are useful in estimating the costs of durable goods: plant accounting records; engineering-architecture estimates of building costs; and data supplied by manufacturers of equipment and buildings. It will be recalled from the theoretical discussions that the cost of a given input or service of a durable factor is extremely difficult to define. The cost of the aggregate of these inputs consists of an amount necessary to maintain and replace the durable factor over some time period. The objective in measuring the cost of durable items is, then, to provide estimates of these future maintenance and replacement costs.

From this standpoint, the values and charges carried in plant records will usually be of limited value. The records reflect, not future costs of replacement, but past purchases prices at varying dates and price levels. Moreover, "book" charges for depreciation and repair vary considerably from plant to plant and may commonly contain arbitrary allowances for "risk" that are well above any normal requirements for this element, although even under the best of circumstances, some arbitrary judgment is involved in these estimates.

The engineering-architecture approach to this problem consists of first estimating the physical requirements involved in replacing any specified structure-i.e., quantities of various materials, man-hours of various types of construction labor. ${ }^{30}$ To these physical estimates is applied a set of prices which appear most nearly to reflect costs that can be expected to prevail over some future period. The choice of price level is, of course, purely arbitrary. Current prices are commonly used as the best available indication of what may be expected over the not too distant future but by no means are necessarily good estimates of longer term situations.

The process outlined above provides an estimate of investment replacement costs in terms of current or future prices. Estimates of repair costs and expected useful life based on operating and engineering experience are then used with the estimated investment cost to estimate the average long-run cost rates of replacement and maintenance. To these costs there must be added, of course, an allowance to cover insurance, taxes, and interest (including "normal" risks) equivalent to the "going rates" for these items.

Cost estimates for equipment items may be handled essentially as outlined for buildings. In this case, however, the investment replacement cost data are obtained primarily from manufacturers, with as much information as is available concerning rates of wear, deterioration, and repair.

\section{Aggregation and Integration}

The measurement procedures outlined above, when completed, provide a set of "building blocks" for estimating individual plant cost functions. These

\footnotetext{
${ }^{30}$ For example, see H. E. Pulver, Construction Estimates and Costs (New York and London: McGraw Hill Book Company, Inc., 1947).
} 
functions are the basis for comparing the efficiency of alternative technologies and for determining the possible economies that may be associated with the scale of operation. The general procedures for combining these building blocks were described in some detail in the previous section. They involve, first, a simple combination of the fundamental cost-output relations into cost functions for the alternative technologies at each plant stage and, second, a comparison and integration of these and the general cost functions to determine the most efficient technologies and their total costs for plants of varying size and operating under varying conditions-i.e., the long-run optimum cost function. This process is illustrated in the following sections for California pear packing plants.

The previous discussions have stressed the discontinuities in both the long-run functions and in the cost functions for specific plants. It is clear that, with many discontinuities and several products, the problem of calculating the optimum profit position may become overwhelming. As a practical working procedure, areas in the total cost surface with small discontinuities-i.e., small "steps"-might be smoothed into continuous functions so that the total number of discontinuities can be reduced to manageable proportions. This involves a certain amount of arbitrary judgment but if carefully done should not seriously alter the calculations. It may be noted, finally, that cost measurement, as any other empirical study, is only an approximation to the theoretical functions, but if carefully carried out and with proper empirical theoretical models, it should provide fairly close approximations and thus be a useful tool for managerial decision.

\section{PRODUCTION EFFICIENCY IN PEAR PACKING}

The preceding theoretical development involves the two basic elements of economic theory of production-cost functions and revenue functions. These functions have been dealt with in abstract terms, but their application in real problems requires that they be quantified. This usually is an extremely difficult task, due in part to the limitations of available techniques of measurement and analysis. The remaining pages of this paper are devoted to an illustration of how engineering and economic approaches can be used in developing cost functions. Revenue functions-here in terms of charges for packing house services-have not been considered.

The operations studied are those of California fresh pear packing plants. Emphasis is on the construction and interpretation of a long-run cost function for the in-plant or "door to door" aspects of pear packing. A complete analysis of costs would, of course, include assembling the fruit at the plants and selling and transporting to markets as well.

The long-run cost function consists of an aggregation of various component or stage cost functions and represents the most efficient combination of technologies for any size of plant or length of operating season. Technological specifications are given for most of the points on this function-each of which represents a plant-and cost functions are determined for several specific plants to show the relation to the long-run curve. The analysis gives an indication of the economies associated with large-scale production 
and provides a basis for determining the kinds of adjustments which may lead to cost reduction for individual plants.

\section{The Sample of Packing Plants}

Input-output and cost data for this study were obtained in 15 California pear packing plants and eight California apple packing houses. Apple plants are identical to pear plants in many operations and so provide an additional

TABLE 3

GENERAL CHARACTERISTICS OF THE SAMPLE OF PEAR AND APPLE PLANTS

\begin{tabular}{|c|c|c|c|c|c|c|c|}
\hline Plant & $\begin{array}{l}\text { Peak } \\
\text { rates of } \\
\text { output }\end{array}$ & $\begin{array}{c}\text { Per cent } \\
\text { of fruit } \\
\text { packed } \\
\text { for fresh } \\
\text { markets } \dagger\end{array}$ & $\begin{array}{c}\text { Hours } \\
\text { operated } \\
\text { per } \\
\text { season } \ddagger\end{array}$ & $\begin{array}{c}\text { Location } \\
\text { (producing } \\
\text { district) }\end{array}$ & $\begin{array}{c}\text { Legal } \\
\text { organization }\end{array}$ & $\begin{array}{c}\text { Degree of } \\
\text { mechani- } \\
\text { zation§ }\end{array}$ & $\begin{array}{l}\text { Other } \\
\text { products } \\
\text { handled }\end{array}$ \\
\hline & $\begin{array}{l}1,000 \text { lbs. } \\
\text { per hour }\end{array}$ & & & & & & \\
\hline \multicolumn{8}{|l|}{ Apples } \\
\hline A... & 19.9 & 87 & $\ldots$ & Sonoma & Cooperative & Low & None \\
\hline B... & 21.8 & 83 & $\ldots$ & Sonoma & Commercial & Low & None \\
\hline C... & 22.6 & 46 & $\ldots$ & Sonoma & Commerical & Low & None \\
\hline D... & 23.4 & 36 & $\ldots$ & Sonoma & Cooperative & Low & None \\
\hline E. . & 23.8 & . & $\ldots$ & Sonoma & Private & Low & None \\
\hline F. & 26.9 & 58 & $\ldots$ & Sonoma & Cooperative & Low & None \\
\hline G. & 33.2 & 65 & $\ldots$ & Sonoma & Commercial & Low & None \\
\hline $\mathrm{H}$. & 42.0 & 53 & $\ldots$ & Sonoma & Cooperative & Medium & None \\
\hline \multicolumn{8}{|l|}{ Pears } \\
\hline L...... & 22.3 & 77 & 222 & El Dorado & Commercial & Low & None \\
\hline M... & 30.0 & 53 & 249 & Lake & Cooperative & Medium & None \\
\hline $\mathrm{N} \ldots$ & 44.7 & 87 & 150 & Sacramento & Commercial & Low & $\begin{array}{l}\text { Tomatoes, } \\
\text { asparagus }\end{array}$ \\
\hline P. & 45.0 & 86 & 184 & Sacramento & Private & High & Tomatoes \\
\hline Q. . & 46.0 & 97 & $\ldots$ & Santa Clara & Cooperative & High & None \\
\hline R... & 51.6 & 54 & 202 & Mendocino & Cooperative & Medium & Few plums \\
\hline S.... & 55.0 & 65 & 222 & Placer & Cooperative & Low & Plums \\
\hline T... & 55.2 & 37 & 170 & Mendocino & Commercial & Medium & None \\
\hline U... & 66.5 & 84 & 100 & Sacramento & Cooperative & High & Tomatoes \\
\hline V.... & 75.2 & 66 & 239 & Lake & Cooperative & High & None \\
\hline W... & 76.1 & 60 & 249 & Lake & Cooperative & High & None \\
\hline $\mathrm{X} \ldots$ & $25.0 \|$ & . & $\ldots$ & Santa Clara & Commercial & Medium & $\ldots \ldots$ \\
\hline Y... & $30.0 \|$ & .. & $\ldots$ & Santa Clara & Cooperative & High & $\ldots \ldots$ \\
\hline Z..... & $12.0 \|$ & . & $\ldots$ & Lake & Private & Low & None \\
\hline ZZ... & $15.0 \|$ & .. & $\ldots$ & Placer & Cooperative & Low & Plums \\
\hline
\end{tabular}

* Mean of the 3 highest days during the 1949-1950 seasons.

† Applies to percentages observed during the 1949-1950 seasons with average rates of output and full utilization of the plant facilities. As such, these percentages may vary from the average percentages for a season.

$\ddagger$ Equivalent hours with full utilization of facilities based on data for the 1949-1950 seasons.

Indicates approximate degree to which machinery is substituted for hand labor. Specific technologies obsarved are described in more detail in a later chapter.

II Approximate values. Studies in these plants were incomplete or were limited to particular operations.

source of data for some cost components. The objective in selecting the sample was to cover a wide range in plant size and technology, from which to develop basic cost standards. The plants were chosen on a judgmental basis, and no specific attempt was made to design the sample so as to be statistically representative of average conditions throughout the industry. A summary of the characteristics of these sample plants is contained in table 3 . 
The eight apple plants studied are all located in the Sonoma County area. Gravensteins are the leading variety of apple packed. The plants vary in total capacity from about 20,000 pounds per hour to a little over 40,000 pounds, with most of them near the lower figure. The sample, which is large relative to the total number of apple plants, covers the entire range of existing California apple packing plant capacities. ${ }^{40}$

The 15 pear plants studied (out of a total of about 74 in California) are dispersed among six of the major pear-producing districts-three in the Sacramento district, two in Placer, one in El Dorado, four in Lake, two in Mendocino, and three in the Santa Clara district. They represent a wide range in total capacity, varying from less than 20,000 pounds per hour to about 75,000 pounds. However, the very small plants tend to be underrepresented in the sample. All legal forms of organization are represented by both the sample apple and pear plants.

The next to the last column of table 3 gives a rough indication of the degree of mechanization in these plants. The specific technologies involved are described in detail in a following section. Data concerning the costs of certain technologies not actually observed in the sample of California pear and apple plants, but which appeared adaptable to these plants, were obtained in two Washington apple plants and from a separate study of grape packing plants. A considerable amount of data on the operation and costs of equipment was obtained directly from manufacturers as well as from plants. Much of the material presented here may be applicable to both pear and apple plants and to some extent to other types of deciduous fruit packing. However, the specific analysis is in terms of pear plants, and many of the calculations would have to be reoriented for use in other types of plants. ${ }^{41}$

It is not known whether all technologies employed in the entire group of 74 pear packing plants in California are represented in the sample plants. However, visits to a number of plants not actually studied, plus discussions with people familiar with activities throughout the pear packing industry, suggest that at least the major variations in technology are included. In fact, with the supplementary data from grape plants and from the Washington apple plants, the study considers a number of major technologies not now used in Califormia pear packing plants.

\section{Pear Packing Operations}

The primary marketing services performed in pear packing plants and in packing houses in general consist of receiving and sorting field-run fruit into several grades or classes, receiving and assembling packaging materials, placing fruit of different grades in various types of containers, and loading these containers on trucks or cars for shipment to fresh markets or to processing plants. These steps and the flow of product and materials are illustrated in figure 20 .

This chart is based on observation and detailed study in 48 pear, apple,

${ }^{40}$ There were 11 apple packing plants in the Sonoma area in 1950 plus 15 or 20 small plants in the Watsonville area.

${ }^{41}$ This has been done, to a large extent, in a series of reports on Efficiency in Fruit Marketing, published by the University of California, Agricultural Experiment Station, Giannini Foundation of Agricultural Economics. 


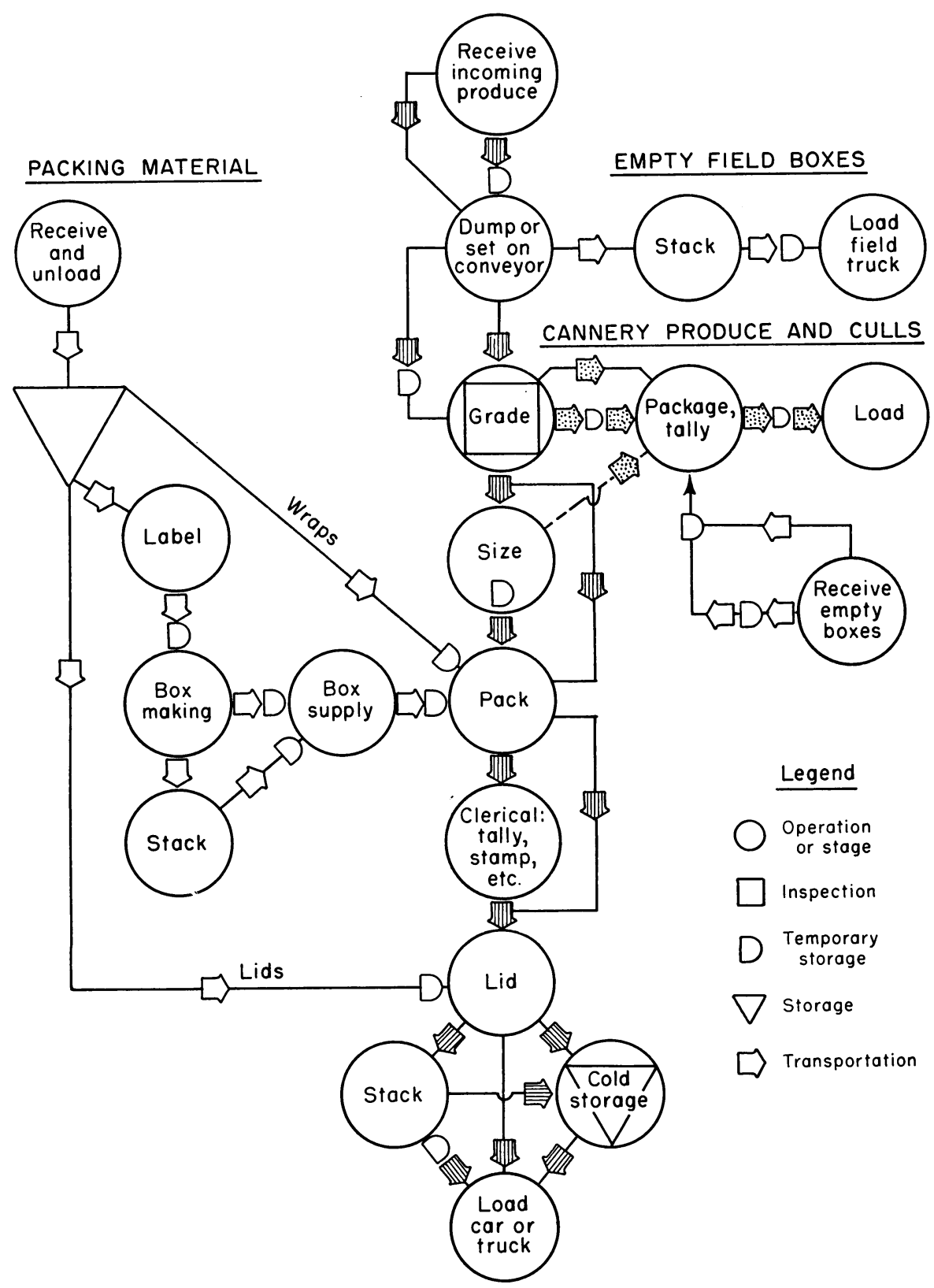

Fig. 20. Process flow diagram for pear packing plants. 
and grape packing plants, plus direct observation without detailed study in approximately 30 additional plants, including some plants handling plums, peaches, tomatoes, and apricots. As in the hypothetical flow diagram in figure 1, figure 20 indicates that packing plant operations are composed of a series of stages and transportation links, with storage playing an important part in the operations.

A selling function is also commonly associated with the packing service and sometimes orchard-to-plant transportation, but these operations are not considered in this study.

An important characteristic of packing plant operations is that the rates of output and daily hours of operation must be adjusted to the quantities of fruit harvested and delivered to the plant. Efficient scheduling of field operations may level out the peaks and troughs of the deliveries, but, in general, total output per day during a particular season is subject to only limited managerial control. This is in contrast to many similar types of industrial production where daily hours and output may be regulated directly and exactly by managerial decision.

\section{Forms of Output}

Fruit at the pear packing house is commonly sorted into four main grades-packed fruit, No. 1 cannery, No. 2 cannery, and culls. No. 1 cannery and packed fruit are of essentially the same quality except that some peelable skin blemishes may be permitted for the cannery grade that are not allowed in packed fruit. There are legal minimum-size requirements for both packed and No. 1 cannery grades. The No. 2 cannery grade consists of fruit that is slightly inferior in shape, size, and surface texture. It commonly goes into strained baby foods. Many of the plants, particularly in the Sacramento district, do not handle any No. 1 cannery fruit. All pears in these plants are either packed fruit, No. 2 cannery, or culls. Culls are the lowest grade of pears and have little value. Some of the fruit that would otherwise be culled is dried.

Grades for packed fruit are defined by the California state agricultural code and the United States Department of Agriculture. ${ }^{42}$ Minimum shipping standards for Bartlett pears are established by the California Tree Fruit Agreement. In many plants only a single grade is packed at any one time, the general level of this grade being determined in large part by the basic quality of the fruit received from the orchards. In other cases, a portion of the fruit may be packed as straight U. S. No. 1, with the remainder making up a U. S. Combination grade that is still within the prescribed tolerances.

Pears are commonly packed in three types of containers: standard pear boxes, San Francisco or "one way" lugs, and Los Angeles lugs. Standard boxes, containing a minimum net weight of 48 pounds, are used primarily for shipment out of the state. The box measures $81 / 2$ inches in depth, $11 \frac{1}{2}$ inches in width, and 18 inches in length, inside. Fruit placed in these boxes

\footnotetext{
${ }^{42}$ California Laws, Statutes, Agricultural Code, 1951, Sacramento: California State Printing Office, 1951, pp. 310-12.

U. S. Agricultural Marketing Service, U. S. Standards for Summer and Fall Pears Such as Bartlett, Hardy, and Other Similar Varieties (effective June 27, 1940), Wash. D.C., 1940 .
} 
is wrapped and the box is lidded. Over 80 per cent of the pears packed in California are shipped in these containers. San Francisco lugs are used for some shipments out of state, but most of the fruit packed in these containers is sold locally. The lugs contain a net weight of about 46 pounds of fruit which is commonly place-packed without wrapping. The lugs measure $61 / 2$ inches in depth, $131 / 2$ inches in width, and $205 / 8$ inches in length, inside. They are usually lidded. Los Angeles lugs are also used primarily for local shipments. They contain about $241 / 2$ pounds of fruit, usually of the larger sizes. The lug measures 53/4 inches in depth, $131 / 2$ inches in width, and $161 / 8$ inches in length, inside. Fruit in these containers is normally packed unwrapped and without lids. ${ }^{43}$

\section{Costs of Packing Services}

An indication of the magnitude of packing costs and the relative importance of the various components of cost, both within and among plants, may be obtained by reference to tables 4 and 5 (Bressler, 1952b). Selected costs of operation are shown for 11 of the sample pear plants in which cost data were obtained for this study. Due to variations in accounting procedures among plants, the breakdown given in these tables is slightly different from that used in estimating stage cost functions for the various alternative technologies considered in the analysis that follows. For example, only the labor costs are separated by stages. Building and all equipment costs are combined into a single figure. Certain of the stages are also combined here, and transportation costs are shown as part of specific stage costs. However, the breakdown is sufficient for illustrative purposes.

These cost estimates are not season averages of accounting costs but-to focus attention on internal efficiency-have been adjusted to represent uniform conditions with respect to wages, hours of operation, type of container, and length of season. Labor costs were standardized to eliminate the effects of differences in wage rates paid by individual plants. All calculations were based on a normal 8-hour day with average rates of operation. Fixed costs were based on estimates of current replacement values for buildings and equipment, uniform procedures for allocating costs between packed and cannery fruit, and the assumption of 30 full packing days in a season. Finally, all costs for packing fresh fruit were expressed relative to standard boxes containing 48 pounds net weight of pears.

These costs are not necessarily the same as those actually incurred or reported in these plants nor do they indicate the charges made for the packing service. The standardizations are such that actual reported costs would probably average a little higher than shown in the tables. However, the estimates serve to emphasize the general importance of the area selected for study-costs averaged about $\$ 1.00$ per box of packed fruit for these plants in 1950. More recent data indicate that 1954 costs would average about 9 per cent higher for materials and about 16 per cent higher for all other items. The estimates also suggest the relative importance of labor and other costs in the total and of the major stages or groups of stages within

\footnotetext{
${ }^{43}$ For more details on pear containers, see California Fruit Exchange, California De. ciduous Fruits, Sacramento, California, 1948, pp. 28-29.
} 


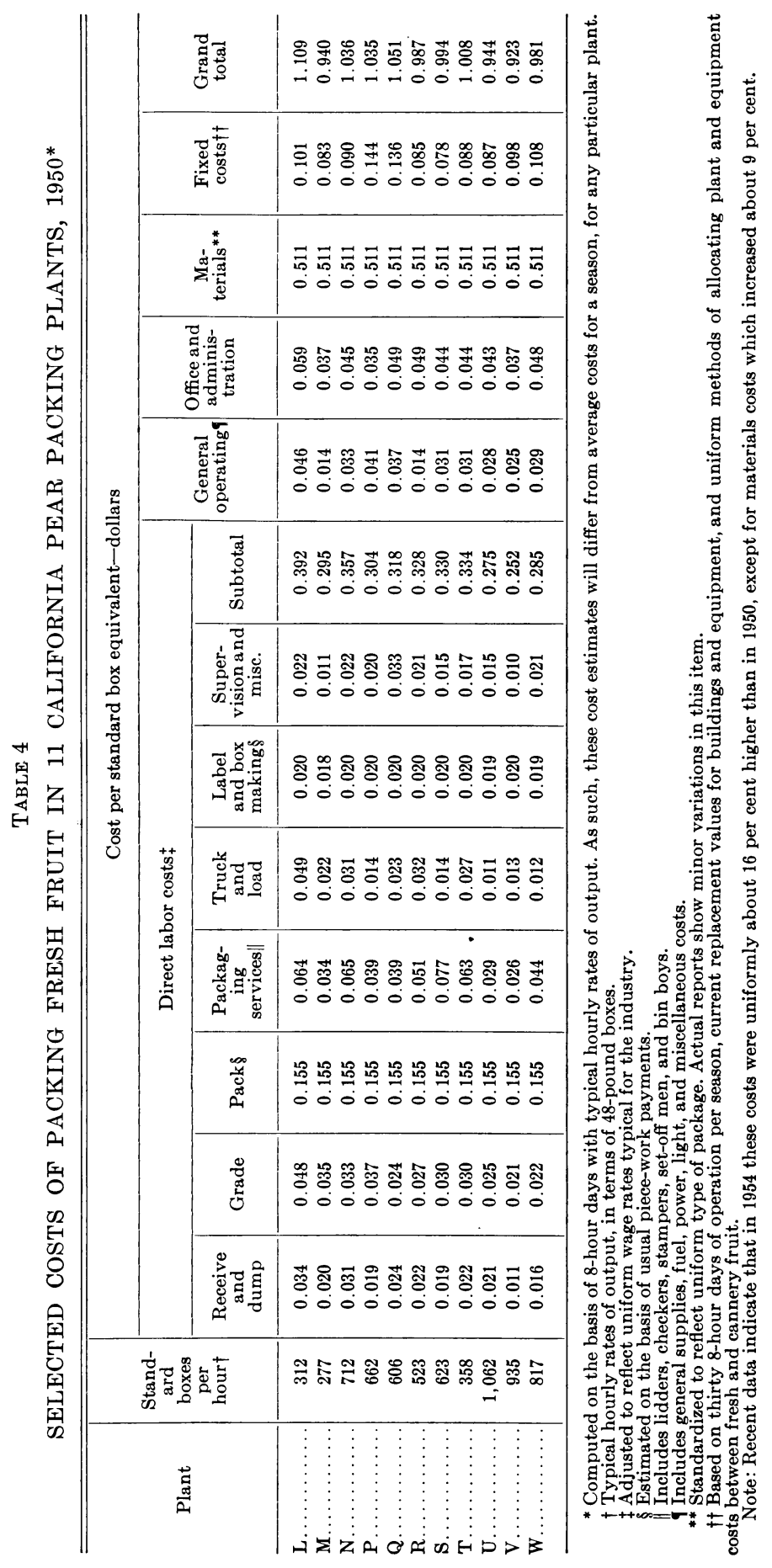


the labor cost component. In broad terms, labor costs account for roughly 30 per cent of total costs, operating and administrative costs for 10 per cent, packing materials, 50 per cent, and average annual costs for building, land, and equipment about 10 per cent. Of the labor component, packing is by far the most costly operation. The tables also stress ranges in costs, presumably reflecting differences in size, organization, and efficiency.

TABLE 5

SELECTED COSTS OF HANDLING CANNERY FRUIT IN 11 CALIFORNIA PEAR PACKING PLANTS, 1950*

\begin{tabular}{|c|c|c|c|c|c|c|c|c|c|c|}
\hline \multirow{3}{*}{ Plant } & \multirow{3}{*}{$\begin{array}{c}\text { Tons } \\
\text { per } \\
\text { hour } \dagger\end{array}$} & \multicolumn{9}{|c|}{ Cost per ton of cannery fruit-dollars } \\
\hline & & \multicolumn{5}{|c|}{ Direct labor cost $\ddagger$} & \multirow[b]{2}{*}{$\begin{array}{c}\text { General } \\
\text { oper- } \\
\text { ating } \S\end{array}$} & \multirow{2}{*}{$\begin{array}{l}\text { Office } \\
\text { and } \\
\text { admin- } \\
\text { istra- } \\
\text { tion }\end{array}$} & \multirow[b]{2}{*}{$\begin{array}{l}\text { Fixed } \\
\text { costs } \|\end{array}$} & \multirow[b]{2}{*}{$\begin{array}{c}\text { Grand } \\
\text { total }\end{array}$} \\
\hline & & $\begin{array}{c}\text { Receive } \\
\text { and } \\
\text { dump }\end{array}$ & Grade & $\begin{array}{l}\text { Pack- } \\
\text { age, } \\
\text { truck } \\
\text { and } \\
\text { load }\end{array}$ & $\begin{array}{c}\text { Super- } \\
\text { vision } \\
\text { and } \\
\text { miscel- } \\
\text { laneous }\end{array}$ & $\begin{array}{l}\text { Sub- } \\
\text { total }\end{array}$ & & & & \\
\hline L. . & 1.9 & 1.42 & 1.99 & 3.60 & 0.91 & 7.92 & 1.93 & 2.44 & 2.49 & 14.78 \\
\hline M. & 5.4 & 0.94 & 0.76 & 2.49 & 0.43 & 4.62 & 0.46 & 1.54 & 1.93 & 8.55 \\
\hline N. & 2.0 & 1.29 & 1.38 & 2.09 & 0.45 & 5.21 & 1.36 & 1.89 & 2.88 & 11.34 \\
\hline P. . & 2.1 & 0.78 & 1.52 & 1.25 & 0.54 & 4.09 & 1.70 & 1.47 & 4.08 & 11.34 \\
\hline Q.... & $\ldots$ & $\ldots$ & $\ldots$ & $\ldots$ & $\ldots$ & $\ldots$ & $\ldots$ & $\ldots$ & $\ldots$ & $\ldots$ \\
\hline R... & 9.9 & 0.90 & 1.02 & 1.30 & 0.79 & 4.01 & 0.60 & 2.04 & 2.09 & 8.74 \\
\hline S.. & 7.3 & 0.81 & 1.25 & 2.55 & 0.55 & 5.16 & 1.29 & 1.82 & 1.55 & 9.82 \\
\hline T... & 13.9 & 0.90 & 0.52 & 1.26 & 0.70 & 3.38 & 1.28 & 1.82 & 1.61 & 8.09 \\
\hline U.... & 3.9 & 0.85 & 1.05 & 1.05 & 0.43 & 3.38 & 1.18 & 1.80 & 2.36 & 8.72 \\
\hline V.. & 10.7 & 0.45 & 0.89 & 1.10 & 0.30 & 2.74 & 1.02 & 1.56 & 2.18 & 7.50 \\
\hline W....... & 12.0 & 0.68 & 0.93 & 1.41 & 0.76 & 3.78 & 1.22 & 1.99 & 2.24 & 9.23 \\
\hline
\end{tabular}

*.Computed on the basis of 8-hour days with typical hourly rates of output. As such, these cost estimates will differ from average costs for a season for any particular plant.

$\$$ Typical hourly rates of output, in tons of cannery fruit.

Adjusted to reflect uniform wage rates typical for the industry.
Includes general supplies, fuel, power, light, and miscellaneous costs.

Based on thirty 8-hour days of operation per season, current replacement values for building and equipment, and uniform methods of allocating plant and equipment costs between fresh and cannery fruit.

Note: Recent data indicate that in 1954 these costs were uniformly about 16 per cent higher than in 1950.

\section{Performance and Cost Standards}

Performance standards and cost standards are quantitative estimates of the input-output and cost-output relations postulated in the earlier discussions of production theory and described in the section on methodology. Such standards are calculated for each of the alternative stage technologies observed in the sample of packing plants. They form a set of fairly large "building blocks" which will be used to estimate the long-run total cost function representing the most efficient combination of technologies for plants of any size and operating under any given set of conditions.

The estimated cost standards are all based on 1950 wages and prices, standardized at levels that appear to be typical of conditions throughout the industry. More recent data indicate that prices of durable items of equipment had increased about 15 to 16 per cent between 1950 and 1954, and 1954 wage rates were 16 to 17 per cent higher than in 1950 . Since relative prices appear to have remained approximately the same, and there have been no important technical innovations during this period, the prin- 
cipal effect of introducing the more recent 1954 data would be to increase the level of all cost estimates by about 16 per cent. Variation in wages and prices paid in specific plants or localities may, of course, influence the level of costs and the relative efficiencies of alternative technologies. The material that follows is suggestive of general relationships and magnitudes rather than the specific situations or special circumstances that may be found in particular plants. However, since the basic estimates are in physical terms, it is not difficult to introduce modifications for plants operating under somewhat different wage and price conditions.

The wage rates used in the analysis represent regular time pay rates and are within the range of rates paid in the plants studied. They tend to correspond to the modal levels of these wages and as such are slightly higher than average rates. In selecting the rates to be used in the study, no allowance was made for costs of workman's compensation insurance, unemployment insurance, and old age benefits, although these items properly represent a labor cost. If included, they would add about 3 to 4 per cent to the rates used. However, the rates would still be generally within the observed range, and this omission has virtually no effect on the choice of technologies.

Estimated costs of replacing and maintaining durable factors are expressed on an annual basis. It was pointed out earlier that, for perishable products, the major opportunities for varying hours of operation in a given plant are contained within a day - this was defined as the demand or sale period. The annual "fixed" costs could be reduced to an average per day and incorporated into the analysis on this basis. But since the days of operation per season vary from locality to locality, it will be convenient for purposes of cost comparison to consider the season or year as the demand period. Operating time then enters into the cost function as hours per season rather than hours per day.

All labor cost standards given include "normal" delays such as rest periods and allowances for personal time but, with certain exceptions, do not include allowances for delays due to "break-for-lots" - the time lost through delays between the running of the lots of fruit for separate growers. The delay between lots is required to determine and record the quantities of fruit in each of the several grade categories for a particular grower. The alternative is to use a sampling system which requires no "break-for-lots" but which requires some additional workers to carry out the sampling process. The separate-lot and sampling systems are discussed in a later section of the report.

The exceptions in which allowances for break-for-lots are included are cases where the standards, on an hourly basis, are approximately the same either with or without breaks-for-lots. For example, this is usually true of the dumping operations. Dumping is an arduous task and delays mean that the workers obtain more rest. With this extra rest, they can work a little faster while actually working. Their "instantaneous" rate increases, but their average rate per hour remains about the same. Since the dumping job, and many others, are "machine paced," the increase in instantaneous labor capacity through added delays may not be realized in the actual operations. 
In most instances, several alternative technologies can be used to carry out the operations involved in each segment of the plant. For a few stages, however, the procedures are either fairly well standardized or variations are difficult to recognize and only a single method is considered. While the performance standards are presented separately for each stage, calculation of the long-run planning function may in some instances require joint consideration of the costs of several stages.

For the analytical purposes of this study, the components of cost in pear packing plants are defined as consisting of nine stages, three major transportation links, and six types of general costs, such as supervision and miscellaneous labor. The components are defined so as to be consistent with the process flow chart.in figure 20. They represent all segments of the internal plant process-"door to door" operations-but do not cover costs of fruit assembly, selling, or plant-to-market transportation.

The nine stages are: (1) dumping; (2) grading; (3) packing; (4) direct clerical jobs such as stamping and tallying; (5) lidding; (6) car and truck loading; (7) boxmaking and labeling; (8) empty packing box and materials supply; and (9) packaging cannery and cull fruit. As was indicated previously, the stages themselves are composed of several more elemental but closely related operations. Sizing is included with the packing stage since the costs of the two operations are sometimes difficult to separate.

The three major transportation links are: (1) transportation of incoming fruit from the truck to the dumping station; (2) transportation of packed fruit from the lidder to the car or truck; and (3) transportation of cannery and cull fruit from the packaging stations to the trucks. Obviously, these are not the only transportation operations in the plant. It is convenient, however, to treat other transportation jobs as intrastage transportation and thus as costs associated with specific stages. The costs of these transportation links may vary with the use of particular technologies since they will, in some cases, substitute intrastage for interstage transportation. In the final determination of transportation cost, it will be necessary to combine at least two of the transportation links since the same labor and equipment are often used for two or even three forms of output.

The six types of general costs are: (1) general plant supervision; (2) miscellaneous plant labor, such as janitors; (3) office and administrative costs; (4) building costs and costs of equipment not associated with specific stages; (5) miscellaneous general expenses such as office supplies; and (6) costs of accounting to growers for fruit delivered to the packing house.

Costs for packaging materials and for such items as business licenses, donations, and water are not included in the analysis. Costs for packaging materials are very much standardized, although prices paid may vary slightly among plants due to location and possible discounts. Costs for packing boxes, wraps, and liners may be added as a constant figure to the unit costs obtained in the study - see table 4. Boxes for packaging cannery produce are usually supplied by the canneries. Boxes for picking and transporting fruit from the orchard are, in some cases, supplied by the growers, in others, by the plant. But the grower eventually bears the cost in any case. Costs for these containers are also quite uniform and will be omitted as a matter 
of convenience. Expenditures for business licenses, donations, and water logically should be included but, as they vary quite irregularly from plant to plant, it was very difficult to establish standards for these costs. Since their inclusion or exclusion will not influence the price relationships in which we are interested, and since they amount to only a fraction of 1 per cent of the total costs, they were omitted from the analysis.

\section{Stage Technologies and Component Cost Standards}

\section{Stage 1. Dumping Incoming Fruit ${ }^{44}$}

Two basic methods for dumping incoming fruit on conveyors to the grading and packing lines were observed in the plants studied. These are handdumping and machine-dumping, and with each method there were several variations. The different procedures are as follows.

Hand-dumping. Two variations of this method are considered. In one, the full lugs are trucked to a point adjacent to the dumper in single stacks five or six high or on pallets containing 30 to 36 lugs. The lugs-usually containing 40 to 45 pounds of fruit-are emptied on the dumping table and the empty lugs stacked by the dumper. Empty lugs are trucked to a storage point and later to the growers' trucks. These steps in the receiving and dumping process are illustrated in figure $21 \mathrm{~A}$. In the second method, two aids to the dumper are introduced. Full lugs are trucked to a conveyor belt leading to the dumping station. The lugs are placed on the belt by a set-on man; each lug is emptied by the dumper who then places the empty lug on a conveyor leading to the empty-lug storage area. At this point, the empty lugs are set off and stacked, then trucked to a temporary storage and, later, to the grower's truck. The steps in this process are illustrated in figure $21 \mathrm{~B}$.

Machine-dumping. The steps in the machine-dumping process are similar to those outlined for hand-dumping, using conveyors for full and empty lugs, except that a dumping machine is used to empty the full lug and to place the empty lug on a conveyor to the lug storage area. One type of dumping machine-the single-box dumper-receives single lugs of fruit from a conveyor, and the receiving and dumping crew consists of set-on men for full lugs and set-off men for empty lugs in addition to the truckers. With a second type of machine - the stack-dumper-the full lugs are carried into the dumping machine in stacks five or six lugs high by a floor chain conveyor. The stacks are placed on the floor chain by a hand trucker, and the crew consists only of truckers and empty lug set-off men. Except for the operations performed mechanically, the process with machine-dumping is similar to that illustrated in figure $21 \mathrm{~B}$.

Several other variations in the above methods are possible. With handdumping, higher rates of output can be achieved if the dumper alternates with a worker on some other job, for example, a trucker or set-on man. Still

${ }^{44}$ The material in this section draws heavily from L. L. Sammet, Costs of Dumping Incoming Fruit as Related to Work Methods-Apple and Pear Packing, Giannini Foundation of Agricultural Economics, Mimeographed Report No. 153, Berkeley, California, 1953. Since quotation is rather extensive, specific quotation marks are omitted. 


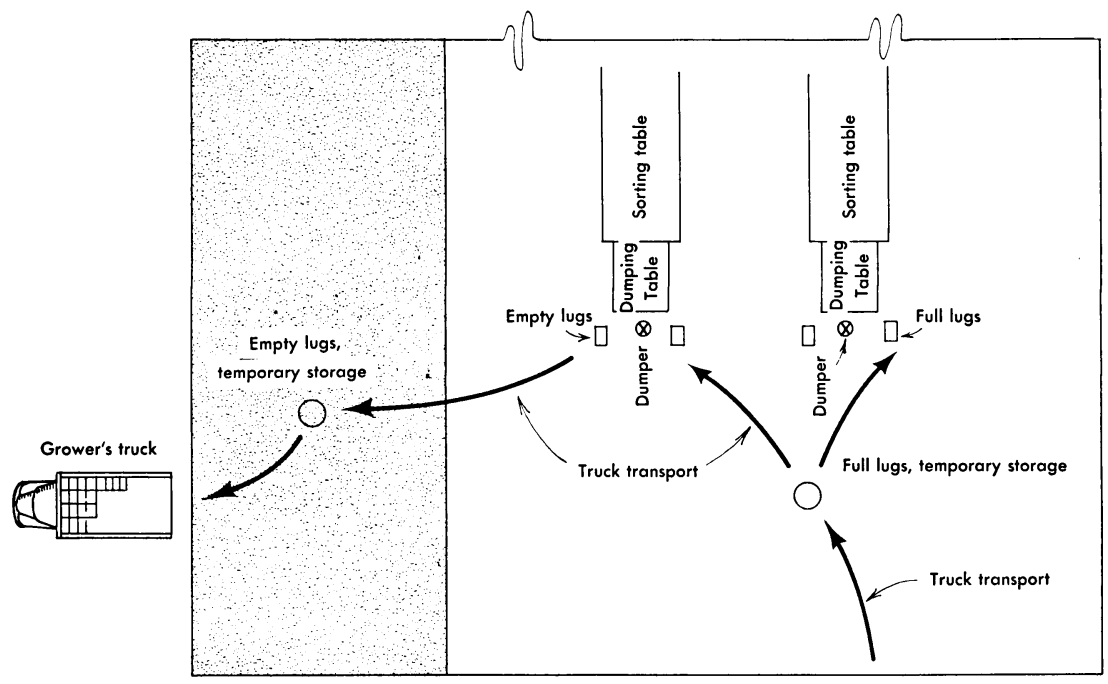

\section{(A) NO LUG-CONVEYORS}
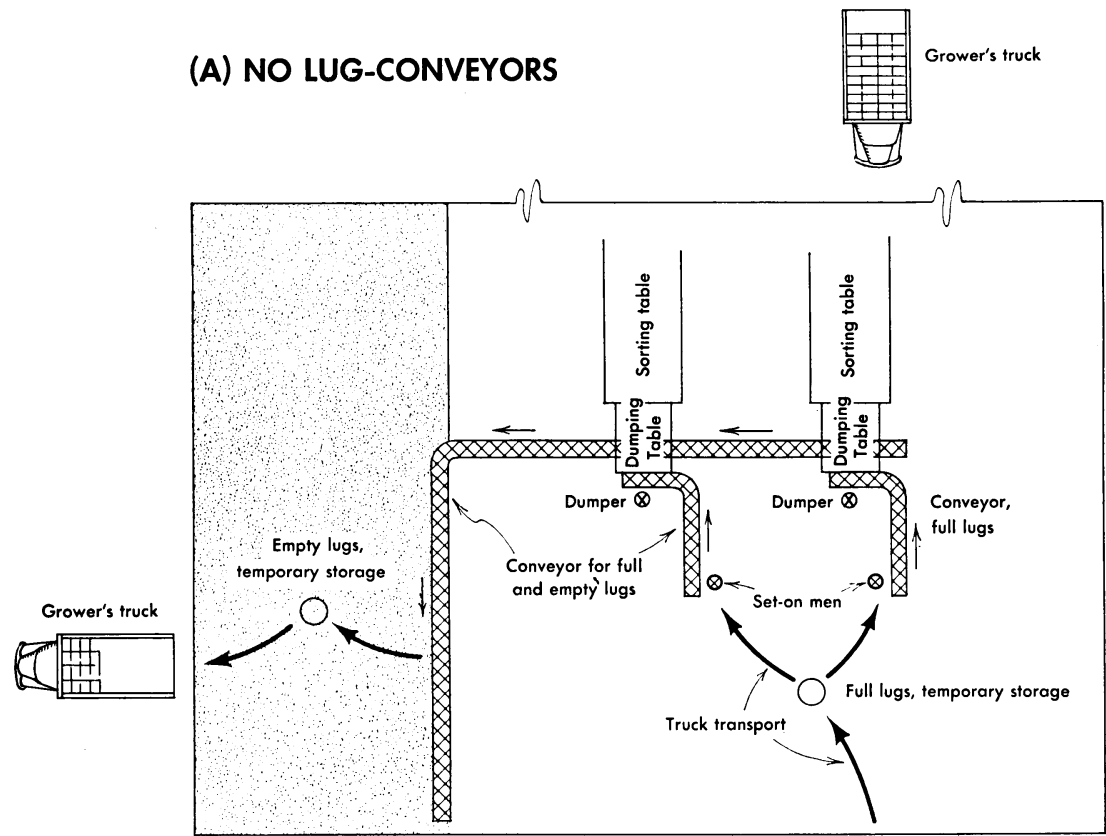

\section{(B) CONVEYORS FOR FULL AND EMPTY LUGS}

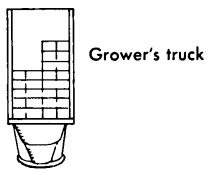

Fig. 21. Typical plant layout and movement of fruit and field lugs in the receiving and dumping operations in pear packing plants. 
higher rates of output can be achieved if, in addition to providing alternate work for the dumper, extra rest time is provided.

Requirements for labor and equipment and estimates of costs with the above methods are presented in the following pages. Labor requirements are based primarily on time and work-sampling studies. ${ }^{45}$ In the final comparison of the costs of these methods and in the development of the total long-run cost curve, the costs of dumping must be considered jointly with the costs of grading. Moreover, the dumping technology used may influence the costs of transportation (receiving) of incoming fruit, and this must also be taken into account. The specific dumping technologies are as follows.

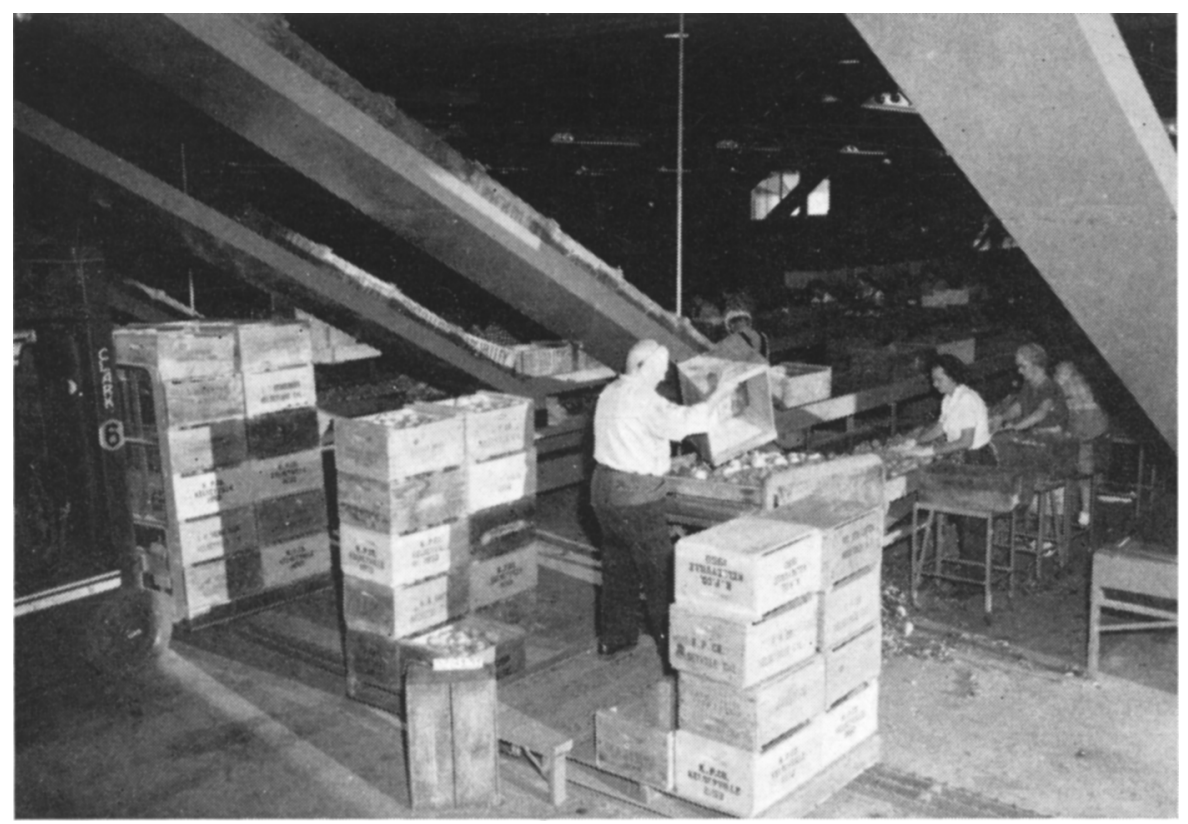

Fig. 22. Hand-dumping without conveyor aids. Floor conveyors for pallets shown above are not considered as aids for the direct act of dumping.

Method A-Hand-dumping Without Conveyor Aids (fig. 22). With this method, the dumper is unaided except for the possibility of alternating with a worker on a different job, such as a trucker. The capacity dumping rate, assuming that the dumper alternates with a trucker, and the equipment requirements and replacement costs are indicated in table 6 .

Labor and equipment requirements and costs using dumping method $\mathrm{A}-$ still assuming that the dumper alternates with the trucker--are presented for different rates of plant operation in table 7 . The estimates are worked out on a step-by-step basis by adding another worker and dumping station as the capacity rate of the dumper is reached. The dumping rates at which these additions occur are given in the columns at the left of the table. Due to the extra dumper time required to move pallets, different capacity rates

${ }^{45}$ The basis on which the level of these standards is established is discussed in Section III. 
are indicated for plants using hand trucks and fork trucks for the trucking operations. Thus, the initial step provides for dumping rates up to 350 lugs per hour in the plants using hand trucks and a rate of 340 lugs per hour in the palletized fork-truck plants. Similarly, the capacity dumping rates for two dumping stations are 700 lugs per hour in the hand-truck plants and 680 lugs per hour in the fork-truck plants.

The estimates of dumping costs given in table 7 are computed from the equipment requirements per station and the equipment cost rates previously given and from crew requirements and wage rates indicated in the table. With two dumping stations, for example, two dumpers and two dumping

TABLE 6

LABOR STANDARDS AND EQUIPMENT REQUIREMENTS FOR DUMPING METHOD A

\begin{tabular}{l|c|c}
\hline \multicolumn{1}{c|}{ Job classification } & \multicolumn{2}{|c}{ Capacity rate } \\
\cline { 2 - 3 } & From floor & From pallet \\
\hline $\begin{array}{c}\text { Dumper: } \\
\text { Lifts full lug from stack on the floor or pallet, } \\
\text { empties the lug, and stacks the empty lug... }\end{array}$ & 350 & 340 \\
\hline \multicolumn{1}{c|}{$\begin{array}{c}\text { Equipment requirements } \\
\text { per dumping station }\end{array}$} & $\begin{array}{c}\text { Estimated } \\
\text { quantity }\end{array}$ & $\begin{array}{c}\text { Replacement } \\
\text { cost,1950 }\end{array}$ \\
\hline $\begin{array}{c}\text { Dumping station: } \\
\text { Table and elevator to sorting table............. }\end{array}$ & 1 & $\$ 500$ \\
\hline
\end{tabular}

tables are required. The direct costs are: labor, $\$ 2.70$ per hour; electric power, 3 cents per hour; equipment repair, 5 cents per hour ; and total direct costs, $\$ 2.78$ per hour. The replacement cost for equipment is estimated at $\$ 1,000$, and annual fixed costs for equipment, at a percentage rate of 13.5, are $\$ 135$. These cost estimates may then be used to compute total costs per season. For example, if the plant were to operate 200 hours per season, the total season cost for two dumping stations would be the annual fixed cost of $\$ 135$ plus direct costs of $\$ 556$ to make a total cost of $\$ 691$ per season. Similarly, season total costs could be estimated for other rates of operation and for different lengths of season.

Method B-Hand-dumping with Conveyor Aids. In this method, the field lugs are dumped by hand, but the dumper is aided by means of conveyors for full and empty lugs (fig. 23). The different job classifications, the capacity rate of operation for each job, and equipment requirements per dumping station are given in table 8. Costs for the labor and equipment required for the dumping operations with this method are summarized for different rates of output in table 9 .

Method C-Hand-dumping with Conveyor Aids Plus Relief. The rate of dumping per station is determined by the number of packers served by one dumping station, the rate of packing, the proportion of cannery and cull fruit, and the capacity of the grading table. In some plants, the required 


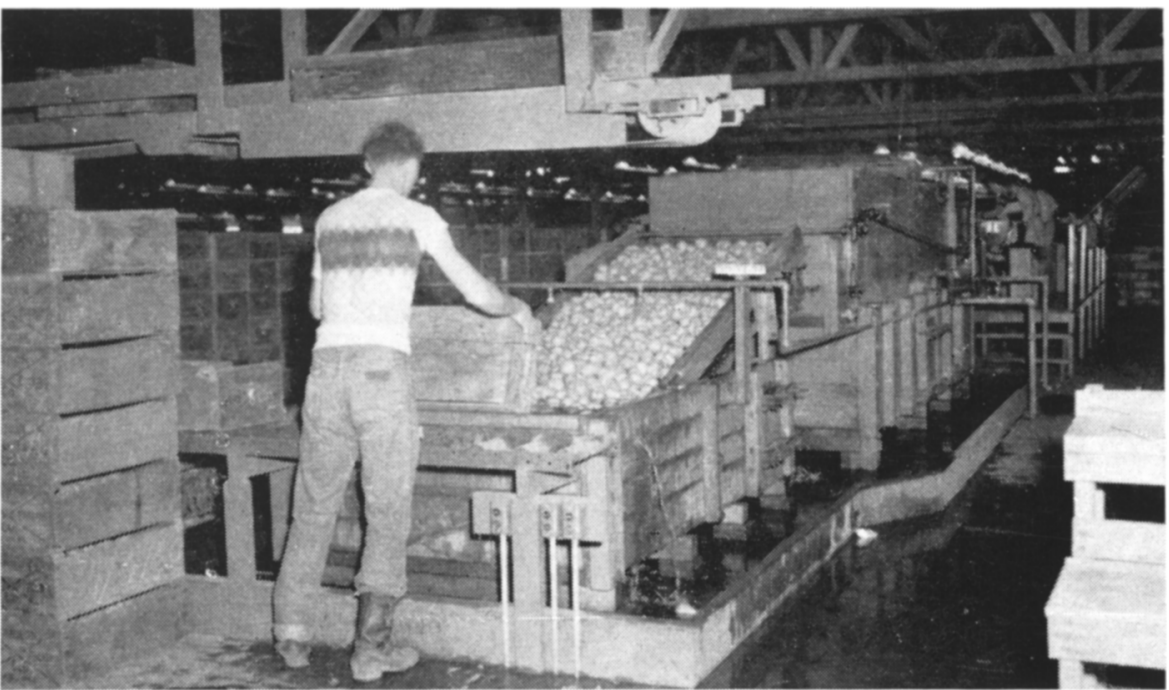

Fig. 23. Hand-dumping with conveyor aids. Note the conveyor for full lugs at right of dumper and empty-lug conveyor overhead.

TABLE 7

HAND-DUMPING-METHOD A: DUMPING-LABOR AND EQUIPMENT REQUIREMENTS AND COSTS IN RELATION TO CAPACITY DUMPING RATE, APPLE AND PEAR PACKING PLANTS

\begin{tabular}{|c|c|c|c|c|c|c|c|c|}
\hline \multirow{3}{*}{$\begin{array}{l}\text { Number of } \\
\text { dumping } \\
\text { stations }\end{array}$} & \multicolumn{2}{|c|}{ Crew capacity* } & \multirow{3}{*}{$\begin{array}{c}\text { Job and number } \\
\text { of workers } \dagger\end{array}$} & \multicolumn{3}{|c|}{ Direct cost } & \multicolumn{2}{|c|}{ Equipment cost } \\
\hline & \multirow{2}{*}{$\begin{array}{l}\text { Hand- } \\
\text { truck } \\
\text { plant }\end{array}$} & \multirow{2}{*}{$\begin{array}{l}\text { Fork- } \\
\text { truck } \\
\text { plant }\end{array}$} & & \multirow[t]{2}{*}{ Labor } & \multirow{2}{*}{$\begin{array}{l}\text { Equip- } \\
\text { ment-- } \\
\text { (power } \\
\text { and } \\
\text { repairs } \ddagger \text { ) }\end{array}$} & \multirow[t]{2}{*}{ Total } & \multirow{2}{*}{$\begin{array}{l}\text { Replace- } \\
\text { ment } \\
\text { cost } \$\end{array}$} & \multirow{2}{*}{$\begin{array}{l}\text { Annual } \\
\text { fixed } \\
\text { cost } \|\end{array}$} \\
\hline & & & & & & & & \\
\hline & \multicolumn{2}{|c|}{ lugs per hour } & & \multicolumn{3}{|c|}{ dollars per hour } & \multicolumn{2}{|c|}{ dollars } \\
\hline 1 & 350 & 340 & 1 & 1.35 & 0.04 & 1.39 & 500 & 68 \\
\hline 2 & 700 & 680 & 2 & 2.70 & 0.08 & 2.78 & 1,000 & 135 \\
\hline 3 & 1,050 & 1,020 & 3 & 4.05 & 0.12 & 4.17 & 1,500 & 203 \\
\hline 4 & 1,400 & 1,360 & 4 & 5.40 & 0.16 & 5.56 & 2,000 & 270 \\
\hline 5 & 1,750 & 1,700 & 5 & 6.75 & 0.20 & 6.95 & 2,500 & 338 \\
\hline 6 & 2,100 & 2,040 & 6 & 8.10 & 0.24 & 8.34 & 3,000 & 405 \\
\hline 7 & 2,450 & 2,380 & 7 & 9.45 & 0.28 & 9.72 & 3,500 & 473 \\
\hline
\end{tabular}

* Capacity dumping rate, assuming dumper alternates with trucker and nonproductive time is 20 per cent of total work time.

† Wage rate: dumper, $\$ 1.35$ per hour.

$\ddagger$ Estimated as 0.5 per cent of replacement cost per 100 hours of use; power cost estimated at $\$ 0.03$ per hour per motor horsepower.

\& Price level for 1950

|| Estimate based on percentage of replacement cost; for dumping table $=13.5$ per cent . 

REQUIREMENTS FOR DUMPING METHOD B

\begin{tabular}{|c|c|c|}
\hline \multirow{2}{*}{ Job classification } & \multicolumn{2}{|c|}{ Capacity rate } \\
\hline & From floor & From pallet \\
\hline & lugs per hour & lugs per hour \\
\hline \\
\hline $\begin{array}{l}\text { Places the full field lug on a conveyor leading to the dumper (alternates with } \\
\text { dumper) } \ldots \ldots \ldots \ldots \ldots \ldots \ldots \ldots \ldots \ldots \ldots \ldots \ldots \ldots \ldots \ldots \ldots \ldots \ldots \ldots \ldots\end{array}$ & 460 & 445 \\
\hline \multicolumn{3}{|l|}{ Dumper: } \\
\hline \multicolumn{3}{|l|}{$\begin{array}{l}\text { Receives the full lug on the conveyor at waist height, empties the lug, and } \\
\text { places it on an empty-lug conveyor leading to the lug-storage area (alternates }\end{array}$} \\
\hline \multicolumn{3}{|l|}{ Set-off man: } \\
\hline \multicolumn{3}{|l|}{ 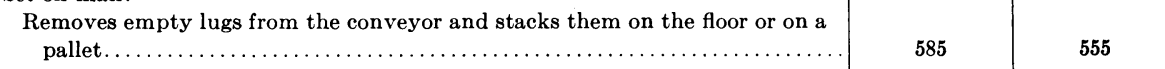 } \\
\hline Equipment requirements per dumping station & $\begin{array}{l}\text { Estimated } \\
\text { quantity* }\end{array}$ & $\begin{array}{l}\text { Replacement } \\
\text { cost, } 1950\end{array}$ \\
\hline Set-on conveyor... & 25 feet & $\$ 530$ \\
\hline \multicolumn{3}{|l|}{ Dumping station: } \\
\hline Table and elevator to sorting table. & 1 & 500 \\
\hline \multicolumn{3}{|l|}{ Empty-lug conveyor: } \\
\hline Power conveyor.... & 30 feet & 530 \\
\hline Gravity conveyor......... & 40 feet & 125 \\
\hline
\end{tabular}

* For a one-station plant. The average quantities per station vary slightly with the number of dumping stations.

TABLE 9

\section{HAND-DUMPING-METHOD B: DUMPING-LABOR AND EQUIPMENT REQUIREMENTS AND COSTS IN RELATION TO CAPACITY DUMPING RATE, APPLE AND PEAR PACKING PLANTS}

\begin{tabular}{|c|c|c|c|c|c|c|c|c|c|c|}
\hline \multirow{2}{*}{$\begin{array}{l}\text { Num- } \\
\text { ber } \\
\text { of } \\
\text { sta- } \\
\text { tions }\end{array}$} & \multicolumn{2}{|c|}{ Crew capacity* } & \multicolumn{3}{|c|}{ Job and number of workers $\dagger$} & \multicolumn{3}{|c|}{ Direct cost } & \multicolumn{2}{|c|}{ Equipment cost } \\
\hline & $\begin{array}{l}\text { Hand- } \\
\text { truck } \\
\text { plant }\end{array}$ & $\begin{array}{l}\text { Fork- } \\
\text { truck } \\
\text { plant }\end{array}$ & Dumper & Set on & Set off & Labor & $\begin{array}{l}\text { Equip- } \\
\text { ment } \\
\text { (power } \\
\text { and } \\
\text { repairs } \ddagger \text { ) }\end{array}$ & Total & $\begin{array}{c}\text { Replace- } \\
\text { ment } \\
\text { cost } \S\end{array}$ & $\begin{array}{l}\text { Annual } \\
\text { fixed } \\
\text { cost } \|\end{array}$ \\
\hline & \multicolumn{2}{|c|}{ lugs per hour } & & & & \multicolumn{3}{|c|}{ dollars per hour } & \multicolumn{2}{|c|}{ dollars } \\
\hline 1 & 460 & 445 & 1 & 1 & 1 & 3.80 & 0.09 & 3.89 & 1,470 & 198 \\
\hline 2 & 585 & 555 & 2 & 2 & 1 & 6.50 & 0.17 & 6.67 & 2,853 & 385 \\
\hline 2 & 920 & 890 & 2 & 2 & 2 & 7.60 & 0.17 & 7.77 & 2,853 & 385 \\
\hline 3 & 1,170 & 1,110 & 3 & 3 & 2 & 10.30 & 0.26 & 10.56 & 4,236 & 572 \\
\hline 3 & 1,380 & 1,335 & 3 & 3 & 3 & 11.40 & 0.26 & 11.66 & 4,236 & 572 \\
\hline 4 & 1,755 & 1,665 & 4 & 4 & 3 & 14.10 & 0.34 & 14.44 & 5,619 & 759 \\
\hline 4 & 1,840 & 1,780 & 4 & 4 & 4 & 15.20 & 0.34 & 15.54 & 5,619 & 759 \\
\hline
\end{tabular}

* Capacity dumping rate, assuming dumper alternates with set-on man and nonproductive time is 20 per cent of total work time.

† Wage rates: dumper, $\$ 1.35$; set on, $\$ 1.35$; and set off, $\$ 1.10$.

$\ddagger$ Estimated at 0.5 per cent of replacement cost per 100 hours of use; power cost estimated at $\$ 0.03$ per hour per motor horsepower.

Price level for 1950 .
Estimate based on percentage of replacement cost; for dumping table and conveyors-13.5 per cent. 


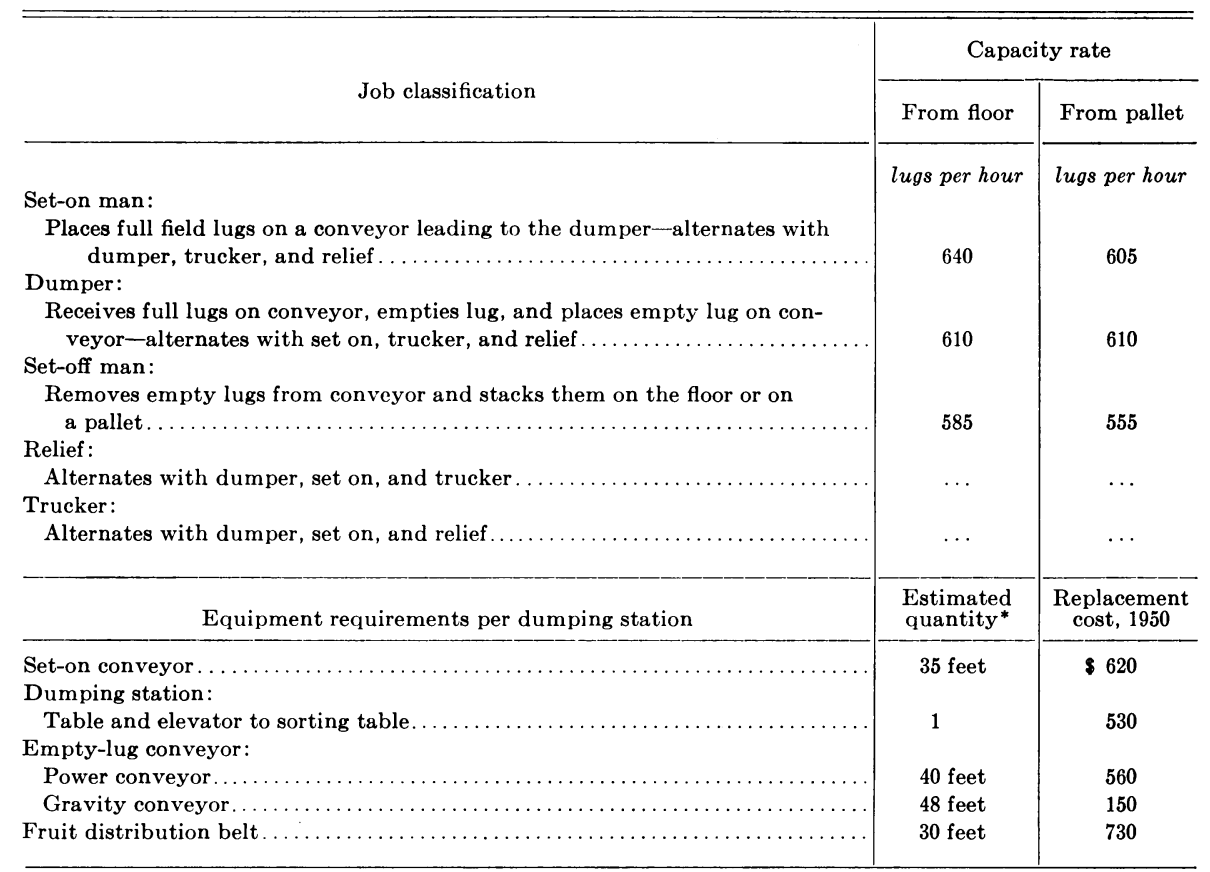

${ }^{*}$ For a one-station plant. The average quantities per station vary slightly with the number of stations.

TABLE 11

\section{HAND-DUMPING-METHOD C: DUMPING-LABOR AND EQUIPMENT REQUIREMENTS AND COSTS IN RELATION TO CAPACITY DUMPING RATE, PEAR PACKING PLANTS}

\begin{tabular}{|c|c|c|c|c|c|c|c|c|c|c|c|}
\hline \multirow{2}{*}{$\begin{array}{c}\text { Number } \\
\text { of } \\
\text { dump- } \\
\text { ing } \\
\text { stations }\end{array}$} & \multicolumn{2}{|c|}{ Crew capacity* } & \multicolumn{4}{|c|}{ Job and number of workers $\dagger$} & \multicolumn{3}{|c|}{ Direct cost } & \multicolumn{2}{|c|}{ Equipment cost } \\
\hline & $\begin{array}{c}\text { Hand- } \\
\text { truck } \\
\text { plant }\end{array}$ & $\begin{array}{l}\text { Fork- } \\
\text { truck } \\
\text { plant }\end{array}$ & $\underset{\text { er }}{\text { Dump- }}$ & Set on & Relief & Set off & Labor & $\begin{array}{l}\text { Equip- } \\
\text { ment } \\
\text { (power } \\
\text { and } \\
\text { repairs } \ddagger \text { ) }\end{array}$ & Total & $\begin{array}{c}\text { Replace- } \\
\text { ment } \\
\text { cost } \S\end{array}$ & $\begin{array}{l}\text { Annual } \\
\text { fixed } \\
\text { cost } \|\end{array}$ \\
\hline & \multicolumn{2}{|c|}{ lugs per hour } & & & & & \multicolumn{3}{|c|}{ dollars per hour } & \multicolumn{2}{|c|}{ dollars } \\
\hline 1 & 585 & 555 & 1 & 1 & 1 & 1 & 5.15 & 0.14 & 5.29 & 2,470 & 333 \\
\hline 1 & 610 & 590 & 1 & 1 & 1 & 2 & 6.25 & 0.14 & 6.39 & 2,470 & 333 \\
\hline 2 & 1,170 & 1,110 & 2 & 2 & 1 & 2 & 8.95 & 0.27 & 9.22 & 4,780 & 645 \\
\hline 2 & 1,220 & 1,180 & 2 & 2 & 1 & 3 & 10.05 & 0.27 & 10.32 & 4,780 & 645 \\
\hline 3 & 1,755 & 1,665 & 3 & 3 & 2 & 3 & 14.10 & 0.40 & 14.50 & 7,090 & 957 \\
\hline 3 & 1,830 & 1,770 & 3 & 3 & 2 & 4 & 15.20 & 0.40 & 15.60 & 7,090 & 957 \\
\hline 4 & 2,340 & 2,220 & 4 & 4 & 2 & 4 & 17.90 & 0.53 & 18.43 & 9,400 & 1,269 \\
\hline
\end{tabular}

* Capacity dumping rate, assuming dumper, set-on men, and truckers alternate and extra rest time of approximately 20 per cent of total work time.

$\dagger$ Wage rate: dumper, $\$ 1.35$; set on, $\$ 1.35$; relief, $\$ 1.35$; set off, $\$ 1.10$ per hour.

$\ddagger$ Estimated as 0.5 per cent of replacement cost per 100 hours of use; power cost estimated at $\$ 0.03$ per hour per motor horsepower.

$\$$ Price level for 1950 .

if Estimate based on percentage of replacement costs; for dumping table and conveyor $=13.5$ per cent. 
rate of dumping per station exceeds the capacity for hand-dumpingMethod B. One means of increasing the dumping rate per station is to provide additional rest for the dumper, thus allowing him to operate at an accelerated pace while actually working. Labor performance standards for this method and equipment requirements are given in table 10, and estimates of costs based on these standards and requirements are given in table 11. The estimates are based on dumping rates applicable when the additional rest time is approximately 20 per cent of the total work time. For one dumping station, the "dumping erew" organization would consist of one set-on man, one dumper, two truckers, and one relief man. This five-man crew then rotates through the various jobs with one of the five men always in a rest status.

With the addition of the relief element, the capacity rate for the dumper and set-on man (in plants using hand trucks) increases from 460 lugs per hour with dumping method B to 610 lugs per hour with dumping method C. There also is a substantial change in the conveyor requirements. While the requirements for the lug conveyors would increase only slightly, the increased dumping rate would require-in most plants - an additional belt to carry sorted fruit to the "packing lines." This change is necessary because a rate of dumping of 610 lugs per hour would exceed the normal capacity of the usual packing line unless the proportion of cull and cannery fruit was unusually high. A distribution belt for loose fruit then would be necessary in order to route sorted fruit to two, or more, different packing lines. ${ }^{16}$

Method D-Single-box Machine-dumper (fig. 24). The dumping operations with this method are similar to those in method B-hand-dumping with conveyor aids-except that the full lug is fed into a dumping machine which automatically dumps the contents and places the empty lug on the emptylug conveyor.

The various job categories, capacity rates, and equipment requirements are summarized in table 12 . In this summary, a range in replacement costs for the dumping machine is indicated, reflecting costs for machines of different manufacture and differing as to mechanical details. With each type of machine, a variable speed drive is provided so that the rate of dumping can be varied over a considerable range but with an upper limit. The machine capacities as estimated by the manufacturer ranged from 720 to 1,000 lugs per hour. The number of dumping stations actually required is determined by the size and number of grading tables. One machine might be required for each table with a capacity of 500 or more boxes per hour. With smaller grading tables, one dumping machine might serve two grading tables. $^{47}$

${ }^{46}$ The distribution belt is actually a transportation link between the dumping-grading stages and the packing stage. For convenience, it is included in the dumping stage, although the results would be the same if treated separately.

${ }^{47}$ Two advantages in the use of the machine-dumping methods may influence costs although their effects would be difficult to measure and are not evaluated in this report. A more even flow of fruit to the sorting table is possible with machine-dumping, and changes in dumping rate with variations in fruit quality are more easily controlled. These effects appear to result in a small increase in the efficiency of the sorting operations. Also, the dumping job is considered particularly arduous, and the use of dumping machines simplifies the problem of recruiting workers. 
Estimates of the direct costs for labor and equipment and of the annual fixed costs for the dumping operations are given in table 13 for different dumping rates in plants using fork trucks or hand trucks in the receiving operations. The costs given in table 13 are based on the lower replacement cost indicated above for dumping machines. If the higher machine cost were

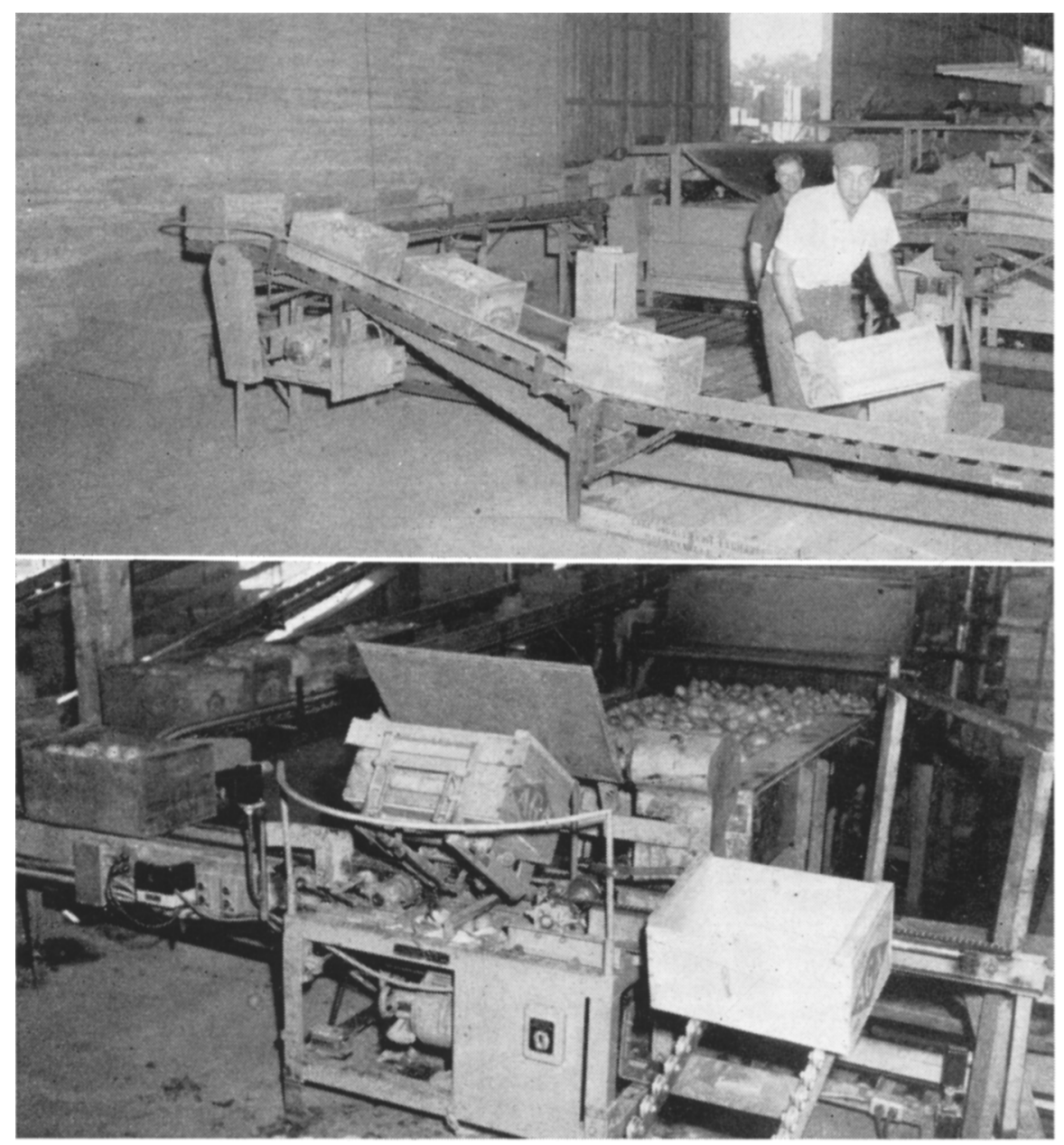

Fig. 24. Single-box dumping machines: Above-box tipped by chain conveyor; below-box tipped by mechanical arm.

used, the annual fixed costs per dumping station would be greater than indicated by about $\$ 200$ per dumping station, and the direct costs would be greater by about 8 cents per station. The use of the lower replacement cost should, however, give a satisfactory indication of the relative costs with different methods. Presumably, the low-cost machine would be chosen unless the higher cost machines were superior in terms of capacity or quality of 
TABLE 12

LABOR PERFORMANCE STANDARDS AND EQUIPMENT REQUIREMENTS FOR DUMPING METHOD D

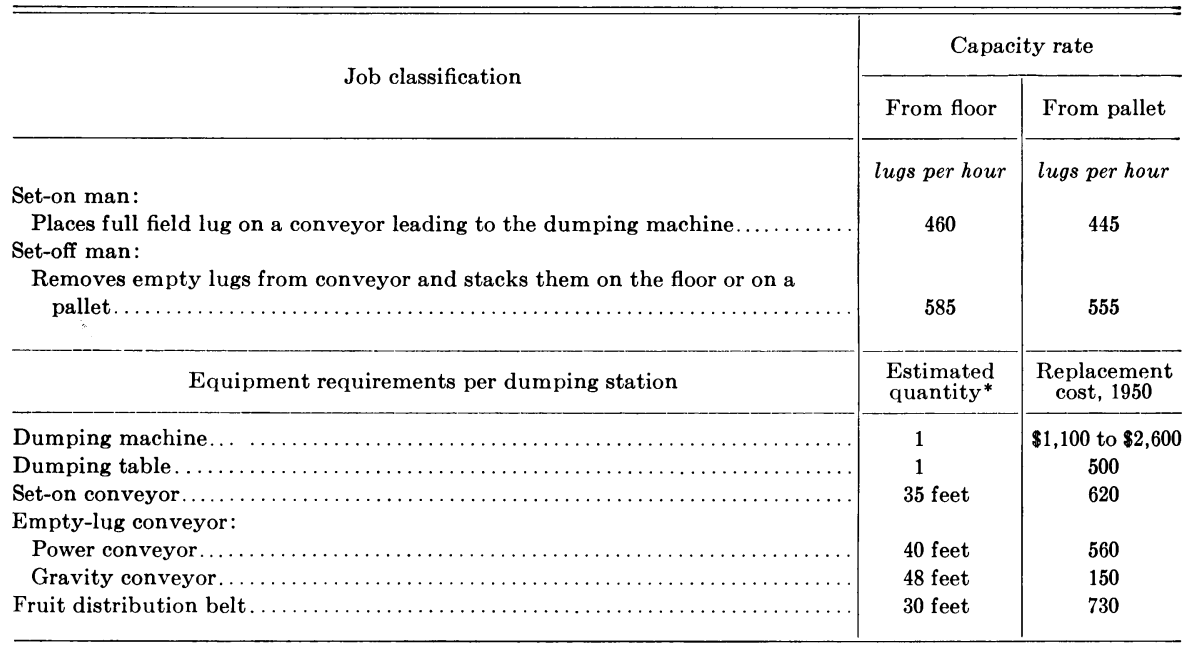

* For a one-station plant. The average quantities per station vary slightly with the number of stations.

TABLE 13

MACHINE-DUMPING, SINGLE BOX-METHOD D: DUMPING-LABOR AND EQUIPMENT REQUIREMENTS AND COSTS IN RELATION TO CAPACITY DUMPING RATE, APPLE ·AND PEAR PACKING PLANTS

\begin{tabular}{|c|c|c|c|c|c|c|c|c|c|}
\hline \multirow{2}{*}{$\begin{array}{c}\text { Number } \\
\text { of } \\
\text { dumping* } \\
\text { stations }\end{array}$} & \multicolumn{2}{|c|}{ Crew capacity $\dagger$} & \multicolumn{2}{|c|}{$\begin{array}{c}\text { Job and number } \\
\text { of workers } \ddagger\end{array}$} & \multicolumn{3}{|c|}{ Direct cost } & \multicolumn{2}{|c|}{ Equipment cost } \\
\hline & $\begin{array}{l}\text { Hand- } \\
\text { truck } \\
\text { plant }\end{array}$ & $\begin{array}{l}\text { Fork- } \\
\text { truck } \\
\text { plant }\end{array}$ & Set on & Set off & Labor & $\begin{array}{l}\text { Equip- } \\
\text { ment } \\
\text { (power } \\
\text { and } \\
\text { repairs§) }\end{array}$ & Total & $\begin{array}{c}\text { Replace- } \\
\text { ment } \\
\text { cost } \|\end{array}$ & $\begin{array}{l}\text { Annual } \\
\text { fixed } \\
\text { costq }\end{array}$ \\
\hline & \multicolumn{2}{|c|}{ lugs per hour } & & & \multicolumn{3}{|c|}{ dollars per hour } & \multicolumn{2}{|c|}{ dollars } \\
\hline 1 & 460 & 445 & 1 & 1 & 2.45 & 0.23 & 2.68 & 3,660 & 494 \\
\hline 1 & 585 & 555 & 2 & 1 & 3.80 & 0.24 & 4.04 & 3,660 & 494 \\
\hline 1 & 920 & 890 & 2 & 2 & 4.90 & 0.25 & 5.15 & 3,660 & 494 \\
\hline 2 & 1,170 & 1,110 & 3 & 2 & 6.25 & 0.49 & 6.74 & 7,145 & 965 \\
\hline 2 & 1,380 & 1,335 & 3 & 3 & 7.35 & 0.49 & 7.84 & 7,145 & 965 \\
\hline 2 & 1,755 & 1,665 & 4 & 3 & 8.70 & 0.49 & 9.19 & 7,145 & 965 \\
\hline 2 & 1,840 & 1,780 & 4 & 4 & 9.80 & 0.49 & 10.29 & 7,145 & 965 \\
\hline 3 & 2,300 & 2,220 & 5 & 4 & 11.15 & 0.73 & 11.88 & 10,630 & 1,435 \\
\hline
\end{tabular}

* Expressed in terms of dumping equipment capacity. The actual number of stations required must be considered jointly with size and number of grading tables.

$\dagger$ Capacity dumping rate, assuming nonproductive time is 20 per cent of total work time.

$\ddagger$ Wage rate: set on, $\$ 1.35$; set off, $\$ 1.10$ per hour.

\$stimated as 0.5 per cent of replacement cost per 100 hours of use; power cost estimated at $\$ 0.03$ per hour per motor horsepower.

I Erice level for 1950 . 
performance or unless the rate of depreciation and expected operating costs were lower by an amount sufficient to offset the higher initial cost.

Method E-Stack Dumper (fig. 25). The procedure with this method is the same as that with method $D$-the single-box dumper-except that the full lugs are fed into the dumping machine in stacks of five or six lugs. ${ }^{48}$

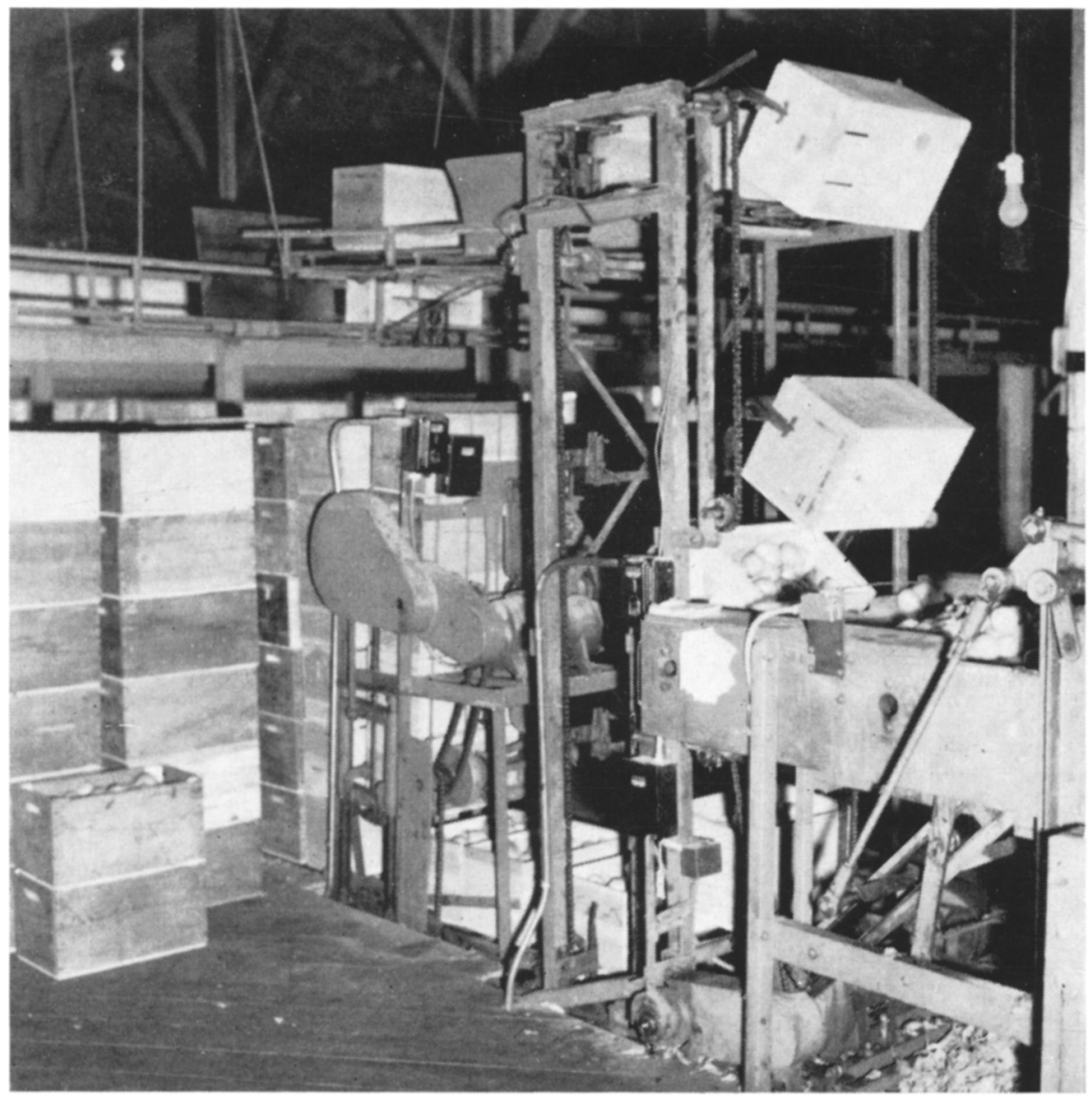

Fig. 25. One type of stack dumper.

Job categories, capacity rates, and equipment requirements per dumping station with the stack dumper are summarized in table 14. A range of replacement costs is given, indicating the range in costs for equipment of different manufacturers. As with the single-box dumping machine, the lower replacement cost was used in the analysis. With each type of machine, the rate of dumping may be varied over a considerable range by means of a variable speed drive. The manufacturer's estimates of maximum dumping rate range

${ }^{48} \mathrm{~A}$ machine for mechanically de-stacking lugs from pallets is reported to be under development in the Pacific Northwest, but equipment of this type is not yet available for plant use. 
from 800 to 1,200 lugs per hour. As with method D, the number of dumping machines required is determined by the size and number of grading tables.

Direct costs and annual fixed costs for equipment required for the dumping operations with the stack dumper are given in table 15. Because the dumping crew organization in the fork-truck and hand-truck plants is different, crew requirements and costs in relation to dumping rate are given separately in table 15 for plants using hand trucks or fork trucks in the receiving operations.

\section{TABLE 14}

LABOR PERFORMANCE STANDARDS AND EQUIPMENT REQUIREMENTS FOR DUMPING METHOD E

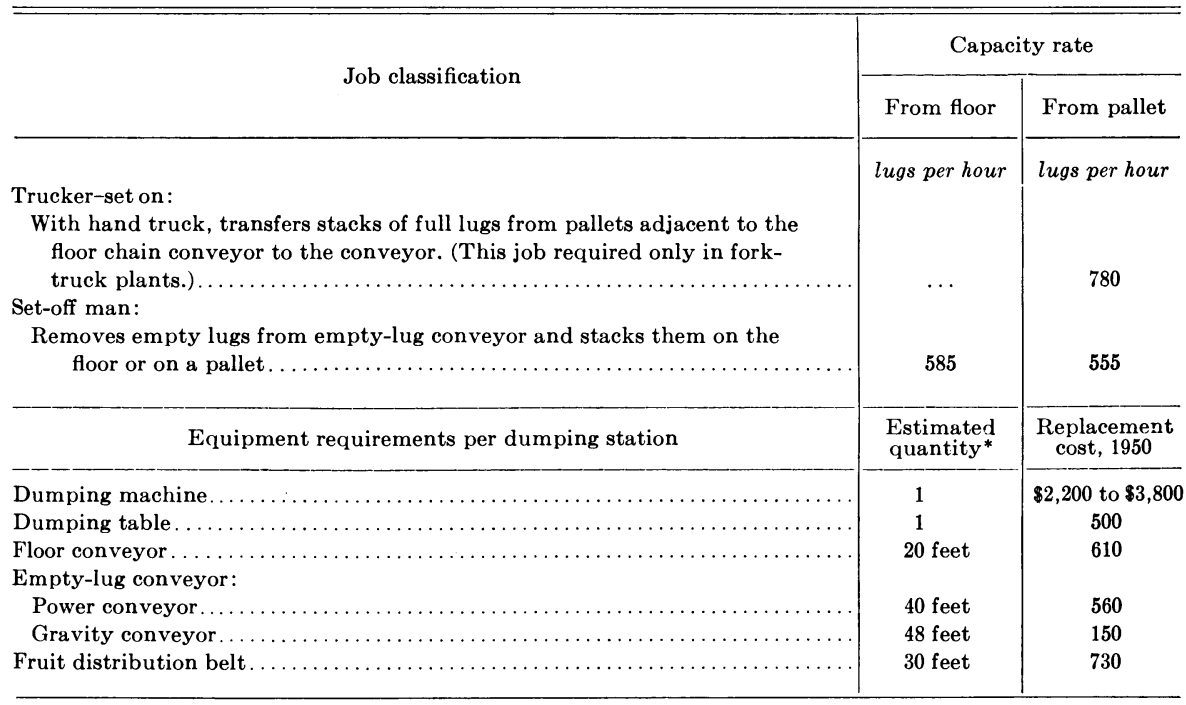

* For a one-station plant. The average quantities per station vary slightly with the number of stations.

In the plants with hand-truck receiving, the direct costs include only the cost of power and direct repair expense for the equipment, plus the labor cost for the empty-lug set-off men. In the fork-truck plants, however, an additional labor cost is included for a hand trucker who transfers stacks of full lugs from pallets to the floor conveyor. ${ }^{49}$ None of the costs of the other trucking operations is included.

\section{Stage 2. Grading ${ }^{50}$}

Grading or sorting in pear packing houses consists of inspecting the field-run fruit and separating it into grades for packing or for diversion to processing and cull uses. The job must be carefully done in order to meet the established standards for the several grades, for these grades are used

${ }^{49}$ The transfer of lugs from pallet to floor conveyor could be made singly by a set-on man, but the cost would be higher than with a hand truck.

${ }^{50}$ This material is based on a more detailed report on grading costs by R. G. Bressler and B. C. French, Efficiency in Fruit Marketing: Grading Costs for Apples and Pears, Giannini Foundation of Agricultural Economics, Mimeographed Report No. 128, June, 1952. 
TABLE 15

MACHINE-DUMPING, S'TACK DUMPER, METHOD E: DUMPING-LABOR AND EQUIPMENT REQUIREMENTS AND COSTS IN RELATION TO CAPACITY DUMPING RATE

\begin{tabular}{|c|c|c|c|c|c|c|c|c|}
\hline \multirow{2}{*}{$\begin{array}{l}\text { Number of } \\
\text { dumping } \\
\text { stations* }\end{array}$} & \multirow{2}{*}{$\begin{array}{c}\text { Crew } \\
\text { capacity } \dagger \\
\text { lugs per hour }\end{array}$} & \multicolumn{2}{|c|}{$\begin{array}{l}\text { Job and number } \\
\text { of workers } \ddagger\end{array}$} & \multicolumn{3}{|c|}{$\begin{array}{l}\text { Direct cost } \\
\text { (dollars per hour) }\end{array}$} & \multicolumn{2}{|c|}{$\underset{\text { (dollars) }}{\text { Equipment cost }}$} \\
\hline & & Set off & $\underset{\text { trucker }}{\text { Hand }}$ & Labor & $\begin{array}{c}\text { Equipment } \\
\text { (power and } \\
\text { repairs§) }\end{array}$ & Total & $\begin{array}{c}\text { Replace- } \\
\text { ment cost } \|\end{array}$ & $\begin{array}{l}\text { Annual } \\
\text { fixed } \\
\text { cost }\end{array}$ \\
\hline
\end{tabular}

Hand-truck receiving

\begin{tabular}{l|r|r|l|l|l|l|r|r|r}
\hline 1 & 585 & 1 & $\ldots$ & 1.10 & 0.30 & 1.40 & 4,750 & 641 \\
1 & 1,170 & 2 & $\ldots$ & 2.20 & 0.30 & 2.50 & 4,750 & 641 \\
2 & 1,755 & 3 & $\ldots$ & 3.30 & 0.59 & 3.89 & 9,325 \\
2 & 2,340 & 4 & $\ldots$ & 4.40 & 0.59 & 4.99 & 9,325 & 1,259 \\
\hline
\end{tabular}

Fork-truck receiving

\begin{tabular}{r|r|r|r|r|r|r|r|r}
\hline 1 & 555 & 1 & 1 & 2.35 & 0.30 & 2.65 & 4,816 & 650 \\
1 & 780 & 2 & 1 & 3.45 & 0.30 & 3.75 & 4,816 & 650 \\
1 & 1,110 & 2 & 2 & 4.70 & 0.30 & 5.00 & 4,816 & 650 \\
2 & 1,560 & 3 & 2 & 5.80 & 0.59 & 6.39 & 9,457 & 1,277 \\
2 & 1,665 & 3 & 3 & 7.05 & 0.59 & 7.64 & 9,457 & 1,277 \\
2 & 2,220 & 4 & 3 & 8.15 & 0.59 & 8.74 & 9,457 & 1,277 \\
\hline
\end{tabular}

* Expressed in terms of capacity per dumping machine. The actual number of stations required is determined jointly with number and size of grading tables.

t Capacity dumping rate, assuming nonproductive time is 20 per cent of the total work time.

$\ddagger$ Wage rate: set off, $\$ 1.10$; hand trucker, $\$ 1.25$ per hour. Requirements for set off labor are related directly to volume and are independent of the number of dumping stations.

$\S$ Estimated as 0.5 per cent of replacement cost per 100 hours of use; power cost estimated at $\$ 0.03$ per hour per motor horsepower.

$\|$ Price level for 1950 .

I Estimate based on percentage of replacement cost; for dumping machines, conveyor, and hand truck $=13.5$ per cent.

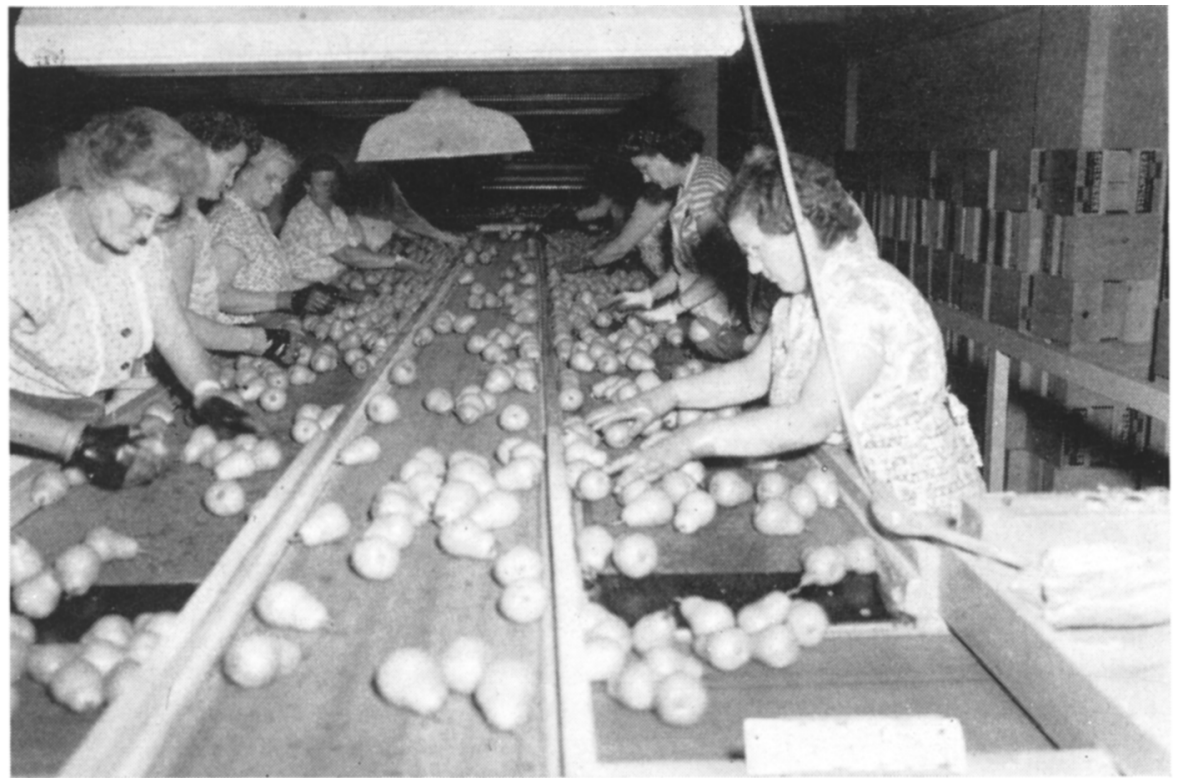

Fig. 26. The belt conveyor type of sorting table commonly used in California. 
as a basis for sale and so have an impact on prices. In addition, the job is also important as an element of packing house labor costs, accounting for roughly 25 per cent of all hourly rate labor and 15 per cent of total labor costs in pear packing houses.

Many minor variations in sorting tables were observed, but basic arrangements are fairly uniform. In packing fresh California pears, sorting tables are usually of the belt-conveyor type (fig. 26). Performance standards for

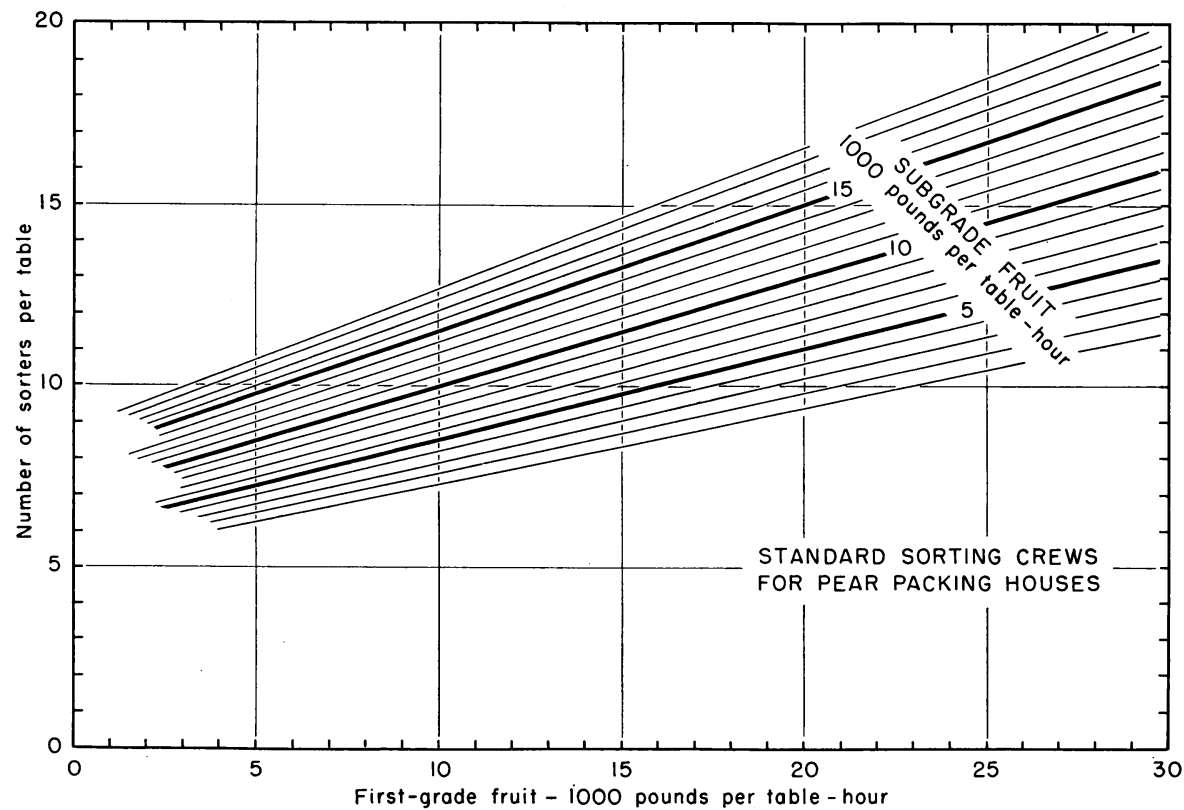

Fig. 27. Labor standards for efficient grading of pears.

grading pears with this type of equipment and based on an analysis of plant record data are given in figure 27. These standards are generally applicable to the sorting job in spite of minor modifications in the arrangement described above. They indicate the approximate effects of the amount of first-grade and subgrade fruit ${ }^{51}$ per hour per sorting table on the number of sorters required under reasonably efficient operating conditions. ${ }^{52}$

The relationships illustrated in figure 27 are converted to a cost basis in figure 28, using typical 1950 wage rates for sorting labor of $\$ 1.05$ per hour. The diagram takes account of the fact that workers must be hired in whole units, which gives rise to discontinuities in the cost function. If, for example, the performance standard calls for from 7.1 to 8.0 sorters per table-hour, as a practical matter eight workers must be hired. The diagram is thus

${ }^{51}$ As indicated previously, fruit is commonly sorted into three or more grades. For purposes of simplicity in estimating grading labor requirements, however, all fruit has been classified under two grades corresponding in general to the method of treatment on the sorting table: (1) first-grade fruit, including all fruit to be packed plus No. 1 cannery fruit and (2) all other fruit, usually consisting of culls plus lower grades of cannery fruit.

${ }^{52}$ See Section III for a further discussion of "reasonable" efficiency. 
TABLE 16

APPROXIMATE CAPACITIES, INVESTMENTS, AVERAGE ANNUAL COSTS, AND OPERATING COSTS FOR SORTING TABLES

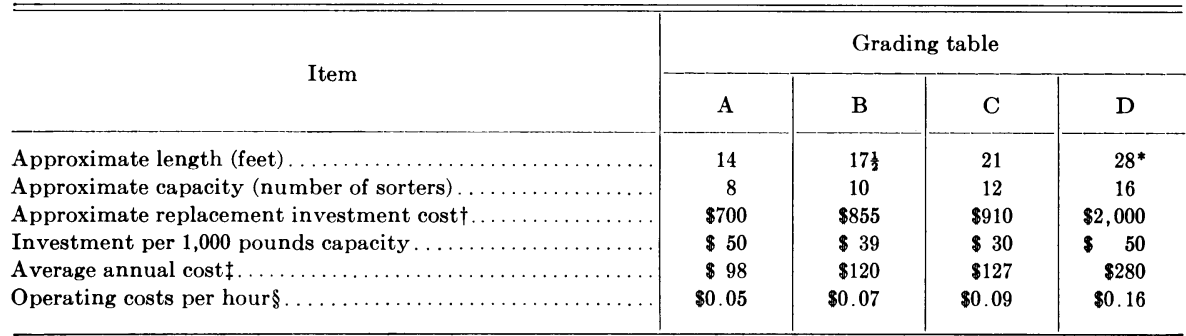

* Custom made; others are standard equipment.

$\dagger$ At 1950 prices and including installation charges.

I Based on the following standardized charges: depreciation, 5 per cent; repairs, including new belts, 4 per cent; insurance 1 per cent; interest 3 per cent (approximately equivalent to 5 per cent on the undepreciated balance); and taxes, 1 per cent.

\$ Includes power cost estimated at $\$ 0.03$ per hour per horse power and variable repairs at 0.5 per cent of the investment per 100 hours of use.

TABLE 17

GRADING TABLE A-DIRECT AND FIXED COSTS IN RELATION TO RATES OF TOTAL OUTPUT WITH 80 PER CENT FIRST-GRADE AND 20 PER CENT SUBGRADE FRUIT

\begin{tabular}{|c|c|c|c|c|}
\hline \multirow{2}{*}{ Total plant output } & \multicolumn{3}{|c|}{ Direct cost } & \multirow{2}{*}{$\begin{array}{c}\text { Average } \\
\text { annual } \\
\text { fixed } \\
\text { cost }\end{array}$} \\
\hline & Labor & Operating & Total & \\
\hline 1,000 lbs per hour & dollars & dollars & dollars & dollars \\
\hline $0-5.0 \ldots \ldots \ldots \ldots \ldots \ldots$ & 6.30 & 0.05 & 6.35 & 98 \\
\hline $5.1-9.1 \ldots \ldots \ldots \ldots \ldots \ldots \ldots$ & 7.35 & 0.05 & 7.40 & 98 \\
\hline $9.2-13.5 \ldots \ldots \ldots \ldots \ldots \ldots \ldots \ldots$ & 8.40 & 0.05 & 8.45 & 98 \\
\hline $13.6-14.1 \ldots \ldots \ldots \ldots \ldots \ldots \ldots$ & 13.65 & 0.10 & 13.75 & 196 \\
\hline $14.2-18.2 \ldots \ldots \ldots \ldots \ldots \ldots$ & 14.70 & 0.10 & 14.80 & 196 \\
\hline $18.3-22.6 \ldots \ldots \ldots \ldots \ldots \ldots$ & 15.75 & 0.10 & 15.85 & 196 \\
\hline $22.7-27.0 \ldots$ & 16.80 & 0.10 & 16.90 & 196 \\
\hline $27.1-31.7 \ldots \ldots \ldots$ & 23.10 & 0.15 & 23.25 & 294 \\
\hline $31.8-36.1 \ldots \ldots \ldots \ldots \ldots$ & 24.15 & 0.15 & 24.30 & 294 \\
\hline $36.2-40.5 \ldots \ldots \ldots \ldots \ldots$ & 25.20 & 0.15 & 25.35 & 294 \\
\hline $40.6-45.2 \ldots \ldots \ldots \ldots$ & 31.50 & 0.20 & 31.70 & 392 \\
\hline $45.3-49.6 \ldots$ & 32.55 & 0.20 & 32.75 & 392 \\
\hline $49.7-54.0 \ldots \ldots \ldots \ldots \ldots$ & 33.60 & 0.20 & 33.80 & 392 \\
\hline $\mathbf{5 4 . 1 - 5 8 . 7 \ldots \ldots \ldots \ldots \ldots}$ & 39.90 & 0.25 & 40.15 & 490 \\
\hline $58.8-63.1 \ldots \ldots \ldots$ & 40.95 & 0.25 & 41.20 & 490 \\
\hline $63.2-67.5 \ldots \ldots \ldots \ldots \ldots$ & 42.00 & 0.25 & 42.25 & 490 \\
\hline $67.6-72.2 \ldots$ & 48.30 & 0.30 & 48.60 & 588 \\
\hline $72.3-76.6 \ldots \ldots \ldots \ldots \ldots \ldots \ldots$ & 49.35 & 0.30 & 49.65 & 588 \\
\hline $76.7-81.0 \ldots \ldots \ldots \ldots \ldots \ldots \ldots$ & 50.40 & 0.30 & 50.70 & 588 \\
\hline $81.1-85.7 \ldots \ldots \ldots \ldots \ldots \ldots \ldots$ & 56.70 & 0.35 & 57.05 & 686 \\
\hline $85.8-90.1 \ldots \ldots \ldots \ldots$ & 57.75 & 0.35 & 58.10 & 686 \\
\hline $90.2-94.5 \ldots$ & 58.80 & 0.35 & 59.15 & 686 \\
\hline $94.6-98.2 \ldots$ & 65.10 & 0.40 & 65.50 & 784 \\
\hline $98.3-103.6 \ldots \ldots \ldots \ldots \ldots$ & 66.15 & 0.40 & 66.55 & 784 \\
\hline
\end{tabular}


marked off into zones within which any combination of rates of output of first-grade and subgrade fruit yield the same hourly cost.

The grading labor requirements must be coördinated, of course, with the capacities of the grading tables used. Approximate costs and total capacities for four sizes of grading tables commonly used in California pear-packing plants are given in table 16. As defined here, each of these sizes involves a different technology. Other sizes would be possible, of course, but for sim-

TABLE 18

GRADING TABLE B-DIRECT AND FIXED COSTS IN RELATION TO RATES OF TOTAL OUTPUT WITH 80 PER CENT FIRST-GRADE AND 20 PER CENT SUBGRADE FRUIT

\begin{tabular}{|c|c|c|c|c|}
\hline \multirow{2}{*}{ Total plant output } & \multicolumn{3}{|c|}{ Direct cost } & \multirow{2}{*}{$\begin{array}{l}\text { Average } \\
\text { annual } \\
\text { fixed } \\
\text { cost }\end{array}$} \\
\hline & Labor & Operating & Total & \\
\hline 1,000 lbs per hour & dollars & dollars & dollars & dollars \\
\hline $0-5.0 \ldots \ldots \ldots \ldots \ldots$ & 6.30 & 0.07 & 6.37 & 120 \\
\hline $5.1-9.1 \ldots \ldots \ldots \ldots \ldots \ldots \ldots$ & 7.35 & 0.07 & 7.42 & 120 \\
\hline $9.2-13.5 \ldots \ldots \ldots \ldots \ldots \ldots \ldots \ldots$ & 8.40 & 0.07 & 8.47 & 120 \\
\hline $13.6-17.5 \ldots$ & 9.45 & 0.07 & 9.52 & 120 \\
\hline $17.6-21.2 \ldots \ldots \ldots$ & 10.50 & 0.07 & 10.57 & 120 \\
\hline $21.3-22.6 \ldots \ldots \ldots \ldots \ldots$ & 15.75 & 0.14 & 15.89 & 240 \\
\hline $22.7-27.0 \ldots \ldots$ & 16.80 & 0.14 & 16.94 & 240 \\
\hline $27.1-31.0 \ldots$ & 17.85 & 0.14 & 17.99 & 240 \\
\hline $31.1-35.0 \ldots$ & 18.90 & 0.14 & 19.04 & 240 \\
\hline $35.1-38.7 \ldots$ & 19.95 & 0.14 & 20.09 & 240 \\
\hline $38.8-42.4 \ldots$ & 21.00 & 0.14 & 21.14 & 240 \\
\hline $42.5-44.5 \ldots$ & 26.25 & 0.21 & 26.46 & 360 \\
\hline $44.6-48.5 \ldots \ldots \ldots \ldots \ldots$ & 27.30 & 0.21 & 27.51 & 360 \\
\hline $48.6-52.5 \ldots \ldots$ & 28.35 & 0.21 & 28.56 & 360 \\
\hline $52.6-56.2 \ldots \ldots \ldots \ldots \ldots \ldots \ldots \ldots$ & 29.40 & 0.21 & 29.61 & 360 \\
\hline $56.3-59.9 \ldots \ldots \ldots \ldots \ldots \ldots \ldots \ldots$ & 30.45 & 0.21 & 30.66 & 360 \\
\hline $60.0-63.6 \ldots \ldots \ldots \ldots \ldots \ldots \ldots$ & 31.50 & 0.21 & 31.71 & 360 \\
\hline $63.7-66.0 \ldots \ldots \ldots \ldots \ldots \ldots \ldots \ldots$ & 36.75 & 0.28 & 37.03 & 480 \\
\hline $66.1-70.0 \ldots \ldots \ldots \ldots \ldots \ldots \ldots \ldots$ & 37.80 & 0.28 & 38.08 & 480 \\
\hline $70.1-73.7 \ldots \ldots \ldots \ldots \ldots \ldots \ldots$ & 38.85 & 0.28 & 39.13 & 480 \\
\hline $73.8-77.4 \ldots \ldots \ldots \ldots \ldots \ldots \ldots$ & 39.90 & 0.28 & 40.18 & 480 \\
\hline $77.5-81.1 \ldots \ldots \ldots \ldots \ldots \ldots \ldots \ldots$ & 40.95 & 0.28 & 41.23 & 480 \\
\hline $81.2-84.8 \ldots \ldots \ldots \ldots \ldots \ldots \ldots \ldots$ & 42.00 & 0.28 & 42.28 & 480 \\
\hline $84.9-87.5 \ldots \ldots \ldots \ldots \ldots$ & 47.25 & 0.35 & 47.60 & 600 \\
\hline $87.6-91.2 \ldots \ldots \ldots \ldots \ldots$ & 48.30 & 0.35 & 48.65 & 600 \\
\hline $91.3-94.9 \ldots \ldots \ldots \ldots \ldots$ & 49.35 & 0.35 & 49.70 & 600 \\
\hline $95.0-98.6 \ldots \ldots \ldots \ldots$ & 50.40 & 0.35 & 50.75 & 600 \\
\hline $98.6-102.3 \ldots \ldots \ldots \ldots \ldots \ldots \ldots \ldots$ & 51.45 & 0.35 & 51.80 & 600 \\
\hline
\end{tabular}

plicity only the four sizes actually observed will be considered. Capacities are expressed in terms of numbers of sorters and the corresponding capacity outputs of first-grade and subgrade fruit for each number of sorters can be read from figures 27 and 28 . For short periods, these capacities might be slightly exceeded, which may be important in adding to the flexibility of the operation. The standards as such apply to rates which might be sustained over a fairly long period.

Labor, operating, and average annual fixed costs for each type of grading table are summarized in relation to rates of total output in tables 17, 18, 19, 
and 20, where it is assumed that 80 per cent of the fruit is first grade and 20 per cent is subgrade. Similar costs for other proportions of first-grade and subgrade fruit can be calculated from the material in figure 28 and table 16. For brevity, the costs for only one proportion are illustrated here, although other proportions are considered in the over-all development of planning functions in the following chapter.

TABLE 19

GRADING TABLE C-DIRECT AND FIXED COSTS IN RELATION TO RATES OF TOTAL OUTPUT WITH 80 PER CENT FIRST-GRADE AND 20 PER CENT SUBGRADE FRUIT

\begin{tabular}{|c|c|c|c|c|}
\hline \multirow{2}{*}{ Total plant output } & \multicolumn{3}{|c|}{ Direct cost } & \multirow{2}{*}{$\begin{array}{c}\text { Average } \\
\text { annual } \\
\text { fixed } \\
\text { cost }\end{array}$} \\
\hline & Labor & Operating & Total & \\
\hline 1,000 lbs per hour & dollars & dollars & dollars & dollars \\
\hline $0-5.0 \ldots \ldots \ldots \ldots \ldots$ & 6.30 & 0.09 & 6.39 & 127 \\
\hline $5.1-9.1 \ldots \ldots \ldots \ldots \ldots$ & 7.35 & 0.09 & 7.44 & 127 \\
\hline $9.2-13.5 \ldots \ldots \ldots \ldots$ & 8.40 & 0.09 & 8.49 & 127 \\
\hline $13.6-17.5 \ldots \ldots \ldots$ & 9.45 & 0.09 & 9.54 & 127 \\
\hline $17.6-21.2 \ldots \ldots \ldots$ & 10.50 & 0.09 & 10.59 & 127 \\
\hline $21.3-25.0 \ldots \ldots$ & 11.55 & 0.09 & 11.64 & 127 \\
\hline $25.1-28.5 \ldots \ldots \ldots$ & 12.60 & 0.09 & 12.69 & 127 \\
\hline $28.6-31.0 \ldots \ldots \ldots$ & 17.85 & 0.18 & 18.03 & 254 \\
\hline $31.1-35.0 \ldots \ldots$ & 18.90 & 0.18 & 19.08 & 254 \\
\hline $35.1-38.7 \ldots \ldots$ & 19.95 & 0.18 & 20.13 & 254 \\
\hline $38.8-42.4 \ldots \ldots \ldots \ldots$ & 21.00 & 0.18 & 21.18 & 254 \\
\hline $42.5-46.2 \ldots \ldots \ldots \ldots$ & 22.05 & 0.18 & 22.23 & 254 \\
\hline $46.3-50.0 \ldots \ldots \ldots \ldots$ & 23.10 & 0.18 & 23.28 & 254 \\
\hline $50.1-53.5 \ldots \ldots \ldots \ldots \ldots$ & 24.15 & 0.18 & 24.33 & 254 \\
\hline $53.6-57.0 \ldots \ldots \ldots \ldots \ldots$ & 25.20 & 0.18 & 25.38 & 254 \\
\hline $57.1-59.9 \ldots \ldots \ldots \ldots \ldots$ & 30.45 & 0.27 & 30.72 & 381 \\
\hline $60.0-63.6 \ldots \ldots \ldots \ldots \ldots$ & 31.50 & 0.27 & 31.77 & 381 \\
\hline $63.7-67.4 \ldots \ldots \ldots \ldots \ldots$ & 32.55 & 0.27 & 32.82 & 381 \\
\hline $67.5-71.2 \ldots \ldots \ldots \ldots \ldots$ & 33.60 & 0.27 & 33.87 & $38 \mathrm{i}$ \\
\hline $71.3-75.0 \ldots \ldots \ldots \ldots$ & 34.65 & 0.27 & 34.92 & 381 \\
\hline $75.1-78.5 \ldots \ldots$ & 35.70 & 0.27 & 35.97 & 381 \\
\hline $78.6-82.0 \ldots \ldots \ldots \ldots$ & 36.75 & 0.27 & 37.02 & 381 \\
\hline $82.1-85.5 \ldots \ldots \ldots \ldots$ & 37.80 & 0.27 & 38.07 & 381 \\
\hline $85.6-88.6 \ldots \ldots \ldots \ldots \ldots$ & 43.05 & 0.36 & 43.41 & 508 \\
\hline $88.7-94.2 \ldots$ & 44.10 & 0.36 & 44.46 & 508 \\
\hline $94.3-96.2 \ldots$ & 45.15 & 0.36 & 45.51 & 508 \\
\hline $96.3-100.0 \ldots \ldots \ldots \ldots$ & 46.20 & 0.36 & 46.56 & 508 \\
\hline
\end{tabular}

Dumping and Grading Combined. As previously indicated, the costs of grading must be considered jointly with the costs of dumping. With minor modifications and adjustments in equipment requirements, the four sizes of grading tables and the five methods of dumping can be combined into 20 alternative dumping-grading technologies. Preliminary calculations have indicated, however, that a number of these combinations are relatively uneconomical under all conditions. In the final analysis, only six combinations of technologies are considered. These are as follows:

1A-2A: Hand-dumping without conveyor aids and with grading table A (capacity, eight sorters).

1A-2B: Hand-dumping without conveyor aids and with grading table B (capacity, ten sorters). 
1A-2C: Hand-dumping without conveyor aids and with grading table C (capacity, 12 sorters). The equivalent of two dumping stations and two dumpers is required for each grading table. In addition, with this size sorting unit, a distribution belt is required for each grading table. This adds about $\$ 100$ per year and 10 cents per hour to the cost for each grading table.

TABLE 20

GRADING TABLE D-DIRECT AND FIXED COSTS IN RELATION TO RATES OF TOTAL OUTPUT WITH 80 PER CENT FIRST-GRADE AND 20 PER CENT SUBGRADE FRUIT

\begin{tabular}{|c|c|c|c|c|}
\hline \multirow{2}{*}{ Total plant output } & \multicolumn{3}{|c|}{ Direct cost } & \multirow{2}{*}{$\begin{array}{l}\text { Average } \\
\text { annual } \\
\text { fixed } \\
\text { cost }\end{array}$} \\
\hline & Labor & Operating & Total & \\
\hline 1,000 lbs per hour & dollars & dollars & dollars & dollars \\
\hline $0-5.0$. & 6.30 & 0.16 & 6.46 & 280 \\
\hline $5.1-9.1 \ldots \ldots \ldots \ldots$ & 7.35 & 0.16 & 7.51 & 280 \\
\hline $9.2-13.5 \ldots \ldots \ldots \ldots \ldots \ldots \ldots$ & 8.40 & 0.16 & 8.56 & 280 \\
\hline $13.6-17.5 \ldots \ldots \ldots \ldots \ldots \ldots \ldots$ & 9.45 & 0.16 & 9.61 & 280 \\
\hline $17.6-21.2 \ldots \ldots \ldots \ldots \ldots \ldots \ldots$ & 10.50 & 0.16 & 10.66 & 280 \\
\hline $21.3-25.0 \ldots \ldots \ldots \ldots \ldots \ldots \ldots$ & 11.55 & 0.16 & 11.71 & 280 \\
\hline $25.1-28.5 \ldots \ldots \ldots \ldots \ldots \ldots \ldots$ & 12.60 & 0.16 & 12.76 & 280 \\
\hline $28.6-31.6 \ldots \ldots \ldots \ldots \ldots \ldots \ldots$ & 13.65 & 0.16 & 13.81 & 280 \\
\hline $31.7-35.2 \ldots \ldots \ldots \ldots \ldots \ldots \ldots \ldots$ & 14.70 & 0.16 & 14.86 & 280 \\
\hline $35.3-39.2 \ldots \ldots \ldots \ldots \ldots \ldots \ldots$ & 15.75 & 0.16 & 15.91 & 280 \\
\hline $39.3-41.4 \ldots \ldots \ldots \ldots \ldots \ldots \ldots$ & 16.80 & 0.16 & 16.96 & 280 \\
\hline $41.5-42.4 \ldots \ldots \ldots \ldots \ldots \ldots \ldots$ & 21.00 & 0.32 & 21.32 & 560 \\
\hline $42.5-46.2 \ldots \ldots \ldots \ldots \ldots \ldots \ldots$ & 22.05 & 0.32 & 22.37 & 560 \\
\hline $46.3-50.0 \ldots \ldots \ldots \ldots \ldots \ldots \ldots$ & 23.10 & 0.32 & 23.42 & 560 \\
\hline $50.1-53.5 \ldots \ldots \ldots \ldots \ldots \ldots \ldots$ & 24.15 & 0.32 & 24.47 & 560 \\
\hline $53.6-57.0 \ldots \ldots \ldots \ldots \ldots \ldots \ldots$ & 25.20 & 0.32 & 25.52 & 560 \\
\hline $57.1-60.1 \ldots \ldots \ldots \ldots \ldots \ldots \ldots$ & 26.25 & 0.32 & 26.57 & 560 \\
\hline $60.2-63.2 \ldots \ldots \ldots \ldots \ldots \ldots \ldots$ & 27.30 & 0.32 & 27.62 & 560 \\
\hline $63.3-66.8 \ldots \ldots \ldots \ldots \ldots \ldots \ldots$ & 28.35 & 0.32 & 28.67 & 560 \\
\hline $66.9-70.2 \ldots \ldots \ldots \ldots \ldots \ldots \ldots$ & 29.40 & 0.32 & 29.72 & 560 \\
\hline $70.3-74.4 \ldots \ldots \ldots \ldots \ldots \ldots \ldots$ & 30.45 & 0.32 & 30.77 & 560 \\
\hline $74.5-78.4 \ldots \ldots \ldots \ldots \ldots \ldots \ldots$ & 31.50 & 0.32 & 31.82 & 560 \\
\hline $78.5-80.6 \ldots \ldots \ldots \ldots \ldots \ldots \ldots$ & 32.55 & 0.32 & 32.87 & 560 \\
\hline $80.7-82.8 \ldots \ldots \ldots \ldots \ldots \ldots \ldots$ & 33.60 & 0.32 & 33.92 & 560 \\
\hline $84.9-85.5 \ldots \ldots \ldots \ldots \ldots \ldots \ldots \ldots$ & 37.80 & 0.48 & 38.28 & 840 \\
\hline $85.6-88.6 \ldots \ldots \ldots \ldots \ldots \ldots \ldots$ & 38.85 & 0.48 & 39.33 & 840 \\
\hline $88.7-91.7 \ldots \ldots \ldots \ldots \ldots \ldots \ldots$ & 39.90 & 0.48 & 40.38 & 840 \\
\hline $91.8-94.8 \ldots \ldots \ldots \ldots \ldots \ldots \ldots \ldots$ & 40.95 & 0.48 & 41.43 & 840 \\
\hline $94.9-98.4 \ldots \ldots \ldots \ldots \ldots \ldots \ldots \ldots$ & 42.00 & 0.48 & 42.48 & 840 \\
\hline $98.5-102.0 \ldots \ldots \ldots \ldots \ldots \ldots \ldots$ & 43.05 & 0.48 & 43.53 & 840 \\
\hline
\end{tabular}

1D-2D: Single-box machine dumper and grading table D (capacity 16 sorters). A distribution belt is required in this case also.

1E-2C: Stack dumper and grading table C (12 sorters per table) plus distribution belt. 1E-2D: Stack dumper and grading table D (16 sorters per table) plus distribution belt.

Costs for these dumping-grading alternatives are obtained by combining the separate dumping and sorting costs reported in previous pages. It will be noted that dumping methods involving the use of conveyor aids are not considered above. Cost calculations indicate that there are no ranges where these dumping methods ( $\mathrm{B}$ or $\mathrm{C}$ ) give the lowest dumping or combined 
dumping-grading costs. But the conveyor aids do make the dumping job easier and so more attractive, which may facilitate labor recruitment. ${ }^{53}$

\section{Stage 3. Packing ${ }^{54}$}

The job of packing consists of placing fruit firmly and uniformly in boxes so as to avoid damage in transport and to present an attractive appearance to the buyer. The main elements of the work operation include obtaining and placing the box, stamping the box with the packer's number, placing

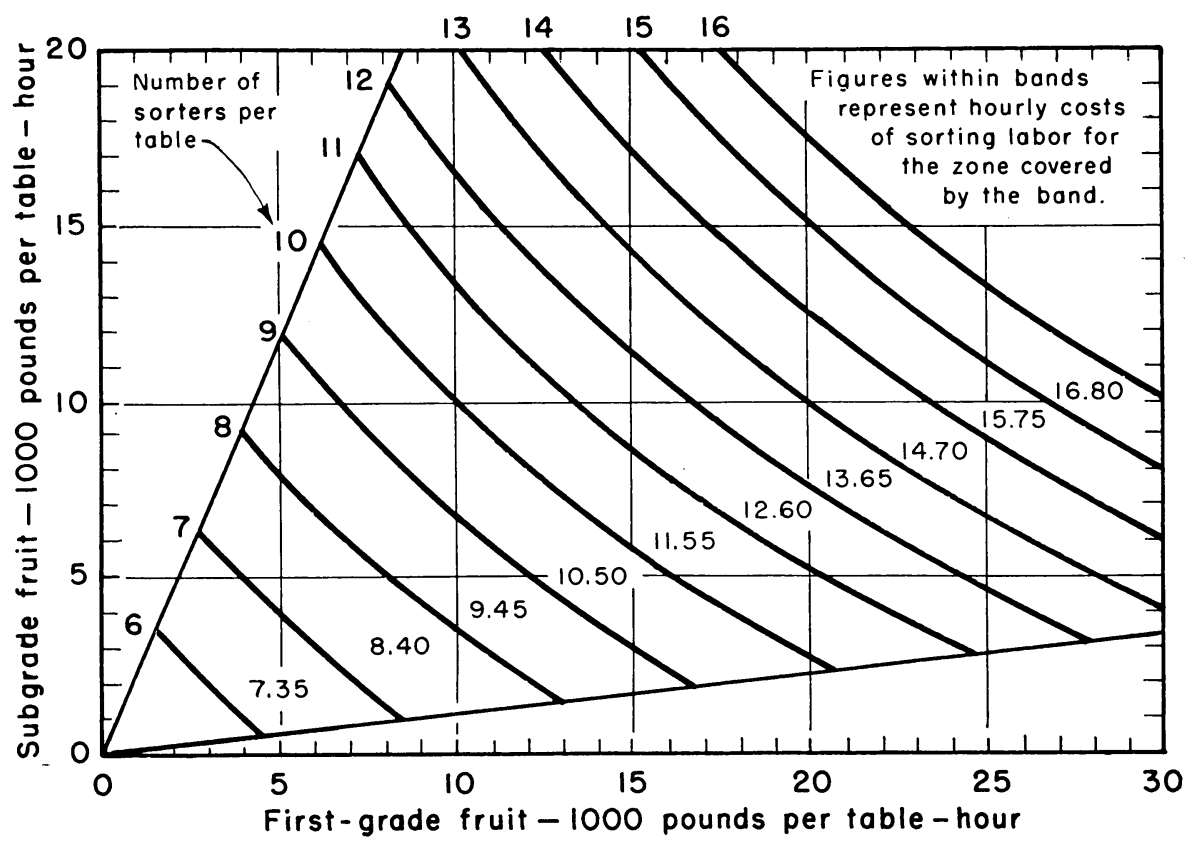

Fig. 28. Cost of sorting labor per table-hour in relation to rates of output of first-grade and subgrade fruit. Radial lines indicate the common extremes in proportions of first- and subgrade fruit.

and adjusting pads and liners, wrapping and place-packing the fruit, and moving the packed box from the packing stand to the conveyor that transports it to the lidder. A small amount of time is occasionally needed to obtain a new supply of wrapping materials from a central storage place.

As already reported, three types of containers are commonly used. Most pears shipped out of the state are wrapped and packed in standard pear boxes containing 48 pounds of fruit. The bulk of the pears for local markets, and some for out of state, is packed naked or unwrapped in San Francisco lugs holding about 48 pounds of pears or in Los Angeles lugs usually containing 24 to 25 pounds of fruit.

${ }^{53}$ For a more detailed discussion and comparison of dumping costs with conveyor aids, see L. L. Sammet, Costs of Dumping Incoming Fruit ..., op. cit.

${ }^{54}$ For a more detailed account of this operation, see B. C. French, Packing Costs for California Apples and Pears, Giannini Foundation of Agricultural Economics, Mimeographed Report No. 138, October, 1952. 
Four types of packing equipment-canvas bins, large- and small-sized tubs, and continuous belts-were observed in the pear plants studied (fig. $29)$. Only one type of tub-the large size-is considered in the analysis that follows. This size was more commonly used, but both show about the same levels of costs.

Detailed time and work-sampling studies of the pear-packing operation failed to reveal any consistent differences in packing labor efficiency among these three types of equipment (French, 1952; pp. 15-17). A set of performance standards based on these studies and applicable to all types of equipment is summarized in table 21. The data apply only to Bartlett pears-by far the leading variety. However, time requirements for packing

TABLE 21

PERFORMANCE STANDARDS FOR PACKING CALIFORNIA BARTLETT PEARS*

\begin{tabular}{c|c|c|c|c|c|c|c|c}
\hline \hline \multirow{2}{*}{ Bartlett pears } & \multicolumn{7}{c}{ Size-number of fruit per standard box } \\
\cline { 2 - 8 } & 90 & 100 & 110 & 120 & 135 & 150 & 165 & 108 \\
\hline Standard boxes per packer-hour.......... & 20.9 & 18.7 & 17.0 & 15.5 & 13.8 & 12.4 & 11.2 & 10.3 \\
San Francisco lugs per packer-hour...... & 30.7 & 27.2 & 24.5 & 22.2 & 19.6 & $\ldots$ & $\ldots$ & $\ldots$ \\
Los Angeles lugs per packer-hour......... & 61.4 & 56.2 & 51.7 & 47.9 & 43.4 & $\ldots$ & $\ldots$. & $\ldots$ \\
\hline
\end{tabular}

${ }^{*}$ The standards include allowances of 4.2 per cent for rest periods, 0.8 per cent for changing stations, and 4.0 per cent for personal time.

other varieties appear to be about the same. These standards are calculated in terms of boxes per hour, including allowances for rest periods, changing stations and personal time, and for fruit of several sizes. When expressed in terms of the average sizes of fruit packed in each type of container during the 1949 and 1950 seasons, the standards are: 13 standard boxes per packer-hour, 21.4 San Francisco lugs per hour, and 46.6 Los Angeles lugs per hour.

Estimated equipment costs, operating costs, and labor costs for packing are summarized in table 22. Packing labor is commonly paid by the box so that the total direct cost of this labor is obtained by multiplying the piece rate by the number of boxes. However, the packing performance standards given in table 21 are instrumental in determining the capacities of the different types of equipment. Note also that the cost of bin boy labor is included in the costs for bins. Some variation in the size of these packing lines, particularly with belts, would be possible. For simplicity, only units of the commonly used sizes are considered. The data in this table provide the basis for estimates of the total costs associated with each of these technologies for any length of season and rate of output.

\section{Stage 4. Direct Clerical Labor}

Direct clerical labor includes the following jobs: (1) tallying the number of boxes packed by each packer; (2) tallying the number of boxes packed by size for each grower; (3) stamping the size of fruit (count per box) on each box; (4) stamping lot numbers, grade, or variety on boxes; 

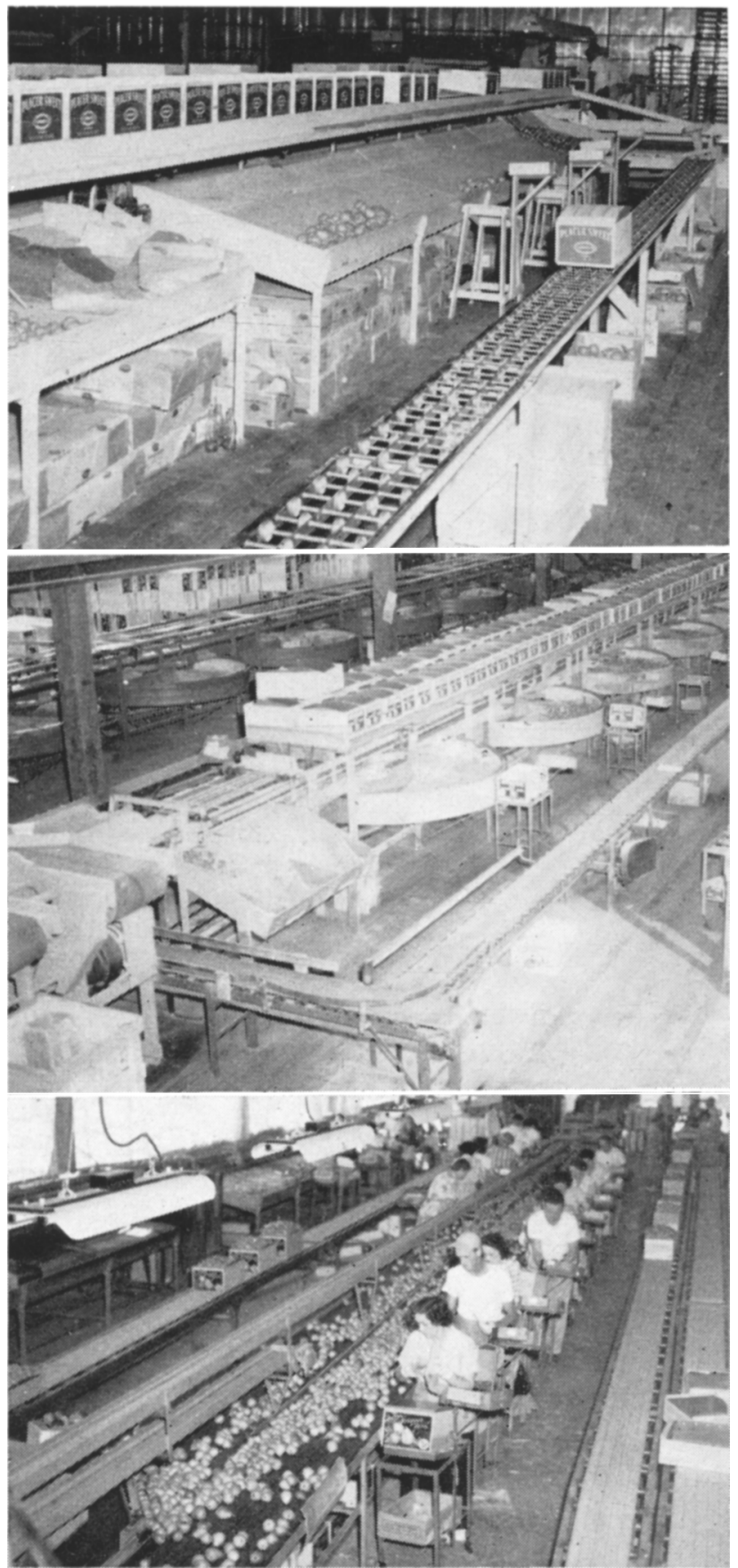

Fig. 29. Three types of pear packing equipment: Top-bins; center-large tubs; bottom-conveyor belts. 
and (5) check-weighing the packed boxes to ascertain if they are within the range of minimum and maximum weight requirements. Other clerical jobs are sometimes performed by supervisory help, but these are included in a miscellaneous category in the analysis that follows.

The general nature of the tallying and stamping operations is illustrated in figures 30 and 31. Check-weighing, not illustrated, consists merely of reading a scale placed in the conveyor line and checking the weight registered as each box passes. If the box fails to meet the weight specifications, it is returned to the packer to be repacked.

TABLE 22

ESTIMATED COSTS OF OPERATING BIN, TUB, AND BELT PACKING LINES, BARTLETT PEARS*

\begin{tabular}{|c|c|c|c|}
\hline \multirow{2}{*}{ Item } & A & B & $\mathrm{C}$ \\
\hline & Bins & Tubs $†$ & Belts \\
\hline Approximate length per packing section (feet). & 42 & 80 & 60 \\
\hline Packers per section.$\ldots \ldots \ldots \ldots \ldots \ldots \ldots \ldots$ & $12-14$ & $18-20$ & $15-17$ \\
\hline Normal capacity: standard boxes per hour.... & 169 & 247 & 208 \\
\hline San Francisco lugs per hour $\ddagger \ldots \ldots \ldots \ldots$ & 278 & 407 & 342 \\
\hline Los Angeles lugs per hour $\ddagger \ldots \ldots \ldots \ldots \ldots \ldots \ldots$ & 606 & 885 & 746 \\
\hline Installed cost, $1950 \S$ (dollars per section) $\ldots \ldots \ldots \ldots \ldots \ldots \ldots \ldots \ldots$ & $\$ 1,300$ & $\$ 6,520$ & $\$ 4,100$ \\
\hline Average annual equipment $\operatorname{cost} \| \ldots \ldots \ldots \ldots \ldots \ldots \ldots \ldots \ldots \ldots$ & $\$ 200$ & 815 & 574 \\
\hline 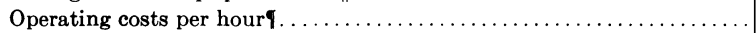 & $\$ 0.080$ & 0.446 & 0.325 \\
\hline Bin boy labor cost per hour** $\ldots \ldots \ldots \ldots \ldots \ldots \ldots \ldots \ldots$ & $\$ 2.100$ & $\ldots \ldots$ & $\ldots$. \\
\hline Total hourly costs.... & $\$ 2.180$ & 0.446 & 0.325 \\
\hline \multicolumn{4}{|l|}{ Packing labor costs per box, 1950} \\
\hline Standard box............. & $\$ 0.155$ & $\$ 0.155$ & $\$ 0.155$ \\
\hline San Francisco lug........ & 0.100 & 0.100 & 0.100 \\
\hline Los Angeles lug......... & 0.060 & 0.060 & 0.060 \\
\hline
\end{tabular}

* Based on 1950 prices.

† Based on large tubs-7 per section. Costs for small tubs slightly higher, depending on spacing of tubs.

† These figures were obtained by multiplying the usual number of packers per section by the packing standard for the average size fruit packed in each type of container. Since larger sizes are normally packed in the San Francisco and Los Angeles lugs, these rates probably could not be sustained if only San Francisco or Los Angeles lugs were being packed.

\$Includes cost of packed box conveyors with powered belts for tub and belt plants and gravity conveycr for bin plants.

|| Total allowance for average annual replacement costs: bins-15.4 per cent; tubs-12.5 per cent; belts-14.0 per cent.

Includes power cost estimated at $\$ 0.03$ per hour per horse power and variable repairs at 0.5 per cent of the investment per 100 hours of use.

** Two bin boys per section at $\$ 1.05$ per hour each.

Not all of the clerical jobs listed are performed in all plants. For example, a plant handling the fruit of a single grower or a plant using a sampling system (considered later) might not require a grower tally girl. Studies in the sample plants showed that very few plants used more than one of the lot, grade, or variety stamping operations.

While minor variations were observed among plants in the forms used for tallying or in the work place for stampers, the basic procedures used to perform the clerical operations were essentially the same in all plants. ${ }^{55}$

${ }_{55}$ Mechanical stamping devices, not observed in the sample pear and apple packing plants, have been used successfully in grape plants for operations such as lot or variety stamp. If a separate worker is required for this job, the mechanical stamp will generally 
The labor performance standards given in table 23 may be accepted as applying generally to all of these variations. The standards are the same for all types of box, although Los Angeles lugs usually are not checkweighed. Equipment requirements and replacement costs as of 1950 are summarized in the last two columns of the table.

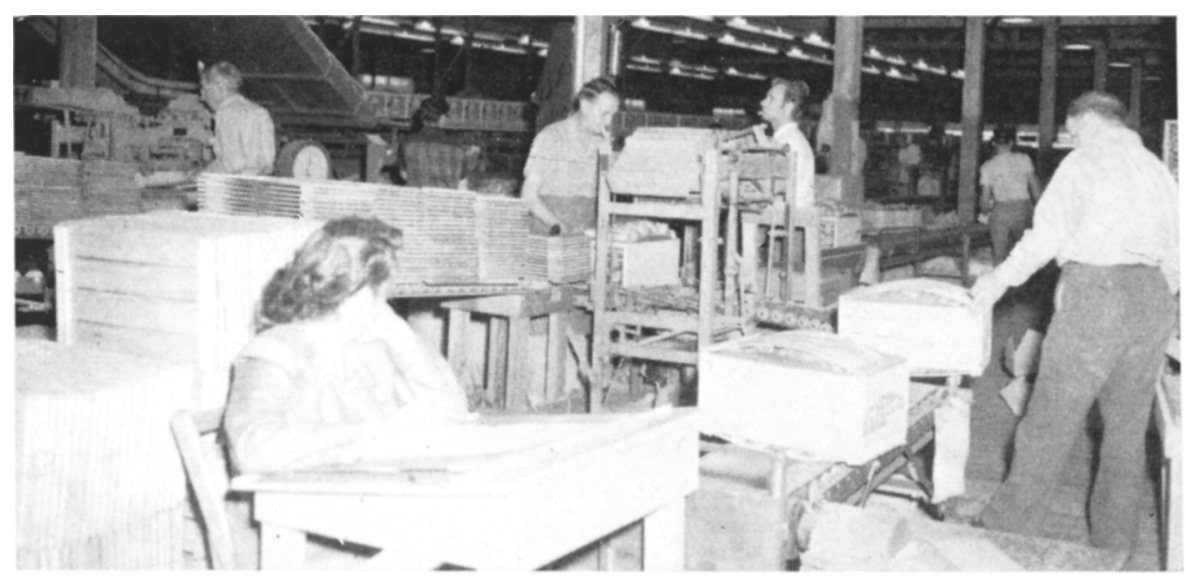

Fig. 30. Tallying packer numbers.

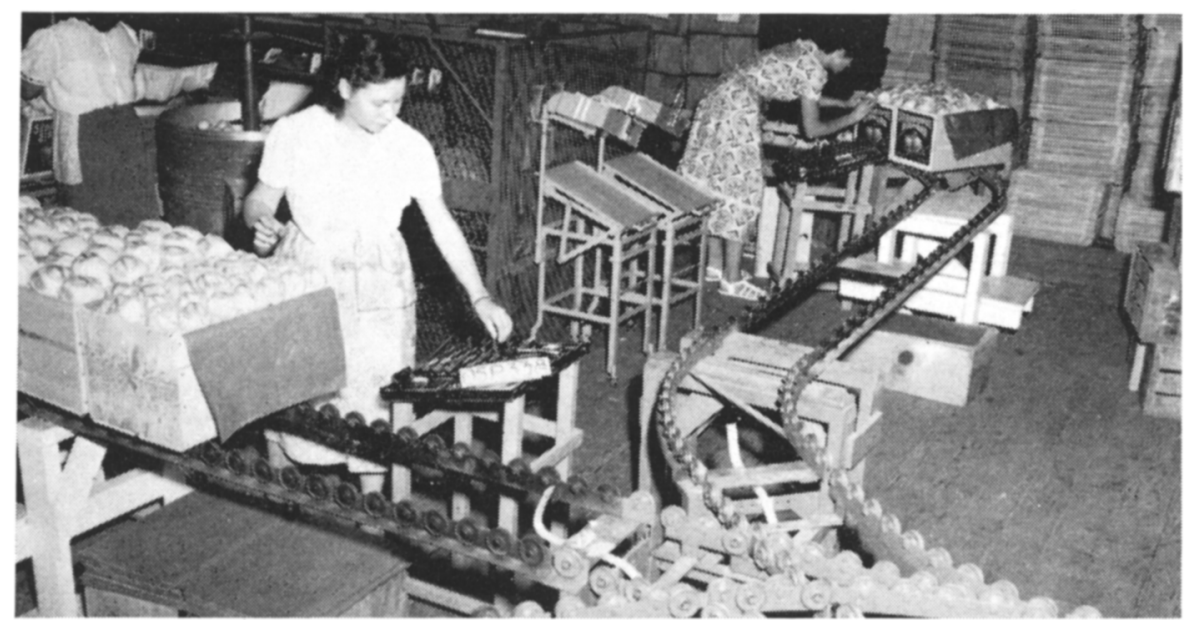

Fig. 31. Stamping size count on packed boxes.

The jobs listed do not necessarily require separate and specialized workers. If the rates of output are low enough, the grower tally and packer tally jobs can be performed by one person. Similarly, size stamp, grade, lot or variety stamp, and check-weighing can be combined. Table 24 summarizes the labor and equipment costs for the combined tally jobs in relation to

be the most economical. However, when the job is combined with operations such as lidder helper or check weigh, the advantage of the mechanical stamp becomes restricted to fairly narrow ranges. Only hand stamping is considered here. 
rate of output. The combined costs of stamping and check-weighing are not given here as they are linked with the lidding operation. The workers performing these jobs may aid the lidder operator by placing the top pad on the box. A table of combined costs for lidding, stamping, and checkweighing is given in the next section.

TABLE 23

PERFORMANCE STANDARDS AND EQUIPMENT REQUIREMENTS FOR DIRECT CLERICAL JOBS

\begin{tabular}{|c|c|c|c|}
\hline \multirow[b]{2}{*}{ Job } & \multirow{2}{*}{$\begin{array}{c}\text { Capacity, } \\
\text { number } \\
\text { of boxes } \\
\text { per hour }\end{array}$} & \multicolumn{2}{|c|}{ Equipment requirements } \\
\hline & & Type & $\begin{array}{l}\text { Investment } \\
\text { cost, each } \\
(1950)\end{array}$ \\
\hline & & & dollars \\
\hline Grower tally or packer tally. & 715 & desk, tally forms, pencils & 10.00 \\
\hline Size stamper.............. & 515 & stamp stand, stamps & 15.00 \\
\hline Lot or grade or variety stamp. & 820 & & \\
\hline Check weigh $\ldots \ldots \ldots \ldots \ldots \ldots$ & 705 & bench scales (dial type $\dagger$ ) & 175.00 \\
\hline
\end{tabular}

* Represents costs of a single group such as one stamp stand and the required stamps.

$\dagger$ Number of scales usually corresponds to the number of lidding machines.

TABLE 24

COSTS OF GROWER-PACKER TALLY LABOR COMBINED AND ASSOCIATED EQUIPMENT IN RELATION TO RATE OF PLANT OUTPUT

\begin{tabular}{|c|c|c|}
\hline Boxes per hour & $\begin{array}{l}\text { Labor cost } \\
\text { per hour* }\end{array}$ & $\begin{array}{c}\text { Equipment cost } \\
\text { per year } \dagger\end{array}$ \\
\hline & dollars & dollars \\
\hline $0-\quad 360 \ldots$. & $\$ 1.05$ & 1.50 \\
\hline $361-715 \ldots \ldots$ & 2.10 & 3.00 \\
\hline $716-1,070 \ldots$ & 3.15 & 4.50 \\
\hline $1,071-1,430 \ldots$ & 4.20 & 6.00 \\
\hline$\ldots \ldots \ldots \ldots \ldots \ldots$ & 5.25 & 7.50 \\
\hline
\end{tabular}

* Figured at 1950 typical wage rate of $\$ 1.05$ per hour.

+ Based on annual charge for depreciation, repairs, insurance, interest and taxes of 15 per cent of investment cost.

\section{Stage 5. Lidding ${ }^{58}$}

The lidding operation consists of placing a top pad on the box, inserting the box and a lid in the machine, and pressing a foot lever to drive the nails. A small amount of time is devoted to obtaining supplies of lids and nails and oiling and adjusting the machine. Three types of lidders may be used in pear packing houses (figures 32,33 , and 34 ).

Estimated machine capacities, normal working capacities, and approximate installed investment costs for each type are given in table 25. The machine capacities represent the mechanical capabilities of the equipment.

\footnotetext{
${ }^{58}$ For further details, see B. C. French, "Efficiency in Fruit Marketing: Costs of Lidding Packed Fruit Boxes Influenced by Type of Equipment, Size of Plant, Length of Season," California Agriculture, January, 1953.
} 


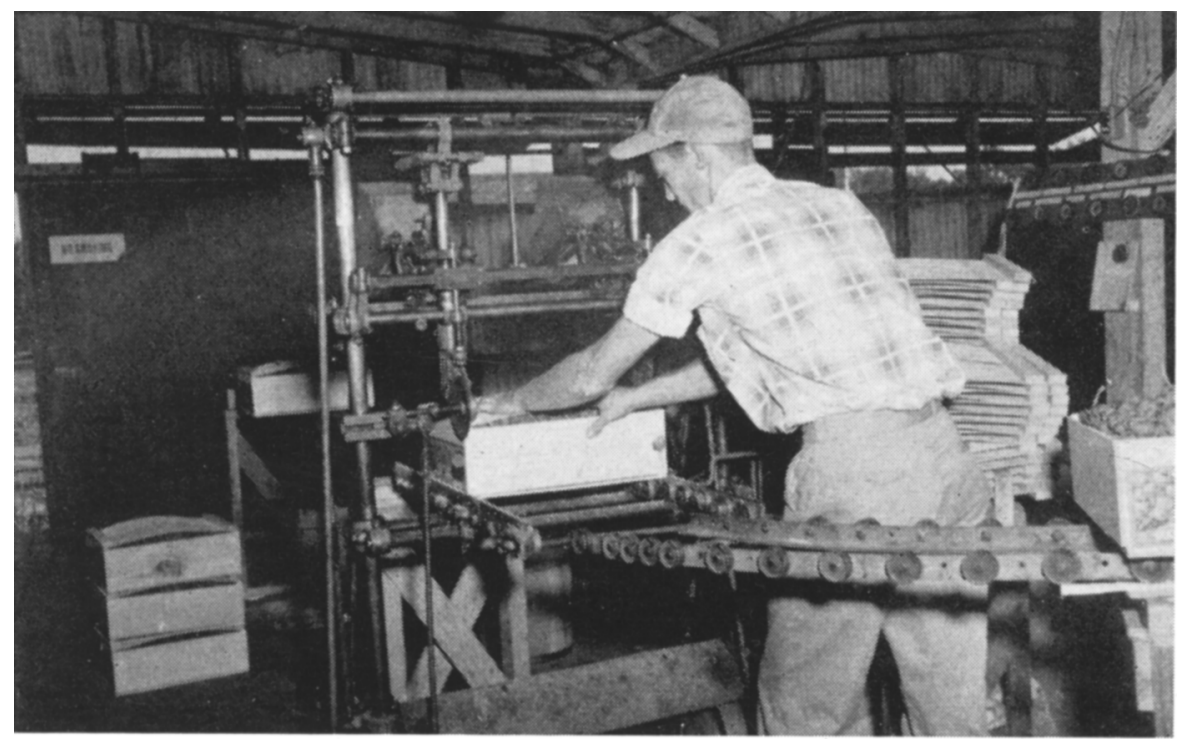

Fig. 32. The stitcher-type lidder.

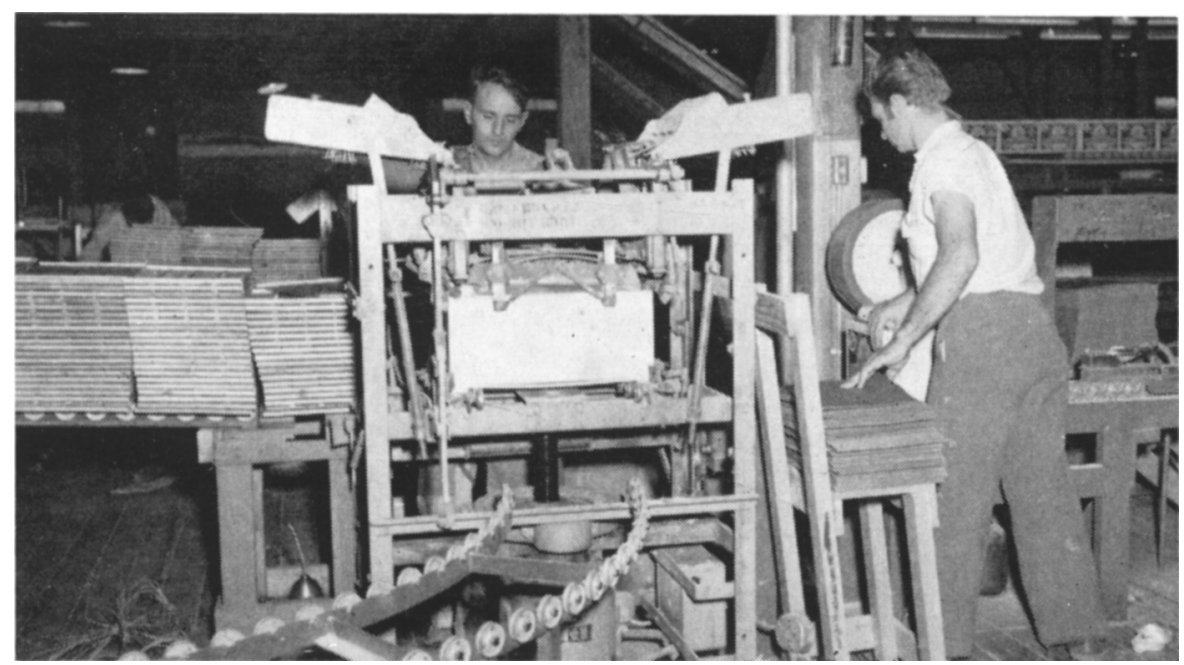

Fig. 33. The low-speed lidder.

The normal working capacities are based on time and work-sampling studies of individual operators. Unavoidable irregularities in the rate of flow of boxes to the lidder require the operator to work at speeds approaching the machine rates during some periods to achieve the indicated standards. The standards thus apply to average rates of output that can be sustained over a period of time. They represent reasonably high levels of efficiency but should be exceeded by some workers. ${ }^{57}$

${ }^{57}$ See Section III for further discussion of performance standards. 
As was indicated in the previous section, the top pad may be placed on the box by a stamper or check-weigher as well as by the lidder or a special helper. Tables 26, 27, and 28 summarize the combined costs of lidding, stamping, and check-weighing in relation to rates of output for each type

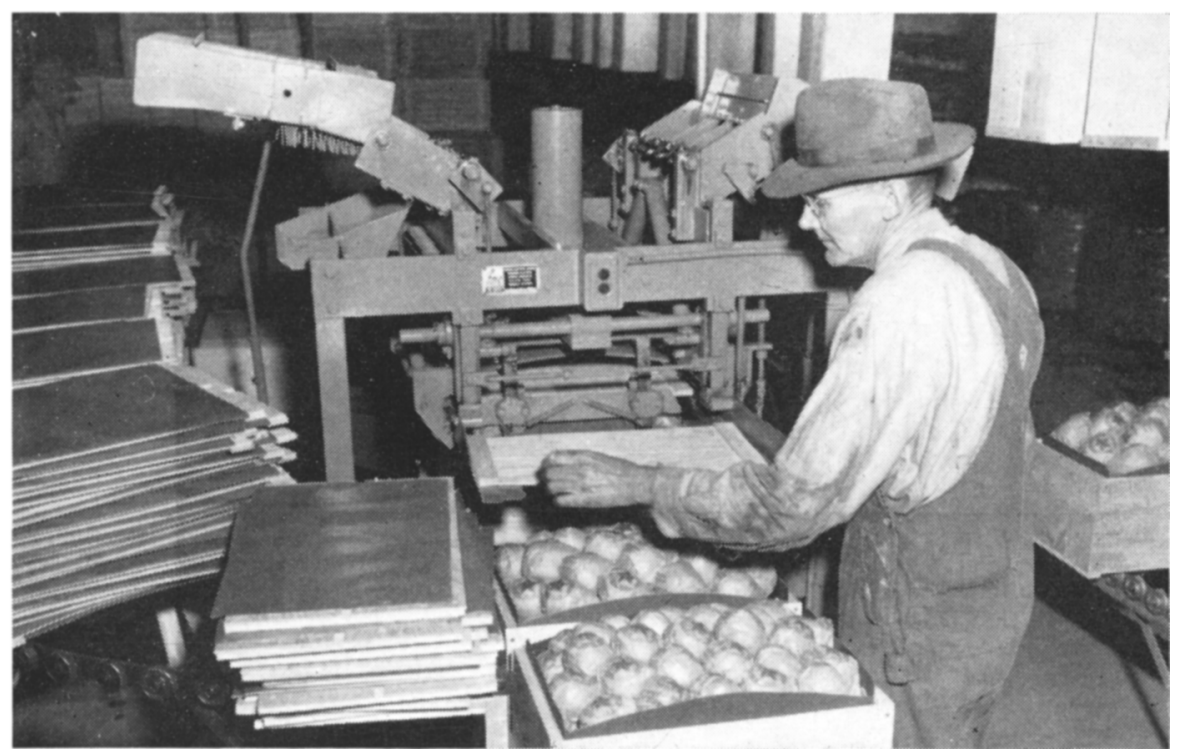

Fig. 34. The high-speed semi-automatic lidder

TABLE 25

LIDDING PERFORMANCE STANDARDS AND EQUIPMENT INVESTMENT COSTS

\begin{tabular}{|c|c|c|c|}
\hline Item & $\begin{array}{l}\text { Stitcher-type } \\
\text { lidder* }\end{array}$ & $\begin{array}{l}\text { Low-speed } \\
\text { lidder }\end{array}$ & $\begin{array}{l}\text { High-speed } \\
\text { lidder }\end{array}$ \\
\hline & \multicolumn{3}{|c|}{ boxes per hour } \\
\hline Maximum machine capacity..... & 500 & 720 & 1,600 \\
\hline \multicolumn{4}{|l|}{ Normal working capacity $\dagger$} \\
\hline Helper places top pad. & 370 & 460 & 1,010 \\
\hline Machine operator places top pad $\ldots \ldots \ldots \ldots \ldots \ldots \ldots \ldots \ldots$ & 280 & 330 & 540 \\
\hline Approximate installed cost, $1950 .$. & $\$ 1,500$ & $\$ 2,000$ & $\$ 3,400 \ddagger$ \\
\hline Average annual cost $\S \ldots \ldots \ldots \ldots \ldots \ldots \ldots \ldots$ & 205 & 275 & 465 \\
\hline
\end{tabular}

* Standards are based on an average of three nails per side.

† Includes allowances of 4.2 per cent for rest periods, 4 per cent for personal time, and 10 per cent for getting supplies of lids, oiling machine, and miscellaneous.

$\ddagger$ Includes cost of an accumulator.
Based on annual charges for depreciation, repairs, insurance taxes, and interest totaling 13.7 per cent.

of lidding machine. The following clerical jobs are represented: size stamp, packer tally, check-weighing, and any one of lot, grade, or variety stamp. One scale is provided for each lidding machine..$^{58}$

${ }^{58} \mathrm{~A}$ grower tally girl is required if a separate-lot system of accounting to growers is used. However, it will be more convenient to specify the operation initially without breaksfor-lots. 
TABLE 26

STITCHER-TYPE LIDDER-LIDDING METHOD A COMBINED COSTS OF LIDDING, STAMPING, AND CHECK-WEIGHING IN RELATION TO RATE OF OUTPUT

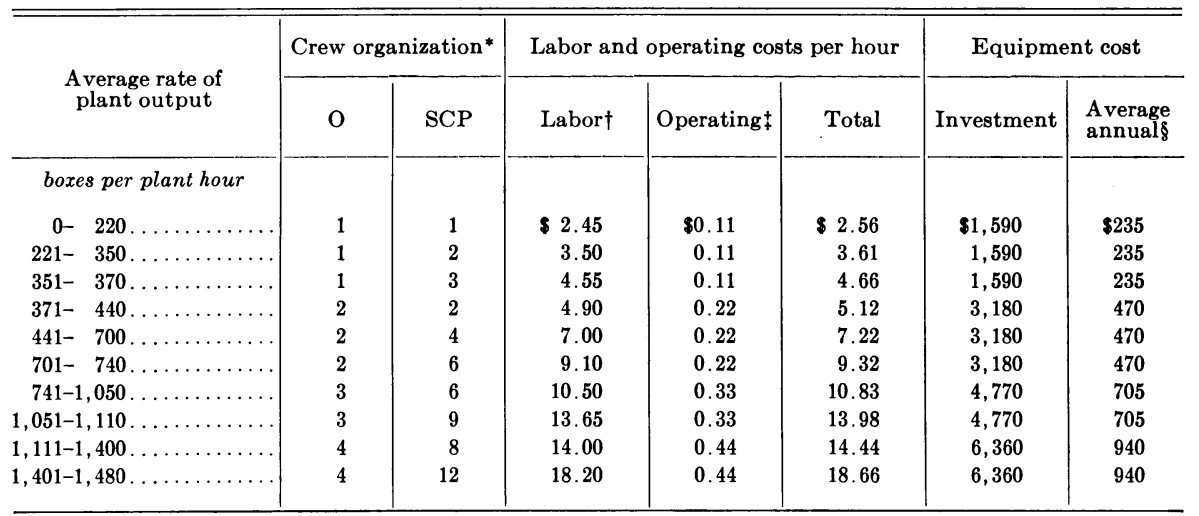

* O-lidder operator; S-stampers; C-check-weighers; P-place top pad.

t Based on typical 1950 wage rates of $\$ 1.40$ for the lidder operator and $\$ 1.05$ for the others.

$\ddagger$ Costs of power and repairs for the lidder, figured on basis of $\$ 0.03$ per hour per horse power for power and 0.5 per cent of investment cost per 100 hours of use for repairs.

$\S$ Based on following annual charges for depreciation, repair, insurance, interest and taxes: stamp stand-15 per cent; stamps-38 per cent; scales-13 per cent; lidder 13.7 per cent.

\section{TABLE 27}

LOW-SPEED-TYPE LIDDER-LIDDING METHOD B COMBINED COSTS OF LIDDING, STAMPING, AND CHECK-WEIGHING IN RELATION TO RATE OF OUTPUT

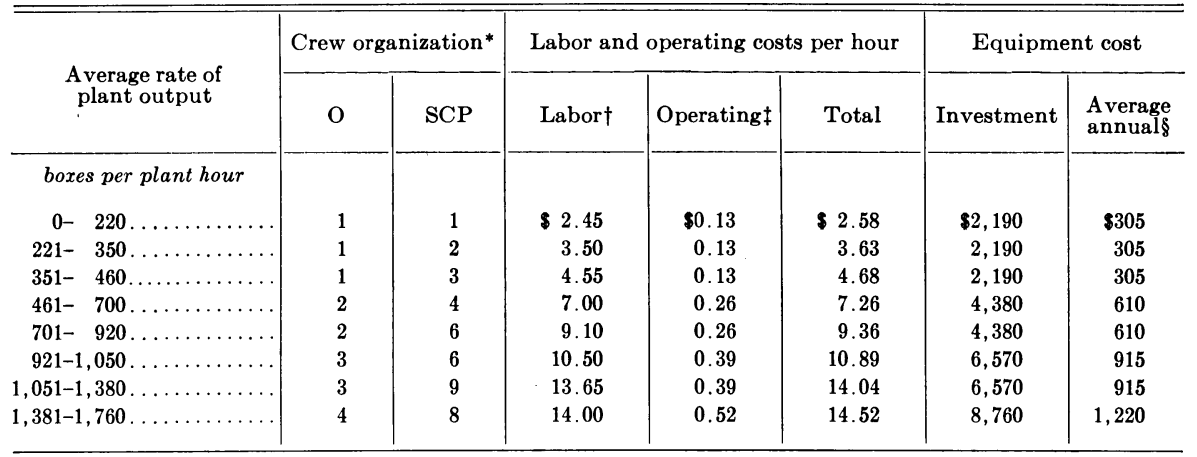

* O-lidder operator; S-stampers; C-check-weighers; P-place top pad.

+ Based on typical 1950 wage rates of $\$ 1.40$ for the lidder operator and $\$ 1.05$ for the others.

$\ddagger$ Costs of power and repairs for the lidder, figured on basis of $\$ 0.03$ per hour per horse power for power and 0.5 per cent of investment cost per 100 hours of use for repairs.

\$ Based on following annual charges for depreciation, repair, insurance, interest and taxes: stamp stand-15 per cent; stamps-38 per cent; scales-13 per cent; lidder-13.7 per cent. 
These standards and costs are based on hourly pay rates. With piece rates, the normal output rate may be increased by 25 or 30 per cent. With very short seasons and in some output ranges, it may be advantageous to increase rates by incurring the higher labor-cost piece rates, rather than purchasing another machine. For example, the normal working capacity of one operator on a low-speed lidder is 460 boxes per hour if paid by the hour and about 575 boxes if paid at the typical incentive wage of 80 cents

TABLE 28

HIGH-SPEED-TYPE LIDDER-LIDDING METHOD C

COMBINED COSTS OF LIDDING, STAMPING, AND CHECK-WEIGHING IN RELATION TO RATE OF OUTPUT

\begin{tabular}{|c|c|c|c|c|c|c|c|}
\hline \multirow{2}{*}{$\begin{array}{l}\text { Average rate of } \\
\text { plant output }\end{array}$} & \multicolumn{2}{|c|}{ Crew organization* } & \multicolumn{3}{|c|}{ Labor and operating costs per hour } & \multicolumn{2}{|c|}{ Equipment cost } \\
\hline & $\mathrm{O}$ & SCP & Labor $\dagger$ & Operating $\ddagger$ & Total & Investment & $\begin{array}{l}\text { Average } \\
\text { annual§ }\end{array}$ \\
\hline boxes per plant hour & & & & & & & \\
\hline $0-220$. & 1 & 1 & $\$ 2.15$ & $\$ 0.32$ & $\$ 2.47$ & $\$ 3,590$ & $\$ 495$ \\
\hline $221-440 \ldots$ & 1 & 2 & 3.20 & 0.32 & 3.52 & 3,590 & 495 \\
\hline $441-540 \ldots$ & 1 & 3 & 4.25 & 0.32 & 4.57 & 3,590 & 495 \\
\hline $541-700 \ldots$ & 1 & 4 & 5.30 & 0.32 & 5.62 & 3,605 & 500 \\
\hline $701-875 \ldots \ldots$ & 1 & 5 & 6.35 & 0.32 & 6.67 & 3,780 & 523 \\
\hline $876-1,010 \ldots \ldots \ldots$ & 1 & 6 & 7.40 & 0.32 & 7.72 & 3,780 & 523 \\
\hline $1,011-1,050 \ldots \ldots \ldots$ & 2 & 6 & 8.50 & 0.74 & 9.24 & 7,180 & 988 \\
\hline $1,051-1,400 \ldots$ & 2 & 8 & 10.60 & 0.74 & 11.34 & 7,195 & 993 \\
\hline $1,401-1,750 \ldots$ & 2 & 10 & 12.70 & 0.74 & 13.44 & 7,205 & 1,000 \\
\hline
\end{tabular}

* O-lidder operator; S-stampers; C-check-weighers; P-place top pad.

+ Based on typical 1950 wage rates of $\$ 1.10$ for the lidder operator (Note: Less skill required than with other machines) and $\$ 1.05$ for other workers.

$\ddagger$ Costs of power and repairs for the lidder, figured on basis of $\$ 0.03$ per hour per horse power for power and 0.5 per cent of investment cost per 100 hours of use for repairs.

\& Based on following annual charges for depreciation, repair, insurance, interest and taxes: stamp stand-15 per cent; stamps - 38 per cent; scales-13 per cent; lidder-13.7 per cent.

per 100 boxes. Suppose that the plant rate of packed output is 550 boxes per hour. With hourly rates of pay, two machines would be required. The cost per hour would be $\$ 2.80$ for lidding labor and 26 cents for operating costs. Fixed costs would amount to an average of $\$ 610$ per year, including scales, et cetera (table 27 ).

On the other hand, with incentive pay rates only one machine would be required. Hourly costs would amount to $\$ 4.40$ for lidding labor and 13 cents for operating costs. Average annual fixed costs would be $\$ 310$. Thus, the incentive pay system adds $\$ 1.47$ in hourly cost but saves $\$ 300$ in average annual fixed costs. In this case, incentive rates give the lowest cost for seasons of less than 204 hours, and hourly rates are most economical beyond 204 hours. Similar calculations can be made for other rates of output. The differences are not great in most cases, and the output ranges, where incentive rates are most economical, are fairly narrow. 


\section{Stage 6. Carloading and Truckloading}

Carloading and truckloading consist of stacking packed boxes in railroad cars or trucks for shipment to distant markets. The main elements of the job are stacking, nailing strips to hold the boxes in place, and bracing the loaded car to prevent the load from shifting en route. A typical carloading operation is illustrated in figures 35 and 36. A minor amount of additional time is usually involved in transferring conveyors and moving to new cars.

While there is some variation in the way the boxes are stacked in cars-

TABLE 29

COSTS OF CARLOADING LABOR IN RELATION TO RATES OF PLANT OUTPUT

\begin{tabular}{|c|c|c|c|}
\hline Average rate of plant output & $\begin{array}{l}\text { Labor cost } \\
\text { per hour }\end{array}$ & $\begin{array}{l}\text { Investment in } \\
\text { equipment }\end{array}$ & $\begin{array}{c}\text { Average } \\
\text { annual cost } \\
\text { of } \\
\text { equipment }\end{array}$ \\
\hline \multicolumn{4}{|l|}{ packed boxes per hour* } \\
\hline $0-220 \ldots$ & $\$ 1.45$ & $\$ 950$ & $\$ 137$ \\
\hline $221-440 \ldots \ldots \ldots \ldots \ldots$ & 2.90 & 950 & 137 \\
\hline $441-660 \ldots \ldots \ldots \ldots \ldots \ldots$ & 4.35 & 1,000 & 142 \\
\hline $661-880 \ldots \ldots \ldots \ldots \ldots \ldots \ldots$ & 5.80 & 1,000 & 142 \\
\hline $881-1,100 \ldots \ldots \ldots \ldots \ldots \ldots \ldots \ldots$ & 7.25 & 1,050 & 147 \\
\hline $1,101-1,320 \ldots \ldots \ldots \ldots \ldots \ldots \ldots \ldots$ & 8.70 & 1,050 & 147 \\
\hline $1,321-1,540 \ldots \ldots \ldots \ldots \ldots \ldots \ldots$ & 10.15 & 1,100 & 152 \\
\hline
\end{tabular}

* Standard boxes and San Francisco lugs loaded in cars.

† Based on typical 1950 wage rate of $\$ 1.45$ per hour. This does not include overtime rates of pay, although because of scheduling problems car loaders of ten work a part of the time at these higher rates.

$\ddagger$ Includes 1950 replacement cost of car squeeze and loading ramps to cars. Small plants might get by with no car squeeze or with a cheaper model, but this would increase labor requirements. One ramp for two carloaders.

$\S$ Based on annual charges for depreciation, repairs, interest, insurance and taxes of 14.7 per cent for the car squeeze and 10 per cent for the ramp.

on end, on their sides-the time requirements per box appear to be approximately the same for all methods. Time and work-sampling studies indicate that a reasonably efficient carloader can stack, strip, and brace cars at a rate of about 285 boxes per hour. The studies also indicate that typically about 23 per cent unavoidable delay may be expected with this job. The performance standard then amounts to 220 boxes per hour per carloader. This applies to standard boxes and San Francisco lugs loaded in refrigerator cars.

Nearly all Los Angeles lugs and most San Francisco lugs are shipped in trucks. Studies of labor requirements for truckloading have not been carried out in detail, but a rough approximation can be obtained from the studies of carloading. The main differences between car- and truckloading appear to be in the stripping and bracing. Truck shipments commonly are not stripped and bracing requirements are greatly reduced. Bracing and a very small amount of stripping that might be needed probably would not require more than a third of the same time spent in loading cars. As stripping and bracing account for about one half of the total carloading time, truckloading labor requirements are estimated to amount to about two thirds of carloading requirements. Table 29 summarizes the costs of carloading labor 


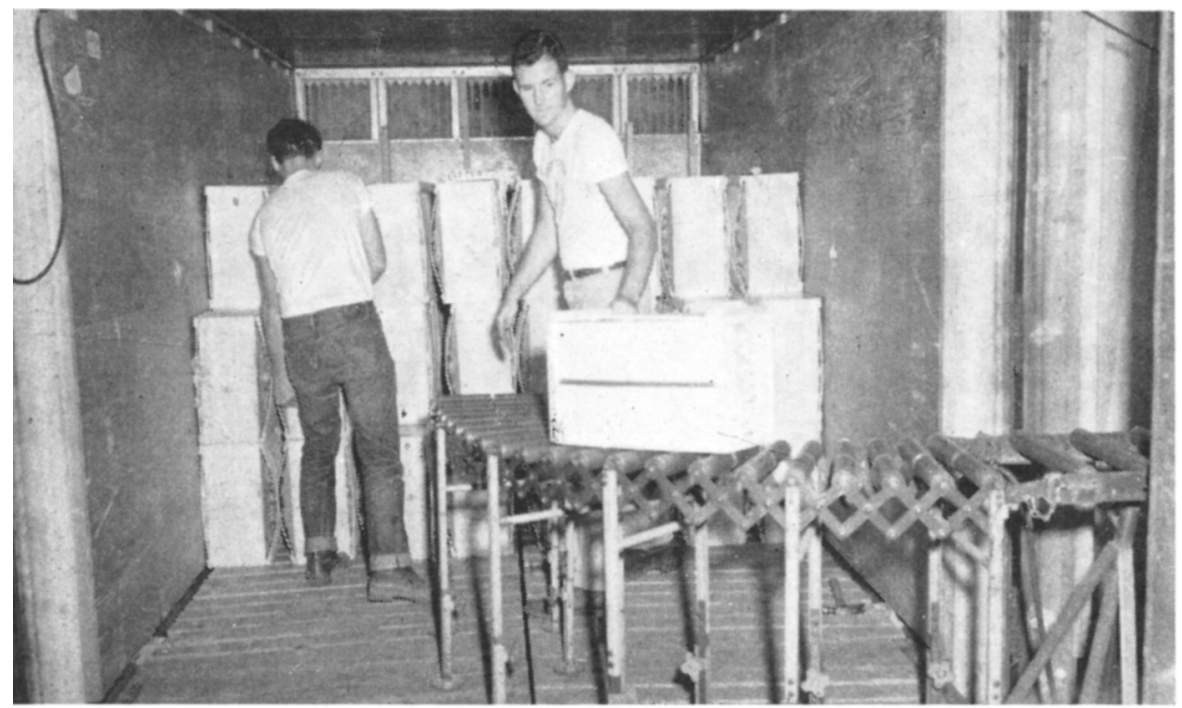

Fig. 35. Stacking boxes in a refrigerator car.

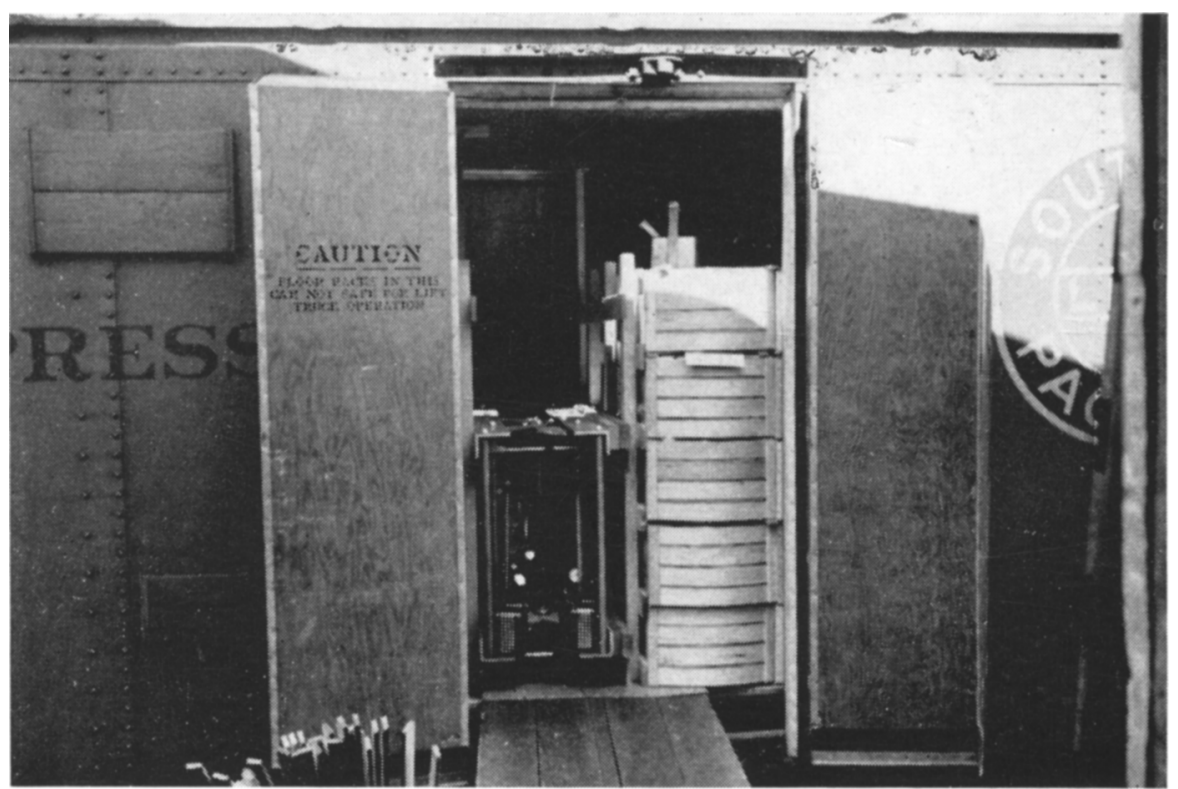

Fig. 36. "Squeezing" the load before adding the final braces.

and equipment (car squeeze and loading ramps) in relation to rates of packed output.

Loading materials-lumber and nails-amount to about 2.2 cents per box for cars and perhaps a fourth of that for trucks. This cost is included with packaging materials as a constant per box. 


\section{Stage 7. Boxmaking and Labeling}

Boxmaking consists of assembling and nailing together the boxes used to ship the packed fruit to fresh markets. Three types of machines are used for making boxes: (A) push-through and side-conveyor semi-automatic machines; (B) automatic end feed machines which feed box ends into the machine automatically, rather than box ends being placed individually by the operator (see fig. 37); and (C) fully automatic machines which feed

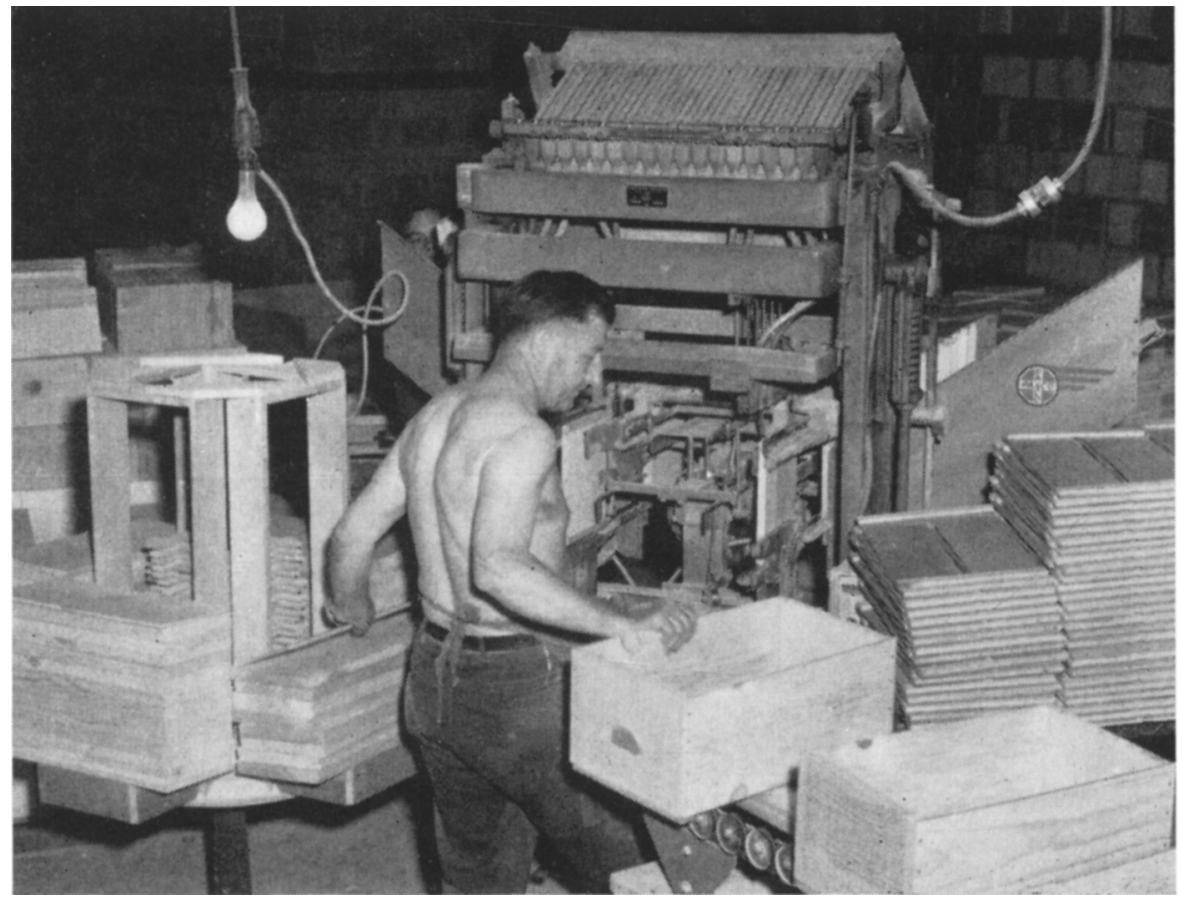

Fig. 37. Boxmaking machine with automatic end feed attachment.

all of the box shook into the machine and nail the box. Labor performance standards for these machines are: (A) 373 standard pear boxes per hour; (B) 480 standard pear boxes per hour; and (C) 600 standard pear boxes per hour (McCauley, 1954). Total labor and equipment costs per season for each of these machines are shown in figure 38 in relation to volume of boxes made per season. The push-through and side-conveyor machine (type A) gives the lowest total cost for season volumes per machine up to about 180,000 boxes-a quantity per machine larger than achieved in most pear plants. Thus, only this method will be considered in the analysis that follows.

Standardized wage rates for boxmaking with this type of machine are 1 cent per box for making the box and 0.5 cent per box for a helper. The 1950 installed price for the machine is approximately $\$ 3,000$. With standardized charges for depreciation, repairs, insurance, and taxes of 14.7 per cent, the average annual fixed cost is $\$ 441$. Since boxmaking equipment may 


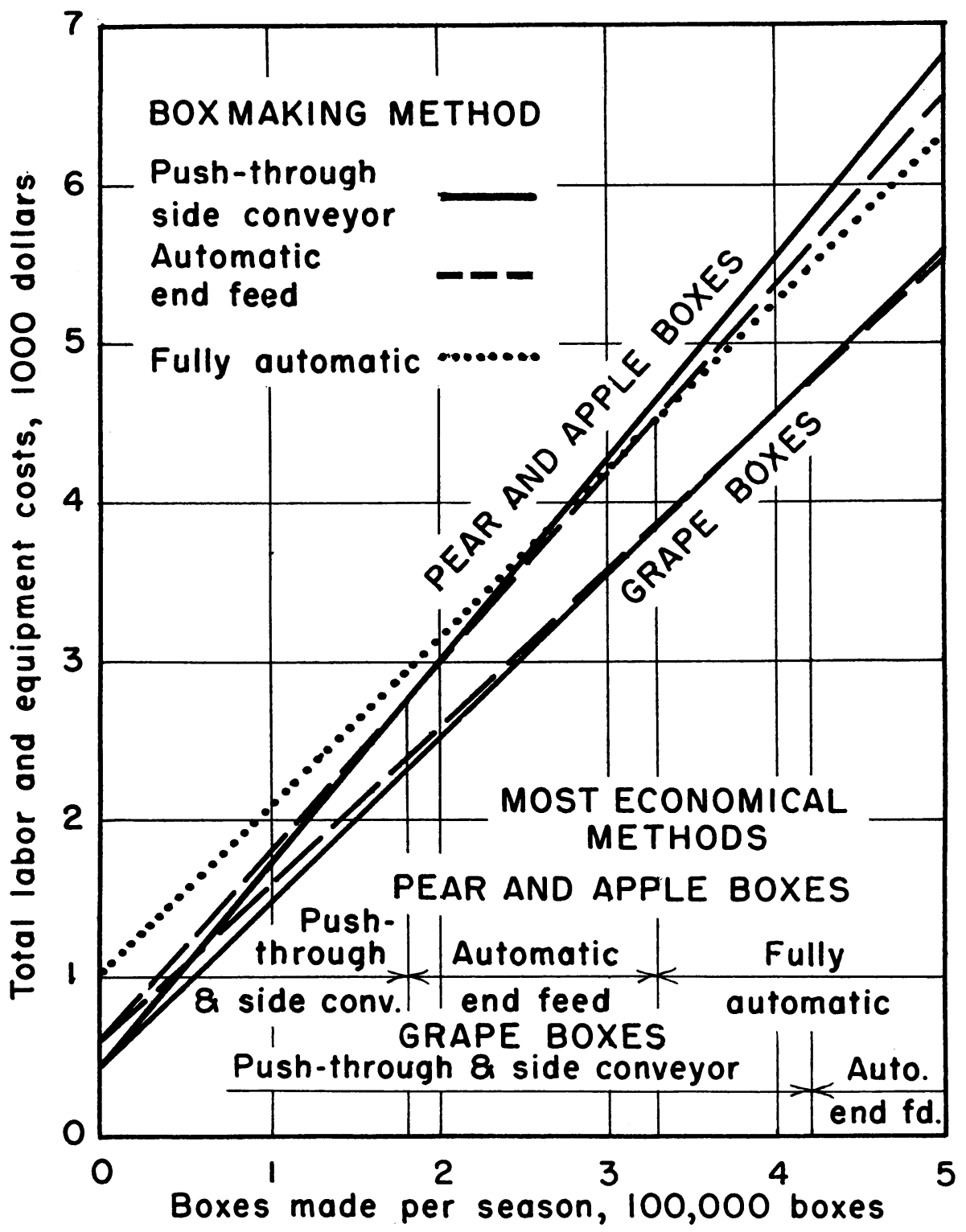

Fig. 38. Total labor and equipment costs per season in relation to boxes made per season for three types of boxmaking machines.

commonly be rented or shifted among plants in multiplant firms, the fixed costs are expressed as an average per box, estimated to be approximately equivalent to contract charges. The per-box charges were derived on the assumption that each machine produces about 90,000 boxes per seasonabout 240 hours of operation at 373 boxes per hour. The hours of boxmaking need not correspond exactly with plant hours and will usually exceed them. 
The figure $\$ 441$ divided by 90,000 gives a cost of about 0.5 cent per box. An additional 0.05 cent is included to cover costs of moving the machine and other miscellaneous rental expenses, giving a total of 0.55 cent per box for equipment.

If the plant owns its own machines and packs as few as 60,000 boxes per season, the equipment cost will be about 0.02 cent per box higher than indicated above. If the volume per machine is as much as 110,000 boxes per season (approximately the amount per machine in the largest sample plants), the costs would be 0.015 cent per box lower than indicated above. In either case, the difference is quite minor.

Labeling consists of pasting labels on the ends of the packing boxes, usually before the boxes are made. Detailed data on the costs of the several types of machines and methods used to label boxes are not available. The standard piece rate for hand-labeling is 0.45 cent per box and this figure will be used in the analysis. Total costs of boxmaking and labeling then amount to 2.5 cents per box.

\section{Stage 8. Empty Packing Box and Materials Supply ${ }^{59}$}

This operation consists of placing pads and liners in packing boxes and moving them to the packers. In most packing houses, the empty boxes are moved to the packing lines directly from a boxmaking machine, although the direct supply from the boxmaker is frequently supplemented with boxes taken from temporary storage. The stored boxes may be the result of preseason boxmaking operations, or they may accumulate during packing periods when the boxmaking rate temporarily exceeds the rate of packing or when the daily hours of boxmaking exceed the hours of plant operation. The costs and efficiency of these operations depend primarily on the type of equipment and methods (technologies) used, although they are affected to minor extent by the type of box, the type of pads and liners used, and the proportion of boxes going into temporary storage.

Five methods of empty box distribution observed in the plants studied are illustrated in figure 39.

Performance standards for the various labor operations involved in the several methods are summarized in table 30 . The standards are based on time and work-sampling studies. They are representative of normal rates of operation under relatively efficient operating conditions as to arrangement of the work place and the effort of the individual worker. The approximate quantities of equipment required with different methods are given in table 31 . With each method, the quantity of equipment required for a given rate of operation is affected by the rate of packing per packing line and by the plant layout. The equipment requirements given in table 31 are estimated for efficient or "standard" rates of packing (see packing performance standards) and "average" layouts that are typical of the more efficient plants. Estimated investment replacement costs and average annual costs for the major items of equipment used in box distribution are summarized in

\footnotetext{
${ }^{59}$ For more detail, see L. L. Sammet, "Packing Box Distribution Costs," California Agriculture, University of California, Berkeley, April, 1955. The analysis in this report is in terms of 1953, rather than 1950, wages and prices.
} 


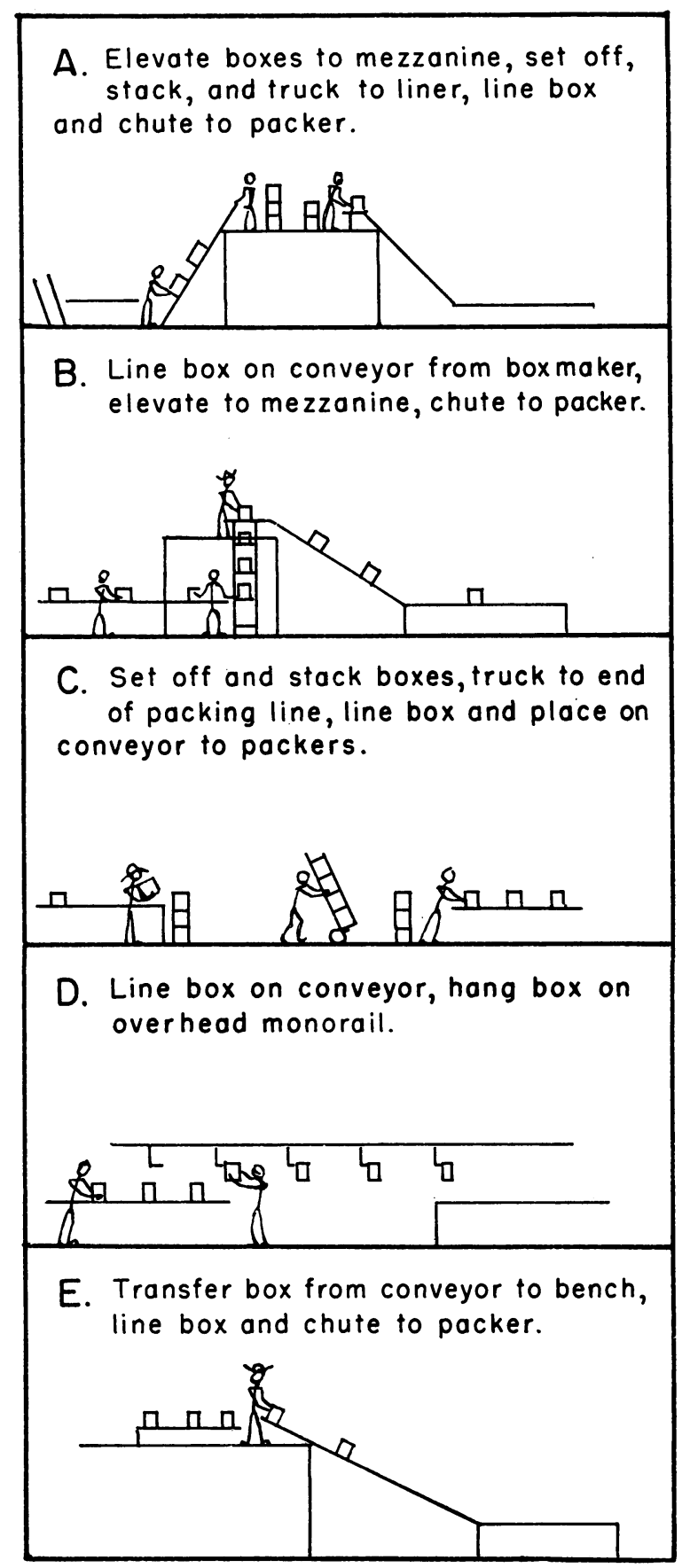

Fig. 39. Five methods of supplying packers with empty boxes. 

UNIT LABOR REQUIREMENTS AND PRODUCTION STANDARDS FOR THE TYPES OF JOBS PERFORMED IN THE DISTRIBUTION OF EMPTY BOXES TO THE PACKERS

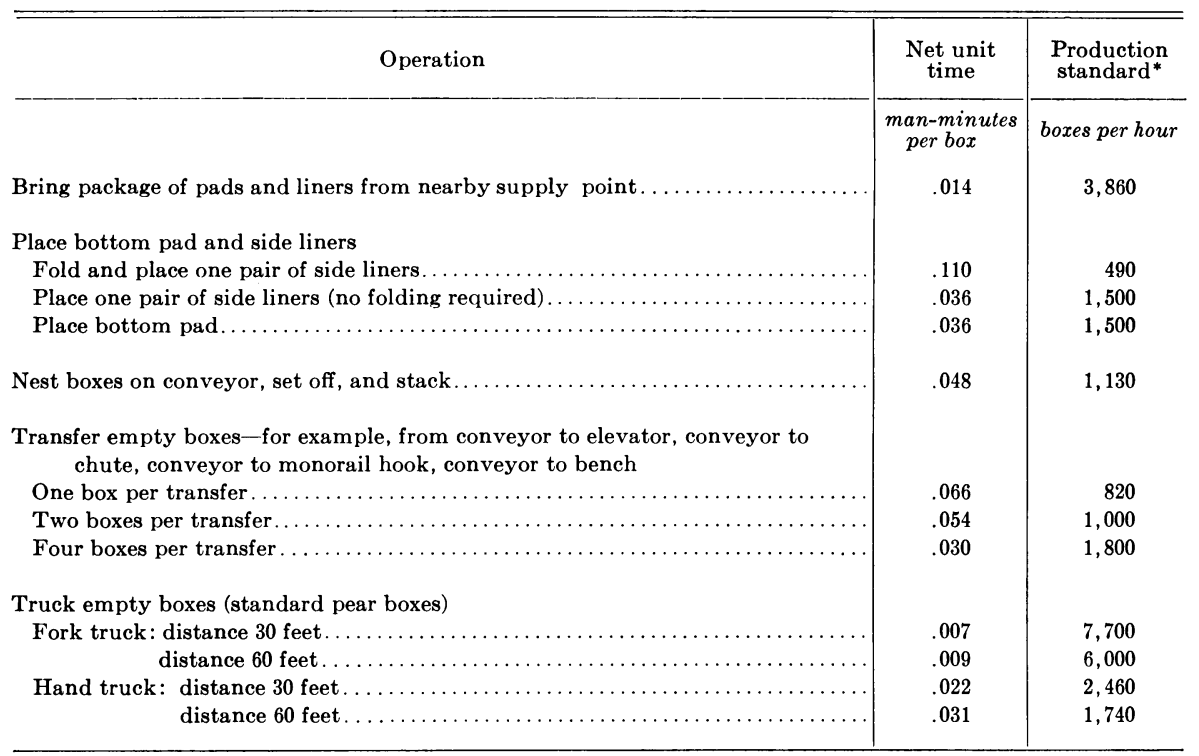

* Based on net time plus allowance for rest and delay of 10 per cent of total work time.

TABLE 31

EQUIPMENT REQUIREMENTS FOR DISTRIBUTION OF EMPTY PACKING BOXES WITH DIFFERENT METHODS

\begin{tabular}{|c|c|c|c|c|c|}
\hline Item & \multicolumn{5}{|c|}{ Method } \\
\hline Work table and box chute per 250 boxes per hour, each... & 1 & . & $1^{*}$ & $\ldots$ & 1 \\
\hline Gravity conveyor per 100 boxes per hour, feet. . . . . . . & 32 & 32 & 32 & . & 32 \\
\hline Box elevator per 2,000 boxes per hour $\ldots \ldots \ldots \ldots \ldots \ldots$ & 1 & 1 & .. & . & . \\
\hline Box mezzanine, floor area per 100 boxes per hour, square feet & 300 & 300 & . & . & . \\
\hline Monorail conveyor per 100 boxes per hour, feet......... & . & $\ldots$ & . & 70 & $\ldots$ \\
\hline
\end{tabular}

* Work table only.

table 32. Table 33 summarizes the labor, operating, and equipment costs for each of the five methods in relation to rates of plant output. ${ }^{80}$

Two possible variations in the over-all boxmaking and box distribution operation-pre-season and overtime boxmaking - should be mentioned, al-

${ }^{80}$ These costs are based on the assumption that the rate of boxmaking is so closely integrated with the rate of packing that no movement of boxes into, and out of, temporary storage is required. A small amount of temporary storage is usually unavoidable in any plant, however. Labor requirements for setting aside temporarily and then returning boxes to the supply line amount to about 1.6 man-hours per 1,000 boxes so handled. 
though for simplicity they are not considered here in any detail. ${ }^{{ }^{11}}$ With pre-season boxmaking, a part of the boxes is made prior to the packing season and stored until needed. With overtime boxmaking, a part of the boxes is made at night after regular plant hours and at higher cost rates. The extra supply is stored temporarily until needed. Both of these procedures may reduce the requirements for boxmaking equipment but will increase the handling costs. In the case of pre-season boxmaking, the higher

TABLE 32

ESTIMATED COSTS FOR THE MAJOR TYPES OF EQUIPMENT USED

IN DISTRIBUTING EMPTY BOXES TO PACKERS

\begin{tabular}{|c|c|c|c|c|}
\hline Item & Unit & $\begin{array}{c}\text { Replacement } \\
\text { cost, } 1950\end{array}$ & $\begin{array}{l}\text { Annual } \\
\text { charge* }\end{array}$ & $\begin{array}{l}\text { Direct } \\
\text { repair } \dagger\end{array}$ \\
\hline & & dollars & dollars & $\begin{array}{c}\text { dollars } \\
\text { per hour }\end{array}$ \\
\hline Work table and chute, box mezzanine to packing line... & Each & 100 & 13 & 0.005 \\
\hline Conveyor: gravity .......... & 8 feet & 25 & 3 & 0.001 \\
\hline belt...... & 20 feet & 400 & 50 & 0.020 \\
\hline & 100 feet & 950 & 125 & 0.050 \\
\hline \multirow{2}{*}{ monorail (overhead) $\ddagger \ldots \ldots \ldots \ldots \ldots \ldots \ldots$} & 100 feet & 800 & 105 & 0.040 \\
\hline & 500 feet & 2,600 & 345 & 0.130 \\
\hline Elevator (inclined slide with chain conveyor).. & Each & 400 & 50 & 0.020 \\
\hline 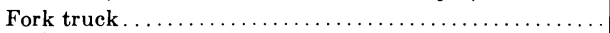 & Each & 3,300 & 545 & 0.165 \\
\hline Hand truck (side clamp) $\ldots \ldots \ldots \ldots \ldots \ldots \ldots \ldots \ldots \ldots \ldots \ldots \ldots$ & Each & 66 & 9 & 0.003 \\
\hline 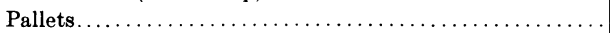 & 100 & 350 & $45 \S$ & 0.018 \\
\hline
\end{tabular}

* For all items except fork truck, estimated as 13.2 per cent of replacement cost, includes: taxes, 1.0 per cent insurance, 1.0 per cent; interest, 3.0 per cent (approximately 5.0 per cent on undepreciated balance); “fixed" repairs, 1.5 per cent; depreciation, 6.7 per cent. Charges for fork truck based on the same percentages except for a charge of 10.0 per cent for depreciation.

$\dagger$ Direct repair costs estimated as 0.5 per cent of replacement cost per 100 hours of use.

\pm Costs for conveyor amounts between 100 and 500 feet can be found by interpolating between 105 and 345 .

$\$$ In previous reports in this series, depreciation rates for pallets were based on a 10-year-use life. For the empty-box operations, however, a 15-year-use life seems reasonable, especially for pallets used in pre-season boxmaking operations where only one use per year could be anticipated.

handling costs may be offset to some extent through the use of "offseason" or permanent labor that might otherwise be partially idle. In any event, the relative economies of these variations will depend on the length of operating season and the size of plant.

\section{Stage 9. Packaging Cannery and Cull Fruit}

Packaging cannery and cull fruit consists of collecting the fruit in cannery lugs as it rolls from a conveyor or out of a temporary storage bin. A typical operation is illustrated in figure 40 . The main elements of the job include waiting for the box to fill, stacking the filled box, and placing empty boxes in filling positions. While some variation was observed among plants in the layout of the work place, the basic method and equipment used are essentially the same. Studies of the job indicate that labor requirements are about the same in all cases.

${ }^{\circ 1}$ The effects of these variations on box supply costs have been analyzed and the results of the study are in manuscript form. In general, the cost differences associated with these variations are quite small with the rates of output and lengths of season observed in the plants studied. 
TABLE 33

EMPTY BOX AND MATERIALS SUPPLY-LABOR, OPERATING, AND EQUIPMENT COSTS IN RELATION TO RATES OF PACKED OUTPUT

\begin{tabular}{|c|c|c|c|c|c|c|}
\hline \multirow[b]{2}{*}{ Volume range } & \multirow{2}{*}{$\begin{array}{c}\begin{array}{c}\text { Number } \\
\text { of } \\
\text { workers }\end{array} \\
\text {. }\end{array}$} & \multicolumn{3}{|c|}{ Direct cost* } & \multicolumn{2}{|c|}{ Equipment } \\
\hline & & Labor & $\begin{array}{c}\text { Equipment } \\
\text { repair and } \\
\text { operation }\end{array}$ & Total & $\begin{array}{l}\text { Replace- } \\
\text { ment cost }\end{array}$ & $\begin{array}{l}\text { Annual } \\
\text { fixed } \\
\text { cost } \dagger\end{array}$ \\
\hline boxes per hour & & \multicolumn{3}{|c|}{ dollars per hour } & \multicolumn{2}{|c|}{ dollars } \\
\hline Method A & & & & & & \\
\hline $0-190 \ldots \ldots \ldots$ & 2 & 2.10 & 0.05 & 2.15 & 1,060 & 130 \\
\hline $190.1-245 \ldots \ldots \ldots \ldots \ldots \ldots \ldots \ldots$ & 3 & 3.15 & 0.05 & 3.20 & 1,240 & 150 \\
\hline $490 \ldots \ldots \ldots \ldots \ldots \ldots \ldots$ & 4 & 4.20 & 0.07 & 4.27 & 2,010 & 240 \\
\hline $735 \ldots \ldots \ldots \ldots \ldots \ldots \ldots$ & 5 & 5.25 & 0.09 & 5.34 & 2,780 & 330 \\
\hline $790 \ldots \ldots \ldots \ldots$ & 6 & 6.30 & 0.09 & 6.39 & 2,950 & 350 \\
\hline$\ldots \ldots \ldots$ & 7 & 7.35 & 0.10 & 7.45 & 3,050 & 360 \\
\hline $980 \ldots$ & 8 & 8.40 & 0.11 & 8.51 & 3,620 & 430 \\
\hline 1,225 & 9 & 9.45 & 0.13 & 9.58 & 4,390 & 520 \\
\hline $1,470 \ldots$ & 10 & 10.50 & 0.15 & 10.65 & 5,160 & 610 \\
\hline $1,580 \ldots$ & 11 & 11.55 & 0.16 & 11.71 & 5,510 & 660 \\
\hline $1,640 \ldots$ & 12 & 12.60 & 0.16 & 12.76 & 5,760 & 690 \\
\hline \multicolumn{7}{|l|}{ Method B } \\
\hline 355. & 2 & 2.10 & 0.06 & 2.16 & 1,520 & 180 \\
\hline 625. & 3 & 3.15 & 0.08 & 3.23 & 2,370 & 280 \\
\hline 730 & 4 & 4.20 & 0.09 & 4.29 & 2,700 & 320 \\
\hline $820 \ldots$ & 5 & 5.25 & 0.10 & 5.35 & 2,980 & 360 \\
\hline $1,250 \ldots \ldots \ldots \ldots \ldots \ldots \ldots$ & 6 & 6.30 & 0.13 & 6.43 & 4,340 & 520 \\
\hline $1,460 \ldots \ldots \ldots \ldots \ldots \ldots \ldots$ & 7 & 7.35 & 0.15 & 7.50 & 5,000 & 590 \\
\hline $1,640 \ldots \ldots \ldots \ldots \ldots \ldots \ldots$ & 8 & 8.40 & 0.16 & 8.56 & 5,570 & 660 \\
\hline \multicolumn{7}{|l|}{ Method C } \\
\hline 225 & 2 & 2.10 & 0.01 & 2.11 & 290 & 40 \\
\hline $445 .$. & 3 & 3.15 & 0.03 & 3.18 & 580 & 80 \\
\hline 660. & 4 & 4.20 & 0.04 & 4.24 & 860 & 110 \\
\hline 870. & 5 & 5.25 & 0.06 & 5.31 & 1,130 & 150 \\
\hline $1,075 \ldots$ & 6 & 6.30 & 0.07 & 6.37 & 1,400 & 180 \\
\hline $1,130 \ldots \ldots \ldots \ldots \ldots \ldots \ldots$ & 7 & 7.35 & 0.08 & 7.43 & 1,530 & 200 \\
\hline $1,290 \ldots \ldots \ldots \ldots \ldots \ldots \ldots$ & 8 & 8.40 & 0.08 & 8.48 & 1,690 & 220 \\
\hline $1,505 \ldots$ & 9 & 9.45 & 0.10 & 9.55 & 1,970 & 260 \\
\hline $1,720 \ldots \ldots \ldots \ldots \ldots \ldots \ldots$ & 10 & 10.50 & 0.12 & 10.62 & 2,250 & 300 \\
\hline \multicolumn{7}{|l|}{ Method D } \\
\hline $355 \ldots \ldots \ldots \ldots$ & 1 & 1.05 & 0.09 & 1.14 & 1,450 & 190 \\
\hline $625 \ldots \ldots \ldots \ldots \ldots \ldots \ldots \ldots$ & 2 & 2.10 & 0.14 & 2.24 & 2,390 & 320 \\
\hline $820 \ldots \ldots \ldots \ldots \ldots \ldots \ldots$ & 3 & 3.15 & 0.16 & 3.31 & 2,580 & 340 \\
\hline $1,250 \ldots \ldots \ldots \ldots \ldots \ldots$ & 4 & 4.20 & 0.21 & 4.41 & 3,700 & 490 \\
\hline $1,640 \ldots \ldots \ldots \ldots \ldots \ldots \ldots$ & 5 & 5.25 & 0.27 & 5.52 & 4,830 & 640 \\
\hline \multicolumn{7}{|l|}{ Method E } \\
\hline $245 \ldots \ldots \ldots \ldots \ldots \ldots$ & 1 & 1.05 & 0.02 & 1.07 & 370 & 50 \\
\hline $490 \ldots \ldots \ldots \ldots \ldots \ldots \ldots$ & 2 & 2.10 & 0.04 & 2.14 & 740 & 100 \\
\hline $735 \ldots \ldots \ldots \ldots \ldots \ldots \ldots$ & 3 & 3.15 & 0.06 & 3.21 & 1,110 & 150 \\
\hline $980 \ldots \ldots \ldots \ldots \ldots \ldots \ldots$ & 4 & 4.20 & 0.08 & 4.28 & 1,470 & 200 \\
\hline $1,225 \ldots \ldots \ldots \ldots \ldots \ldots$ & 5 & 5.25 & 0.10 & 5.35 & 1,840 & 250 \\
\hline $1,470 \ldots \ldots \ldots \ldots \ldots \ldots$ & 6 & 6.30 & 0.12 & 6.42 & 2,210 & 300 \\
\hline $1,715 \ldots \ldots \ldots \ldots \ldots \ldots \ldots$ & 7 & 7.35 & 0.14 & 7.49 & 2,580 & 350 \\
\hline
\end{tabular}

* Direct costs are based on the following: wage rate $\$ 1.05$ per hour; power costs $\$ 0.03$ per motor horsepower per hour; direct repair, 0.5 per cent of replacement cost per 100 hours of use.

$\dagger$ Estimated as 13.2 per cent of replacement cost. See table 36 for additional details. 
Estimated standards of reasonably efficient performance, based on a combination of analyses of plant record data, descriptive models of the plant operations, and work-sampling studies, amount to 0.34 man-hour per thousand pounds of fruit packaged. Cannery lugs averaged about 46 pounds net weight per box, and this figure may be used to convert to a per-lug basis if desired. Labor costs in relation to rate of cannery and cull output are summarized in figure 41 . They are based on a weighted average wage for this job of $\$ 1.20$ per hour ( $\$ 1.05$ for empty box handlers and $\$ 1.25$ per hour for men who fill and set off or stack the boxes). The continuous line

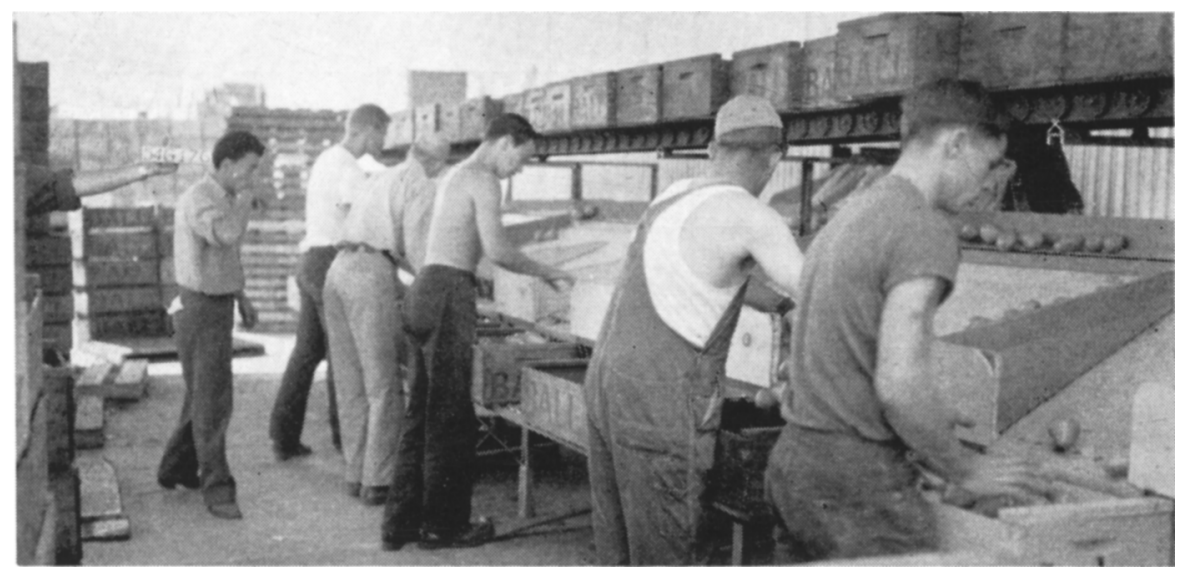

Fig. 40. Packaging cannery pears.

reflects "productive time requirements" and the "steps" represent the actual requirements since men must be hired in whole units. ${ }^{62}$

Investment replacement costs for cannery and cull belts and other items of packaging equipment are summarized in relation to rates of output in figure 41 (Sammet and Davis, 1952). The costs are based on 1950 prices and reflect the requirements for plants with efficient layouts. The line is continuous beyond 5,000 pounds since the amount of belting required can be varied almost continuously as output varies. ${ }^{83}$ The cost line shows increasing average costs with increasing rates of output, reflecting the added distances that the fruit must be conveyed as the size of plant increasesa "classic" example of diseconomies of scale. For small "one line" plants, the belting requirements are very minor. The horizontal section of the cost curve suggests a minimum equipment requirement, regardless of plant size.

Figure 41 converts the investment replacement costs to estimated aver-

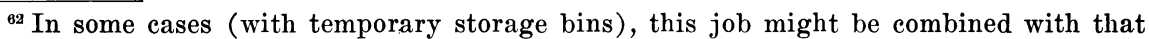
of (say) a trucker and the discontinuity would be reduced. However, the possibilities for this type of combination are fairly limited except in very small plants, and there is some loss in time due to switching from one operation to another.

${ }^{63}$ It is assumed that belts are required for two grades of cannery fruit and for culls. If only one grade of cannery fruit is handled, the number of belts may be reduced, but a wider belt would be required to handle a given volume. Costs would be reduced slightly but the difference would be small. 

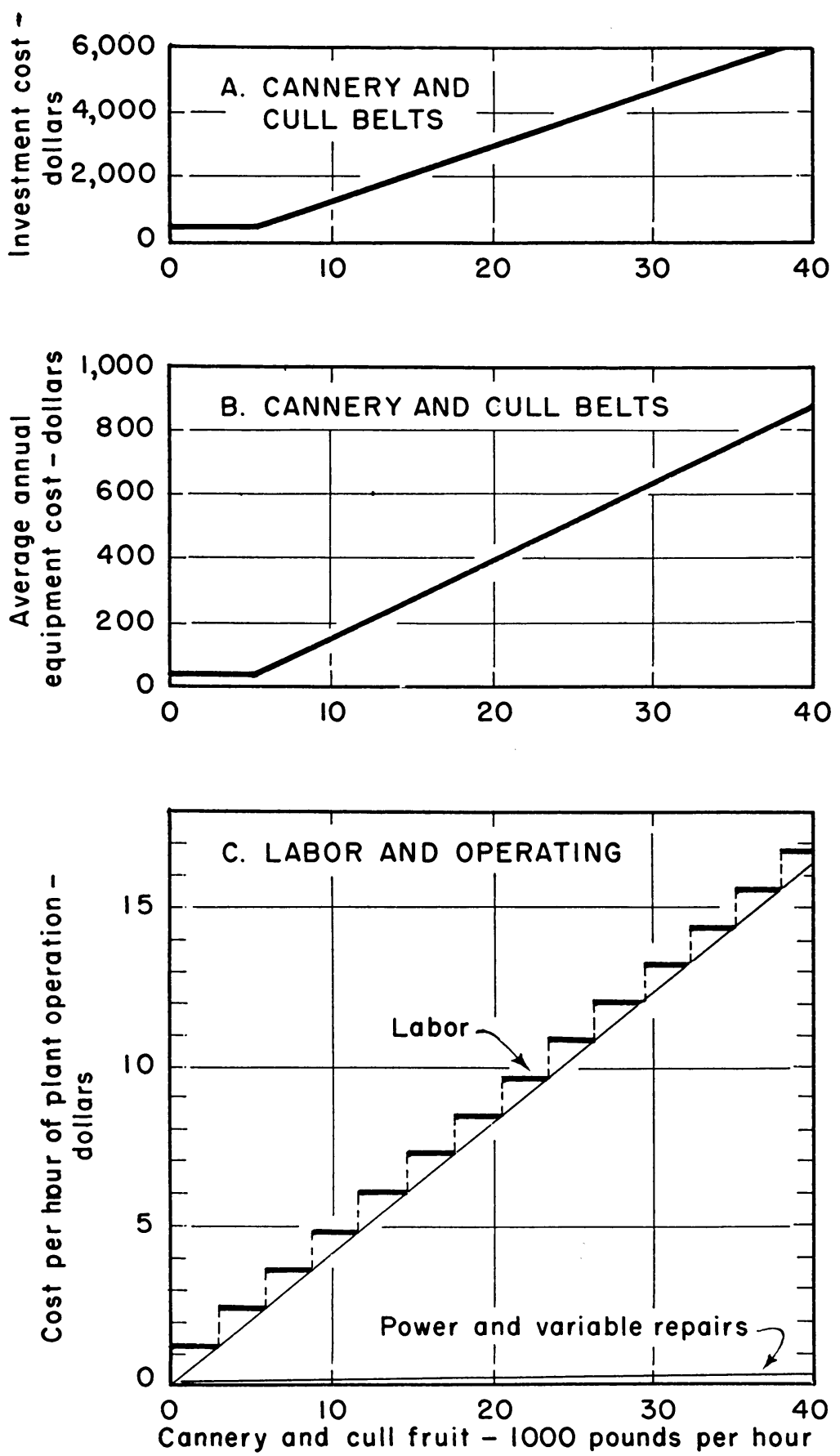

Fig. 41. Equipment, operating, and labor costs for packing cannery and cull fruit. 
age annual costs. These costs are based on charges for depreciation, repairs, insurance, taxes, and interest totaling 14 per cent. Power and variable repair costs are shown in figure 41. The estimates are based on costs of 3 cents per horsepower per hour for power and $1 / 2$ of 1 per cent of the investment cost per 100 hours of use for variable repairs.

\section{Stage 10. In-plant Transportation ${ }^{64}$}

Many types of transportation are involved in maintaining the flow of materials through the plant. Transportation that is closely integrated with the operations at a particular stage is conveniently classified as within

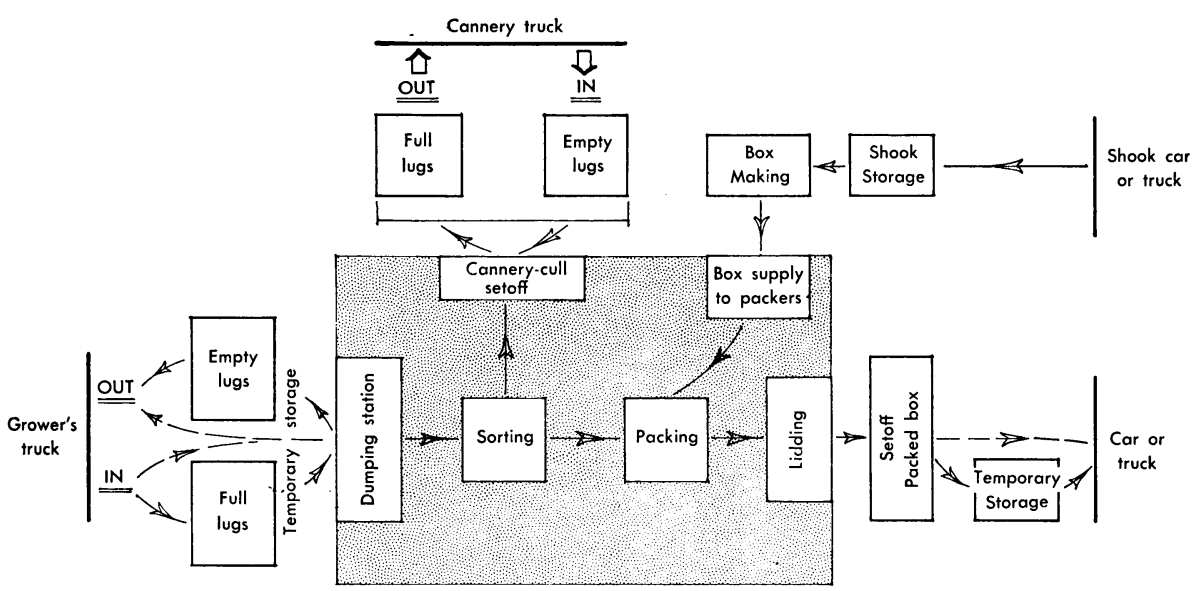

Fig. 42. Process chart for pear packing showing the between-stage transportation operations.

stage transportation and has been included in the group of elements that define a stage. The present section is concerned with the costs and methods of transportation that provide links between the various plant stages. The simplified process chart, figure 42 , indicates the kinds of transportation operations to be considered (Sammet, 1953; p. 18). All transportation within the shaded areas is included as a part of the operations of particular stages. The major transportation jobs outside of this area are as follows: (1) receive incoming fruit; (2) transport cannery and cull fruit; and (3) transport packed fruit from the lidder to the car.

Receiving incoming fruit includes unloading grower trucks and transporting the fruit to temporary storage and then to the dumping station. Empty lugs are transported from the dumping station or set-off point to temporary storage and then to the grower's truck. Two methods of transportation-hand trucks and fork trucks (figure 43, top and middle)-are considered in the receiving operation. ${ }^{65}$

${ }^{64}$ Transportation operations were earlier distinguished from stage operations. However, for convenience, in-plant transportation will be referred to as a stage.

${ }^{65}$ Powered hand trucks (fig. 43 lower) can be used in combination with fork trucks, but this method is useful mainly as an economical means of adapting old construction to more rapid methods of transportation, rather than in planning new plants. For details on the 

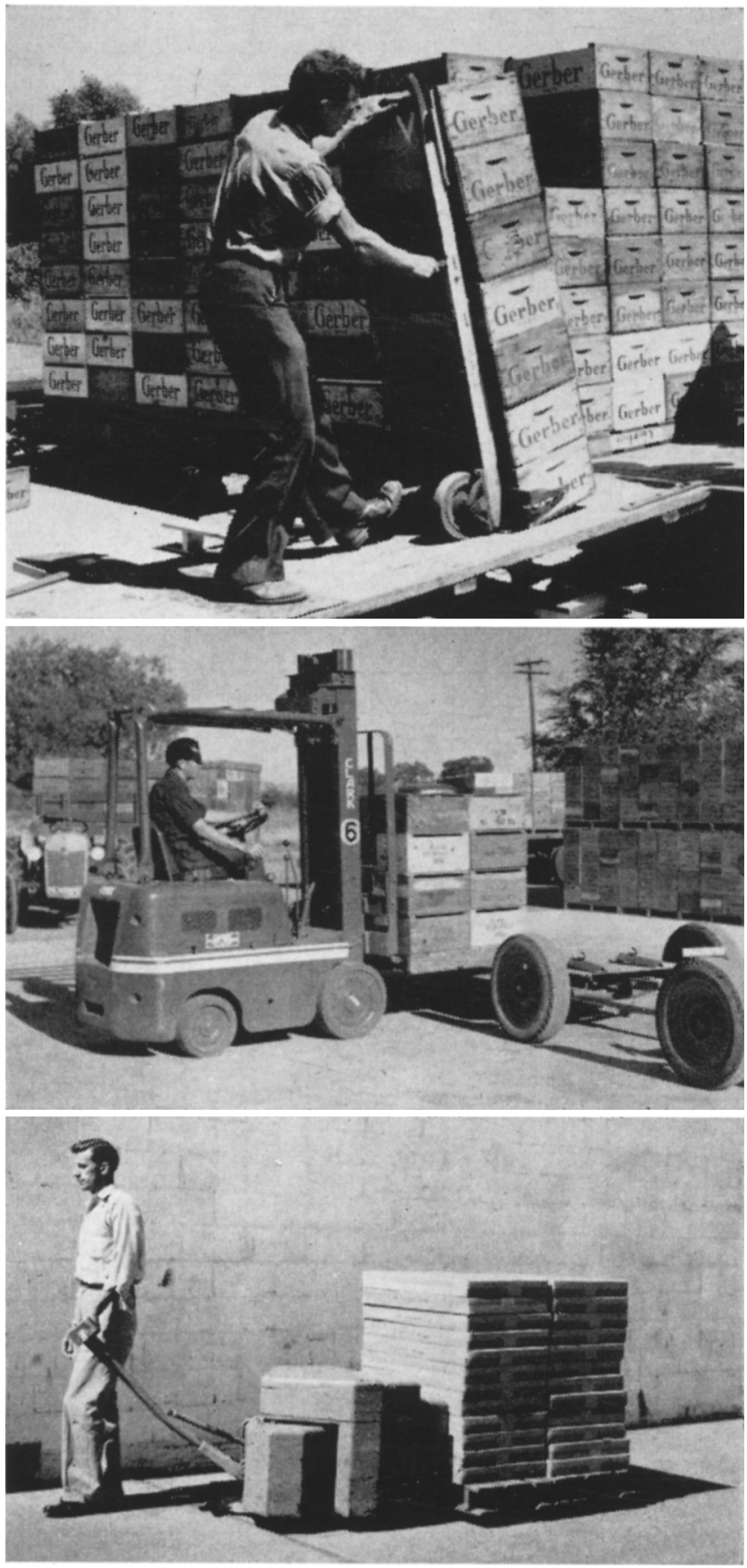

Fig. 43. Equipment for transporting fruits and materials: Top-hand truck ; center-fork truck; bottom-powered hand truck. 
The job of transporting cannery and cull fruit consists of transporting empty lugs from the cannery truck to storage, then to the cannery packaging stations from which full lugs are transported first to storage, then to the cannery truck. A similar process is followed with culls. Again, hand trucks and fork trucks are considered as alternative methods.

Three alternative methods of transporting packed fruit-hand trucks, fork trucks, and conveyors-are considered. If either hand trucks or fork trucks are used, the operation consists of setting off and stacking boxes at

TRANSPORTATION PERFORMANCE STANDARDS WITH STANDARDIZED TRUCKING DISTANCES, LOAD SIZES, AND OPERATIONS

\begin{tabular}{|c|c|c|c|}
\hline \multirow{2}{*}{ Item } & \multicolumn{3}{|c|}{1,000 pounds per truck-hour* } \\
\hline & Hand truck & Fork truck & Conveyor \\
\hline \multicolumn{4}{|l|}{ Receive incoming fruit } \\
\hline \multicolumn{4}{|l|}{ Dumper has no conveyor aids: } \\
\hline One dumping station..... & 6,800 & 19,800 & \\
\hline Two dumping stations.... & 6,600 & 19,350 & \\
\hline Three dumping stations $\ldots \ldots \ldots \ldots \ldots \ldots \ldots$ & 6,250 & 18,900 & \\
\hline Four dumping stations or more $\ldots \ldots \ldots \ldots \ldots \ldots \ldots \ldots \ldots$ & 5,950 & 18,500 & \\
\hline \multicolumn{4}{|l|}{ Dumper has conveyor aids } \\
\hline All numbers of stations..................... & 7,250 & 20,450 & \\
\hline 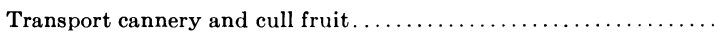 & 6,900 & 25,000 & \\
\hline \multicolumn{4}{|l|}{ Transport packed fruit } \\
\hline Truck operator..... & 10,000 & 46,000 & \\
\hline Set off............. & 24,000 & 24,000 & \\
\hline 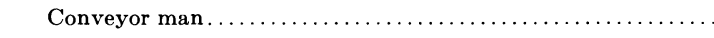 & $\ldots \ldots$ & $\ldots \ldots$ & 60,000 \\
\hline Transport shook and materials $\dagger$ & 92,300 & 272,700 & \\
\hline Miscellaneous transportation $\ddagger$. & 23,700 & 83,100 & \\
\hline
\end{tabular}

* Truck hours equal man-hours, one man per truck.

$\dagger$ Expressed on the basis of the volume of packed fruit.

$\ddagger$ Expressed on the basis of total plant volume.

the lidder, then trucking the fruit to a car or truck for loading. Strictly speaking, the "set-off" job is not a transportation operation, but it is included here since with the third method of transportation-the conveyor system-it is eliminated. With the conveyor method, the fruit moves directly from the lidder to the car, and the only labor required is a "conveyor man" who routes the boxes to the various cars and helps move mobile conveyors.

An additional amount of transport time is required for the movement of shook and materials and other miscellaneous transportation jobs. These operations are performed by either hand trucks or fork trucks.

Performance standards for the various transportation operations, based

costs of this method, see L. L. Sammet, In-Plant Transportation Costs as Related to Materials Handling Methods-Apple and Pear Packing, Giannini Foundation of Agricultural Economics, Mimeographed Report No. 141, 1952. 
on a standardized set of distances, load sizes, and operations are summarized in table 34. Trucking distances remain almost constant regardless of plant size. This is due to the fact that "in plant" transportation consists largely of inward and outward movements of materials (movement at right angles rather than parallel to the building walls) around the edges of a "center core" of floor area containing the packing equipment. ${ }^{\circ}$ The standards do differ, depending on whether the dumping job is aided by conveyors for

TABLE 35

EQUIPMENT, LABOR AND OPERATING COSTS FOR HAND TRUCKS AND FORK TRUCKS

\begin{tabular}{|c|c|}
\hline \multicolumn{2}{|l|}{ Direct and fixed costs per truck* } \\
\hline \multicolumn{2}{|l|}{ Hand trucks } \\
\hline \multicolumn{2}{|l|}{ Fixed costs per truck: } \\
\hline Replacement: hand truck. &.$\$ 66.00$ \\
\hline Annual fixed cost at 13.5 per cent... & 9.00 \\
\hline \multicolumn{2}{|l|}{ Direct costs per truck: } \\
\hline Labor, per hour..... & 1.250 \\
\hline Direct repair expense per hour.... & 0.003 \\
\hline Total, per hour. & 1.253 \\
\hline \multicolumn{2}{|l|}{ Fork trucks } \\
\hline \multicolumn{2}{|l|}{ Fixed costs per truck: } \\
\hline Replacement: Fork truck and pallets $\dagger .$. & $. \$ 3,740.00$ \\
\hline Annual fixed cost at 16.5 per cent....... &.$\$ 618.00$ \\
\hline \multicolumn{2}{|l|}{ Direct costs per truck: } \\
\hline Labor, per hour............... & 1.300 \\
\hline Direct repair expense, per hour..... & 0.185 \\
\hline Gasoline and oil, per hour $\ldots \ldots \ldots \ldots \ldots \ldots \ldots \ldots \ldots \ldots \ldots \ldots \ldots \ldots$ & 0.150 \\
\hline Total, per hour. . & 1.635 \\
\hline
\end{tabular}

* Price level for 1950 .

$\dagger$ Approximately 125 field pallets per truck. This number is estimated to be adequate for $1 \frac{1}{2}$ to 2 days' operation without reuse of pallets.

full and empty field lugs as this affects the distance of transport. If there are no aids, the trucking distance for empty boxes increases with the number of dumping stations. Thus, separate standards are indicated for plants with one, two, three, and four or more dumping stations.

Table 35 summarizes the costs of operating fork trucks and hand trucks. Figure 44 summarizes the costs of conveyor equipment in relation to rates of packed output. Table 36 summarizes the combined costs of transporting incoming fruit, cannery and cull fruit, shook and materials, and miscellaneous transportation in relation to rates of total plant output with 80 per cent packed fruit and 20 per cent cannery and culls. Other proportions are considered in the final analysis. Table 37 gives the costs of transporting packed fruit to cars or trucks, with hand trucks or fork trucks, in relation to rates of output of packed fruit. These tables and diagrams provide the basis for calculating the total transportation costs for any length of season

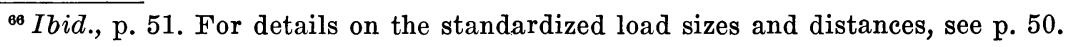



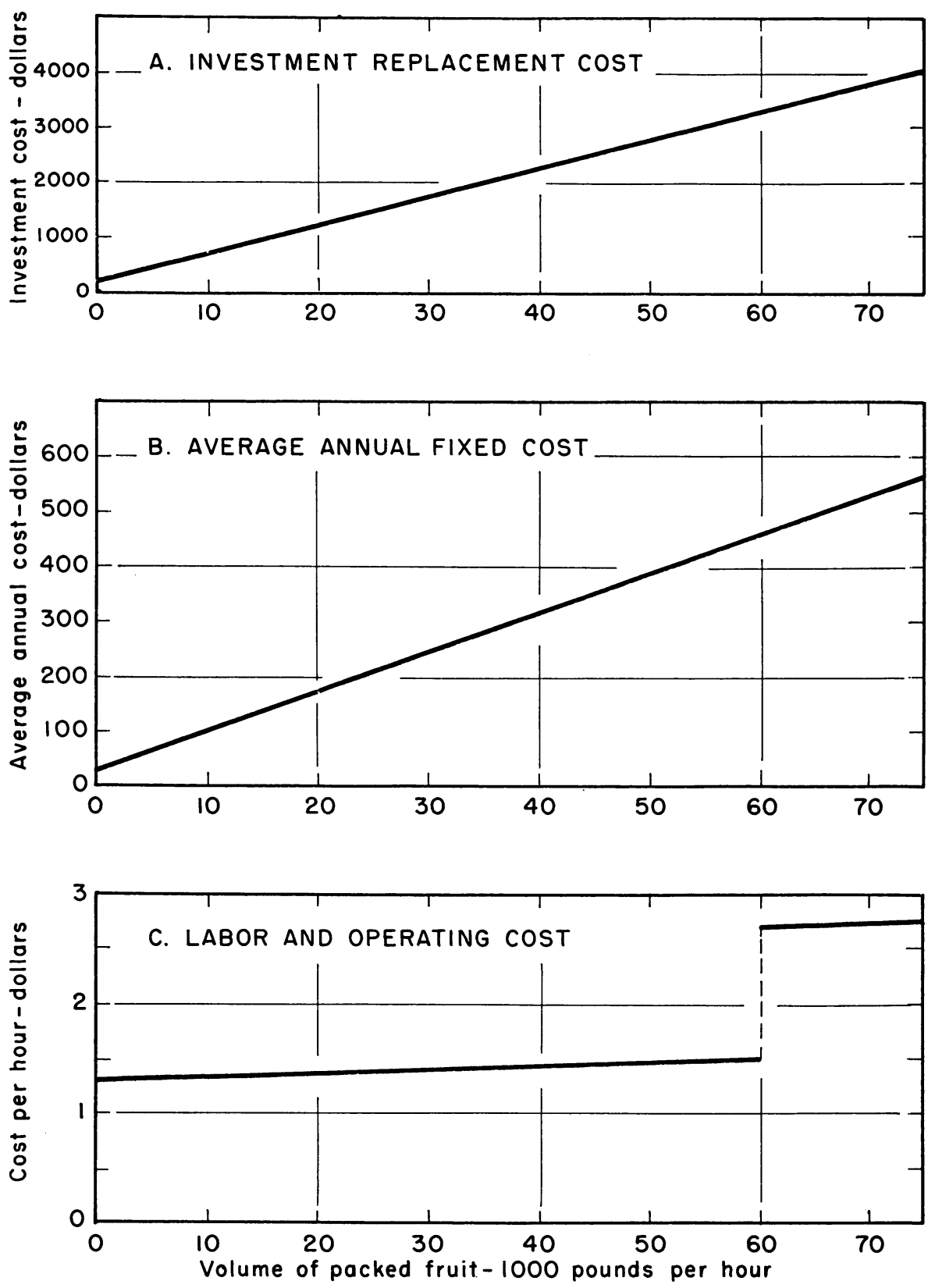

Fig. 44. Costs of transporting packed fruit from the lidder to the car with conveyor equipment. 
for four alternative combinations of transportation technologies-all hand trucks, all fork trucks, conveyors for packed fruit and the rest hand truck, and conveyor for packed fruit and the rest fork truck. ${ }^{67}$ In cases where all

TABLE 36

TOTAL COSTS OF TRANSPORTATION, EXCEPT PACKED FRUIT, IN RELATION TO TOTAL RATES OF PLANT OUTPUT WITH 80 PER CENT PACKED AND 20 PER CENT CANNERY ,AND CULLS

\begin{tabular}{|c|c|c|c|c|c|c|}
\hline \multirow{3}{*}{$\begin{array}{c}\text { Labor, } \\
\text { operating and } \\
\text { variable } \\
\text { repair expense }\end{array}$} & \multirow{3}{*}{$\begin{array}{c}\text { Average } \\
\text { annual } \\
\text { equipment } \\
\text { cost }\end{array}$} & \multicolumn{5}{|c|}{ Rate of total plant output $-1,000$ pounds per hour } \\
\hline & & \multicolumn{4}{|c|}{ No conveyor aids } & \multirow{2}{*}{$\begin{array}{l}\text { With } \\
\text { conveyor } \\
\text { aids }\end{array}$} \\
\hline & & 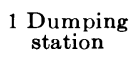 & 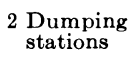 & $\begin{array}{l}3 \text { Dumping } \\
\text { stations }\end{array}$ & $\begin{array}{l}4 \text { Dumping } \\
\text { stations }\end{array}$ & \\
\hline dollars per hour & dollars & \multicolumn{4}{|c|}{ Hand truck } & \\
\hline 1.253 & 9.0 & $0-4.4$ & $0-4.3$ & $0-4.15$ & $0-4.05$ & $0-4.6$ \\
\hline 2.506 & 18.0 & 8.8 & 8.6 & 8.30 & 8.10 & 9.2 \\
\hline 3.759 & 27.0 & 13.2 & 12.9 & 12.45 & 12.15 & 13.8 \\
\hline 5.012 & 36.0 & 17.6 & 17.2 & 16.60 & 16.20 & 18.4 \\
\hline 6.265 & 45.0 & 22.0 & 21.5 & 20.75 & 20.25 & 23.0 \\
\hline 7.518 & 54.0 & 26.4 & 25.8 & 24.90 & 24.30 & 27.6 \\
\hline 8.771 & 63.0 & 30.8 & 30.1 & 29.05 & 28.35 & 32.2 \\
\hline 10.024 & 72.0 & 35.2 & 34.4 & 33.20 & 32.40 & 36.8 \\
\hline 11.277 & 81.0 & 39.6 & 38,7 & 37.35 & 36.45 & 41.4 \\
\hline 12.530 & 90.0 & 44.0 & 43.0 & 41.50 & 40.50 & 46.0 \\
\hline 13.783 & 99.0 & 48.4 & 47.3 & 45.65 & 44.55 & 50.6 \\
\hline 15.036 & 108.0 & $\ldots$ & 51.6 & 49.80 & 48.60 & 55.2 \\
\hline 16.289 & 117.0 & $\ldots$ & 55.9 & 53.95 & 52.65 & 59.8 \\
\hline 17.542 & 126.0 & $\ldots$ & 60.2 & 58.10 & 56.70 & 64.4 \\
\hline 18.745 & 135.0 & $\ldots$ & 64.5 & 62.25 & 60.75 & 69.0 \\
\hline 20.048 & 144.0 & $\ldots$ & 68.8 & 66.40 & 64.80 & 73.6 \\
\hline 21.301 & 153.0 & $\ldots$ & 73.1 & 70.55 & 68.85 & 78.2 \\
\hline 22.554 & 162.0 & $\ldots$ & 77.4 & 74.70 & 72.90 & 82.8 \\
\hline 23.807 & 171.0 & $\ldots$ & 81.7 & 78.85 & 76.95 & 87.4 \\
\hline 25.060 & 180.0 & $\ldots$ & 86.0 & 83.00 & 81.00 & 92.0 \\
\hline 26.313 & 189.0 & $\ldots$ & 90.3 & 87.15 & 85.05 & 96.6 \\
\hline 27.566 & 198.0 & $\ldots$ & $\ldots$ & 91.30 & 89.10 & 101.2 \\
\hline 28.819 & 207.0 & $\ldots$ & $\ldots$ & 95.45 & 93.15 & 105.8 \\
\hline 30.072 & 216.0 & $\ldots$ & $\ldots$ & 99.60 & 97.20 & 110.4 \\
\hline \multirow[t]{2}{*}{31.325} & 225.0 & $\ldots$ & $\ldots$ & 103.75 & 101.25 & \multirow[t]{2}{*}{$\ldots$} \\
\hline & & \multicolumn{4}{|c|}{ Fork truck } & \\
\hline 1.653 & 618.0 & $0-13.6$ & $0-13.4$ & $0-13.15$ & $0-12.95$ & $0-13.9$ \\
\hline 3.306 & $1,236.0$ & 27.2 & 26.8 & 26.30 & 25.90 & 27.8 \\
\hline 4.959 & $1,854.0$ & 40.8 & 40.2 & 39.45 & 38.85 & 41.7 \\
\hline 6.612 & $2,472.0$ & 54.4 & 53.6 & 52.60 & 51.80 & 55.6 \\
\hline 8.265 & $3,090.0$ & $\ldots$ & 67.0 & 65.75 & 64.75 & 69.5 \\
\hline 9.918 & $3,708.0$ & $\ldots$ & 80.4 & 78.90 & 77.70 & 83.4 \\
\hline 11.571 & $4,326.0$ & $\ldots$ & 93.8 & 92.05 & 90.65 & 97.3 \\
\hline 13.224 & $4,944.0$ & $\ldots$ & 107.2 & 105.20 & 103.60 & 111.2 \\
\hline
\end{tabular}

hand trucks or fork trucks are used, the cannery and cull fruit might be transported by the packed-fruit crew rather than by the receiving crew as suggested by table 36 . However, this would have little effect on the total transportation costs.

${ }^{67}$ Ibid., pp. 19-36, for details on several other variations. 
TABLE 37

COSTS OF TRANSPORTING PACKED FRUIT WITH HAND
TRUCKS AND FORK TRUCKS IN RELATION TO THE
RATE OF OUTPUT OF PACKED FRUIT

\begin{tabular}{|c|c|c|c|c|}
\hline \multirow{2}{*}{$\begin{array}{c}\text { Rate of output, } 1,000 \text { pounds } \\
\text { packed per hour }\end{array}$} & \multicolumn{3}{|c|}{ Labor and truck costs per hour-dollars } & \multirow{2}{*}{$\begin{array}{c}\text { Average } \\
\text { annual } \\
\text { equipment } \\
\text { cost }\end{array}$} \\
\hline & Set off & Truck & Total & \\
\hline & \multicolumn{3}{|c|}{ Hand Truck } & dollars \\
\hline $0-7.0$ & $\ldots$ & $\ldots$ & 1.253 & 9.00 \\
\hline $7.1-14.0^{*}$. & 1.25 & 1.253 & 1.506 & 9.00 \\
\hline $14.1-20.0$. & 1.25 & 2.506 & 2.756 & 18.00 \\
\hline $20.1-24.0$ & 1.25 & 3.759 & 5.009 & 27.00 \\
\hline $24.1-30.0$. & 2.50 & 3.759 & 6.259 & 27.00 \\
\hline $30.1-40.0 \ldots$ & 2.50 & 5.012 & 7.512 & $36: 00$ \\
\hline $40.1-48.0 \ldots$ & 2.50 & 6.265 & 8.765 & 45.00 \\
\hline $48.1-50.0$. & 3.75 & 6.265 & 10.015 & 45.00 \\
\hline $50.1-60.0 \ldots$ & 3.75 & 7.518 & 11.268 & 54.00 \\
\hline $60.1-70.0 \ldots \ldots \ldots \ldots$ & 3.75 & 8.771 & 12.521 & 63.00 \\
\hline $70.1-72.0 \ldots \ldots \ldots \ldots$ & 3.75 & 10.024 & 13.774 & 72.00 \\
\hline $72.1-80.0 \ldots$ & 5.00 & 10.024 & 15.024 & 72.00 \\
\hline $80.1-90.0 \ldots$ & 5.00 & 11.277 & 16.277 & 81.00 \\
\hline $90.1-96.0$. & 5.00 & 12.530 & 17.530 & 90.00 \\
\hline \multirow[t]{2}{*}{$96.1-100.0$. } & 6.25 & 12.530 & 18.780 & \multirow[t]{2}{*}{90.00} \\
\hline & \multicolumn{3}{|c|}{ Fork truck } & \\
\hline $0-15.0$. & $\ldots$ & $\ldots \ldots$ & 1.653 & 618.00 \\
\hline $15.1-24.0^{*} \ldots \ldots \ldots$ & 1.25 & 1.653 & 2.903 & 618.00 \\
\hline $24.1-46.0 \ldots \ldots \ldots \ldots \ldots$ & 2.50 & 1.653 & 4.153 & 618.00 \\
\hline $46.1-48.0 \ldots \ldots \ldots \ldots \ldots$ & 2.50 & 3.306 & 5.806 & $1,236.00$ \\
\hline $48.1-72.0 \ldots$ & 3.75 & 3.306 & 7.056 & $1,236.00$ \\
\hline $72.1-92.0 \ldots \ldots \ldots \ldots$ & 5.00 & 3.306 & $8: 306$ & $1,236.00$ \\
\hline $92.1-96.0 \ldots \ldots \ldots \ldots$ & 5.00 & 4.959 & 9.959 & $1,854.00$ \\
\hline $96.1-120.0 \ldots \ldots \ldots$ & 6.25 & 4.959 & 11.209 & $1,854.00$ \\
\hline
\end{tabular}

* For very small plants trucking and set off may be performed by one worker.

\section{Cost Component 11. Direct Supervision and Miscellaneous Labor}

Several categories of plant labor are not associated with any specific stage (as defined here) in the plant process. These include: direct supervision-general foreman, packing bosses, and the like; "nightmen" (janitors and watchmen) ; seasonal office clerks; weighmasters; and utility men. The duties of supervisors and janitors are fairly obvious. Seasonal office clerks consist of payroll clerks and general temporary office workers. Permanent "year around" bookkeepers and accountants are not included in this category because of the difficulty of separating the costs of permanent office workers from administrative costs. The two are considered jointly in a following section.

The duties of the weighmaster consist of weighing incoming and outgoing trucks on truck scales or of "sample weighing" a part of each load on a smaller scale to estimate the weight of fruit received. For small plants, 
this job may be performed by a trucker or perhaps by an office clerk. ${ }^{8}$ In larger plants, one man may be assigned full time to this job. The weighing hours are commonly determined by the plant policy as to hours for receiving incoming fruit.

TABLE 38

COSTS OF MISCELLANEOUS PLANT LABOR AND DIRECT SUPERVISION IN RELATION TO RATES OF TOTAL PLANT OUTPUT*

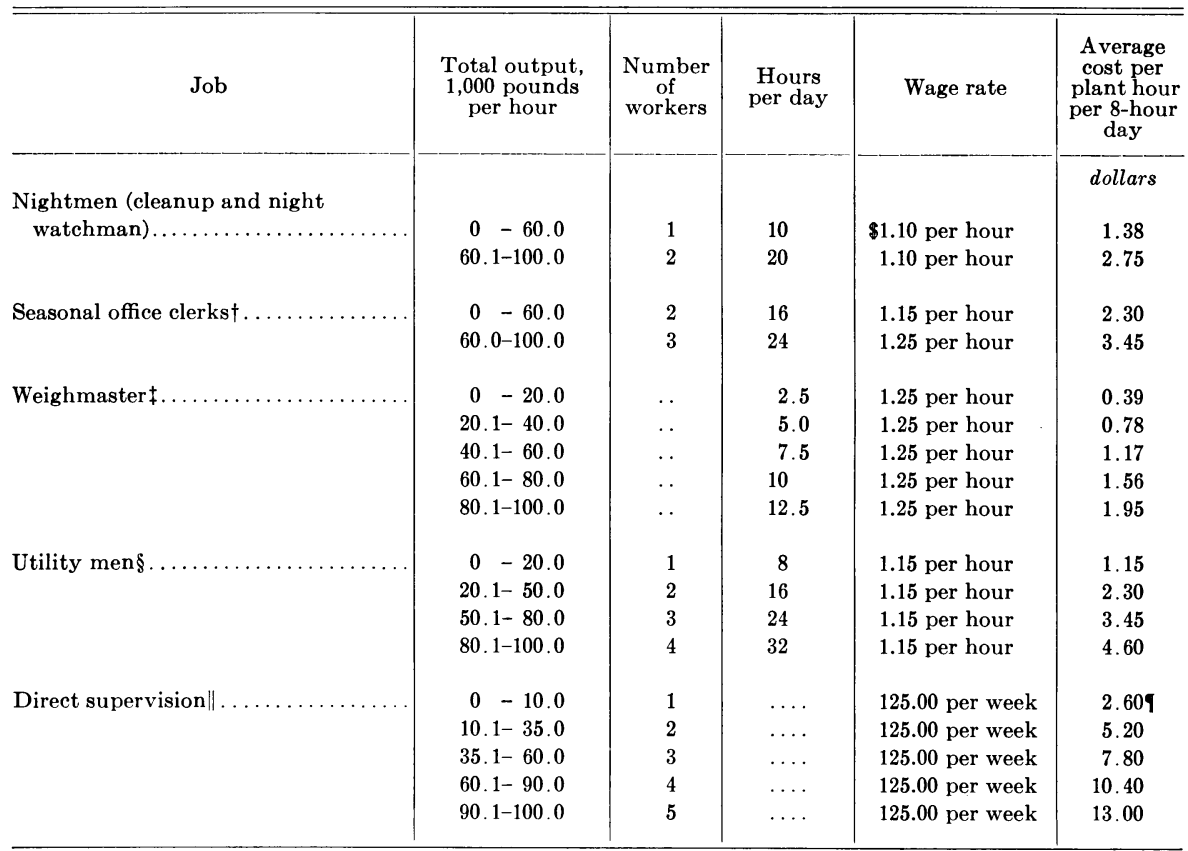

* 1950 wage rates.

$\dagger$ Does not include permanent bookkeepers and accountants.

$\ddagger$ For small plants this job may be performed by a trucker, an office clerk or someone similarly employed. Large plants may employ a specialized weighmaster. Hours per day are commonly determined by the policy with regard to hours during which incoming fruit is received.

$\S$ Covers jobs such as supplying wraps to packers, repairing damaged lidded boxes, and miscellaneous jobs as needed.

|| Includes general foremen, packing bosses, et cetera, but not plant managers.

Figured on the basis of a 6-day week.

Utility men perform jobs such as supplying packers with wraps, repairing damaged lidded boxes, oiling machinery, and other miscellaneous jobs as needed. They also provide a temporary "safety valve" in the event that some workers fail to report for work on any given day. Labor requirements and costs for these jobs are summarized in table 38 in relation to rates of total plant output. For convenience, costs of foremen are expressed on an hourly basis, assuming an eight-hour day, six-day week.

\section{Cost Component 12. Miscellaneous Equipment}

Figure $45 \mathrm{~A}$ shows the estimated investment replacement cost in relation to rates of capacity output for two groups of miscellaneous equipment

${ }^{68}$ Where only a sample of boxes is weighed out of each load, rather than the entire load on a truck scale, there may be some additional trucking (hand or fork) requirements. These are quite small, however, and have virtually no effect on the analysis. 

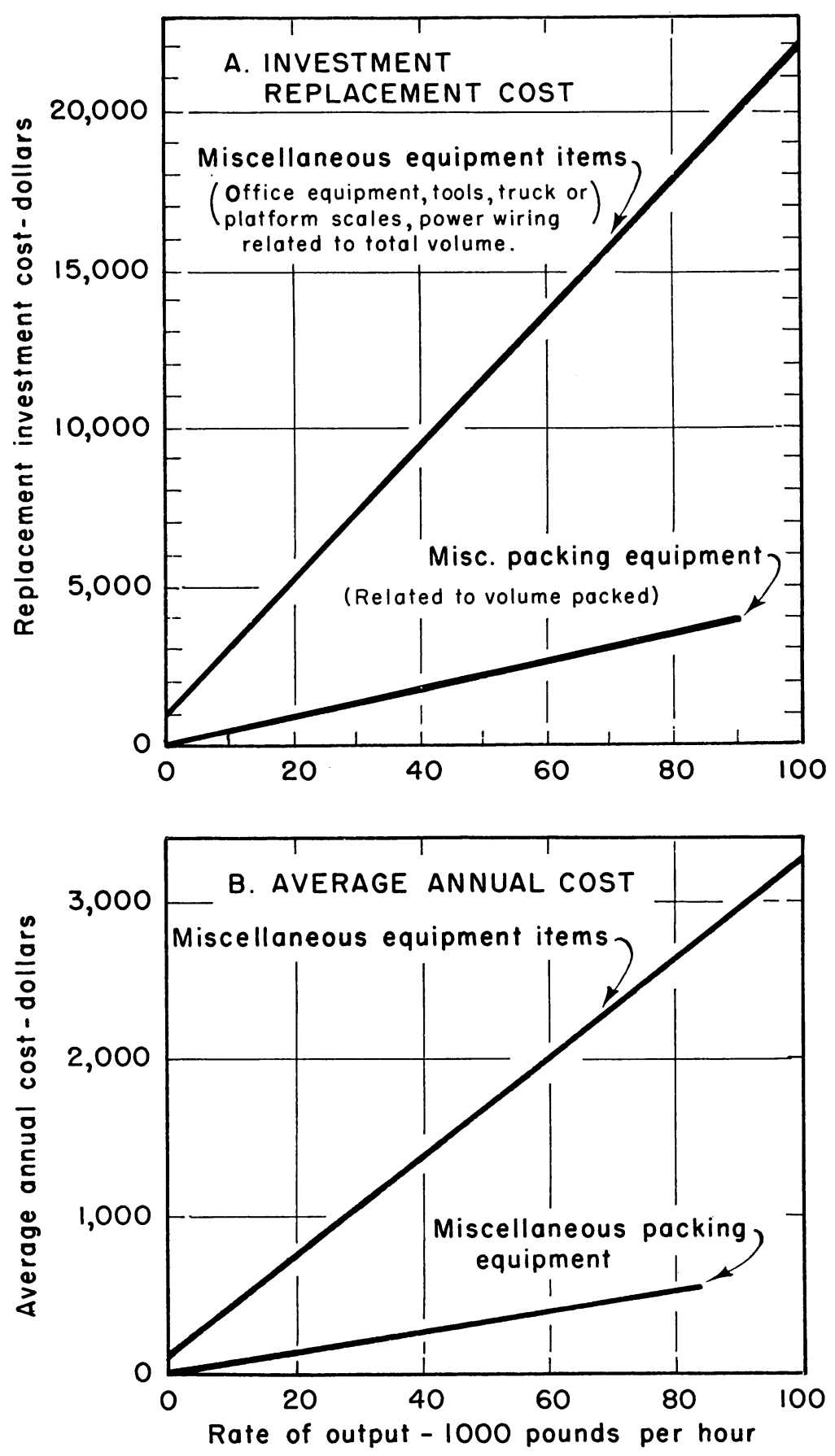

Fig. 45. Costs of miscellaneous equipment in relation to capacity rates of plant output. 
items. ${ }^{69}$ The first group includes items such as office equipment, miscellaneous tools, truck or platform scales, and power wiring. These costs are related to the capacity rates of total plant output. The second group includes miscellaneous items of packing equipment, such as packing stands and paper racks. These items might have been included in the costs for the packing stage, but this would not affect the relative costs of the alternative packing technologies and it is more convenient to consider them separately. The costs are related to the capacity rate of packed output.

Figure 45B converts the investment costs to an estimated average annual cost basis. These costs are based on charges of 14.7 per cent of the investment cost per year for depreciation, repairs, insurance, taxes, and interest. Prices are at the 1950 level.

\section{Cost Component 13. Office and Administrative Labor Costs}

Office and administrative costs consist of the salaries of permanent "office" employees-bookkeepers, accountants-and managers and field men. It is difficult to separate these costs in the plant records and in the actual operations. In some cases, managers may perform part of the bookkeeping duties and many workers who are ostensibly bookkeepers or clerks also act in minor administrative capacities. Therefore, the costs of these jobs are considered jointly in this analysis.

Logically, office and administrative costs are related to both size of plant and total volume per season-i.e., these costs are a joint function of both rates and hours of operation. However, to derive. a meaningful function in these joint terms proved to be impossible. First, data were available from only nine plants. Second, the information that was available was of uncertain content. Part of these costs reflects a selling function, but there is no way to tell which part of the costs is associated with production and which with selling. Farm supplies are also handled in some plants, and this again may be reflected in administrative costs. In other cases, managers' wages may include a share of profits and in all cases, of course, the market for managerial labor is highly imperfect. Finally, the variation in length of season among the plants for which data were available was fairly small, which further increased the difficulties of determining the effect of hours. Moreover, the level of office and administrative costs is probably influenced by the average length of several seasons rather than only one or two years.

Although the separate effects of rates and hours of operation could not be determined, plant capacity appears to be the more significant variable. The relationship between capacity and administrative and office costs, based on observations in nine plants, is illustrated in figure 46. The correlation coefficient is 0.89 . While the function shown in figure 46 lacks precision, it gives an approximation to the office and administrative cost relation for the range in hours of operation per season observed in the sample plants and considered in this analysis.

${ }^{9}$ These items are included in L. L. Sammet and I. F. Davis, Building and Equipment Costs, Apple and Pear Packing, Giannini Foundation of Agricultural Economies, Mimeographed Report No. 141, 1952, but the groupings are somewhat different. 


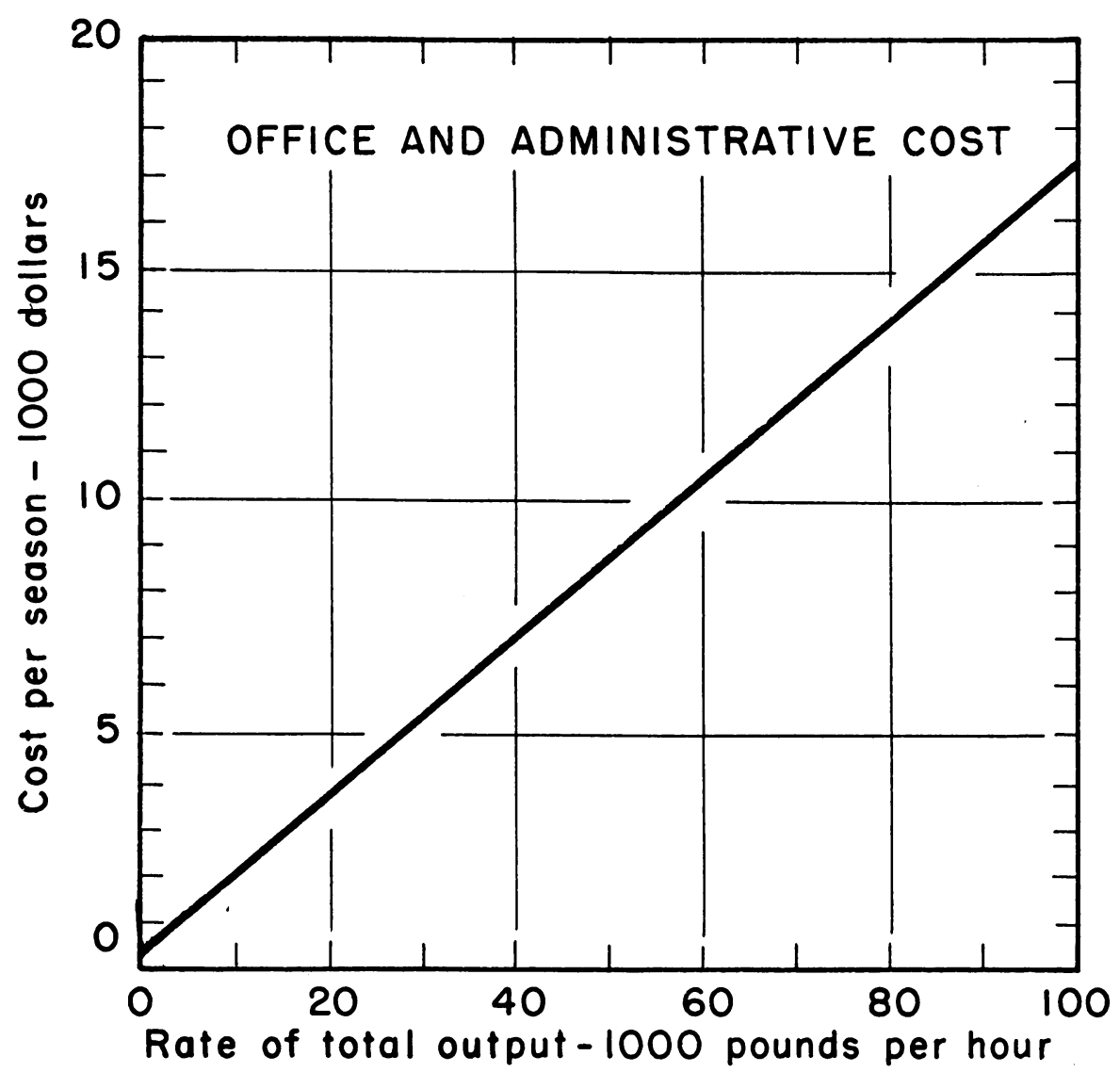

Fig. 46. Costs of office and administrative labor in relation to capacity rates of plant output.

\section{Cost Component 14. Building Costs $^{70}$}

The costs of plant buildings used in this study are based on engineering estimates of replacement costs for plants of various types of construction, using one of three types of packing equipment, and with differing capacity rates of output. In general, the procedure used to develop the costs was to determine floor space requirements in relation to rates of packed and total plant output and for the three commonly used types of packing equipmentbins, belts, and tubs. Floor space requirements were then related to building construction costs for several types of construction.

The relation between floor space requirements and capacity rates of packed and total output is illustrated in figure 47 . Figure 48 shows the relation between floor space and construction cost for several types of buildings. Although related to roofed area only, the construction costs indicated

${ }^{70}$ Material in this section is drawn from L. L. Sammet and I. F. Davis, op. cit. 

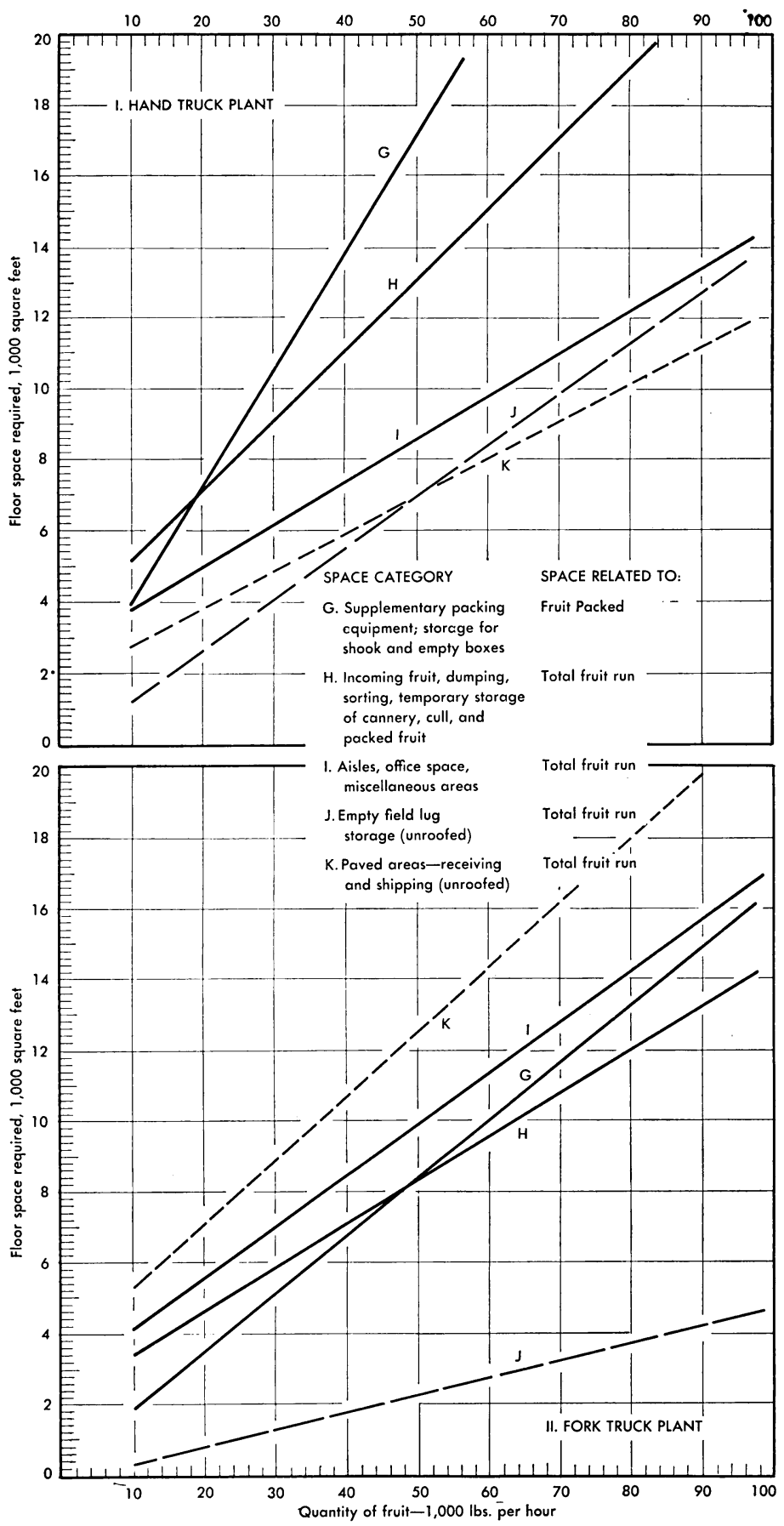

Fig. 47. Effect of capacity rate of plant operation on floor space requirements in hand-truck and fork-truck plants for packing apples and pears. 
include the cost of open storage and paved areas. The construction cost of a railroad siding is also included but not the cost of land.

The building replacement costs for hand-truck plants are based on a wood frame structure with a wood floor constructed at truck-bed height. Exterior walls are surfaced with a single layer of wood sheathing-except office spaces which have an interior finish. The clear height from the floor to the underside of the roof trusses is 12 feet. Roof spans are relatively short-30 to 40 feet. All spaces are roofed except the area for storage of empty field lugs which consists of an open platform.

The costs for fork truck plants are based on structures with concrete sidewalls and with the clear height to the underside of the trusses 18 feet throughout the building. ${ }^{71}$ A relatively long-span roof construction is employed-75 to 100 feet-to reduce the interference of the roof supports with the operation of the fork trucks. The floor of the plant consists of a concrete slab at ground level.

Total building investment replacement cost functions for each type of construction are summarized below. By combining the curves in figures 47 and 48 , the costs are expressed as functions of two variables- the capacity rate of packing and the capacity rate of total output. Separate equations are shown for plants using bin, belt, or tub packing equipment, reflecting the difference in floor space requirements for these types of equipment. The terms $V_{p}$ and $V_{t}$ refer to packed and total rates of plant output, respectively, measured in 1,000 pound units.

\section{Investment Replacement Cost Functions for Buildings}

1. Hand-truck plants

$$
\begin{aligned}
& \text { Bins } C=\$ 16,996+\$ 614 V_{p}+\$ 466 V_{t} \\
& \text { Belts } C=\$ 17,143+\$ 589 V_{p}+\$ 466 V_{t} \\
& \text { Tubs } C=\$ 17,584+\$ 656 V_{p}+\$ 466 V_{t}
\end{aligned}
$$

2. Fork-truck plants

$$
\begin{aligned}
& \text { Bins } C=\$ 22,485+\$ 568 V_{p}+\$ 604 V_{t} \\
& \text { Belts } C=\$ 22,712+\$ 529 V_{p}+\$ 604 V_{t} \\
& \text { Tubs } C=\$ 23,393+\$ 631 V_{p}+\$ 604 V_{t}
\end{aligned}
$$

These equations are converted to an average annual cost basis below. The conversion was accomplished by multiplying each function by a percentage representing the charges estimated to be appropriate for depreciation, repairs, insurance, taxes, and interest. These charges amounted to 10.5 per cent for hand-truck plants and 8.9 per cent for fork-truck plants. ${ }^{72}$

\footnotetext{
${ }^{71}$ See L. L. Sammet and I. F. Davis, op. cit., pp. 15-16, for a consideration of the costs for fork truck plants with wood sidewalls and with combination wood and concrete. Only the concrete structure was observed in use and it is the only type considered here. While it is somewhat higher in cost, the cost of fire insurance would be lower and the building could be more easily adapted to other uses-say, for a warehouse.

${ }^{72}$ Ibid., pp. 18-24, for more detail on the estimates of useful building life and on the annual charges.
} 


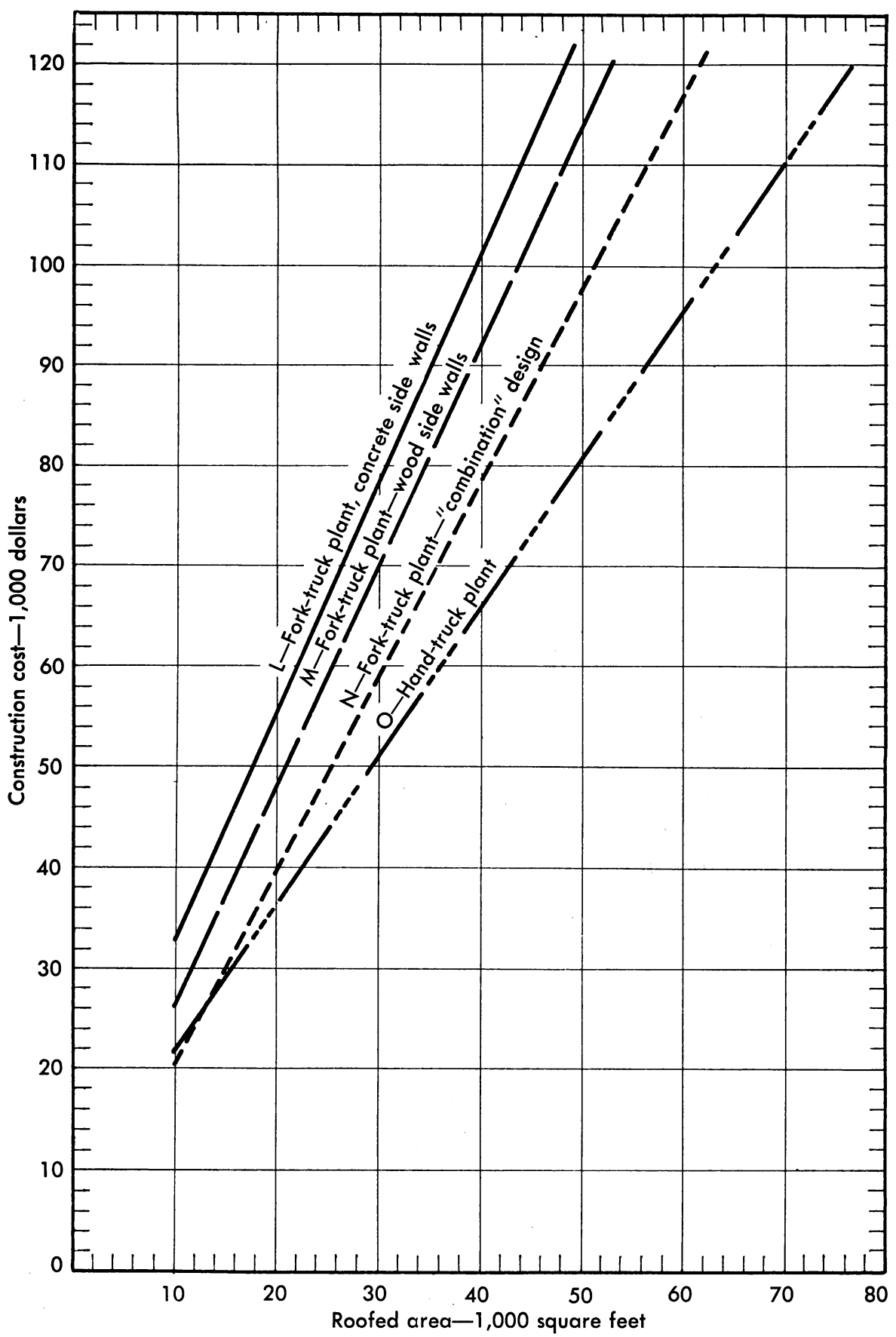

Fig. 48. Effect of size of building on packing house construction costs (1950 price level). 


\section{Average Annual Cost Functions for Buildings}

1. Hand-truck plants

Bins $C=\$ 1,785+\$ 64.5 V_{p}+\$ 48.9 V_{t}$

Belts $C=\$ 1,800+\$ 61.8 V_{p}+\$ 48.9 V_{t}$

Tubs $C=\$ 1,846+\$ 68.9 V_{p}+\$ 48.9 V_{t}$

2. Fork-truck plants

Bins $C=\$ 2,001+\$ 50.6 V_{p}+\$ 53.8 V_{t}$

Belts $C=\$ 2,021+\$ 47.1 V_{p}+\$ 53.8 V_{t}$

Tubs $C=\$ 2,082+\$ 56.2 V_{p}+\$ 53.8 V_{t}$

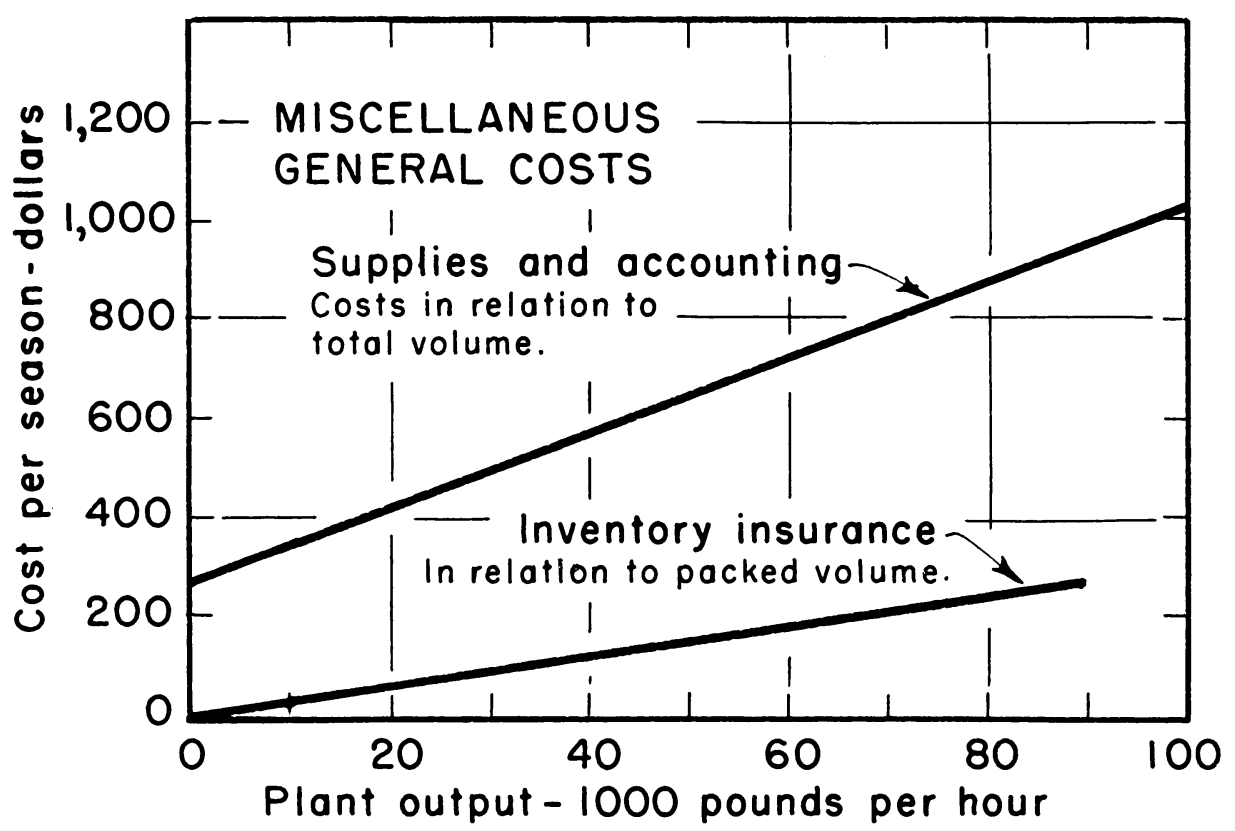

Fig. 49. Miscellaneous general costs in relation to capacity rates of plant output.

\section{Cost Component 15. Miscellaneous General Costs}

Included in this group of costs are items such as office and general janitorial and rest room supplies, legal and accounting expenses not covered by the office and administrative costs, and insurance on inventories of materials and supplies. Estimates of these costs, based on plant accounting records, are shown in figure 49 in relation to capacity rates of output. This is not strictly correct for office and general supplies since they, like office and administrative expenses, are related to both capacity and season volume. However, the data here were even thinner and more variable than for office and administrative expenses. Only five of the sample plants showed these items separately on their operating statements, and the year-to-year variation within plants is almost as large as the variation among plants. However, it was possible to derive an approximate relation which, because of 
the smallness of the cost item, is probably not far off in terms of absolute value. A similar situation existed for the other items in this group except that they appear to be related more closely to capacity alone. Although these estimates are unavoidably rough, they probably are not far off over the range in season hours considered in this analysis.

\section{Cost Component 16. Accounting to Growers for Fruit Received at the Packing House ${ }^{73}$}

Most packing houses handle fruit for a number of different growers. This creates problems and costs not encountered in plants servicing only a single grower, for a separate accounting must be made to each grower for the quantities of his fruit falling in each of the several grade classifications. To account accurately to each grower requires determination of the weight or count of fruit for each of these grades. Two methods are commonly used to obtain such information: (1) the separate-lot system where each producer's product is kept separate from all others as it is handled in the plant; and (2) the sampling system, where a small portion of each lot is selected and the distribution of the entire lot estimated from the proportions observed in the sample. With the sampling procedure, the fruit of different growers may be commingled in plant operations.

The Separate-lot System. With the separate-lot system the individual identity of each grower's product must be maintained until it is sorted, graded, sized, and the amount in each grade determined. To prevent the mixing of fruit from several growers, each lot is run separately with a delay or break in plant operations at the end of each lot. During this delay period, the amounts of product in each of the several classifications are determined and recorded. The delay also permits the packing of fruit remaining in the bins or packing belts so that the actual packout can be determined.

The direct cost of a separate-lot system includes the cost of weighing and tallying the amount of fruit in the several grades, but a more important effect is the impact of the plant delays or breaks on over-all output and efficiency. The interruption of the flow of fruit through the plant means that some workers will be completely idle during this period while others are forced to work at lowered rates of activity. And as a long-run consideration, this means that a greater amount of durable facilities is required to handle a given amount of fruit than would be required in the absence of these delays.

The determination of the cost of the separate-lot system may be viewed as consisting of three steps: first, a determination of the loss of time with this procedure; second, use of the idle time figure to determine the "realized" average hourly rate of output with the separate-lot system; and third, subtraction of the total costs for plants of given rates of output, and without separate accounting to growers, from the total cost of plants of the same rate of output with separate-lot procedures.

${ }^{73}$ For a more detailed discussion of this cost component, see B. C. French and R. G. Bressler, Economy and Accuracy in Accounting to Growers for Fruit Received at the Packing House, Giannini Foundation of Agricultural Economics, Mimeographed Report No. 149, June, 1953. 
The loss of effective working time depends on such factors as the size of plant in terms of "instantaneous" rates of output, the number of dumping units, the average size of lot for individual growers, and the length of the breaks-for-lot period. The working-time loss for a plant of any instantaneous capacity (rate of output without separate-lot delays) is determined by calculating the average number of lots run per hour per dumping unit and multiplying this figure by the average break time per lot. The number of dumping units depends, of course, on the methods of dumping and grading and on the size of the plant. Average lot size varies considerably from plant to plant, with 10,000 pounds appearing to be fairly typical. Break time averaged about three minutes per lot in the plants studied that used this procedure, although with efficient operation two minutes appear to be a more appropriate figure.

The amount of working time lost due to breaks-for-lots determines the average rate of output per hour that will be realized in a plant of any given instantaneous capacity. Without breaks-for-lots the instantaneous rate is also the realized rate. Total plant cost is determined by the instantaneous rate which, under a separate-lot system, is higher than the realized rate. Therefore, to achieve any given realized rate of output involves a higher plant cost with breaks-for-lots than without.

The Sampling System. The alternative to separate-lot systems is to use a sampling system which permits the fruit of all growers to be commingled in the handling and thus eliminates the need for breaks-for-lots. With any sampling system, the estimates of the proportions of fruit in each grade will be subject to some error because the distribution of grades in the small part of the fruit that is sampled may differ somewhat from the distribution of grades for all fruit delivered by the grower. The probable magnitude of such differences can be reduced by increasing the size of the sample for each grower, but this also increases the cost of the sampling procedure. Relations among sample size, accuracy, and total deliveries per grower are illustrated in figure $50 .^{74} \mathrm{In}$ deciding on the accuracy desired and in comparing the costs of sampling and separate-lot systems, each plant manager must balance the desire for increased accuracy against the cost of this accuracy. The specific evaluation of these considerations may be expected to vary among managers and, therefore, no single generally acceptable standard of accuracy can be established.

The costs of sample-grading include the costs for workers who collect, sort, weigh, tally, and transport the fruit that is sampled and the costs of sample grading equipment. ${ }^{75}$ The sampling equipment consists of items such as grading tables and seales for weighing the fruit. Mechanical sampling devices for sample selection, used in some plants, are not included here. $^{\text {78 }}$

Estimates of these costs, based on time studies and studies of plant rec-

${ }^{74}$ Details of how this chart was derived and additional charts and procedures for calculating accuracy directly in terms of money payments are given in French and Bressler, op. cit.

${ }^{75}$ Since the fruit that is sample-graded does not have to be run over the main graders, only part of the sample sorting labor has been treated as an added sampling cost.

${ }^{76}$ Ibid., p. 10 for a brief description of the nature of these devices. 
ords, are summarized in table 39. Two levels of equipment costs are indicated. For small plants-volume below 20,000 pounds per hour-a small grading table with space for one or two sorters is adequate. Larger plants or plants with a large volume of fruit sampled may require a larger table with room for three or four sorters and with power-driven belts. Labor inputs are expressed as a constant per thousand pounds of fruit sampled rather than as a "step" function since sampling hours usually are not re-

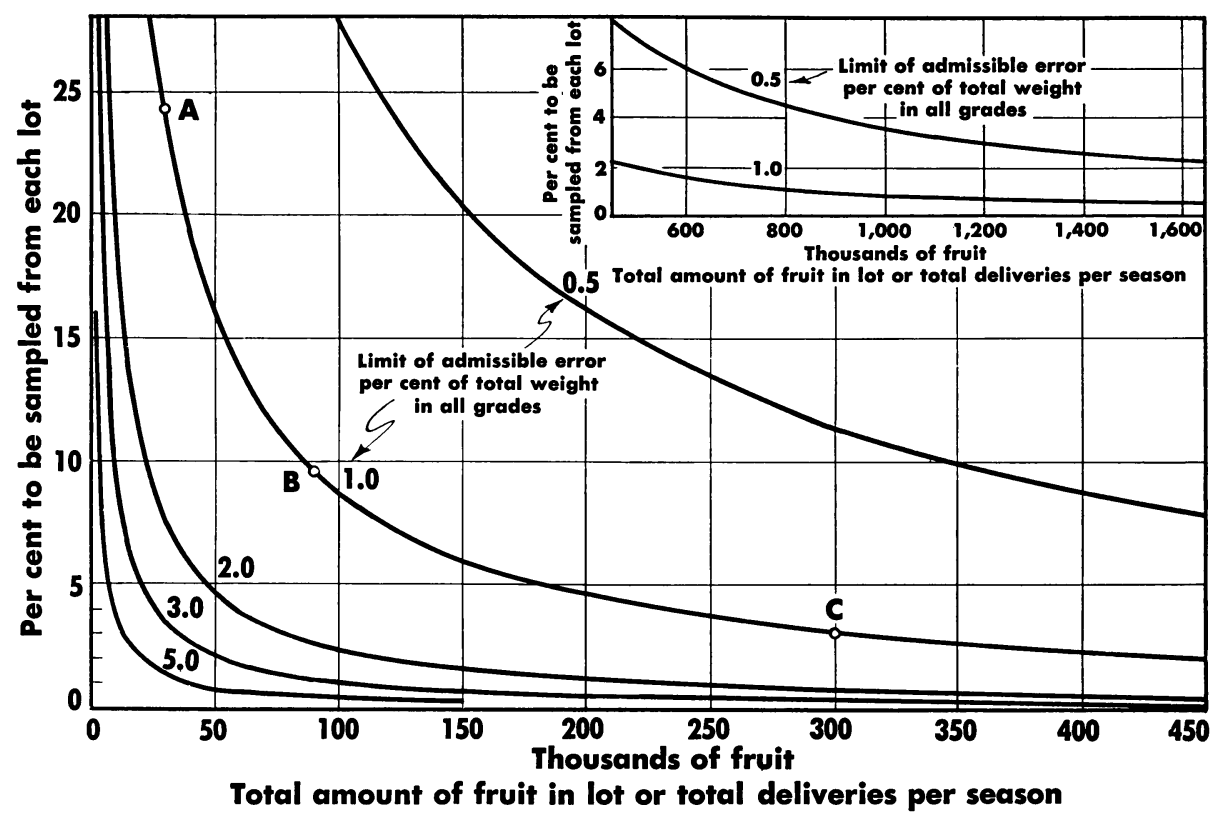

Fig. 50. Effect of the desired degree of accuracy and total quantity of fruit per lot or per season on the per cent to be sampled from each lot.

lated directly to rates of output but to total volume per day. Since sampling hours need not correspond exactly to plant hours, the physical labor inputs can be adjusted more closely to the actual volume sampled.

The costs given in table 39 represent only average annual costs of equipment and the labor cost per 1,000 pounds of fruit in the samples. Total costs of sample-grading depend on the quantity or per cent of fruit received that is sample-graded and this, in turn, depends on the desired degree of accuracy, the total volume handled per season in the packing house, and the distribution of the total deliveries among the individual growers. These factors vary from plant to plant so any single over-all statement of sampling costs is impossible.

For the plants included in this study, the estimated cost of the sampling system with a limit of admissible error of 1 per cent of the total weight of fruit for the average grower is, in all cases, less than the cost of the sepa- 
rate-lot systems-even where the break period is reduced to two minutes. If it is desired to limit the admissible error to one half of 1 per cent, the cost of sampling is sharply increased. However, even in this ease sampling costs are less than separate-lot costs in the majority of the plants studied.

It should be clear from the foregoing that the costs of these alternative accounting systems cannot be compared in general but must be evaluated in terms of the conditions in specific plants and in terms of the judgment of individual managers in balancing the costs and accuracy of the separatelot and sampling systems. ${ }^{77}$ For the percentage sample and resulting error

TABLE 39

ESTIMATED LABOR AND EQUIPMENT COSTS FOR SAMPLE GRADING

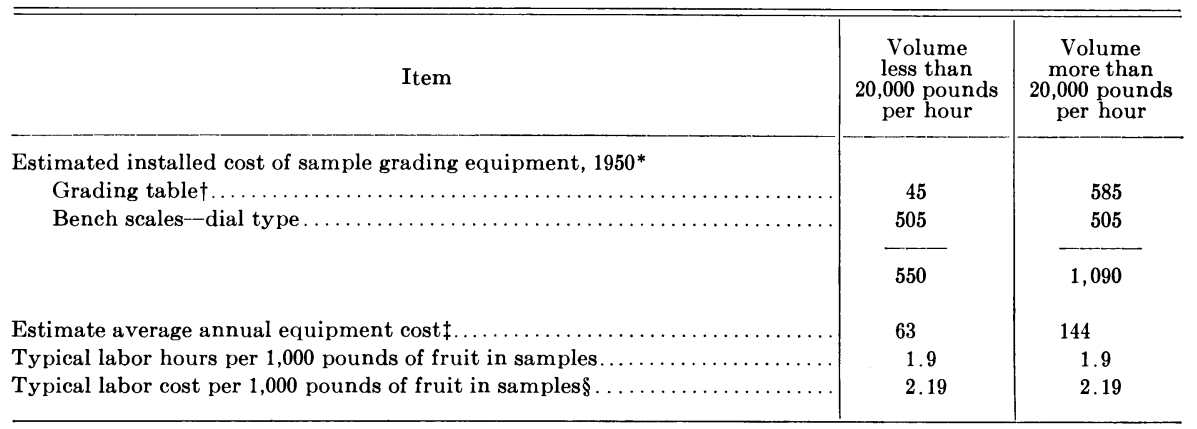

* Does not include costs of mechanical devices for sample selection.

† Table for small plants has capacity for two sorters. Table for larger plants has powered belts and capacity for four sample sorters.

$\ddagger$ Based on a standardized set of annual charges for depreciation, repairs, insurance, interest and taxes: grading tables, 14.7 per cent; scales, 10 per cent plus $\$ 6.75$ per year for repairs and maintenance. Since they are extremely small, operating costs and variable repairs are included in the fixed costs above.

$\S$ Based on typical average wage of $\$ 1.15$ per hour for sample grading labor.

range suggested above, the sampling system would prove more economical in most of the plants studied. ${ }^{78}$ This procedure will, therefore, be regarded as generally the more efficient, and the over-all cost functions developed in the following section will be appropriate for plants using sampling systems rather than separate-lot procedures. It will be assumed that 5 per cent of the fruit is sample-graded from each grower's lot. For the plants studied, this would give a limit of possible error in the estimates for the average grower of between $1 / 2$ and 1 per cent of the total weight of all fruit delivered during the season. ${ }^{7 n}$ With this assumption, sampling labor cost amounts to 11 cents per 1,000 pounds of total plant volume. In instances where the plant policy for grower relations does not permit the use of a sampling system, the accounting costs would usually be somewhat higher but in line with the costs indicated above.

${ }^{77}$ In order to reduce the break period between lots, certain short-cut procedures are often used to estimate the quantities of fruit and this leads to possible errors. A discussion of this problem is given in ibid., p. 2.

${ }^{78}$ Ibid., pp. $20-23$.

${ }^{79}$ Based on a probability of exceeding this limit once out of 20 times. 


\section{The Long-Run Cost Function}

The material in the preceding section provides a set of "building blocks" for constructing an estimate of the long-run cost or "planning" function for California pear packing plants. This function consists of an equation (or set of equations) which relates the total cost of pear packing with leastcost combinations of technologies to rates of plant output and length of operating season. The building blocks from which this function is constructed also can be used to estimate the short-run variable cost functions associated with any point on the long-run curve and to determine the combinations of technologies (and their cost functions) that appear most efficient for plants that must operate with various rates of output.

This section is concerned with the specific analytical procedures involved in combining the building blocks into an estimate of the long-run cost function and with interpretations of this function in the choice of technologies and the effects of rate of operation and length of season on operating costs.

\section{Simplifications and Specifications}

In order that the number of variables and variations to be considered may be reduced to manageable proportions the following simplifications are introduced.

(1) All packed fruit is assumed to be placed in standard boxes.

(2) No. 2 cannery and culls (subgrade fruit) are assumed never to exceed 20 per cent of the total volume. This is typical of the average situation in the plants studied, although larger proportions were noted on some days. As No. 1 cannery is packaged and transported in the same manner as No. 2 cannery and culls, this assumption influences only the costs of grading labor.

(3) Lidder operators are assumed paid by the hour. Typical piece rates result in a higher cost in most ranges, although in a few instances they might give a slightly lower total cost.

(4) All packed fruit is assumed to be loaded in railroad cars-none in trucks.

(5) The major portion of the packing boxes is assumed to be made during the season at regular time rates of pay. The boxmaking operation is assumed to be integrated so closely with box distribution that little or no rehandling in and out of temporary storage is required.

(6) Costs for miscellaneous labor, usually paid constant wages per day or per week, are converted to average hourly rates on the basis of an eight-hour day and a six-day week. These costs are shown in table 38 in the previous section.

In all cases other than those mentioned above, the costs and operations are as specified in the previous section. As developed initially, the long-run cost function will apply to plants that operate at constant rates of output for some given number of hours per season. The effects of operating with variable rates of output and proportions of products are considered in following sections.

\section{Combining the Building Blocks}

The development or synthesis of a long-run cost function from the various stage cost functions-combining the building blocks - is primarily a simple case of addition. It is complicated somewhat, however, by the alternative technologies that are available at many stages and by the necessity of finding the combination of technologies at each rate of output that gives a lower 
total cost than any other combination. Where stages are independent, the least cost technologies may be selected stage by stage and costs representing efficient technologies for each rate of output aggregated into a total cost function. If stages are jointly related-i.e., the technology used at one stage determines or influences the cost of a technology at another stage-the joint technical stages must be redefined into a single economic stage for purposes of cost comparisons. The number of possible combinations of methods to be considered then increases as the product of the number of alternative technologies considered at each stage. Even with only two or three joint stages and a few alternatives at each stage, this can run into a fairly large number of possibilities and so an enormous number of calculations-particularly with discontinuous cost functions.

Costs for some of the joint packing house stages were combined into a single economic stage in the presentation of performance standards in the previous section. Lidding, stamping, and check-weighing were combined as were dumping and grading. In addition, in selecting efficient technologies, attention must be given to the fact that building costs are influenced by the type of packing equipment employed and by the type of transportation equipment used. The grading-dumping method used influences transportation costs and this also is considered in the selection of the least-cost methods of grading, dumping, and transportation.

To compare the costs of alternative technologies requires that the hours of operation per season be specified, as some of the costs remain fixed regardless of the length of season and others vary with hours of operation. The technology or combination of technologies that provides the least cost may differ with the length of season since the various technologies commonly employ fixed and variable factors in different proportions. The first step in the development of the planning function, then, is to convert cost functions for all of the plant segments to a season basis. Costs for four lengths of season-100, 200, 300, and 400 hours-are given in Appendix A for each technology used in the several stages at which alternatives are available. The lengths of season considered encompass the range in operating season observed among the plants studied. The season costs are expressed relative to hourly rates of output and the stage technologies which give the least aggregate cost are then selected for each rate of output and length of season.

The selection process is illustrated specifically in table 40 (taken from Appendix A) which gives the costs for the independent combined lidding, stamping, and check-weighing operation. Least costs for each rate of output and length of season are underlined. In several instances, there are "jumps" back from the high-speed machine to the stitcher or low-speed lidder. The jumps arise because of the "step" type discontinuities in these functions which result in overlapping corners in a very few ranges. However, the exact points at which these steps occur are only approximate and as a practical matter the overlapping corners or jumps might be ignored. Thus, with a 100-hour season, lidder $\mathrm{C}$ might be used for all plants with capacities greater than 22,000 pounds per hour rather than jumping back to machine A for outputs from 48.5 to 53.2 thousand pounds per hour. The cost differences for the two machines are very small over this range. 
The costs italicized in table 40 and their corresponding technologies are incorporated in the total cost function. For some stages only one technology is available, and there is no problem of selection, but costs for these stages are also converted to a season basis so that all costs will be expressed uniformly for purposes of aggregation.

The next step is to aggregate the stage and other elemental cost functions into an over-all function. To simplify the aggregation process, total costs have been calculated for a number of specific but closely spaced rates of

TABLE 40

TOTAL SEASON COSTS IN RELATION TO RATES OF PACKED OUTPUT FOR THE LID-STAMP-CHECKWEIGH OPERATION

\begin{tabular}{|c|c|c|c|c|c|c|c|c|c|c|c|c|}
\hline \multirow{4}{*}{$\begin{array}{l}\text { Rate of packed } \\
\text { output }\end{array}$} & \multicolumn{12}{|c|}{ Total cost per season } \\
\hline & \multicolumn{3}{|c|}{100 hours per season } & \multicolumn{3}{|c|}{200 hours per season } & \multicolumn{3}{|c|}{300 hours per season } & \multicolumn{3}{|c|}{400 hours per season } \\
\hline & A & B & $\mathrm{C}$ & A & B & $\mathrm{C}$ & A & $\mathrm{B}$ & $\mathrm{C}$ & A & B & $\mathrm{C}$ \\
\hline & $\begin{array}{c}\text { Stitch- } \\
\text { er }\end{array}$ & $\begin{array}{l}\text { Low } \\
\text { speed }\end{array}$ & $\begin{array}{l}\text { High } \\
\text { speed }\end{array}$ & $\begin{array}{c}\text { Stitch- } \\
\text { er }\end{array}$ & $\begin{array}{l}\text { Low } \\
\text { speed }\end{array}$ & $\begin{array}{l}\text { High } \\
\text { speed }\end{array}$ & $\begin{array}{c}\text { Stitch- } \\
\text { er }\end{array}$ & $\begin{array}{l}\text { Low } \\
\text { speed }\end{array}$ & $\begin{array}{l}\text { High } \\
\text { speed }\end{array}$ & $\begin{array}{l}\text { Stitch- } \\
\text { er }\end{array}$ & $\begin{array}{c}\text { Low } \\
\text { speed }\end{array}$ & $\begin{array}{l}\text { High } \\
\text { speed }\end{array}$ \\
\hline 1,000 pounds & \multicolumn{12}{|c|}{ dollars } \\
\hline $0-10.5$. & 491 & 563 & 742 & 747 & 821 & 989 & 1,003 & 1,079 & 1,236 & 1,259 & 1,337 & 1,483 \\
\hline $10.6-16.8 \ldots$ & 596 & 668 & 847 & 957 & 1,031 & 1,199 & 1,318 & 1,394 & 1,551 & 1,679 & 1,757 & 1,903 \\
\hline $16.9-17.7$. & 701 & 773 & 847 & 1,167 & 1,241 & 1,199 & 1,633 & 1,709 & 1,551 & 2,099 & 2,177 & 1,903 \\
\hline $17.8-21.1$ & 982 & 773 & 847 & 1,494 & 1,241 & 1,199 & 2,006 & 1,709 & 1,551 & 2,518 & 2,177 & 1,903 \\
\hline $21.2-22.0$. & 1,192 & 773 & 952 & 1,914 & 1,241 & 1,409 & 2,636 & 1,709 & 1,866 & 3,358 & $2,17 \gamma$ & 2,323 \\
\hline $22.1-25.9 \ldots$ & 1,192 & 1,336 & 952 & 1,914 & 2,062 & 1,409 & 2,636 & 2,788 & 1,866 & 3,358 & 3,514 & 2,323 \\
\hline $26.0-33.6$. & 1,192 & 1,336 & 1,062 & 1,914 & 2,062 & 1,624 & 2,636 & 2,788 & 2,186 & 3,358 & 3,514 & 2,748 \\
\hline $33.7-35.5 \ldots$ & 1,402 & 1,546 & 1,190 & 2,334 & 2,482 & 1,857 & 3,266 & 3,418 & 2,524 & 4,198 & 4,354 & 3,191 \\
\hline $35.6-42.0$. & 1,788 & 1,546 & 1,190 & 2,871 & 2,482 & 1,857 & 3,954 & 3,418 & 2,524 & 5,037 & 4,354 & 3,191 \\
\hline $42.1-44.1$. & 1,788 & 1,546 & 1,295 & 2,871 & 2,482 & 2,067 & 3,954 & 3,418 & 2,839 & 5,037 & 4,354 & 3,611 \\
\hline $44.2-48.4$ & 1,788 & 2,004 & 1,295 & 2,871 & 3,093 & 2,067 & 3,954 & 4,182 & 2,839 & 5,037 & 5,271 & 3,611 \\
\hline $48.5-50.4$ & 1,788 & 2,004 & 1,912 & 2,871 & 3,093 & 2,836 & 3,954 & 4,182 & 3,760 & 5,037 & 5,271 & 4,684 \\
\hline $50.5-53.2$. & 2,103 & 2,319 & 2,127 & 3,501 & 3,723 & 3,261 & 4,899 & 5,127 & 4,395 & 6,297 & 6,531 & 5,529 \\
\hline $53.3-66.2 \ldots \ldots$ & 2,384 & 2,319 & 2,127 & 3,828 & 3,723 & 3,261 & 5,272 & 5,127 & 4,395 & 6,716 & 6,531 & 5,529 \\
\hline $66.3-67.2 \ldots \ldots \ldots$ & 2,384 & 2,672 & 2,127 & 3,828 & 4,124 & 3,261 & 5,272 & 5,556 & 4,395 & 6,716 & 7,028 & 5,529 \\
\hline $67.3-71.1 \ldots \ldots \ldots$ & 2,806 & 2,672 & 2,344 & 4,672 & 4,124 & 3,688 & 6,538 & 5,556 & 5,032 & 8,404 & 7,028 & 6,376 \\
\hline
\end{tabular}

output rather than for the entire range of possible rates. In the final analysis, a smooth function is fitted to these points.

There are three reasons for following this procedure. First, it greatly reduces the required number of calculations. With discontinuous inputoutput relations for nearly every stage, it is clear that the aggregate function would contain a very large number of "steps" or breaks which would be quite cumbersome to calculate. Second, only a limited number of discrete equipment sizes were considered for some stages. For example, only four sizes of grading table were included in the analysis. But in the long run, units of other sizes presumably could be constructed. This would tend to reduce the magnitude of some of the discontinuities, and the discontinuous function would approach a continuous curve. Smoothing the discontinuities rather than dealing with units of many sizes may tend to impart a slight upward bias to the cost curve because of cutting off the lower corners of 
the "steps." However, this allows for some slight excess capacity to adjust to changing proportions of various grades of fruit, the latter being unavoidable in most plants. Finally, the points at which these discontinuities occur are only approximations and smoothing tends to average out these estimates.

Table 41 illustrates the procedures involved and the work sheet used in the aggregation of the season costs into a total cost function. The material in the table applies to a season of 200 hours and to a situation where 70 per cent of the fruit is packed and the remainder consists of cannery and cull fruit. It is assumed that standard boxes are used for packed fruit and that 10 per cent of the total is No. 1 cannery produce. The various columns give, for each of the plant elements described previously, the total season cost for specific rates of total output ranging from 10,000 to 100,000 pounds of pears per hour. Total costs are entered at the bottom of the table. Packing and carloading material costs are not included but would be constant per unit for all output rates. The footnotes for a number of the columns indicate the particular technology represented by the cost figures. These are the technologies which in combination with all other technologies at other stages give the least total cost of operation.

Computations similar to those in table 41 were carried out for other lengths of season and for other proportions of packed and cannery fruit-90, 80, 60 , and 50 per cent packed. For brevity, the other detailed tables are omitted. However, the total costs computed by these procedures for several proportions packed and for four lengths of season are summarized in table 42.

These costs are plotted against total rates of output in figures 51, 52, 53, 54 , and 55. The points fall almost perfectly in a series of straight lines. This linearity may be in part "built in" through the predominantly linear estimates of the elemental cost relations and thus comes as no great surprise. Elements of slight cost curvilinearity in some ranges such as were noted on a per table basis for the grading operation are lost in the aggregate function. Although the total cost curve is actually discontinuous, it would appear that the smooth linear functions that are drawn to these points give very good approximations to the discontinuous functions.

Equations were computed for each of these curves and consistent linear relationships were noted among the coefficients of these functions and the length of season and the proportions packed. This suggested that the 20 separate equations might be formed into a single general function that would be an even more convenient and useful expression and which at the same time would depart little from the original functions.

The graphic equation established the form of the long-run total cost function, and a final approximation was obtained by mathematically fitting this type of function to the calculated total cost-output observations given in table 42. The resulting mathematically fitted equation which conforms very closely with the graphic function shown in figures 51 to 55 is as follows:

$$
C=\$ 2,781+\$ 16 H+\$ 437 V_{p}+\$ 320 V_{c}+\$ 5.22 V_{p} H+\$ 1.56 V_{c} H
$$

where $C$ is the total cost per season, $V_{p}$ is the volume packed per hour in 1,000 pounds, $V_{c}$ is the volume of cannery and cull fruit in 1,000 pounds per hour, and $H$ represents hours of operation per season. The (corrected) 


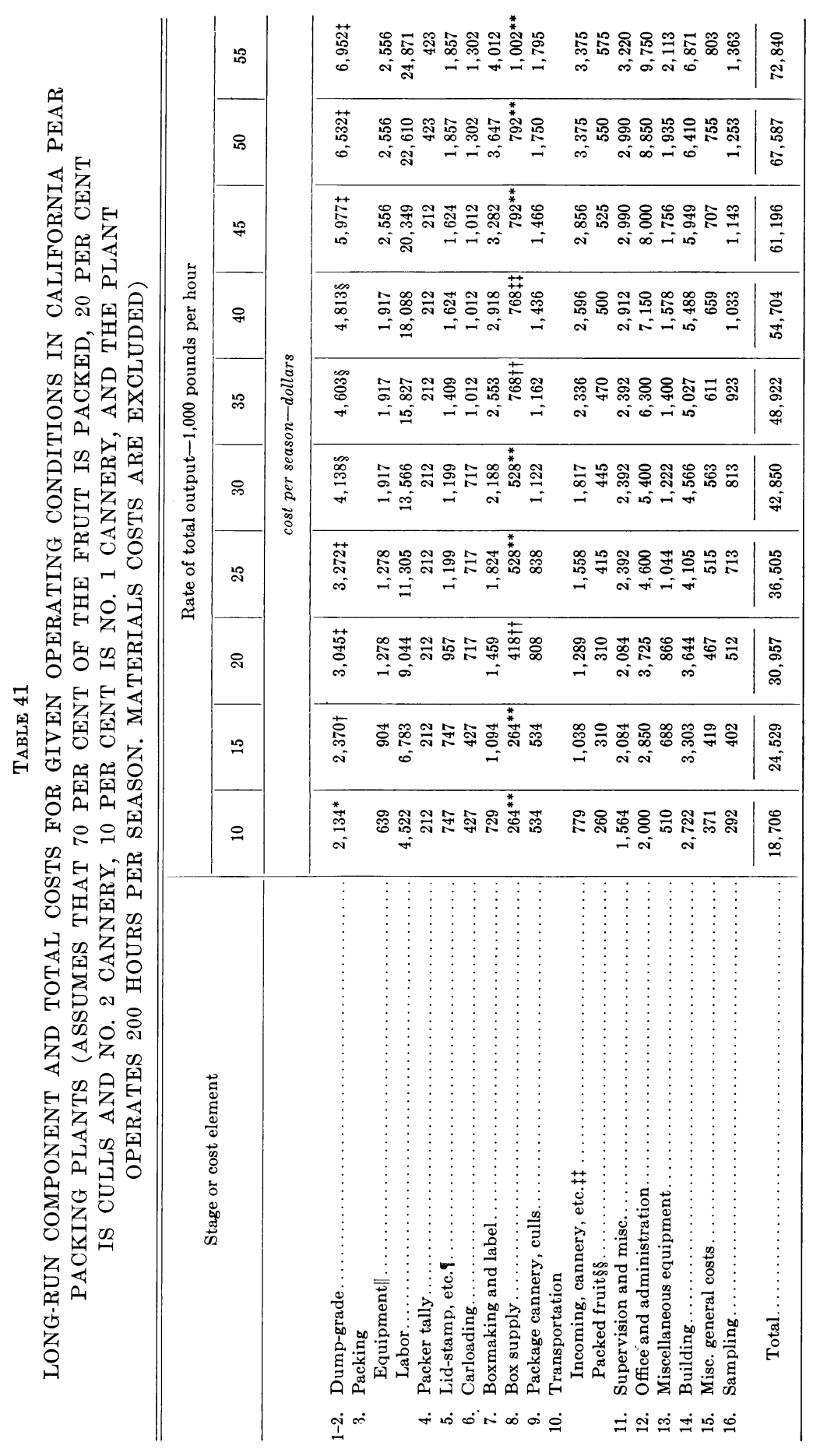




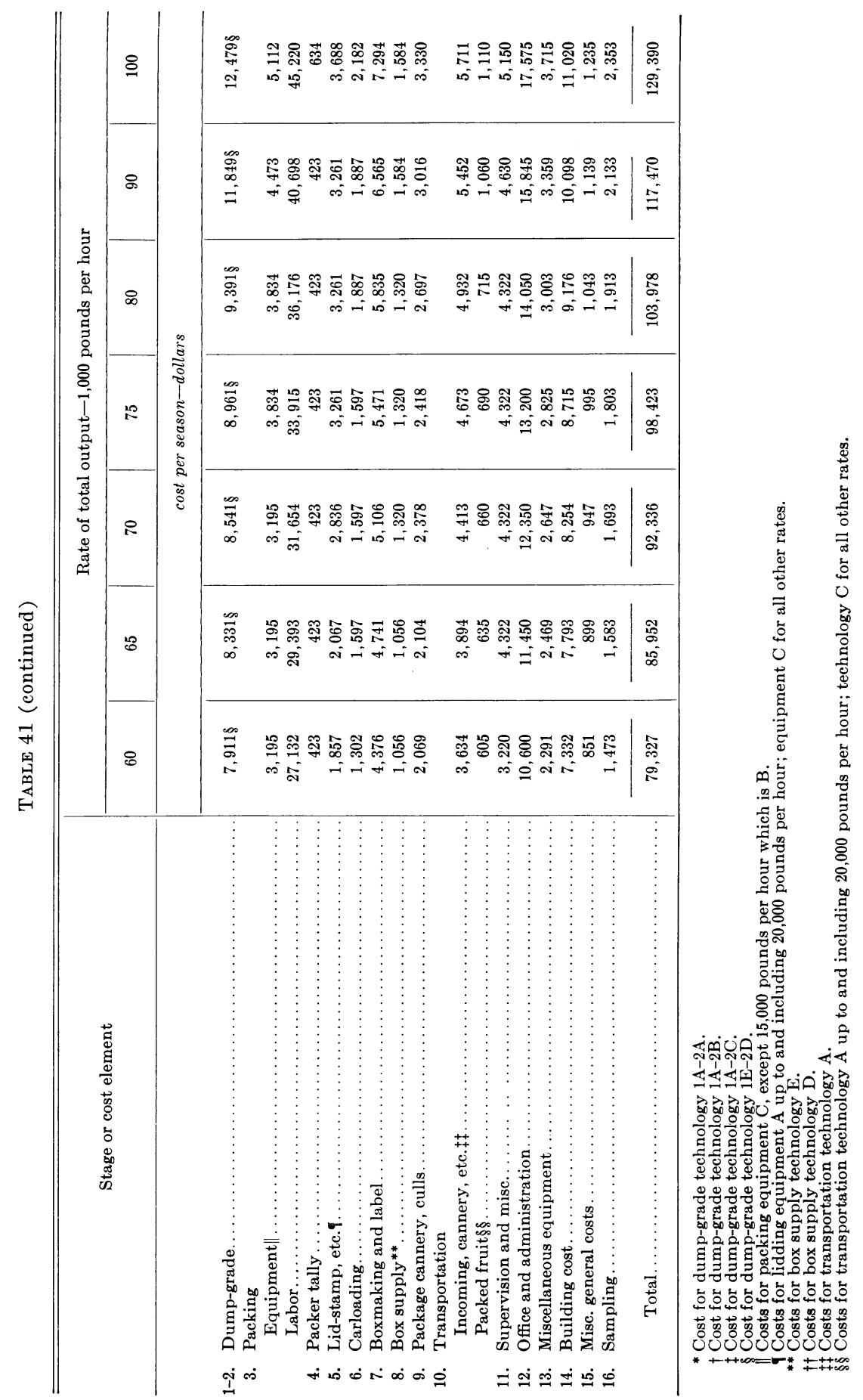


TABLE 42

LONG-RUN TOTAL COSTS IN RELATION TO RATES OF TOTAL OUTPUT, RATES OF PACKED OUTPUT, AND HOURS

OF OPERATION PER SEASON*

\begin{tabular}{|c|c|c|c|c|c|}
\hline \multirow{3}{*}{$\begin{array}{l}\text { Total volume } \\
\text { per hour } \\
\left(V_{t}\right)\end{array}$} & \multirow{3}{*}{$\begin{array}{c}\text { Packed volume } \\
\text { per hour } \\
\left(V_{p}\right)\end{array}$} & \multicolumn{4}{|c|}{ Total cost per season (C) (in thousands of dollars) } \\
\hline & & \multicolumn{4}{|c|}{ Hours of operation per season } \\
\hline & & 100 & 200 & 300 & 400 \\
\hline 1,000 pounds & 1,000 pounds & \multicolumn{4}{|c|}{90 per cent packed $\dagger$} \\
\hline 10 & 9 & 13.4 & 20.1 & 26.7 & 33.3 \\
\hline 15 & 13.5 & 18.1 & 27.5 & 36.7 & 45.7 \\
\hline 20 & 18 & 22.8 & 34.1 & 45.3 & 56.5 \\
\hline 25 & 22.5 & 27.0 & 41.1 & 54.9 & 68.5 \\
\hline 30 & 27 & 32.0 & 48.0 & 63.8 & 79.7 \\
\hline 35 & 31.5 & 35.7 & 54.5 & 72.6 & 90.7 \\
\hline 40 & 36 & 40.6 & 61.6 & 82.2 & 102.9 \\
\hline 45 & 40.5 & 44.6 & 68.9 & 92.3 & 115.5 \\
\hline 50 & 45 & 49.1 & 75.3 & 101.0 & 126.2 \\
\hline 55 & 49.5 & 54.2 & 82.5 & 110.7 & 137.6 \\
\hline 60 & 54 & 59.3 & 90.4 & 120.9 & 151.9 \\
\hline 65 & 58.5 & 64.1 & 97.1 & 130.2 & 163.1 \\
\hline 70 & 63 & 68.0 & 104.2 & 139.6 & 175.0 \\
\hline 75 & 67.5 & 72.4 & 110.5 & 148.3 & 187.0 \\
\hline \multirow[t]{2}{*}{80} & 72 & 76.8 & 117.4 & 157.3 & 197.3 \\
\hline & & \multicolumn{4}{|c|}{80 per cent packed $\dagger$} \\
\hline 10 & 8 & 13.0 & 19.3 & 25.5 & 31.7 \\
\hline 15 & 12 & 17.6 & 26.6 & 35.2 & 43.8 \\
\hline 20 & 16 & 21.4 & 32.3 & 42.8 & 53.2 \\
\hline 25 & 20 & 25.7 & 38.9 & 51.5 & 64.0 \\
\hline 30 & 24 & 30.3 & 45.8 & 60.3 & 75.5 \\
\hline 35 & 28 & 34.4 & 51.4 & 68.0 & 85.2 \\
\hline 40 & 32 & 38.4 & 58.1 & 77.0 & 96.5 \\
\hline 45 & 36 & 43.1 & 65.5 & 87.3 & 109.2 \\
\hline 50 & 40 & 46.8 & 71.8 & 95.1 & 118.9 \\
\hline 55 & 44 & 51.2 & 77.7 & 103.7 & 129.1 \\
\hline 60 & 48 & 55.8 & 84.4 & 112.3 & 140.9 \\
\hline 65 & 52 & 61.2 & 92.8 & 123.5 & 154.3 \\
\hline 70 & 56 & 64.8 & 98.3 & 131.0 & 165.0 \\
\hline 75 & 60 & 69.0 & 104.7 & 139.3 & 175.1 \\
\hline 80 & 64 & 73.1 & 110.9 & 148.0 & 185.3 \\
\hline \multirow[t]{2}{*}{90} & 72 & 82.1 & 124.9 & 166.8 & 208.9 \\
\hline & & \multicolumn{4}{|c|}{70 per cent packed $\dagger$} \\
\hline 10 & 7 & 12.6 & 18.7 & 24.6 & 30.5 \\
\hline 15 & 10.5 & 16.5 & 24.5 & 32.3 & 40.0 \\
\hline 20 & 14 & 20.5 & 30.8 & 40.8 & 50.6 \\
\hline 25 & 17.5 & 24.9 & 36.5 & 48.2 & 60.4 \\
\hline 30 & 21 & 28.6 & 42.8 & 56.4 & 70.0 \\
\hline 35 & 24.5 & 33.1 & 48.9 & 64.3 & 80.3 \\
\hline 40 & 28 & 36.8 & 54.7 & 72.5 & 90.3 \\
\hline
\end{tabular}

* 1950 price level. 
TABLE 42 (continued)

\begin{tabular}{|c|c|c|c|c|c|}
\hline \multirow{3}{*}{$\begin{array}{l}\text { Total volume } \\
\text { per hour } \\
\left(V_{t}\right)\end{array}$} & \multirow{3}{*}{$\begin{array}{l}\text { Packed volume } \\
\text { per hour } \\
\left(V_{p}\right)\end{array}$} & \multicolumn{4}{|c|}{ Total cost per season (C) (in thousands of dollars) } \\
\hline & & \multicolumn{4}{|c|}{ Hours of operation per season } \\
\hline & & 100 & 200 & 300 & 400 \\
\hline 1,000 pounds & 1,000 pounds & \multicolumn{4}{|c|}{70 per cent packed $\dagger$} \\
\hline 45 & 31.5 & 40.4 & 61.2 & 81.3 & 101.5 \\
\hline 50 & 35 & 44.8 & 67.2 & 89.6 & 111.0 \\
\hline 55 & 38.5 & 48.5 & 72.8 & 97.0 & 120.9 \\
\hline 60 & 42 & 53.0 & 79.3 & 105.2 & 131.2 \\
\hline 65 & 45.5 & 57.2 & 85.9 & 114.3 & 142.3 \\
\hline 70 & 49 & 61.9 & 92.3 & 122.8 & 153.5 \\
\hline 75 & 52.5 & 65.4 & 98.4 & 130.8 & 163.3 \\
\hline 80 & 56 & 69.1 & 104.0 & 138.3 & 173.2 \\
\hline 90 & 63 & 77.6 & 117.5 & 156.2 & 194.4 \\
\hline \multirow[t]{2}{*}{100} & 70 & 85.4 & 129.4 & 172.5 & 215.1 \\
\hline & & \multicolumn{4}{|c|}{60 per cent packed $\ddagger$} \\
\hline 10 & 6 & 12.1 & 17.9 & 23.4 & 28.9 \\
\hline 15 & 9 & 16.0 & 23.1 & 30.4 & 37.8 \\
\hline 20 & 12 & 19.7 & 29.3 & 38.3 & 47.5 \\
\hline 25 & 15 & 23.3 & 34.8 & 45.6 & 56.5 \\
\hline 30 & 18 & 27.6 & 40.3 & 53.0 & 65.7 \\
\hline 35 & 21 & 30.8 & 45.6 & 59.8 & 74.1 \\
\hline 40 & 24 & 35.1 & 51.5 & 67.8 & 84.1 \\
\hline 45 & 27 & 38.8 & 57.7 & 76.4 & 95.1 \\
\hline 50 & 30 & 42.0 & 63.0 & 83.2 & 103.4 \\
\hline 55 & 33 & 46.1 & 69.2 & 91.0 & 112.2 \\
\hline 60 & 36 & 50.4 & 74.5 & 98.4 & 122.0 \\
\hline 65 & 39 & 54.0 & 80.3 & 106.2 & 132.6 \\
\hline 70 & 42 & 57.7 & 85.9 & 113.6 & 141.3 \\
\hline 75 & 45 & 61.2 & 91.3 & 120.9 & 150.2 \\
\hline 80 & 48 & 64.8 & 96.2 & 127.9 & 158.7 \\
\hline 90 & 54 & 73.7 & 110.0 & 145.5 & 181.4 \\
\hline \multirow[t]{2}{*}{100} & 60 & 80.6 & 120.8 & 159.6 & 197.5 \\
\hline & & \multicolumn{4}{|c|}{50 per cent packed $\ddagger$} \\
\hline 10 & 5 & 11.7 & 17.1 & 22.0 & 27.4 \\
\hline 15 & 7.5 & 14.9 & 21.9 & 28.4 & 35.4 \\
\hline 20 & 10 & 18.7 & 27.4 & 35.6 & 43.8 \\
\hline 25 & 12.5 & 22.2 & 32.8 & 43.0 & 53.0 \\
\hline 30 & 15 & 25.8 & 37.8 & 49.4 & 61.0 \\
\hline 35 & 17.5 & 29.4 & 42.6 & 55.8 & 68.9 \\
\hline 40 & 20 & 32.7 & 48.0 & 62.8 & 77.6 \\
\hline 45 & 22.5 & 36.4 & 54.1 & 71.2 & 87.9 \\
\hline 50 & 25 & 40.1 & 58.9 & 77.1 & 95.6 \\
\hline 55 & 27.5 & 43.4 & 63.9 & 84.2 & 103.3 \\
\hline 60 & 30 & 47.2 & 69.5 & 91.0 & 111.9 \\
\hline 65 & 32.5 & 51.4 & 75.4 & 99.1 & 123.0 \\
\hline 70 & 35 & 54.5 & 80.1 & 105.4 & 129.3 \\
\hline 75 & 37.5 & 57.7 & 84.8 & 111.6 & 139.0 \\
\hline 80 & 40 & 60.9 & 89.9 & 118.3 & 146.5 \\
\hline 90 & 45 & 68.8 & 101.7 & 133.8 & 165.6 \\
\hline 100 & 50 & 76.4 & 112.6 & 148.0 & 183.2 \\
\hline
\end{tabular}

† Balance culls and second-grade cannery fruit.

$\ddagger 20$ per cent second-grade cannery and culls, balance first-grade cannery fruit. 


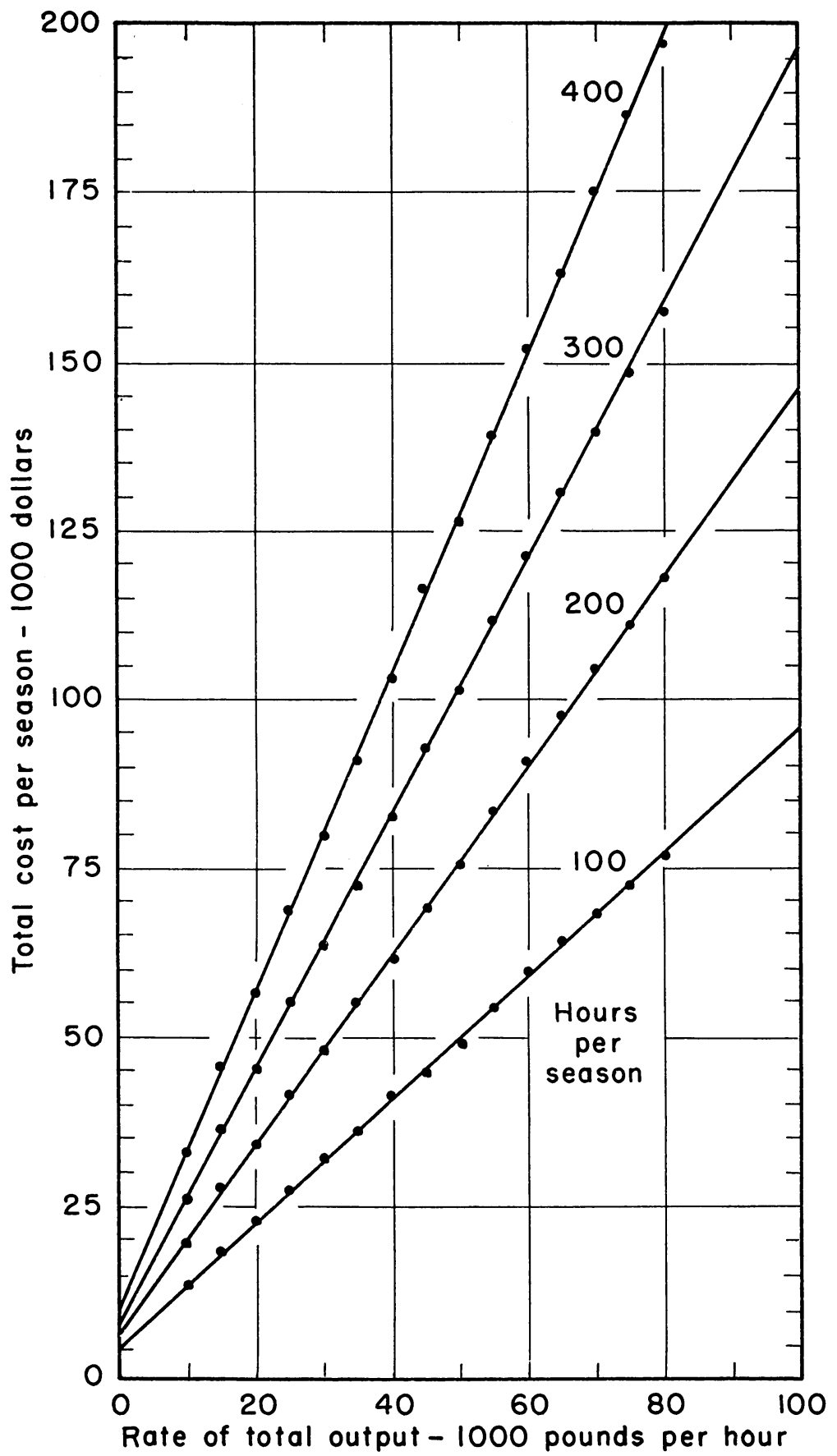

Fig. 51. Long-run total cost per season for pear packing plants in relation to rates of out put with 90 per cent of the produce packed (excludes materials costs). 


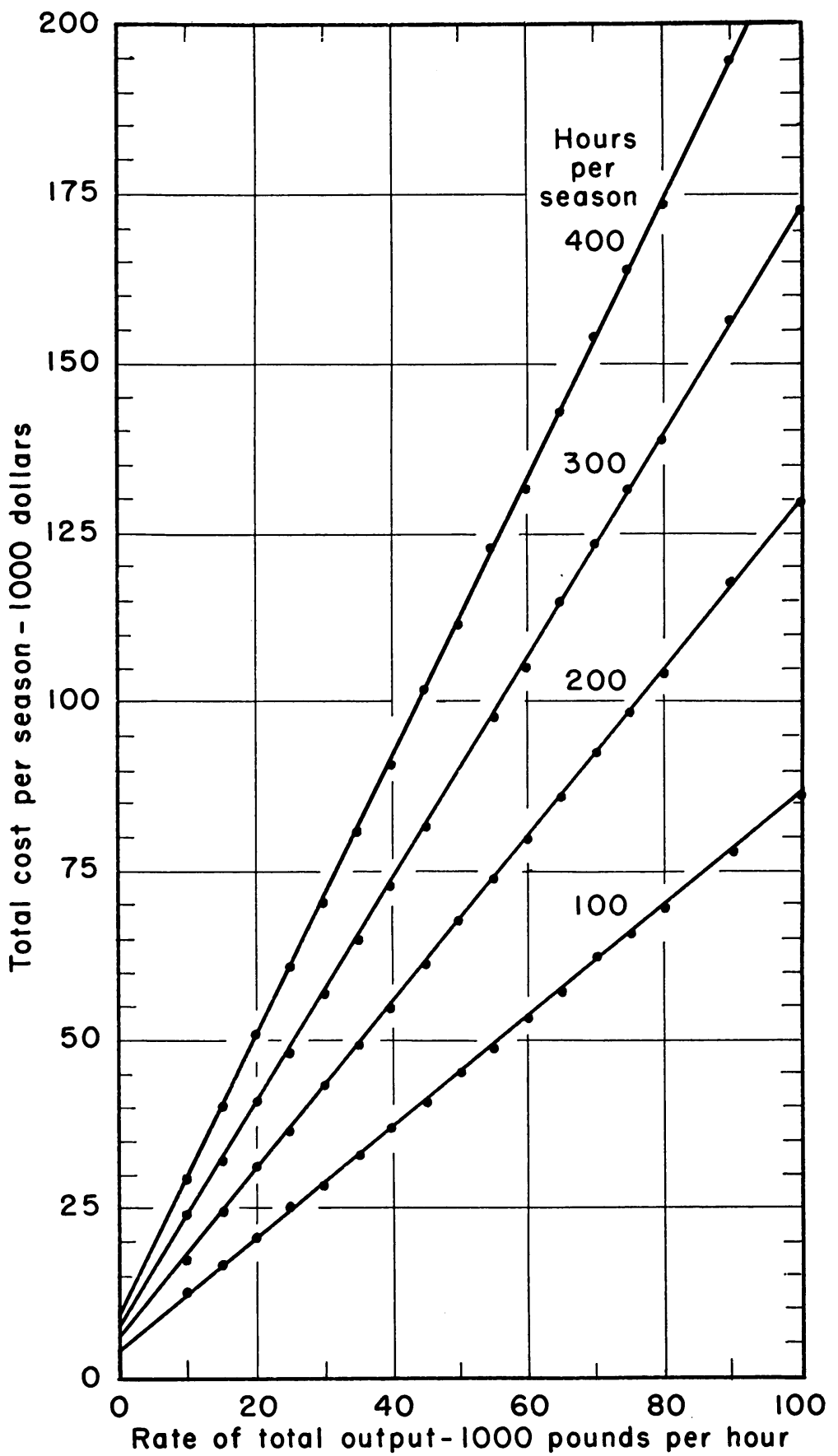

Fig. 52. Long-run total cost per season for pear packing plants in relation to rates of out put with 80 per cent of the produce packed (excludes materials costs). 


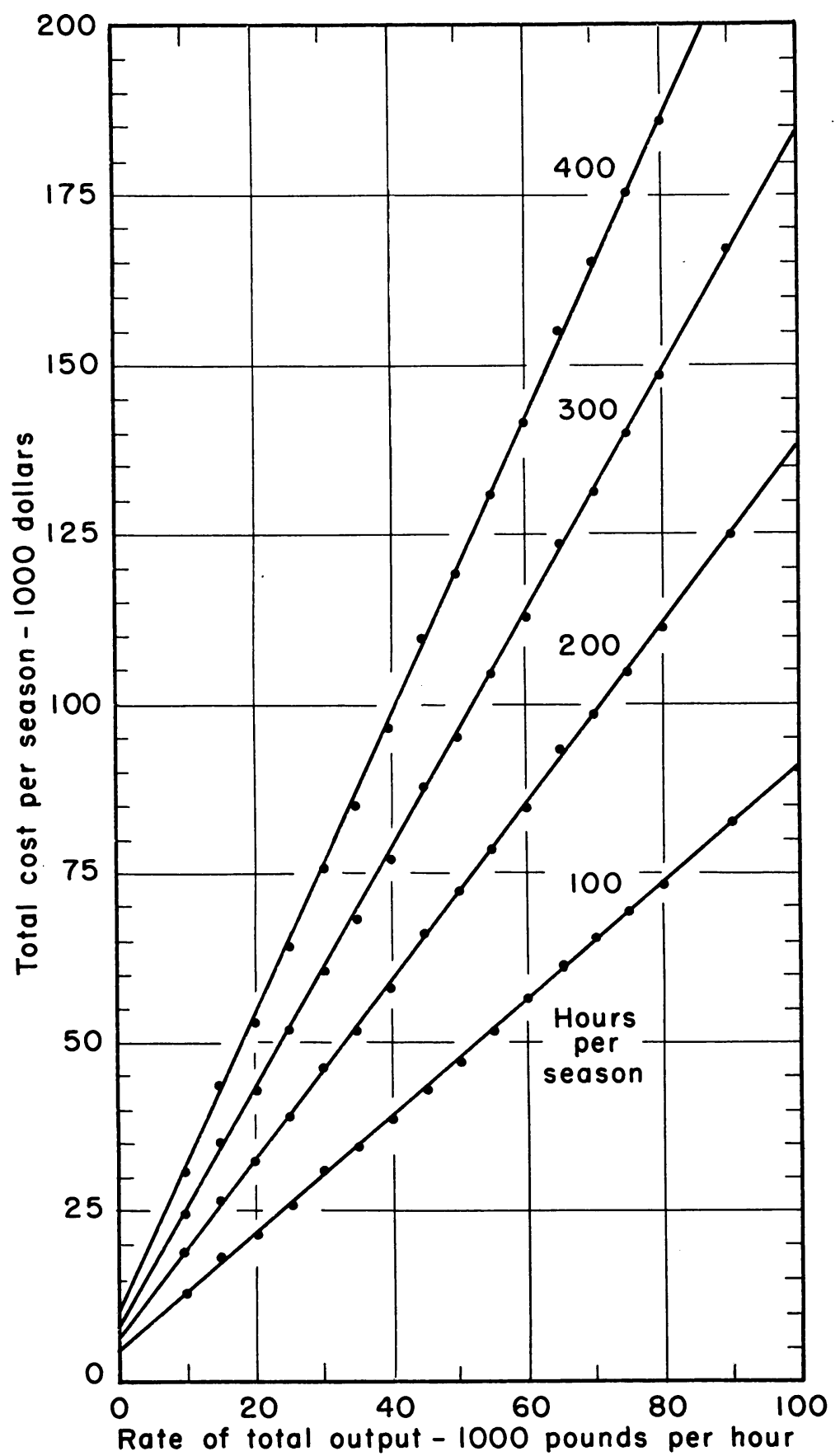

Fig. 53. Long-run total cost per season for pear packing plants in relation to rates of output with 70 per cent of the produce packed (excludes materials costs). 


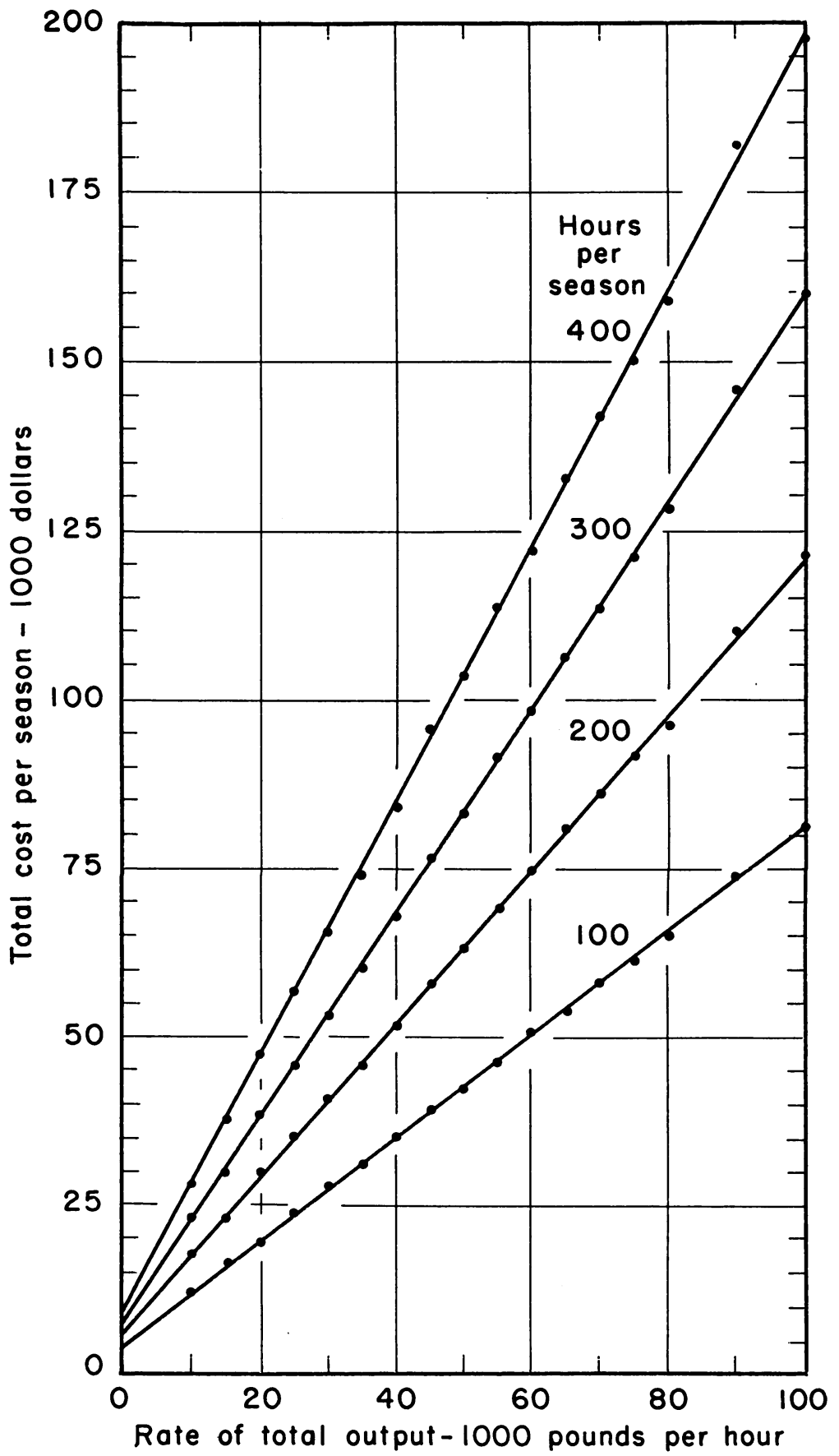

Fig. 54. Long-run total cost per season for pear packing plants in relation to rates of output with 60 per cent of the produce packed (excludes materials costs). 


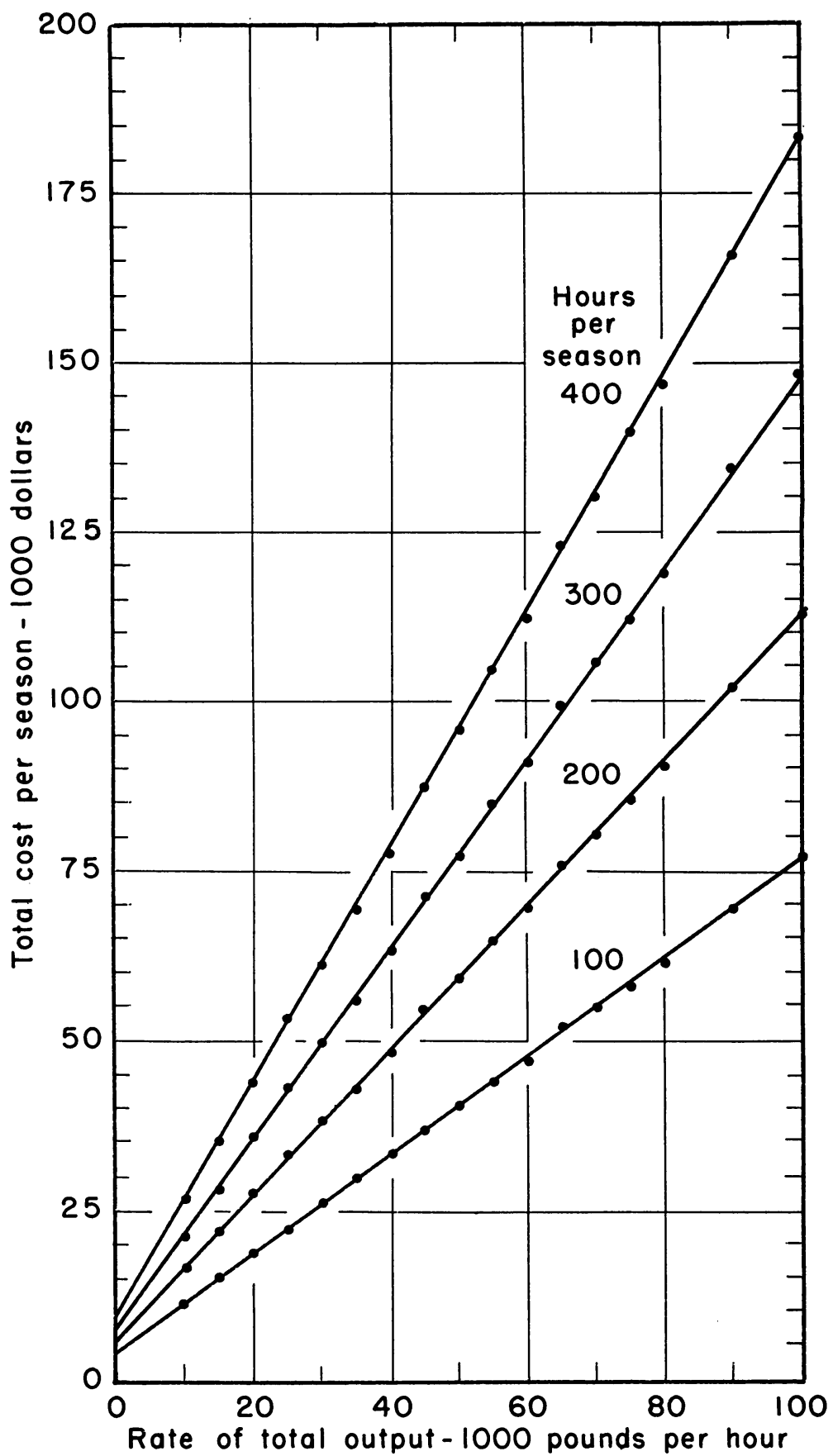

Fig. 55. Long-run total cost per season for pear packing plants in relation to rates of output with 50 per cent of the produce packed (excludes materials costs). 
multiple correlation coefficient is 0.9999 which indicates that the smooth function gives a very close description of the points on the discontinuous functions. Equation 16 will be used throughout the remaining discussion and will be referred to as the long-run cost or planning function. Packing and carloading materials may be added to this equation as a constant per unit packed. ${ }^{\mathrm{so}}$ For produce packed in standard boxes, this amounts to 0.533 cent per box or $\$ 11.04$ per thousand pounds packed.

TABLE 43

TECHNOLOGIES GIVING LEAST AGGREGATE COSTS FOR SELECTED POINTS ON THE LONG-RUN TOTAL COST CURVE (STAGES WITH INPUTS RELATED TO TOTAL VOLUME)*

\begin{tabular}{|c|c|c|c|c|}
\hline \multirow{3}{*}{ Rate of total output } & \multicolumn{4}{|c|}{ Least cost technologies } \\
\hline & \multicolumn{4}{|c|}{ Hours per season } \\
\hline & 100 & 200 & 300 & 400 \\
\hline \multicolumn{5}{|l|}{1,000 pounds per hour } \\
\hline \multicolumn{5}{|l|}{ Dump-grade } \\
\hline $10 \ldots$ & $1 \mathrm{~A}-2 \mathrm{~A}$ & $1 \mathrm{~A}-2 \mathrm{~A}$ & $1 \mathrm{~A}-2 \mathrm{~A}$ & $1 \mathrm{~A}-2 \mathrm{~A}$ \\
\hline $15 \ldots$ & $1 A-2 B$ & $1 \mathrm{~A}-2 \mathrm{~B}$ & $1 \mathrm{~A}-2 \mathrm{~B}$ & $1 \mathrm{~A}-2 \mathrm{~B}$ \\
\hline $20 \ldots$ & $1 \mathrm{~A}-2 \mathrm{C}$ & $1 \mathrm{~A}-2 \mathrm{C}$ & $1 \mathrm{E}-2 \mathrm{C}$ & $1 \mathrm{E}-2 \mathrm{C}$ \\
\hline $25 \ldots \ldots$ & $1 \mathrm{~A}-2 \mathrm{C}$ & $1 \mathrm{~A}-2 \mathrm{C}$ & $1 \mathrm{E}-2 \mathrm{C}$ & $1 \mathrm{E}-2 \mathrm{C}$ \\
\hline $30-35$. & $1 \mathrm{E}-2 \mathrm{D}$ & $1 \mathrm{E}-2 \mathrm{D}$ & $1 \mathrm{E}-2 \mathrm{D}$ & $1 E-2 D$ \\
\hline $40 \ldots$ & $1 \mathrm{E}-2 \mathrm{D}$ & $1 \mathrm{E}-2 \mathrm{D}$ & $1 \mathrm{E}-2 \mathrm{D}$ & $1 \mathrm{E}-2 \mathrm{D}$ \\
\hline $45 \ldots$ & $1 \mathrm{~A}-2 \mathrm{C}$ & $1 \mathrm{~A}-2 \mathrm{C}$ & $1 \mathrm{~A}-2 \mathrm{C}$ & $1 \mathrm{~A}-2 \mathrm{C}$ \\
\hline 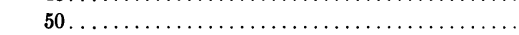 & $1 \mathrm{~A}-2 \mathrm{C}$ & $1 \mathrm{~A}-2 \mathrm{C}$ & $1 \mathrm{E}-2 \mathrm{C}$ & $1 \mathrm{~A}-2 \mathrm{C}$ \\
\hline $55 \ldots \ldots \ldots \ldots \ldots \ldots \ldots \ldots \ldots \ldots \ldots \ldots \ldots \ldots$ & $1 \mathrm{~A}-2 \mathrm{C}$ & $1 \mathrm{~A}-2 \mathrm{C}$ & $1 \mathrm{~A}-2 \mathrm{C}$ & $1 \mathrm{~A}-2 \mathrm{C}$ \\
\hline $60 \ldots \ldots \ldots \ldots \ldots \ldots \ldots \ldots \ldots \ldots \ldots \ldots \ldots$ & $1 \mathrm{E}-2 \mathrm{D}$ & $1 \mathrm{E}-2 \mathrm{D}$ & $1 \mathrm{E}-2 \mathrm{D}$ & $1 \mathrm{E}-2 \mathrm{D}$ \\
\hline $65 \ldots \ldots \ldots \ldots \ldots \ldots \ldots \ldots \ldots \ldots \ldots \ldots \ldots$ & $1 \mathrm{~A}-2 \mathrm{C}$ & $1 \mathrm{E}-2 \mathrm{D}$ & $1 \mathrm{E}-2 \mathrm{D}$ & $1 \mathrm{E}-2 \mathrm{D}$ \\
\hline 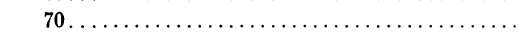 & $1 \mathrm{E}-2 \mathrm{D}$ & $1 \mathrm{E}-2 \mathrm{D}$ & $1 \mathrm{E}-2 \mathrm{D}$ & $1 \mathrm{E}-2 \mathrm{D}$ \\
\hline $75 \ldots \ldots$ & $1 \mathrm{E}-2 \mathrm{D}$ & $1 \mathrm{E}-2 \mathrm{D}$ & $1 \mathrm{E}-2 \mathrm{D}$ & $1 \mathrm{D}-2 \mathrm{D}$ \\
\hline $80-90 \ldots \ldots \ldots \ldots \ldots \ldots \ldots \ldots \ldots \ldots$ & $1 \mathrm{~A}-2 \mathrm{C}$ & $1 \mathrm{E}-2 \mathrm{D}$ & $1 \mathrm{E}-2 \mathrm{D}$ & $1 \mathrm{E}-2 \mathrm{D}$ \\
\hline $100 \ldots$ & $1 \mathrm{E}-2 \mathrm{D}$ & $1 E-2 D$ & $1 \mathrm{E}-2 \mathrm{D}$ & $1 \mathrm{E}-2 \mathrm{D}$ \\
\hline \multicolumn{5}{|l|}{ Transport incoming, cannery and culls } \\
\hline $10-45 \ldots \ldots \ldots \ldots \ldots \ldots \ldots \ldots$ & $\mathrm{A}$ & A & A & A \\
\hline $50-100 \ldots \ldots \ldots \ldots \ldots \ldots$ & $\mathrm{A}$ & A & A & B \\
\hline
\end{tabular}

* For details of the methods identified in abbreviated form, see the section, Stage Technologies and Component Cost Standards, beginning on page 602 .

\section{Technologies, Plant Organization, and Costs}

The long-run cost function developed in the preceding section provides a tool for determining the size of plant to build and the methods of operation to use. In this section, the long-run cost function is interpreted in terms of the particular combinations of technologies and units of labor and equipment that describe the specific plants represented by each point on the long-run cost curve. The nature of the cost functions for the individual plants also is considered. Later sections deal with the characteristics of the

${ }^{80}$ It is possible, of course, that large-scale operation may permit some economies in the purchase of materials. However, data are not available which would permit any estimate of these economies and they may well be in form of "external" rather than internal plant economies. 
long-run cost function, with optimum combinations of hours of operation and rates of output, and with problems of flexibility in the operations.

Technical Organization. The technologies represented by various points on the long-run cost function are indicated in tables 43 and 44 . Only the seven stages or transportation links for which alternative technologies are

\section{TABLE 44}

TECHNOLOGIES GIVING LEAST AGGREGATE COSTS FOR SELECTED POINTS ON THE LONG-RUN TOTAL COST CURVE (STAGES WITH INPUTS RELATED TO PACKED VOLUME)

\begin{tabular}{|c|c|c|c|c|}
\hline \multirow{3}{*}{ Rate of packed output } & \multicolumn{4}{|c|}{ Least cost technologies } \\
\hline & \multicolumn{4}{|c|}{ Hours per season } \\
\hline & 100 & 200 & 300 & 400 \\
\hline \multicolumn{5}{|l|}{1,000 pounds per hour } \\
\hline \multicolumn{5}{|l|}{ Packing } \\
\hline $5.0-9.0$ & $\mathbf{A}$ & C & $\mathrm{C}$ & C \\
\hline $10.0-10.5 \ldots \ldots \ldots \ldots$ & $\mathbf{A}$ & $\mathrm{C}$ & B & $\mathbf{C}$ \\
\hline 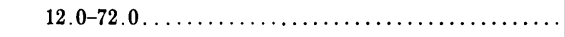 & $\mathbf{A}$ & $\mathrm{C}$ & $\mathrm{C}$ & $\mathbf{C}$ \\
\hline \multicolumn{5}{|l|}{ Lid-stamp-weigh } \\
\hline 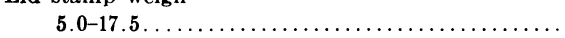 & A & $\mathbf{A}$ & $\mathbf{A}$ & $\mathbf{A}$ \\
\hline $18.0-21.0 \ldots \ldots \ldots \ldots \ldots \ldots \ldots \ldots \ldots \ldots \ldots \ldots$ & B & $\mathrm{C}$ & $\mathrm{C}$ & C \\
\hline $21.5-48.0 \ldots \ldots \ldots \ldots \ldots \ldots \ldots \ldots \ldots \ldots \ldots \ldots$ & $\mathrm{C}$ & $\mathbf{C}$ & $\mathrm{C}$ & $\mathbf{C}$ \\
\hline $49.0-52.5 \ldots \ldots \ldots \ldots \ldots \ldots \ldots \ldots \ldots \ldots \ldots \ldots$ & $\mathrm{A}$ & $\mathrm{C}$ & $\mathrm{C}$ & $\mathbf{C}$ \\
\hline$\ldots \ldots \ldots \ldots \ldots \ldots$ & $\mathrm{C}$ & $\mathrm{C}$ & $\mathbf{C}$ & $\mathbf{C}$ \\
\hline \multicolumn{5}{|l|}{ Box supply } \\
\hline $5.0-10.5$ & $\mathrm{E}$ & $\mathrm{E}$ & $\mathbf{E}$ & $\mathbf{E}$ \\
\hline $12.0-16.0 \ldots$ & $\mathrm{D}$ & $\mathbf{D}$ & $\mathrm{D}$ & $\mathrm{D}$ \\
\hline $17.5-22.5 \ldots \ldots$ & $\mathbf{E}$ & $\mathbf{E}$ & $\mathbf{E}$ & $\mathbf{E}$ \\
\hline $24.0-30.0$ & $\mathbf{E}$ & $\mathrm{D}$ & $\mathrm{D}$ & $\mathrm{D}$ \\
\hline $31.5-35.0$ & $\mathrm{E}$ & $\mathrm{E}$ & $\mathbf{E}$ & $\mathbf{E}$ \\
\hline $36.0-39.0 \ldots$ & $\mathbf{E}$ & $\mathrm{D}$ & D & $\mathrm{D}$ \\
\hline $40.0-45.5$ & $\mathrm{E}$ & $\mathrm{E}$ & $\mathbf{E}$ & $\mathbf{E}$ \\
\hline$\ldots \ldots \ldots \ldots$ & $\mathrm{E}$ & $\mathrm{E}$ & $\overline{\mathrm{D}}$ & $\mathrm{D}$ \\
\hline$\ldots \ldots \ldots \ldots \ldots$ & $\mathrm{D}$ & $\mathrm{D}$ & $\mathbf{D}$ & $\mathrm{D}$ \\
\hline $63.0-70.0 \ldots \ldots \ldots \ldots \ldots \ldots$ & $\mathrm{E}$ & $\mathrm{E}$ & $\mathbf{E}$ & $\mathbf{D}$ \\
\hline 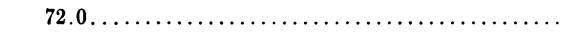 & $\mathrm{E}$ & $\mathbf{D}$ & $\mathbf{D}$ & $\mathrm{D}$ \\
\hline \multicolumn{5}{|l|}{ Transport packed fruit to cars } \\
\hline 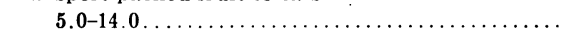 & A & $\mathbf{A}$ & $\mathbf{A}$ & $\mathbf{A}$ \\
\hline $15.0-72.0 \ldots \ldots \ldots \ldots \ldots \ldots \ldots \ldots \ldots \ldots \ldots \ldots$ & $\mathrm{C}$ & $\mathrm{C}$ & $\mathbf{C}$ & $\mathbf{C}$ \\
\hline
\end{tabular}

considered are included in the tables. Total season costs for each of the technologies selected and for the alternatives available at each stage are summarized in Appendix A.

The technologies represented in tables 43 and 44 are estimated to give the least total cost for conditions in which the equipment is used only for pear packing. In many cases, however, some items of equipment may be used in packing other fruit at different times of the year, and this may alter the basis for selection. This is particularly true of transportation equipment-hand trucks, fork trucks, and conveyors-since the equipment is not 
specialized for any one type of commodity and is also easily moved from one plant to another. For example, if the equipment used to transport incoming pears can be used for an equal number of hours per season on other fruits, fork trucks (method B) become most economical over a much broader range-for nearly all plants with pear packing seasons of 300 hours or more and for plants with 200-hour seasons and capacities greater than 50,000 pounds per hour. For large plants with seasons of less than 200 hours, fork-truck rental may in some cases offer enough savings to swing the balance in favor of fork trucks over hand trucks. ${ }^{81}$

In addition to the possible other uses for equipment, there may in some cases be a "nonquantifiable" basis for selecting a method that is slightly higher in cost than another. ${ }^{82}$ The choice of transportation method again may be affected importantly by such considerations. To illustrate for the case where the equipment is used only on pears, hand trucks (method A) are clearly the most economical means of transporting incoming fruit for seasons up to and including 200 hours. ${ }^{83}$ At 300 hours, fork trucks and hand trucks give about the same cost, but when the transportation job is considered jointly with dumping-grading, hand trucks again give the lowest estimated total cost. However, the difference is fairly small with this length of season and the nonquantifiable advantages of fork-truck operationmore rapid unloading of grower trucks and easier adjustment to excessively large deliveries of produce-might easily swing the balance in favor of fork trucks. ${ }^{84}$

A similar situation would be observed in the case of the transportation of packed fruit if only hand trucks or fork trucks could be used for this job. However, before reaching the economical range for fork-truck operation, the conveyor method of transportation becomes much less costly than either of the two trucking methods. ${ }^{85}$ In some instances, the plant policy as to classification or shipment and storage of packed output may not permit the use of the conveyor method. Hand trucks or fork trucks must then be used although costs may be somewhat higher in most ranges.

Another place where nonquantifiable factors may be of importance is in the packing stage. Table 44 shows that only two of the alternative types of packing equipment-bins (type A) and belts (type $\mathrm{C}$ )-are represented in most ranges of the long-run cost function. However, there are some rates of output where tubs (type B) are only slightly higher in cost than the belt equipment. ${ }^{88}$ Since the fruit is sized automatically with tub equipment as compared with hand-sizing with belts, some managers may prefer tubs, although studies fail to indicate any significant difference in packing rates

${ }^{81}$ See L. L. Sammet, In-Plant Transportation, op. cit., p. 43.

${ }^{82}$ See, for example, the discussion of "timeliness of operation" in Section II.

${ }^{83}$ Season costs for each technology are given in Appendix A, table 2.

${ }^{84}$ See L. L. Sammet, op. cit., pp. 46-47. "Squeeze lift trucks" which pick up a single stack of boxes with side clamps (not considered in this study) might reduce the cost in connection with mechanical stack dumping (dumping method $\mathrm{E}$ ) when the fruit is on pallets.

${ }^{85}$ Estimates of season costs for these technologies are contained in Appendix A, table 3 and figure 1.

${ }^{88}$ Season equipment and operating costs for the packing stage are given in Appendix A, table 4. 
per packer among the three types of equipment (French, 1952; pp. 15-17). The tub equipment also may permit the use of somewhat less experienced packers which may be an important advantage at times.

The specific plant organization and equipment requirements for any point on the planning curve may be determined by first referring to tables 43 and 44 and then to the tables of equipment and labor requirements and costs for the technologies at each stage. A set of such summary specifications is illustrated in table 45 for selected plants of 15,000-, 40,000-, and 70,000-pounds-per-hour capacity, 70 per cent packed fruit, 10 per cent firstgrade cannery, and 20 per cent second-grade cannery fruit. The plants are assumed to operate 200 hours per season. Only the major items of equipment are listed in the table. Additional information may be obtained by reference to the discussion of stage technologies and the more detailed reports cited previously.

Individual Plant Costs. Cost relationships for the particular plants described in table 45 are summarized in tables 46, 47, and 48. The first column of each table shows the fixed costs for each plant stage. The remaining columns give the variable cost per hour for operation at any of several selected output rates. For example, if the 40,000 pounds-per-hour plant were operated at capacity the variable cost per hour would be $\$ 177.81$. However, if it were operated at the rate of only 30,000 pounds per hour, the variable costs would be $\$ 136.24$. Fixed costs given in the table remain constant regardless of the rate of output. The variable costs are short-run costs, while the fixed costs have meaning only in the long-run sense. Smoothed lines through the total variable cost points yielded the following short-run variable cost functions: ${ }^{87}$

Plant capacity, 1,000 pounds per hour Cost function

$$
\begin{aligned}
& C_{h}=\$ 16.00+\$ 4.20 V_{t} \\
& C_{h}=\$ 18.00+\$ 4.00 V_{t} \\
& C_{h}=\$ 18.00+\$ 4.00 V_{t}
\end{aligned}
$$$$
70
$$

where $C_{h}$ is the labor and operating cost per hour and $V_{t}$ is the total output per hour in thousand pounds. The constant term represents costs for quasifixed labor, such as foremen and janitors plus a normal minimum if the plant is to operate at all. It would, of course, be possible to obtain some output with one man so the functions actually have meaning only for outputs greater than about 5,000 pounds per hour.

With all of these functions, marginal costs are constant up to rated capacity. However, average "variable" costs decline up to capacity due to a spreading of the quasi-fixed labor elements. No attempt was made to calculate costs for operation in excess of the defined capacity rate. In most cases, it would be very difficult to increase output beyond this point without

${ }^{87}$ The very slight curvature of the stage cost function for grading tends to be lost in the aggregate of costs. 
adding some new equipment or modifying some units of existing equipment, and this would define a new plant. Attempts to increase output beyond the normal capacity rate of the existing equipment, if possible at all, would result in sharply increased marginal cost due to crowding of labor, overloading of equipment, and the use of less efficient nonmechanized methods of handling fruit.

Marginal cost is higher in the smaller plant than in the other two, and average variable costs are higher in the smaller plant for outputs greater than 10,000 pounds per hour. The differences are small, however, since the technological shifts with increased output are small compared with the total plant cost. Most of the major cost reductions through changing technologies have been exhausted by the time output reaches 25,000 pounds per hour-see tables 43 and 44 and the Appendix. This explains the identical variable cost functions for the 40,000- and 70,000-pound-per-hour plants.

If the fixed costs that must be covered in the long run are added, the three cost functions become

Plant capacity,

1,000 pounds per hour Total cost function ${ }^{88}$

70

$$
\begin{aligned}
& C=\$ 8,600+\$ 16 H+\$ 4.2 V_{t} H \\
& C=\$ 19,400+\$ 18 H+\$ 4.0 V_{t} H \\
& C=\$ 32,200+\$ 18 H+\$ 4.0 V_{t} H
\end{aligned}
$$

where $C$ is the total cost per season (excluding materials) and $H$ is the hours of operation per season. Note that $V_{t} H$ represents volume per season. Dividing the total cost functions by this term defines the following average cost function:

Plant capacity, 1,000 pounds per hour Average total cost function

$$
\begin{array}{rl}
15 & A C=\frac{\$ 8,600}{V_{t} H}+\frac{\$ 16}{V_{t}}+\$ 4.2 \\
40 & A C=\frac{\$ 19,400}{V_{t} H}+\frac{\$ 18}{V_{t}}+\$ 4.0 \\
70 & A C=\frac{\$ 32,200}{V_{t} H}+\frac{\$ 18}{V_{t}}+\$ 4.0
\end{array}
$$

The relations between the cost functions for these selected plants and the long-run cost curve are illustrated in figure 56. Part A of the diagram shows total costs and Part B converts these to an average cost per 1,000-pounds basis. The long-run cost curve shown in figure 56 was computed from equation 16 for a 200-hour season and 70 per cent packed fruit. The dotted curves represent cost relationships in the specific plants. They are derived from equations 20 to 25 and are long-run in nature in that they include

\footnotetext{
${ }_{88}$ The constant terms are adjusted slightly to conform to the smoothed long-run curve rather than the specific points to which the long-run curve was fitted.
} 
TABLE 45

LABOR AND EQUIPMENT REQUIREMENTS FOR THREE EFFICIENT PLANTS WITH 70 PER CENT PACKED AND A 200-HOUR SEASON*

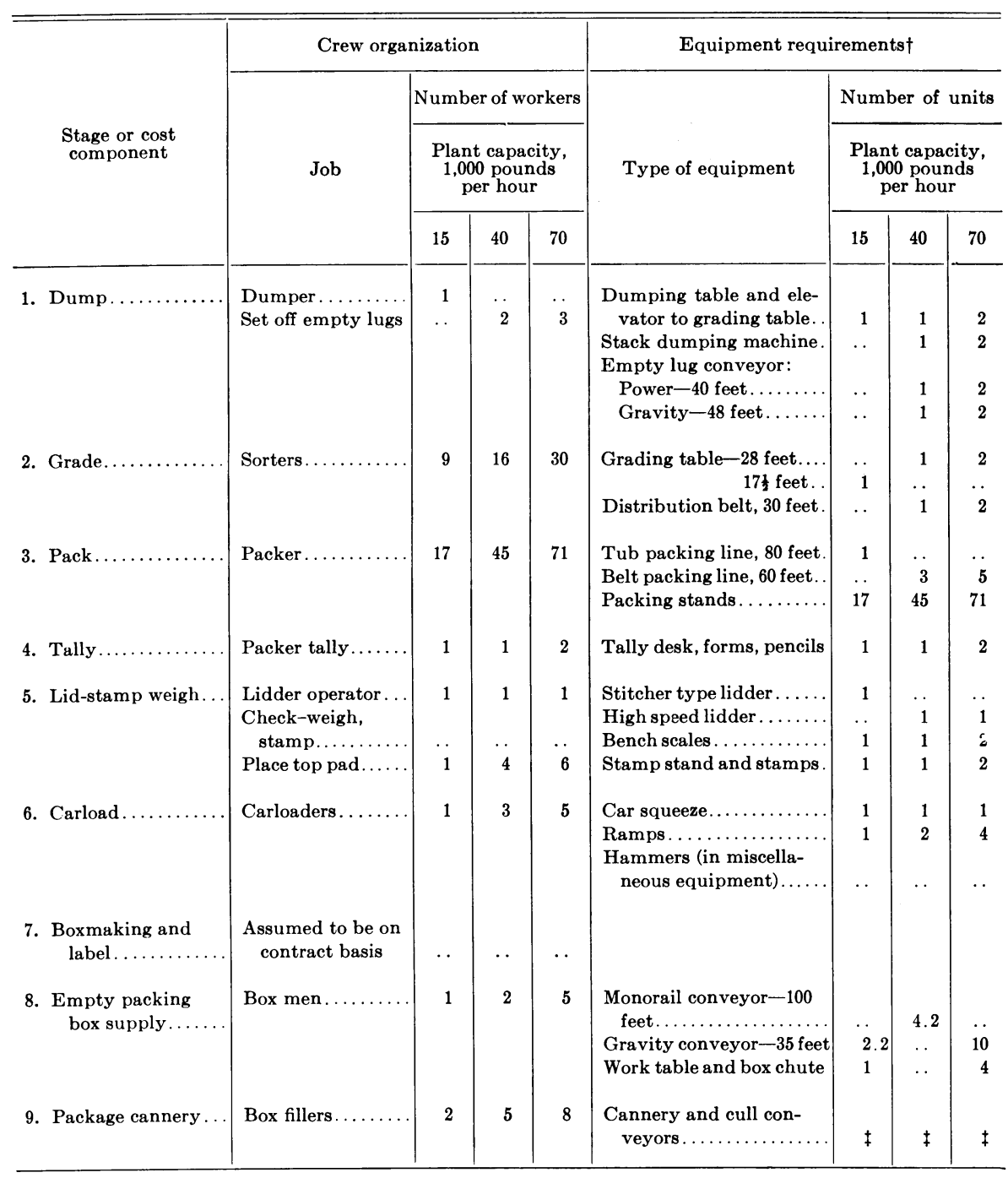

fixed costs. Each of the specific plants is based on the technical organization indicated for its capacity rate of output by the long-run cost function.

For low rates of output, the costs in the selected plants are well above those shown by the planning curve. As rates of output approach the capacity for each plant, the specific plant curves and the long-run curve converge and finally touch at the capacity rate of output for each individual plant. As explained above, no attempt was made to calculate costs for output in excess of capacity, but they would be expected to rise quite sharply. 
TABLE 45 (continued)

\begin{tabular}{|c|c|c|c|c|c|c|c|c|}
\hline \multirow{4}{*}{$\begin{array}{l}\text { Stage or cost } \\
\text { component }\end{array}$} & \multicolumn{4}{|c|}{ Crew organization } & \multicolumn{4}{|c|}{ Equipment requirements $\dagger$} \\
\hline & \multirow{3}{*}{ Job } & \multirow{2}{*}{\multicolumn{3}{|c|}{$\begin{array}{c}\text { Number of workers } \\
\begin{array}{c}\text { Plant capacity, } \\
1,000 \text { pounds } \\
\text { per hour }\end{array}\end{array}$}} & \multirow{3}{*}{ Type of equipment } & \multirow{2}{*}{\multicolumn{3}{|c|}{$\begin{array}{c}\text { Number of units } \\
\begin{array}{c}\text { Plant capacity, } \\
1,000 \text { pounds } \\
\text { per hour }\end{array}\end{array}$}} \\
\hline & & & & & & & & \\
\hline & & 15 & 40 & 70 & & 15 & 40 & 70 \\
\hline \multirow[t]{4}{*}{ 10. Transportation. } & Truckers..... & 5 & 10 & 16 & Hand trucks........... & 5 & 10 & $16 \S$ \\
\hline & Set off packed & & & & Power conveyor-lidder & & & \\
\hline & boxes......... & 1 & $\because$ & $\because$ & to car $\ldots \ldots \ldots \ldots$ & $\cdots$ & $\|$ & $\|$ \\
\hline & Conveyor men. & $\cdots$ & 1 & 1 & $\begin{array}{l}\text { Gravity conveyor-lidder } \\
\text { to car................... }\end{array}$ & .. & $\|$ & $\|$ \\
\hline \multirow[t]{6}{*}{ 11. Miscellaneous labor } & Foremen. & 2 & 3 & 4 & No equipment... & .. & . & .. \\
\hline & Nightmen..... & 1 & 1 & 2 & & & & \\
\hline & Seasonal office & & & & & & & \\
\hline & clerks........ & 2 & 2 & 3 & & & & \\
\hline & Weighmaster $\uparrow$. & 1 & 1 & 1 & & & & \\
\hline & Utility ........ & 1 & 2 & 3 & & & & \\
\hline \multirow{2}{*}{$\begin{array}{l}\text { 12. Office and adminis- } \\
\text { trative labor..... }\end{array}$} & Manager...... & 1 & 1 & 1 & No equipment... & . . & . & . \\
\hline & Bookkeeper... & .. & 1 & 1 & & & & \\
\hline $\begin{array}{l}\text { 13. Miscellaneous } \\
\text { equipment....... }\end{array}$ & No labor............ & .. & . & . & $\begin{array}{l}\text { Small tools, office } \\
\text { equipment, etc. }\end{array}$ & *** & $* *$ & $* *$ \\
\hline 14. Building .......... & No labor.... & .. & . & .. & Floor space-sq. feet $\dagger \dagger$. . & 15,900 & 30,900 & 48,600 \\
\hline \multirow{2}{*}{$\begin{array}{l}\text { 15. Miscellaneous } \\
\text { general costs..... }\end{array}$} & & & & & & & & \\
\hline & No direct labor.... & .. & $\cdots$ & $\cdots$ & No equipmentff.......... & $\cdots$ & $\cdots$ & $\cdots$ \\
\hline \multirow{3}{*}{$\begin{array}{l}\text { 16. Accounting to } \\
\text { growers for fruit } \\
\text { received.......... }\end{array}$} & Sampling labor.... & 2 & 4 & 7 & Sampling table.... & 1 & 1 & 1 \\
\hline & & & & & Bench scales............. & 1 & 1 & 1 \\
\hline & & & & & Hand truck....... & 1 & 1 & 1 \\
\hline Total crew. & $\ldots$ & 50 & 105 & 170 & & & & \\
\hline
\end{tabular}

* Of the total output, 10 per cent is No. 1 cannery and 20 per cent No. 2 cannery and culls. For purposes of conversion from pounds to lugs, field lugs are figured at 44 pounds each.

$t$ Includes only the major items and specifications.

† For more detailed specifications, see L. L. Sammet and I. F. Davis, Building and Equipment Costs, Apple and Pear Packing, California Agricultural Experiment Station, Giannini Foundation of Agricultural Economics, Mimeographed Report No. 153, 1953, p. 37 .

$\S$ Fork trucks might be used in this plant to advantage with little increase in cost-see discussion in text. Equipment requirements would, of course, differ.

$\|$ Details on the types of conveyors and transportation distances are given in L. L. Sammet, In-Plant Transportation Costs as Related to Materials Handling Methods, Apple and Pear Packing, California Agricultural Experiment Station, Giannini Foundation of Agricultural Economics, Mimeographed Report No. 142, 1953, p. 10 and p. 50.

1 Combined with the duties of a trucker in small plants.

** For more detailed specifications, see Sammet and Davis, op. cit., p. 37.

†t See Sammet and Davis, op. cit. for further details.

$\ddagger$ Includes office and general supplies, auditing and legal expense, and insurance on inventories.

\section{Characteristics of the Long-Run Cost Function}

It will be recalled that the estimated long-run total cost function is given in equation 16 as,

$$
C=\$ 2,781+\$ 16 H+\$ 437 V_{p}+\$ 320 V_{c}+\$ 5.22 V_{p} H+\$ 1.56 V_{c} H .
$$

Figure 57 shows the equation in graphic three dimension with the proportion of packed fruit held at 70 per cent. The principal characteristic of this 


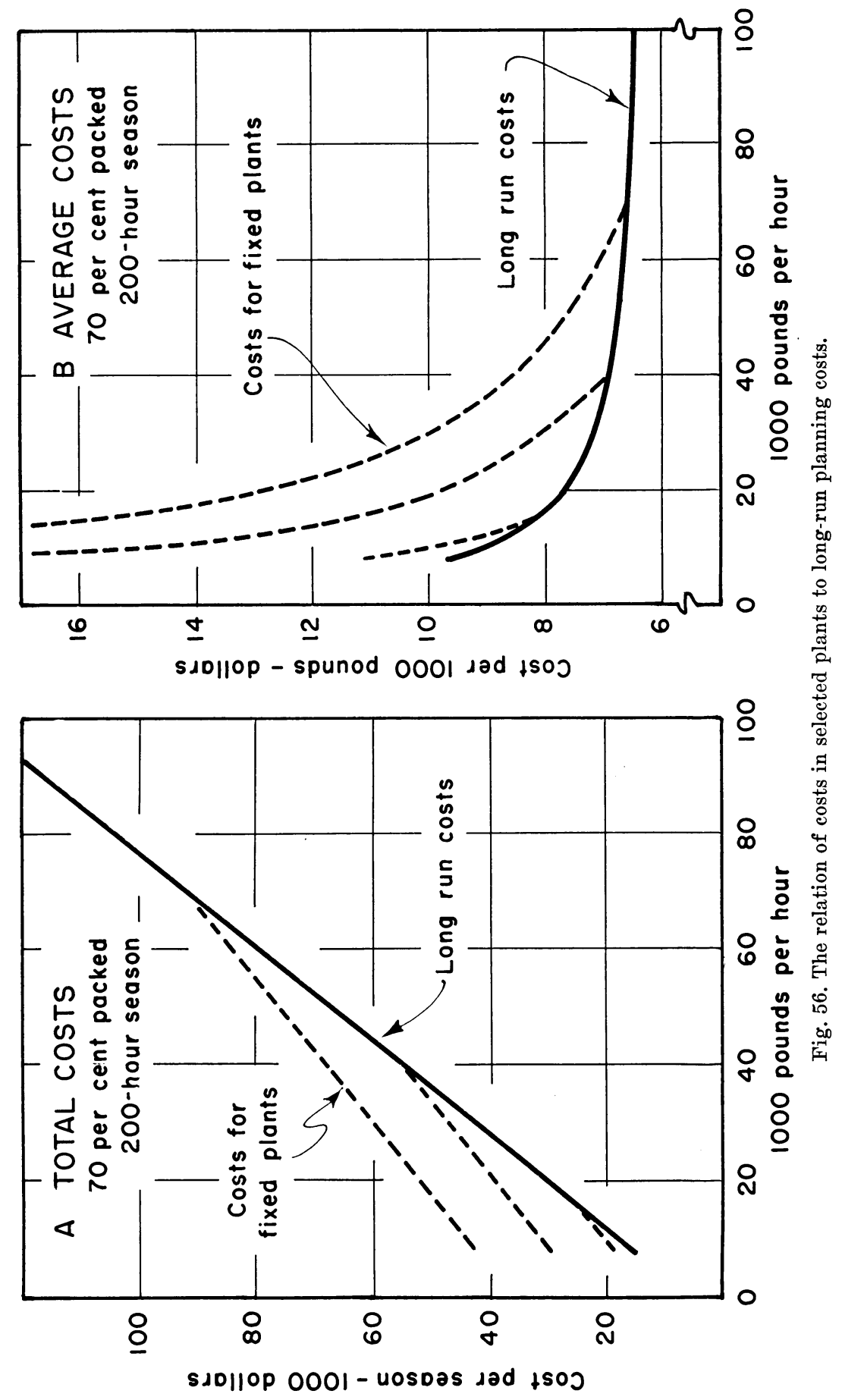


TABLE 46

TOTAL VARIABLE AND FIXED COSTS FOR A PLANT OF 15,000 POUNDS PER HOUR CAPACITY, 70 PER CENT PACKED, AND A 200-HOUR SEASON (TECHNOLOGIES ARE AS SPECIFIED FOR THIS POINT ON THE LONG-RUN COST CURVE)

\begin{tabular}{|c|c|c|c|}
\hline Stage or cost component & $\begin{array}{c}\text { Average } \\
\text { annual fixed } \\
\text { cost }\end{array}$ & \multicolumn{2}{|c|}{$\begin{array}{l}\text { Rate of total output } \\
(1,000 \text { pounds per hour })\end{array}$} \\
\hline & & \multicolumn{2}{|c|}{ cost per hour-dollars } \\
\hline 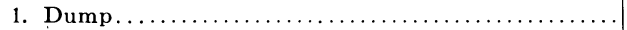 & 68 & 1.39 & 1.39 \\
\hline 2. Grade................... & 120 & 8.49 & 9.52 \\
\hline 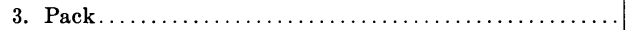 & 815 & 23.05 & 34.35 \\
\hline 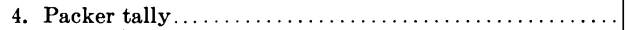 & 2 & 1.05 & 1.05 \\
\hline 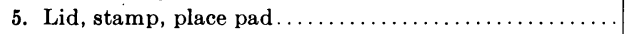 & 235 & 2.56 & 2.56 \\
\hline 10. Transportation $\ldots \ldots \ldots \ldots \ldots \ldots \ldots \ldots \ldots$ & 54 & 5.01 & 7.52 \\
\hline 11. Supervision and miscellaneous $\ldots \ldots \ldots \ldots \ldots \ldots \ldots$ & $\ldots$. & 7.83 & 10.43 \\
\hline 12. Miscellaneous equipment........ & 688 & $\ldots \ldots$ & $\ldots \ldots$ \\
\hline 13. Office and administration $\ldots \ldots \ldots \ldots \ldots \ldots \ldots \ldots$ & 2,850 & $\cdots \cdots$ & $\cdots \cdots$ \\
\hline 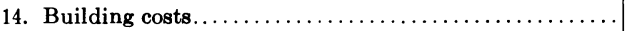 & 3,303 & $\ldots \ldots$ & $\ldots \ldots$ \\
\hline 15. Miscellaneous general costs $\ldots \ldots \ldots \ldots \ldots \ldots \ldots \ldots \ldots \ldots \ldots \ldots \ldots \ldots \ldots \ldots$ & 419 & $\ldots$ & $\ldots \ldots$ \\
\hline 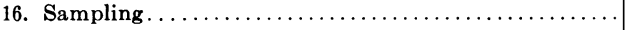 & 72 & 1.10 & 1.65 \\
\hline Total.... & 8,863 & 58.05 & 79.06 \\
\hline
\end{tabular}

TABLE 47

TOTAL VARIABLE COSTS FOR A PLANT OF 40,000 POUNDS PER HOUR CAPACITY, 70 PER CENT PACKED, AND A 200-HOUR SEASON (TECHNOLOGIES ARE AS SPECIFIED FOR THIS POINT ON THE LONG-RUN COST CURVE)

\begin{tabular}{|c|c|c|c|c|c|c|c|c|}
\hline \multirow{2}{*}{ Stage or cost component } & \multirow{2}{*}{$\begin{array}{l}\text { Average } \\
\text { annual } \\
\text { fixed } \\
\text { cost }\end{array}$} & \multicolumn{7}{|c|}{ Rate of total output $-1,000$ pounds per hour } \\
\hline & & 10 & 15 & 20 & 25 & 30 & 35 & 40 \\
\hline & & \multicolumn{7}{|c|}{ cost per hour-dollars } \\
\hline 2. Grade.... & 280 & 8.56 & 9.61 & 10.66 & 11.71 & 13.81 & 14.86 & 16.96 \\
\hline 3. Pack $\ldots \ldots \ldots \ldots$. & 1,722 & 22.94 & 34.58 & 45.88 & 57.19 & 68.82 & 78.13 & 91.43 \\
\hline 4. Packer tally... & 2 & 1.05 & 1.05 & 1.05 & 1.05 & 1.05 & 1.05 & 1.05 \\
\hline 5. Lid, stamp, etc... & 495 & 2.47 & 2.47 & 3.52 & 3.52 & 3.52 & 4.57 & 5.62 \\
\hline 6. Carloading...... & 137 & 1.45 & 1.45 & 2.90 & 2.90 & 2.90 & 4.35 & 4.35 \\
\hline 10. Transportation $\ldots \ldots \ldots \ldots \ldots \ldots$ & 320 & 5.14 & 6.39 & 7.65 & 8.90 & 11.40 & 12.66 & 13.91 \\
\hline 11. Supervision and miscellaneous ..... & $\ldots$ & 7.82 & 10.42 & 10.42 & 11.96 & 11.96 & 11.96 & 14.56 \\
\hline 12. Miscellaneous equipment. ........ & 1,578 & $\ldots$ & $\ldots$ & $\ldots$ & $\ldots$ & $\ldots$ & $\ldots$ & $\ldots$ \\
\hline 13. Office and administration $\ldots \ldots \ldots \ldots$ & 7,150 & $\ldots$ & $\ldots$ & $\cdots$ & $\ldots$ & $\ldots$ & $\ldots$ & $\ldots$ \\
\hline 14. Building costs $\ldots \ldots \ldots \ldots \ldots \ldots \ldots$ & 5,488 & $\ldots$ & $\ldots$ & $\cdots$ & $\ldots$ & $\ldots$ & $\ldots$ & $\ldots$ \\
\hline 15. Miscellaneous general costs $\ldots \ldots \ldots$ & 659 & $\ldots$ & $\ldots$ & $\ldots$ & $\ldots$ & $\ldots$ & $\ldots$ & $\ldots$ \\
\hline 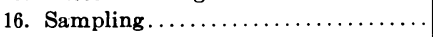 & 153 & 1.10 & 1.65 & 2.20 & 2.75 & 3.30 & 3.85 & 4.40 \\
\hline Total $\ldots \ldots \ldots \ldots \ldots \ldots \ldots$ & 19,145 & 58.12 & 78.23 & 96.77 & 116.54 & 136.24 & 155.93 & 177.81 \\
\hline
\end{tabular}




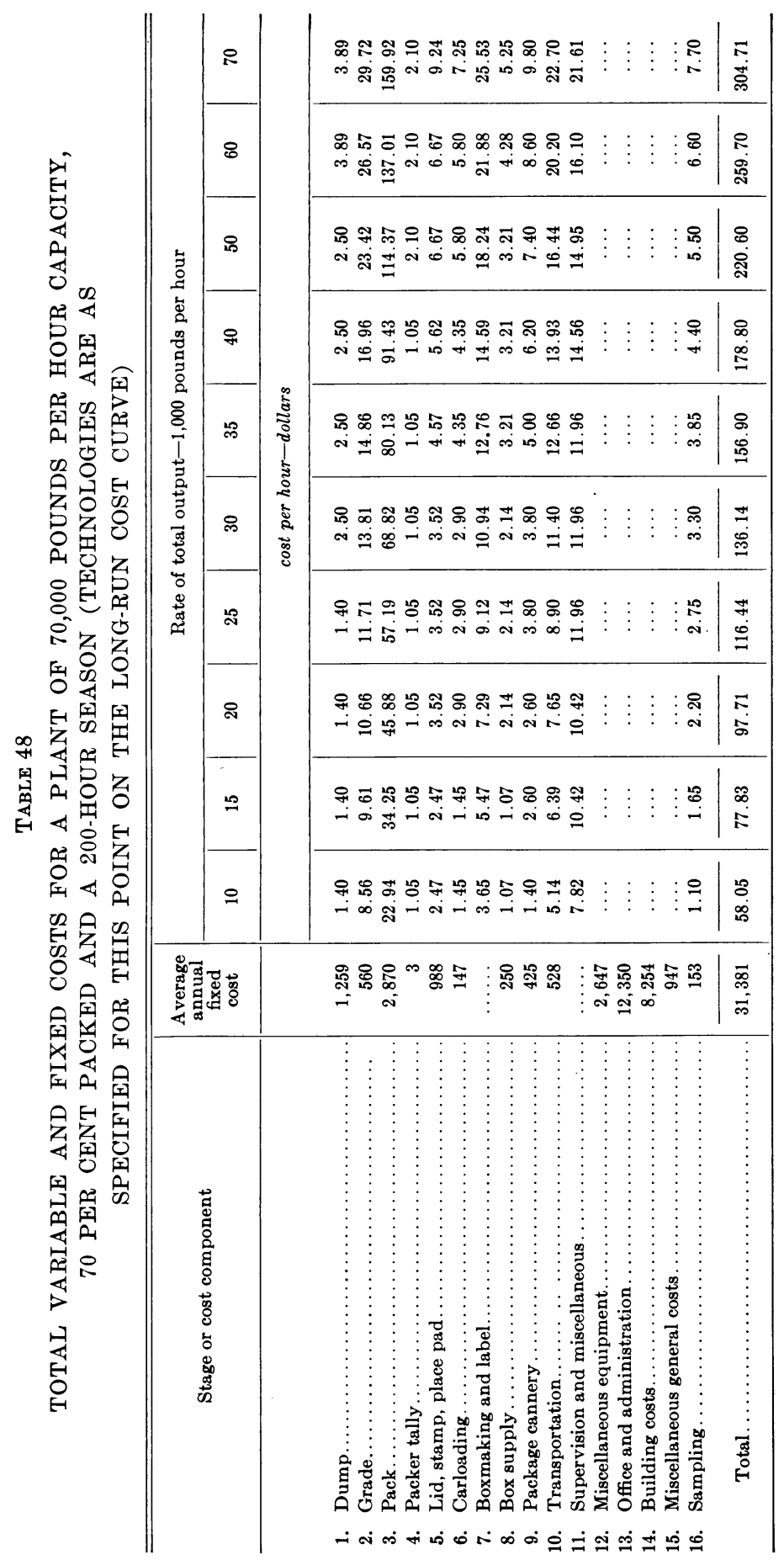


function is its linearity in both the rate and time dimensions. In the rate dimension, increases in plant capacity are obtained primarily through a multiplication of similar types of operating units which results in approximately linear total cost functions. The impact of shifts in technology on costs with increased output is relatively minor. While there are substantial differences in cost among some of the alternative technologies available,

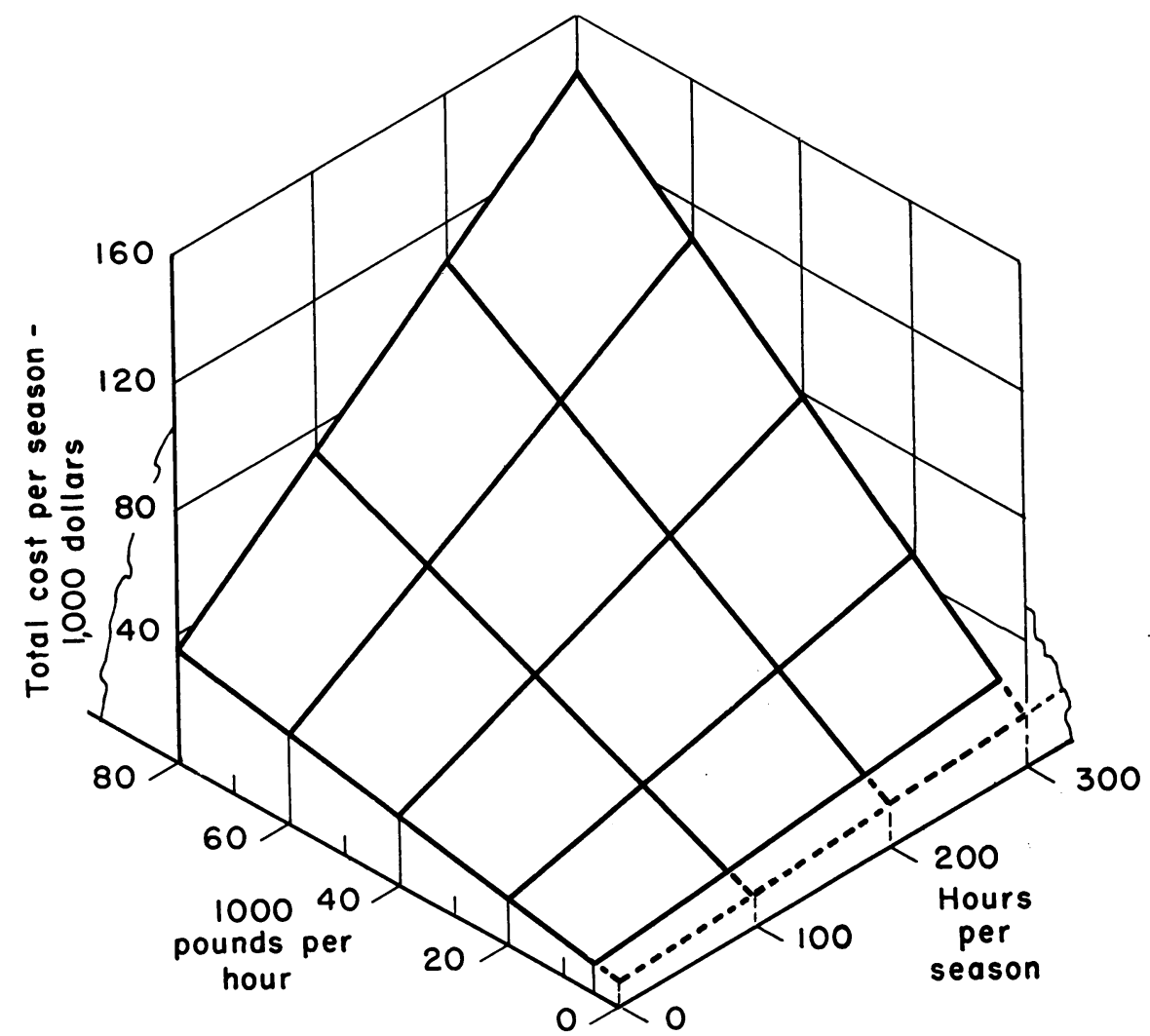

Fig. 57. Long-run total cost surface for pear packing with 70 per cent of the fruit packed.

only a few of these are low enough in cost to be included in the long-run cost function. The differences in cost among the technologies that are included are relatively small, and the major changes have been accomplished by the time rate of output reaches 25,000 pounds per hour-see tables 43 and 44. Thus, although there may be minor discontinuous ranges of curvature, the function tends to be linear over all.

A similar situation is found in the time dimension. Virtually all of the changes in technology have taken place by the time the operating season reaches 200 hours-see tables 43 and 44 . Cost then increases simply as a linear function of time of operation. Since the cost function is linear, the economies of large-scale operation are achieved primarily by spreading the fixed elements over larger volumes of product. 


\section{Optimum Combinations of Hours and Rates}

It is clear that any given season volume of fruit can be handled by many different combinations of plant size and hours of operation and that the particular combination used will have an impact on costs. Institutional restrictions, such as customs and overtime pay, the length of the harvest season, and the number of hours in the day, place limits to these combinations, but within this framework there is room for important variation. To convert the long-run cost function to a true planning function requires that we find the particular combinations of hours and rate of output that give minimum total costs for each set of specified conditions.

Initially, the solution of the problem may be made clearer by ignoring the institutional restrictions and assuming that plants are free to operate as many as 24 hours per day with no increases in cost rates. Following this, consideration will be given to three types of restrictions: (1) limited hours per day but no overtime pay; (2) overtime pay requirements; and (3) the operation of two 8-hour shifts. These situations will be compared as to their impact on costs and on optimum plant size.

No Restrictions. For purposes of illustration, it will be assumed that we are dealing with plants in which 70 per cent of the fruit is packed. This was the average proportion in the sample plants. The major conclusions and general relationships would be approximately the same for other proportions. With this assumption, the long-run cost function becomes:

$$
C=2,781+16 H+401.9 V_{t}+4.122 V_{t} H
$$

Season volume may be expressed as:

Substituting in (26)

$$
S=V_{t} H
$$

$$
C=2,781+16 H+401.9 \frac{S}{H}+4.122 S
$$

To minimize this function for any value of $\mathrm{S}$ :

$$
\begin{gathered}
\frac{d C}{d H}=16-\frac{401.9 S}{H^{2}}=0 . \\
\text { and } H^{2}=\frac{401.9 S}{16}=25.12 S \\
H=5.01 \sqrt{S}
\end{gathered}
$$

Since

$$
\begin{gathered}
S=V_{t} H: \\
V_{t}=\frac{S}{5.01 \sqrt{S}}=\frac{\sqrt{S}}{5.01}
\end{gathered}
$$

Thus, if $S$ is specified, the minimum cost combination of hours of operation and rate of output is given by equations (29) and (30). 
The "expansion path" defined by these combinations is illustrated in figure 58. The solid curves are isocosts (curves of constant total cost) and the broken lines are isoquants (curves of constant season volume). Points of tangency between isocosts and isoquants define the minimum cost combinations of hours and rates of output. Only one point of tangency is shown on the chart but many more could be shown by computing precisely the right curves. The line connecting these points is called an expansion

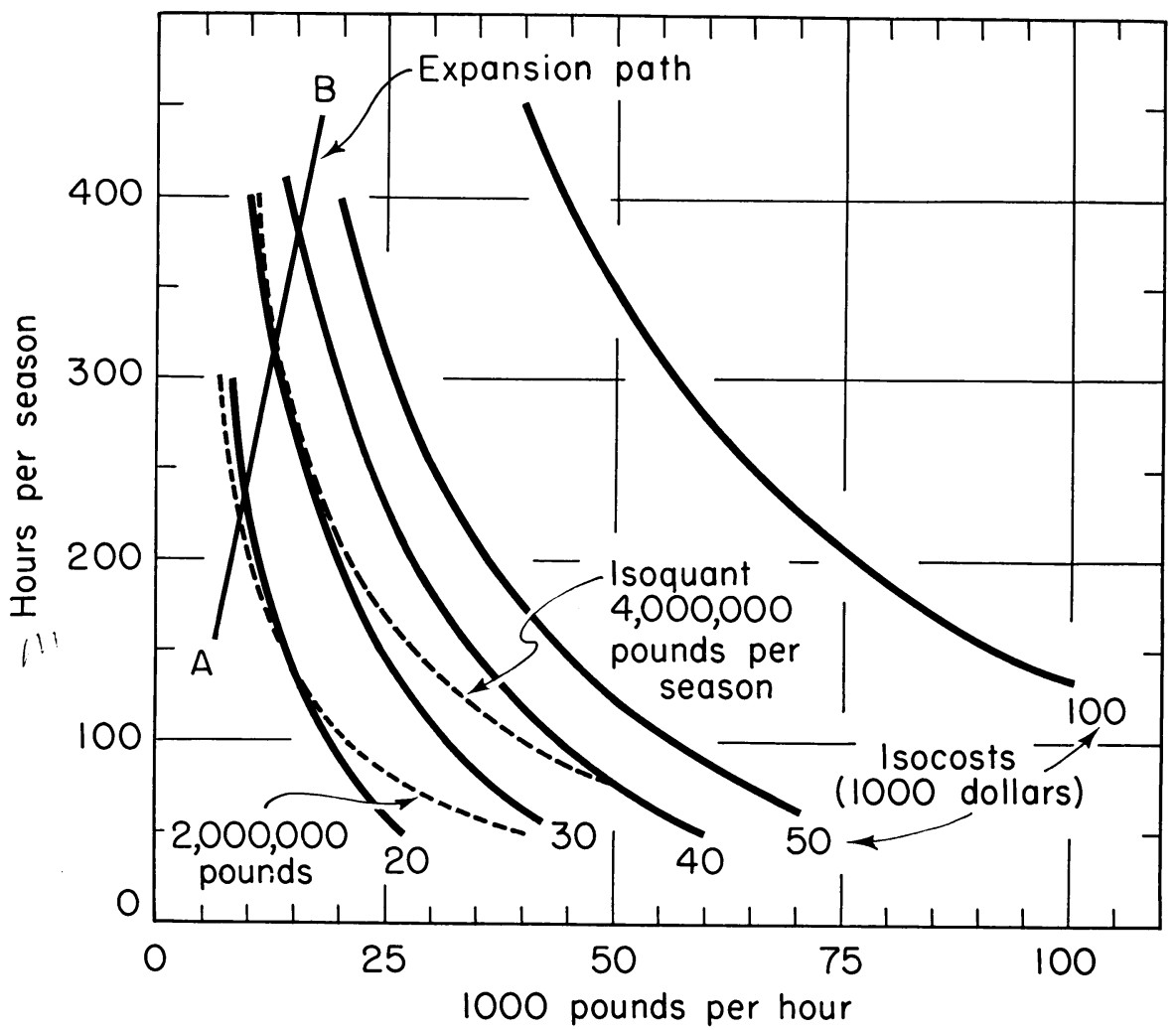

Fig. 58. Isocost-isoquant map for hours of operation per season and rates of output with 70 per cent packed.

path, for it shows the optimum "expansion" in hours and rates with increased season volume. From equations (29) and (30) it may be seen that the equation for this expansion path is:

$$
H=25.12 V_{t}
$$

In other words, hours and rate of output are expanded in constant proportions with increases in season volume in the ratio of approximately 25 hours to 1,000 pounds of fruit per hour.

Substituting the equation for optimum hours (29) in the total cost function (28) gives the following expression:

$$
C=2,781+160.38 \sqrt{S}+4.122 S
$$


In average terms, this becomes

$$
A C=\frac{2,781}{S}+\frac{160.38}{\sqrt{S}}+4.122
$$

Equation (33) - conventionally referred to as an economies of scale curveis shown graphically in figure 59. For plants handling 20,000,000 pounds per season, operation would be for nearly 24 hours per day for a fixed 30 -

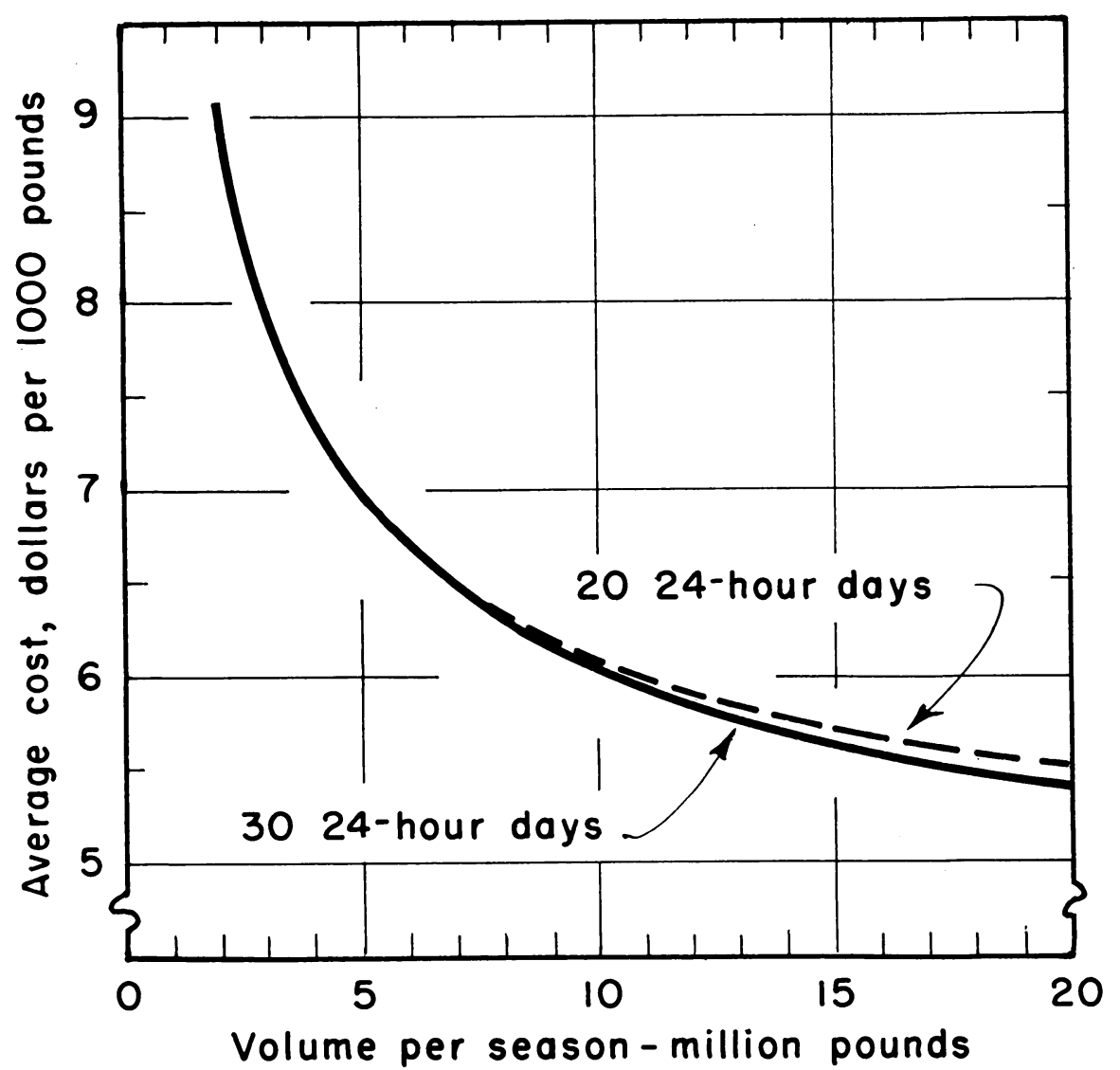

Fig. 59. Minimum long-run average costs in relation to season volume for plants with 70 per cent packed fruit.

day season, with a rate of about 28,000 pounds per hour. Beyond this, of course, volume could only be expanded by increasing rates of output with hours constant. With a 20 -day season, the 24 -hour limit would be reached with a season volume of $7,600,000$ pounds and a plant capacity of 15,900 pounds per hour. Further increases in season volume then would involve only increases in capacity. Average costs then would be as indicated by the dotted curve beginning at 7,600,000 pounds per season.

While this example is unrealistic in that it ignores the institutional and 
cost restrictions on variations in hours of operation per day, it serves to emphasize the importance of the time dimension in affecting costs. In the absence of restrictions on hours of operation, the most efficient plants for the largest season volume observed would be only about a third of the size of the largest pear packing plants observed in this study. The economies of expansion in hours strongly overshadow the gains from expansion in rate capacity.

Limited Hours Per Day. Omitting for the moment any possibility of double-shift operation, 10 hours of operation per day probably represents a practical average maximum that can be expected from a single crew. This means that on some days the plant might work as many as 12 hours but on others it would work eight or less. Assuming that there were no overtime pay requirements, the "expansion path" for any length of harvest period can easily be traced out on figure $58 .^{89}$ With a 30 -day season, for example, hours and capacity rate of output would be expanded along line $A B$ until the 300-hour limit was reached (30 days at 10 hours per day). Thereafter, the expansion path would move horizontally from 300 hours, that is, further increases in season volume could be achieved only by increasing plant capacity. With a 40-day season, line $A B$ would be followed until the 400 hour limit, then horizontally, and similarly for other lengths of harvest period.

The impact of these restrictions in operating time on average cost is illustrated in figure 60 . The solid curve and line of dashes repeat the cost functions shown in figure 59, with no restrictions on daily hours. The broken lines represent minimum average costs with an average 10-hour-per-day limit and with harvest periods of 20 and 30 days. With these restrictions, average costs are considerably higher than for the "no limit" case and the differences increase with increases in season volume and with decreases in length of season. For seasons of 20 days or less, costs are minimized (over the indicated volume range) by operating for the full amount of time available and season volume can be increased only by increasing plant size. With a season limit of 30 days, costs are minimized by varying both hours and rate of output as indicated by the solid line until a season volume of about $3,600,000$ pounds (and 12,000 pounds per hour capacity) is reached. At that point, the 300-hour limit is reached and further increases in season volume can be obtained only by increasing the capacity rate of output.

For all practical purposes, the restrictions on daily hours of operation mean that the hours of potential operation per season are fixed by the length of the harvest period. Except for a few cases where the season is long and the volume quite small, efficient handling of any season volume would always call for a plant capacity such that operation was for the maximum time available. And in the cases excepted, the cost with operation for the full time available would differ little from the costs with "optimum" combination of hours and rates.

\footnotetext{
${ }^{89}$ Agricultural operations are exempt from overtime pay requirements during a 14-week period. Some pear packing plants take advantage of this provision but most, because of union agreements or competition for labor supplies, pay overtime rates for all work in excess of eight hours per day.
} 
Under these circumstances, the curves showing the relationship between average cost and scale of operation can be represented conveniently in terms of capacity rate of output (size of plant) rather than season volume. A family of such economy of scale curves is shown in figures 61 and 62 for several proportions of packed fruit and for four lengths of season. With a simple calculation these curves could also be expressed in terms of volume per season.

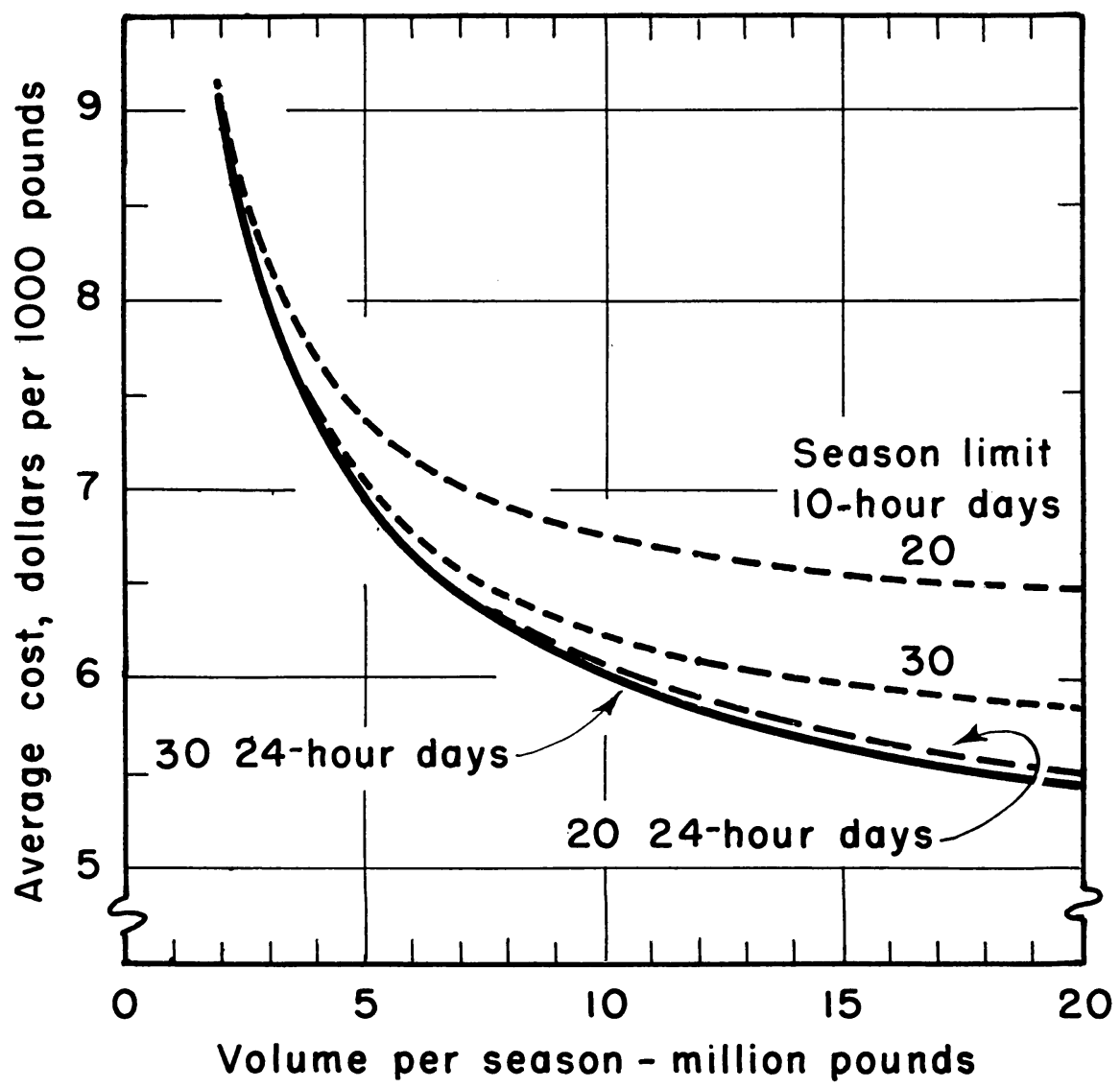

Fig. 60. Relation of average cost to season volume for plants with 70 per cent packed fruit and four levels of restrictions on season hours of operation.

These curves show that the major economies of scale are achieved at fairly low rates of output. This may be brought out most clearly by calculating the first partial derivatives of the average cost functions with respect to $V_{t}$. The long-run average cost function is:

$$
A C=\frac{2,781}{V_{t} H}+\frac{16}{V_{t}}+\frac{320}{H}+\frac{117 P}{H}+3.66 P+1.56
$$


where $A C$ is the average cost per thousand pounds of total output and $P$ is the proportion of fruit packed. The partial derivative with respect to $V_{t}$ is:

$$
\frac{\partial A C}{\partial V_{t}}=\frac{-2,781}{V_{t}^{2} H}-\frac{16}{V_{t}^{2}}
$$

With $H$ held at 200, for example, the rate of reduction in average cost with increased rates of output is given by this equation as 13.3 cents per 1,000 pounds at 15,000 pounds per hour, 7.5 cents at 20,000 pounds, and only 1.2 cents by the time plant size has reached 50,000 pounds per hour. These rates of change are in terms of absolute values. A given percentage increase in rates of output for larger plants will result in a percentage reduction in average cost that compares more favorably with the rates of reduction in smaller plants. But even in these terms, the significant cost reduction possibilities are in the smaller plants, and the major advantages of increased size are largely exhausted by the time the rate of output reaches 50,000 to 60,000 pounds per hour.

Overtime Pay. Introduction of overtime pay rates into the analysis, while leaving the major conclusions and relations essentially unchanged, may affect the optimum plant size and season hours of operation for handling any given season volume of fruit. The increased pay rates for operation in excess of eight hours per day tend to make larger plants with shorter days relatively more economical.

To determine the optimum plant size and hours of operation under these conditions requires an estimate of the effects of varying amounts of overtime operation on total costs..$^{\circ 0}$ For purposes of illustration, it will again be assumed that 70 per cent of the fruit is packed. Overtime rates of pay (time and one half) are assumed to be paid for all operations beyond eight hours per day. The proportion of total hours at overtime rates then is given by the expression:

$$
\frac{H-N(8-1 / 6)}{H}
$$

where $N$ is the number of harvest days per season. The $1 / 6$-hour per 8 -hour day was selected to allow for the fact that to average eight hours per day would usually require overtime operation on some days due to seasonal variation in harvesting rates and rate of delivery to the packing house. With a typical 30-day season, for example, this allowance for overtime would amount to five hours of overtime operation. Observation in the sample plants suggests that this would be a practical minimum if operation were to average 8 hours per day. ${ }^{91}$

${ }^{90}$ It is assumed in this analysis that labor productivity on overtime is the same as on straight time. In some cases, the productivity of workers paid piece rates may increase with overtime pay rates. Usually this will only be sustained for short periods. Fatigue may tend to reduce the productivity of workers paid on a nonincentive basis. For the plants included in this study, however, over-all output rates did not appear to differ greatly with overtime as compared with straight-time operation.

${ }^{21}$ Some additional overtime operation may be required to meet special market situations or peak volumes, but this does not affect this analysis and for simplicity will be ignored. 


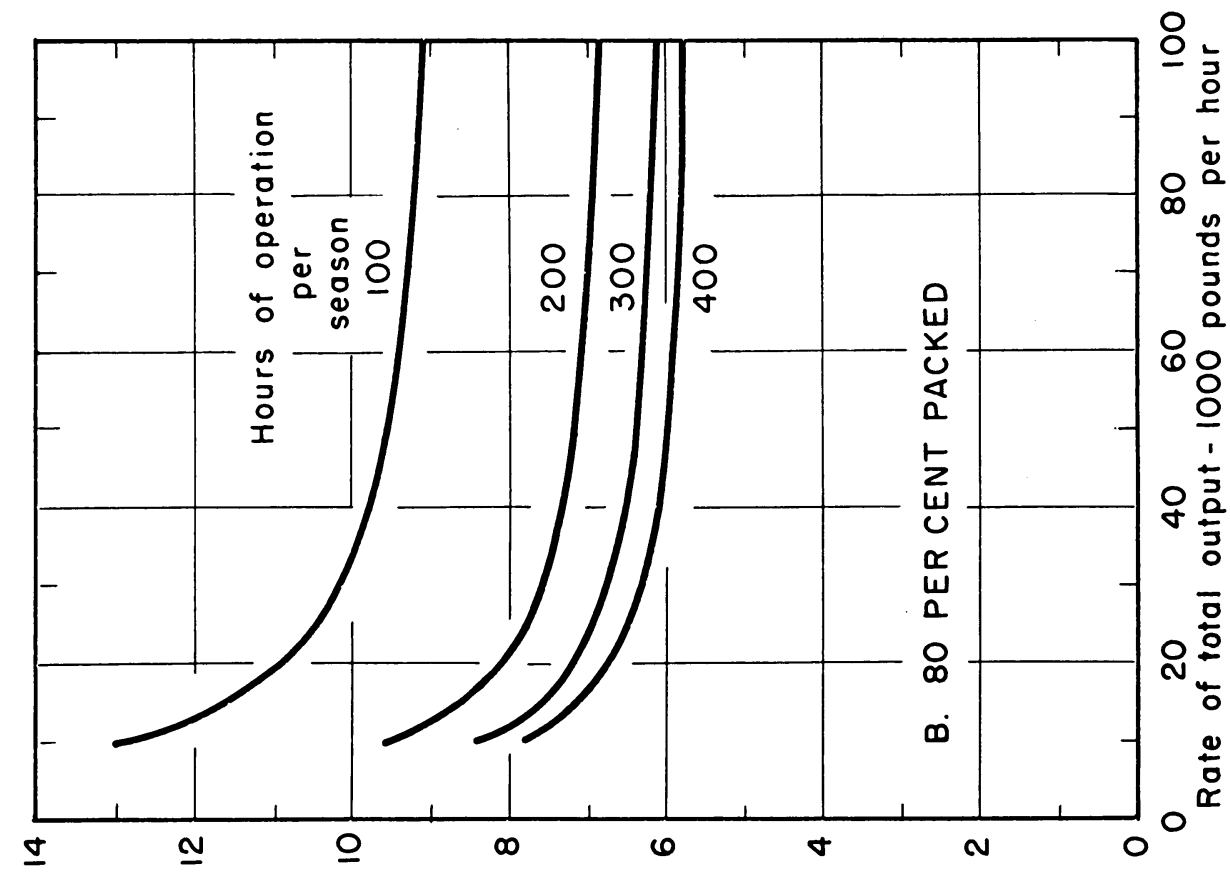

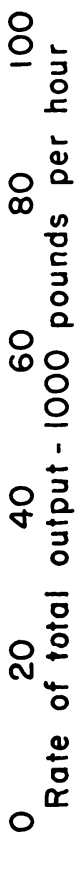

氶

so

:

氖

苛

పี

ฐี శี $4 \%$

○ 葛

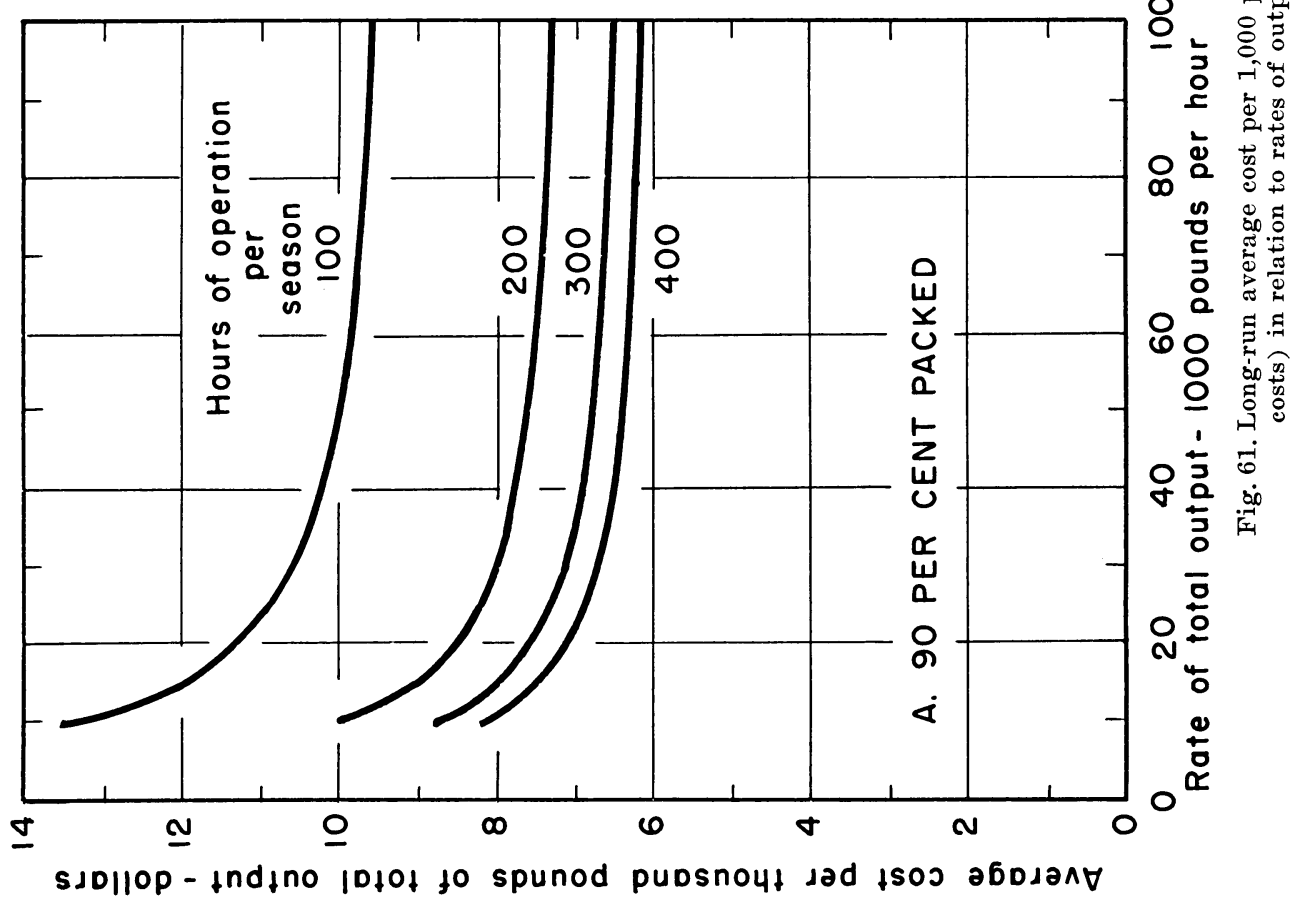




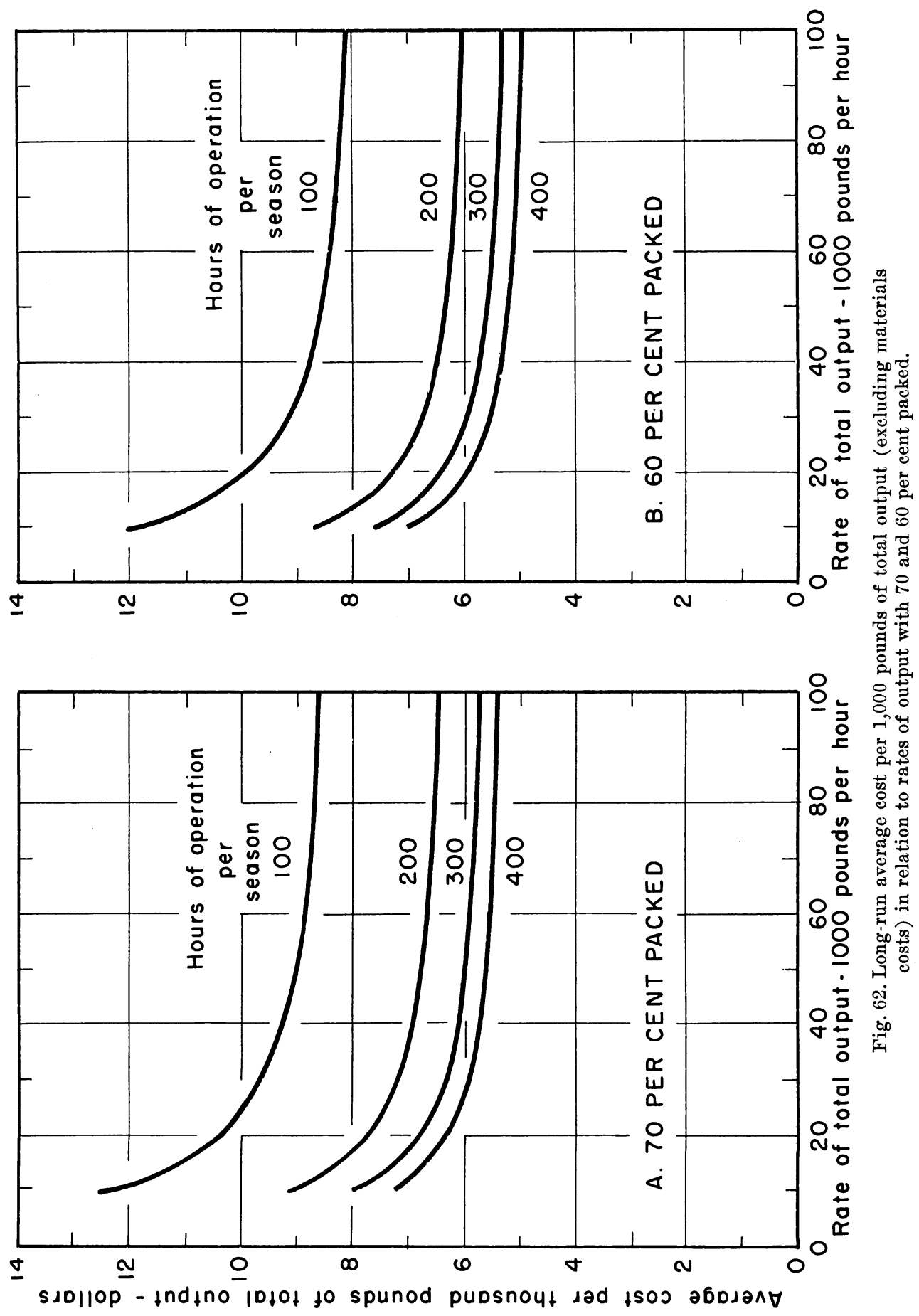


The proportion $r$ of variable to total costs is given by the expression

$$
r=\frac{H}{a / b+H}
$$

in which $a$ represents the annual fixed cost in a given plant and $b$ the variable cost per hour. From the data in tables 46,47 , and 48 the ratio $a / b$ in the above equation has the approximate values at capacity operation of 112 in a plant of 15,000 pounds per hour capacity, and 108 and 103 in plants of 40,000 and 70,000 pounds per hour eapacity. From these values an approximate expression for $r$ is

$$
r=\frac{H}{108+H} .
$$

About 90 per cent of variable costs consists of labor whose wage rates will be increased by 50 per cent during overtime operation. The percentage increase in total costs with overtime operation, therefore, is given by the expression:

$$
\left(\frac{H}{108+H}\right)\left(\frac{H-N(7.83)}{H}\right)(.9)(50)=\frac{45(H-N 7.83)}{108+H}
$$

From equations (28) and (39), total costs for operation in excess of $7.83 \mathrm{~N}$ can be expressed as:

$C=\left[2,781+16 H+401.9 \frac{S}{H}+4.122 S\right]\left[1+\frac{0.45(H-7.83 N)}{108+H}\right]$

Minimizing this function for any value of $S$, as before, determines the expansion path to be followed for season volumes in excess of the amounts that can be handled without overtime operation as indicated along line $A B$ of figure 58. For seasons of 25 days or more, the minimum cost occurs at a corner position at $H=7.83 \mathrm{~N}$ and overtime operation is not economical. This is illustrated in figure 63 which shows, with expanded scale, the $4,000,000$-pound-per-season isoquant and the $\$ 30,000$ isocost from figure 58. In addition, the isocost with overtime operation beginning at $H=7.83 \mathrm{~N}$ $(N=25$ days $)$ is shown. The "kink" in the isocost curve at point A and the lower position of the overtime curve reflect the higher cost rates with overtime operation-that is, with overtime, fewer hours are worked with a given season cost. Cost with a 25-day season is minimized, therefore, at the corner position. With a 30-day season, the expansion path in figure 58 follows line $A B$ to 235 hours $(7.83 N)$ and then moves horizontally at this level.

However, with a season as short as 20 days and with season volumes greater than 5,000,000 pounds, some overtime operation becomes economical. In this case, the expansion path in figure 58 follows line $A B$ to 157 hours $(7.83 \times 20)$ then horizontally to about 30,000 pounds per hour. Between 30,000 and 50,000 pounds per hour the path moves up to the 200-hour limit and thereafter moves horizontally since this is the suggested physical limit to the average hours of operation that can be expected from one crew. 
A significant characteristic of operation in the overtime area is the broad ranges where average costs remain fairly uniform due to a balancing of the higher costs rates with overtime against the cost reductions due to increased hours and so moving closer to the optimum indicated by the expansion path of figure 58. This is illustrated in figure 64 where total costs for handling a given season volume of fruit are shown in relation to hours

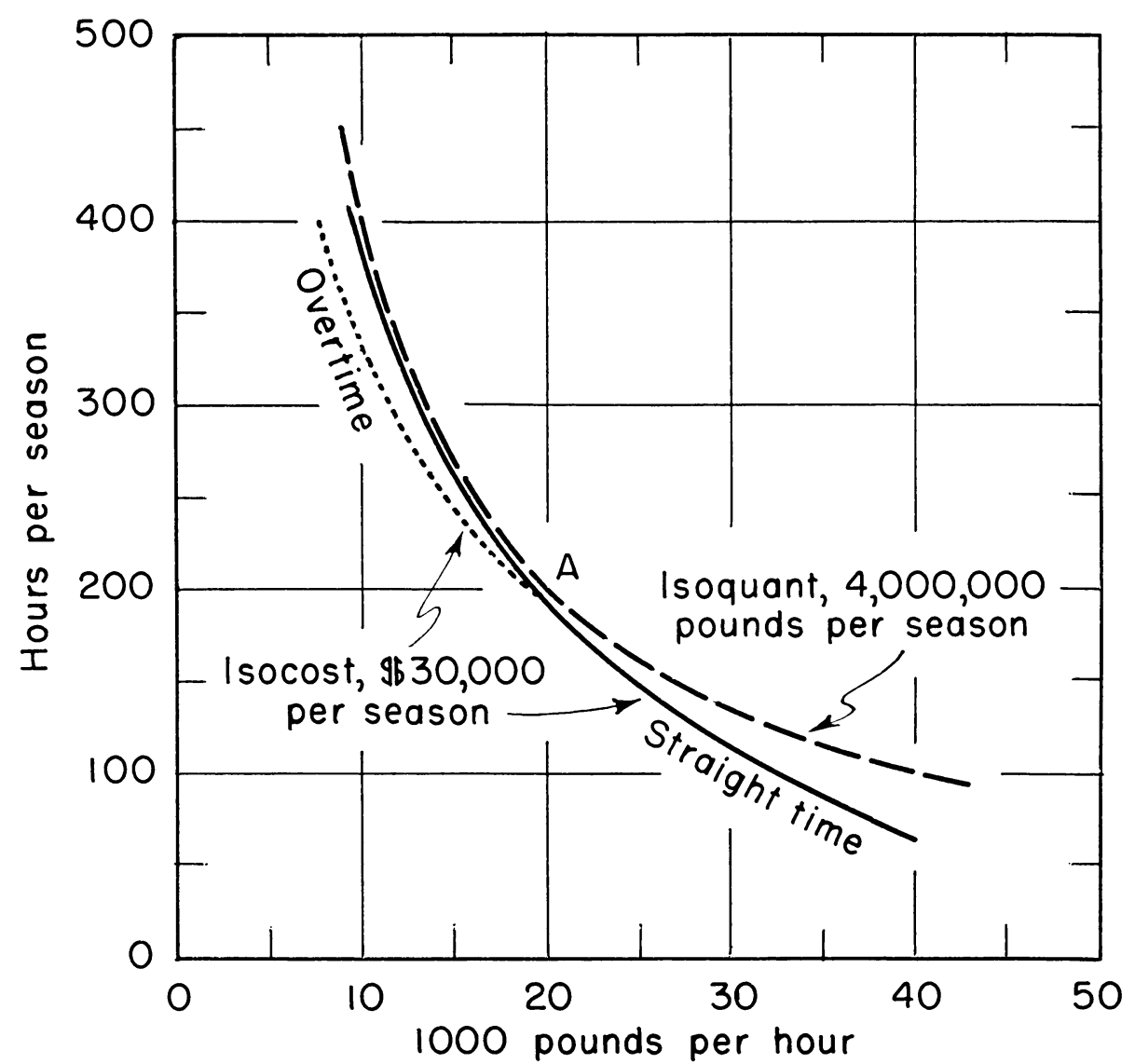

Fig. 63. Isoquant-isocost map for hours of operation per season and rates showing the effect of overtime operation on optimum combination of rate and hours of operation (70 per cent packed).

of operation, assuming a 30-day season. In each case, total costs per season for handling a given quantity of fruit decline as hours of operation are increased (and plant size decreased) and reach a minimum at 235 hoursthe limit of the straight-time pay range. Further increases in hours and decreases in plant size involve higher costs, but the point to be stressed is that these costs increase only slightly over a considerable range. For example, for a season volume of $10,000,000$ pounds, plants with eapacities from about 36,000 to 42,000 pounds per hour give about the same total cost. 


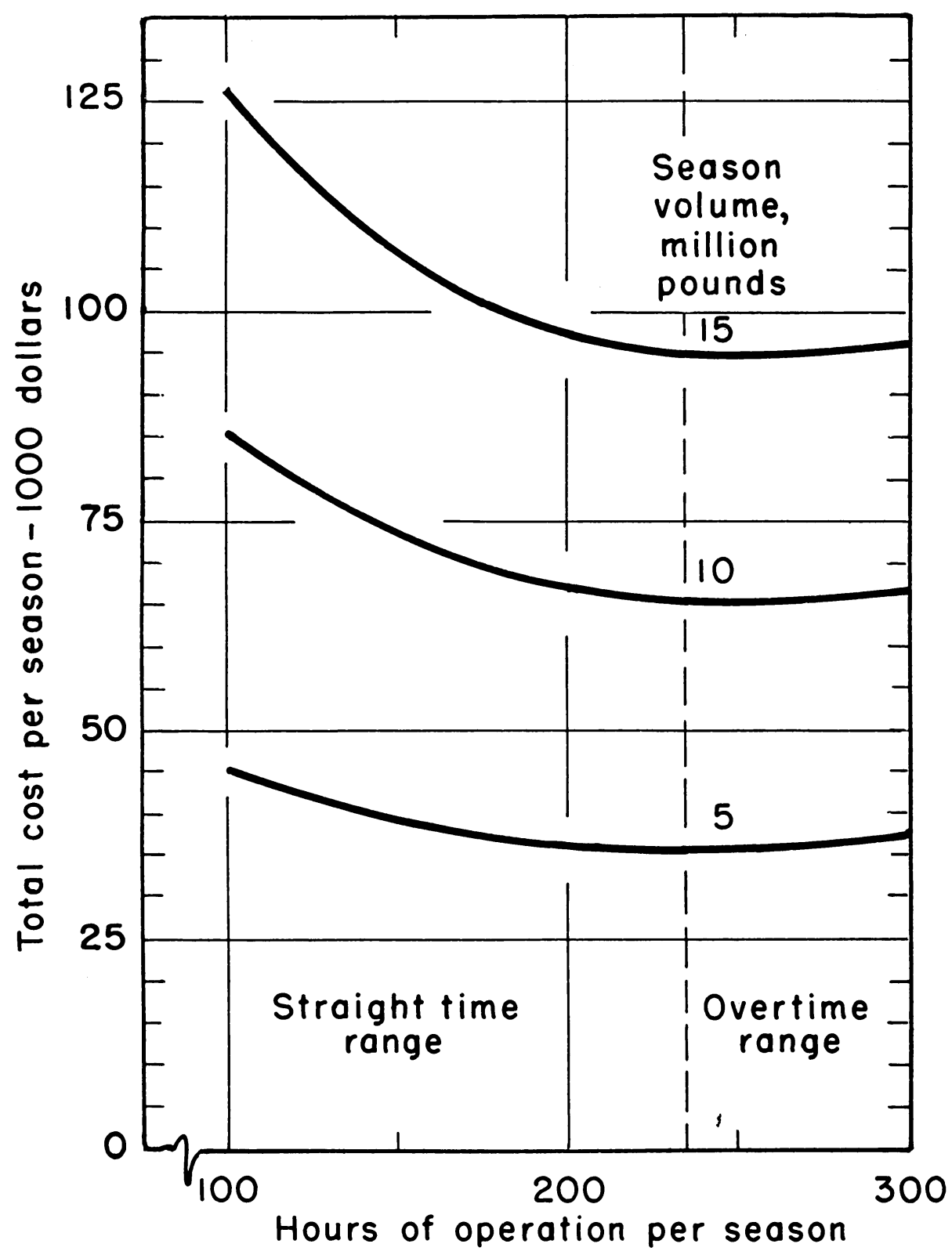

Fig. 64. Relation of total cost to hours of operation per season for given season volumes and overtime pay for all hours over 235 , with 70 per cent packed fruit. 
This means that, if a plant manager misjudges and builds a plant too small to handle his season volume without overtime operation, the penalty is not very great. And if an error is to be made, the diagram suggests that it is better to underbuild than to overbuild, for costs rise less rapidly with deviations from the optimum in the direction of small plants with overtime payments.

A similar condition holds where a plant is "ideally" constructed to handle a given season volume and where the volume unexpectedly increases. This situation is illustrated in figure 65 for a plant of 40,000 pounds per hour capacity and a 30-day season. Average costs for this plant decline continually as season volume increases up to the quantity the plant was designed to handle $(9,400,000$ pounds) and operation reaches an average of 7.83 hours per day for 30 days ( 235 hours per season). Thereafter to increase season volume, the plant must work overtime at increased cost rates. However, the increased costs are almost exactly balanced by reduction in average fixed costs so that average costs remain virtually constant over the range at which the plant is able to operate-an average of ten hours per day. Of course, if the increased season volume could have been anticipated, then a larger plant would have given slightly lower costs as indicated by the long-run cost curve shown in the diagram. But the important point is that, once a plant is constructed, increased season volume, involving overtime operation within the practical limit described above, may be handled with little or no increase in average cost even though overtime pay rates are required.

Two Shifts. One means of obtaining at least a part of the cost advantage of longer seasons would be to operate two shifts. Although this might involve practical difficulties in recruiting labor and maintaining labor relations, it appears to offer enough advantage under some conditions to be worth considering.

The reductions in average costs due to increased hours and volume with two-shift operation must be balanced against the higher costs of the double shifts. Very roughly, increased storage requirements for incoming fruit would add about $\$ 18.50$ per 1,000 pounds of hourly capacity to building costs, and it will be assumed arbitrarily that pay rates for the night shift might be about 10 per cent higher. ${ }^{22}$ Possibilities of reduced productivity with the second shift will be ignored or assumed covered by larger costs based on the increased pay rates. Assuming 70 per cent packed, the percentage increase in total costs due to the higher costs for the second shift is given approximately by the expression:

$$
\frac{H}{108+H}(.9)(.5)(10)=\frac{4.5 H}{108+H}
$$

The addition to total costs with two-shift operation (i.e., costs in addition to those that would have been incurred with a season of the same length but only one shift) then is:

$$
C_{2}-C_{1}=18.50 V_{t}+\left(\frac{.045 H}{108+H}\right) C_{1}
$$

${ }^{82}$ Additions to building costs were estimated on the assumption that receiving floor space would be doubled. See Sammet and Davis, op. cit., for details on floor space requirements. 
where $C_{1}$ and $C_{2}$ are total costs with one- and two-shift operation. The longrun total cost function for two-shift operation (with 70 per cent packed fruit) then is:

$$
C_{2}=18.50 V_{t}+C_{1}\left(1+\frac{.045 H}{108+H}\right)
$$

Again, the expansion path is defined by minimizing the cost function with respect to $H$ subject to the condition that $V_{t} H$ remains constant. For twoshift operation, the expansion path cuts the horizontal (volume) axis at

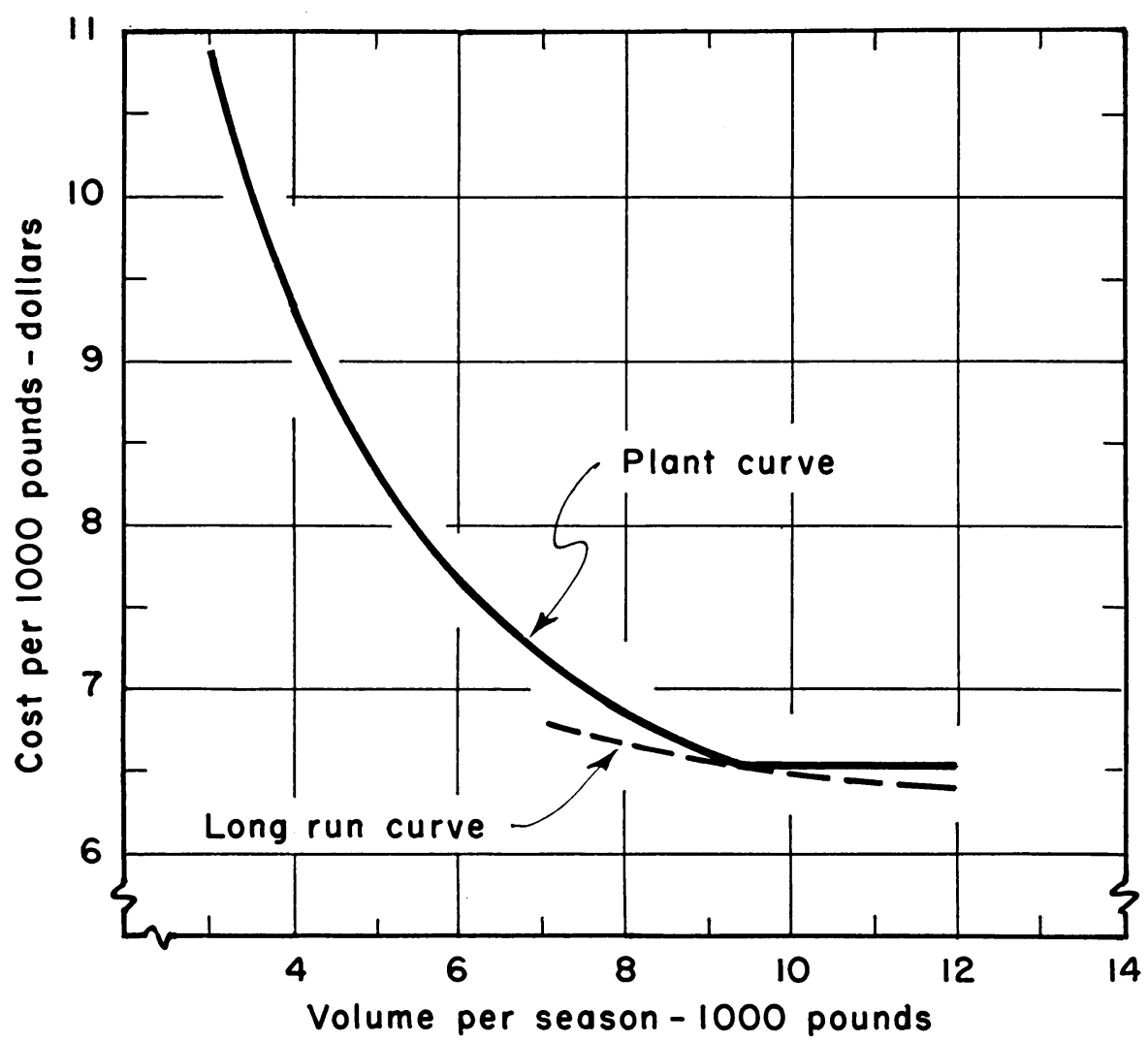

Fig. 65. Relation of average cost to season volume for a plant of 40,000 pounds per hour capacity and a 30-day season with 70 per cent packed fruit.

about 4,000 pounds per hour and then moves diagonally upward, passing through the point 470 hours and 10,600 pounds per hour (fig. 58). With season limits of 30 days (averaging 15.7 hours per day), the expansion path would move horizontally from this point. For 20 days, the path would move horizontally from 312 hours and about 9,000 pounds per hour and so on.

Average costs with double-shift operation are shown in figures 66 and 67 in relation to season volume and in comparison to average costs with the operating situations that have been considered. Figure 66 shows the costs 
for a 20-day season and figure 67 for a 30-day season. For seasons as short as 20 days, the two-shift operation appears to offer an advantage over both the situation where overtime pay is required beyond 8 hours and where plants are free to work as many as 10 hours (on the average) with no increase is cost rates. But with seasons of 30 days, the relative cost advantages are changed. Ten-hour days with no overtime become more economical than

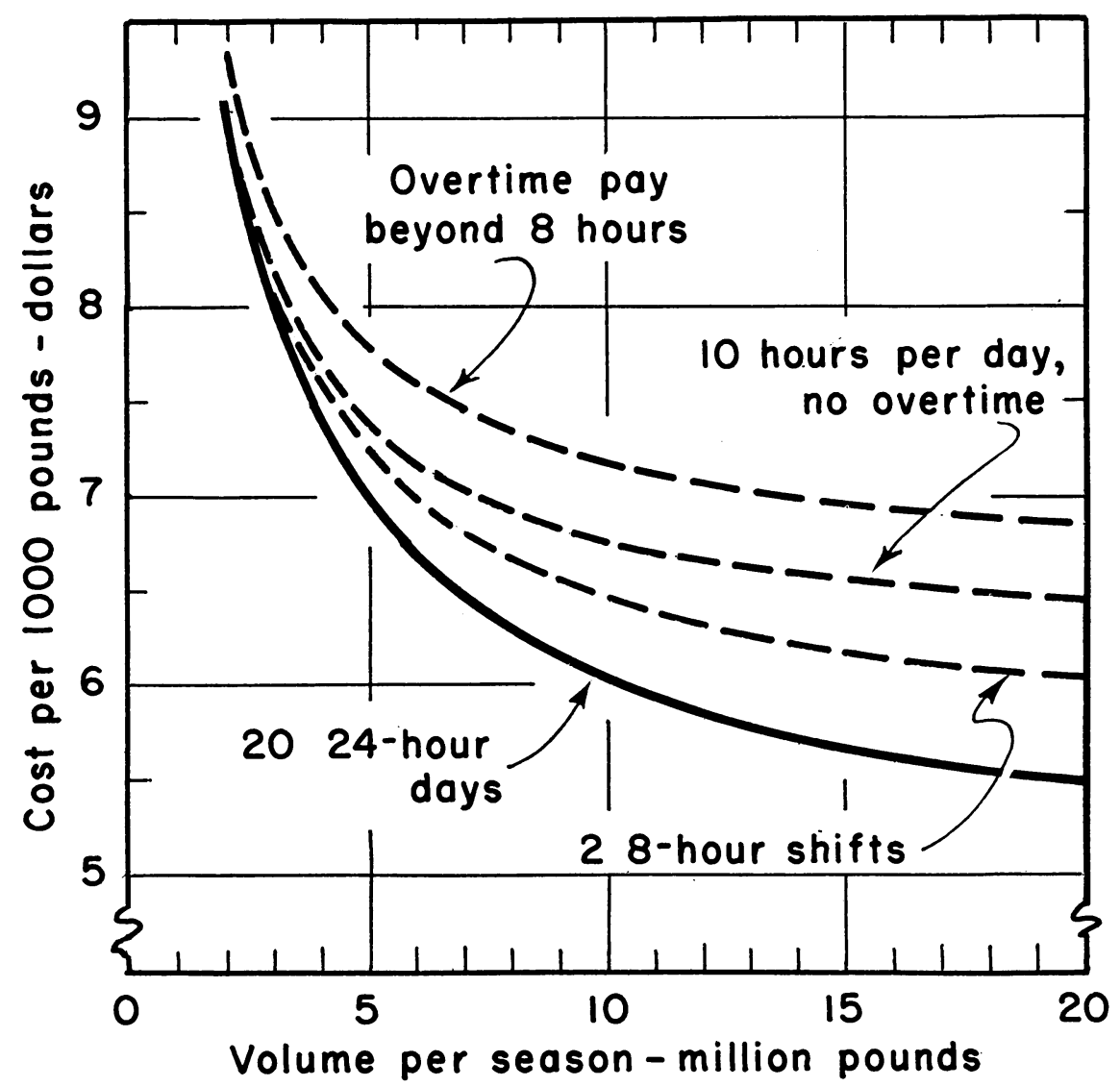

Fig. 66. Relation of average cost to season volume for four operating situations; a 20-day season and 70 per cent packed fruit.

two shifts for season volumes up to about $13,000,000$ pounds. If overtime pay is required, then plants that work 8 hours per day are most economical for season volumes up to about 7,000,000 pounds. And in all ranges, the differences in costs among these situations are narrowed considerably as compared with the 20-day season. As days of operation increase, the curves for 8- and 10-hour days approach the "no limit" curve and all cost differences are further reduced, with the two-shift operation becoming relatively less advantageous. 


\section{Problems of Flexibility}

One of the important problems in pear packing operations is how to adjust economically to considerable fluctuations in daily volume of fruit received throughout the packing season. In most cases output increases fairly rapidly during the early days of the season, levels off near the peak, and then declines rapidly at the end. In some instances a small volume of pro-

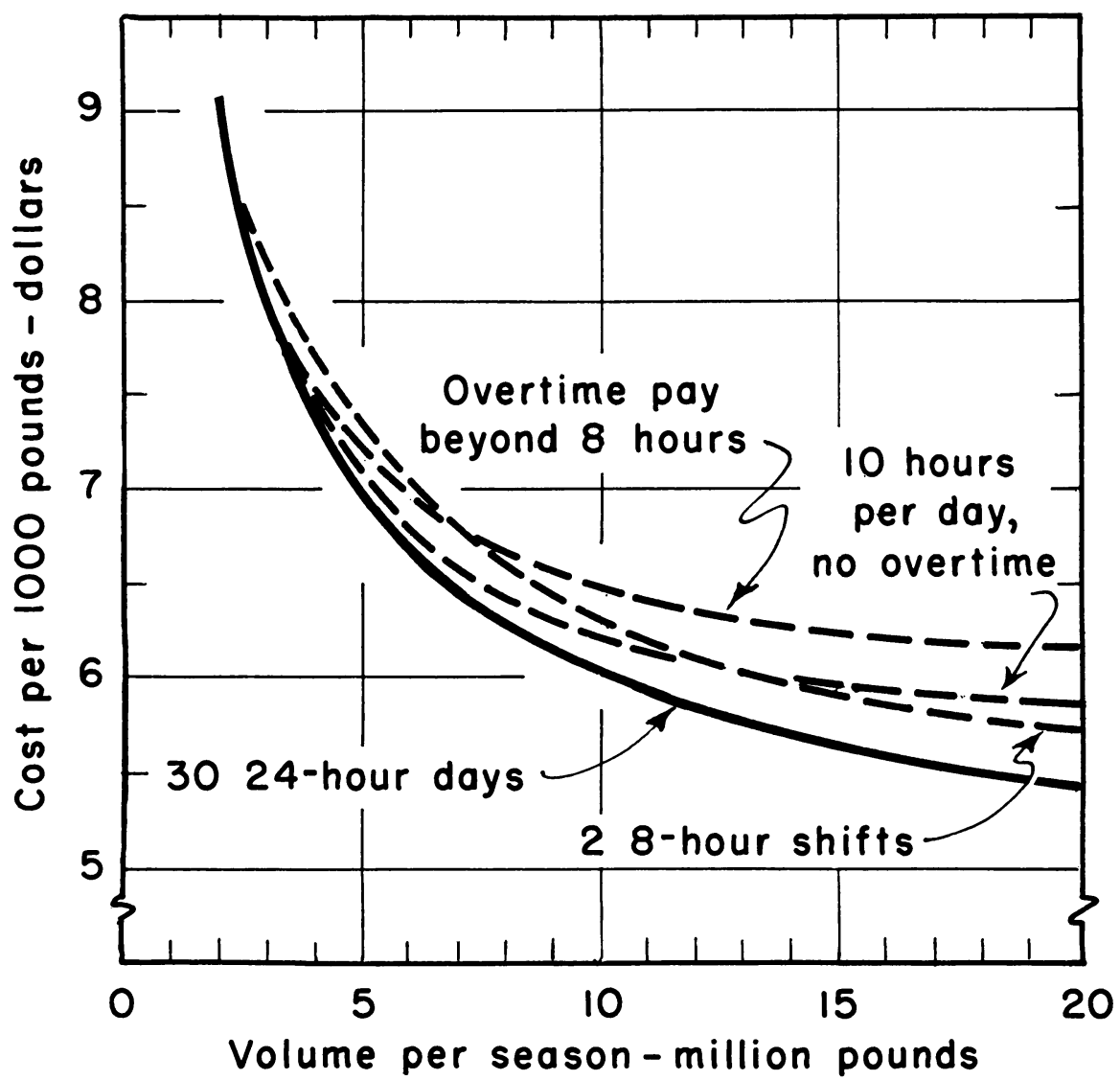

Fig. 67. Relation of average cost to season volume for four operating situations; a 30-day season and 70 per cent packed fruit.

duction may continue for a number of days at the end of the packing season. The major adjustments to these variations occur through variations in daily hours of operation. This permits the plant to operate at its most efficient rates of output with little change in cost rates, except where overtime pay is required-see previous discussion. In the sample of plants studied, overtime operation averaged about 5 per cent of the total hours. However, there was considerable variation in this proportion among plants.

During some days at the beginning and end of the season, the volume of 
produce available could be handled in a very short time if the plant rate capacity were fully utilized. But both legal restrictions and the maintenance of satisfactory labor relations (including holding the erew) may require that workers be paid for some minimum number of hours. Under these circumstances, the total labor force may be reduced and the plant operated at less than capacity rates, but for a greater number of hours per day. In the plants studied, about 75 per cent of the total hours per season represent operation at full capacity rates. Rates of output for the remaining 25 per cent of the time varied within and among plants but averaged about one half of the capacity rates.

To estimate total costs for these situations requires that variable costs per season be calculated for the hours operated at full capacity and at each per cent of capacity. To these costs then are added the fixed costs to give the total cost per season. Costs of alternative technologies for the specified conditions are compared as before and the season costs for each segment of the plant aggregated to obtain total costs.

The earlier parts of this section of the paper contain the data necessary for these calculations, and cost functions can be computed for every alternative situation that might exist with regard to variations in rates of output. Calculations of a number of short-run cost curves for efficient flexible plants suggest that for the average variation observed in the plants studied-approximately 25 per cent of the hours at one-half capacitytotal costs are from 1 to 4 per cent higher with variable than with constant rates of output.

To illustrate, recall that the short-run cost function for a plant designed for 40,000-pounds-per-hour capacity, 70 per cent packed, and a 200-hour season is given in equation 18 as,

$$
C_{h}=18+4.0 V_{t} .
$$

For this plant, labor and operating costs per thousand pounds are approximately 11 per cent higher at one-half than at full capacity $(40,000$ pounds per hour). With 25 per cent of the hours at one-half capacity, this would increase average variable costs by 1.57 per cent as compared with the costs required to handle the same volume at constant rates. For the season volume that could be handled with 200 hours operation at capacity rates of 40,000 pounds per hour $(8,000,000$ pounds), the final increase in total costs would be about 1 per cent. In general, the percentage increase in costs with variable rates tends to increase slightly with decreases in the size of plant and with decreases in proportions of packed fruit.

Variation in rates of operation in a given plant while causing increased total costs, apparently has little effect on the selection of technologies, at least for the range of variation noted above. Costs with variable rates of output were calculated for a dozen or more "borderline" cases where it appeared that the needs for flexibility might cause a shift to a different technology. In each case, however, and holding volume per season at a particular level, the same technology proved to be most efficient for both constant and variable rates. 
Under some circumstances it may be expected that the methods that are most economical for pear packing plants with variable rates of operation will differ from those with constant rates. However, because of the many discontinuities involved, the amount of cost difference will generally be small and will not cause a shift in technology. Thus, there is no great penalty for building a plant in terms of constant rates specifications even though the rates may actually vary. Nearly all technologies provide a considerable amount of flexibility.

This suggests that the combinations of technologies indicated in tables 43 and 44 may give fairly close approximations to the technologies that would be most efficient for the amount of variation that appears to be typical for pear plants. In using the tables for this purpose, hours per season should be modified to read equivalent hours per season at capacity rates of operation. This is just a way of converting the flexible plant to the same volume per season as the constant rate plant. In this case, two hours at one-half capacity would be taken as one hour at full capacity. More precise indications of most efficient methods for flexible plants and estimates of the magnitude of the associated costs can be calculated from the material in the section on stage technologies and component cost standards.

In addition to the variation in total volume during the season, there is also some variation in the proportions of packed and cannery and cull fruit. For small variations in proportions ( 4 to 5 per cent), the average proportions or rates of output of packed and cannery fruit may be substituted in the long-run cost function with little damage to the estimates of plant. costs. The values and standards on which the cost function is based are themselves "averages" which permit a small range of variation around any given rate of output. However, when there is a considerable range in proportions of packed and cannery fruit extending for fairly long periods, the long-run cost function based on constant proportions is no longer appropriate. Cost functions for the given circumstances, and representing effcient operation, can be calculated from the performance and cost data for each stage technology and eost component.

These computations must take account of the impossibility of designing a plant so as to avoid excess capacity in some stages when proportions of products fluctuate around the rates for which the plant was designed. For example, a plant might be designed with a receiving and grading eapacity of 50,000 pounds per hour, a packing capacity of 40,000 pounds per hour, and cannery and cull capacity of 10,000 pounds per hour. As long as the proportions packed remain at 80 per cent, all plant segments could be used to capacity. But with a shift to 90 per cent of packed fruit, the packing equipment would become a "bottleneck" and total output would be reduced to a little under 45,000 pounds per hour. The cannery belts would be only partially utilized. Similarly, if proportions changed to 70 per cent packed, the cannery and cull facilities would become a bottleneck and total output would again be reduced and the packing facilities would not be fully utilized. In general, however, the additional equipment required to handle these variations does not greatly increase the average costs of operation. A 10-per cent increase in receiving, dumping, and grading equipment, for 
example, would usually increase total plant costs (excluding materials) by no more than one half of 1 per cent.

\section{Changes in Prices and Wages}

The standardized wages and prices that have been used, while typical of conditions throughout the industry, will not apply to all individual plants or in all seasons. Local labor conditions and customs, special discounts, opportunities to purchase used equipment and the like may lead to levels of costs and plant organization that differ somewhat from the various "optimums" suggested by this study. Changes in relative costs of labor and equipment over time may have similar effects.

The advantage of the approach used here is that the findings can be adapted to the conditions facing individual plants and to changing levels of prices and wages, for the cost functions are built up from detailed physical input-output relations. Because of space limitations and the many alternatives that could be considered, no attempt will be made here to recombine the basic estimates using other wage rates and prices.

Recombining the stage functions using more recent 1954 wages and prices, rather than the 1950 data actually used, would increase the level of the total cost function but would have little effect on alternative technologies. Building and equipment costs in 1954 were some 15 or 16 per cent higher than in 1950 ; wage rates appear to have increased 16 to 17 per cent. ${ }^{93}$ The wage rate increase was fairly uniform among most jobs. Since equipment and labor prices have increased in roughly the same proportion, the primary effect of introducing 1954 wages and prices would be to increase total costs by about 16 per cent. Materials costs had increased about 9 per cent in 1954 to an average of $\$ 0.559$ per standard box of 48 pounds net weight plus $\$ 0.025$ for loading materials for a total of about $\$ 12.17$ per 1,000 pounds packed. This figure may be added to the long-run cost curve but does not otherwise alter the function.

\section{Potential Cost Savings}

The foregoing analysis has suggested that, aside from possible new innovations, the principal sources of economies in pear packing are in (1) selection of efficient combinations of technologies and (2) increased scale of operations both in terms of larger plants and longer seasons. Comparison of the sample plants with the "optimum" indicated by the long-run cost curve shows that the sample plants have achieved a considerable portion of these economies and are operating, on the average, with a relatively high degree of efficiency. This is particularly true in view of the short seasons and uncertainties concerning supplies of both fruit and labor. However, achievement of some additional long-run economies is still possible.

Table 49 gives a rough indication of the long-run savings that might be achieved in the sample plants through use of the efficient combinations of

${ }^{93}$ Estimates of increased building and equipment costs are based on an extension of indexes of price levels for packing house buildings and equipment appearing in Sammet and Davis, op cit. Estimates of wage rate increases were obtained through a survey of the sample plants with regard to their 1954 wages. 
technologies represented by the long-run cost curve. The first three columns give the rates of output and standardized costs for the plants represented in tables 4 and 5. Rates of output are expressed in terms of 1,000 pounds of total output rather than boxes or tons, with the proportions of packed fruit indicated in the second column. Costs are expressed as averages per 1,000 pounds of total output and are, of course, lower for plants with large proportions of cannery fruit, as the nonpacked produce is less costly to handle. Materials costs are again omitted.

TABLE 49

COMPARISON OF ACTUAL AND POTENTIAL AVERAGE COSTS FOR 11 CALIFORNIA PEAR PACKING PLANTS*

\begin{tabular}{|c|c|c|c|c|c|}
\hline \multirow{2}{*}{ Plant } & \multirow{2}{*}{$\begin{array}{l}\text { Rate of } \\
\text { total out- } \\
\text { put, } 1,000 \\
\text { pounds } \\
\text { per hour }\end{array}$} & \multirow{2}{*}{$\begin{array}{l}\text { Per cent } \\
\text { packed }\end{array}$} & \multicolumn{2}{|c|}{$\begin{array}{l}\text { Average cost per } 1,000 \\
\text { pounds of total output }\end{array}$} & \multirow{2}{*}{$\begin{array}{c}\text { Potential } \\
\text { savings } \\
\text { per } \\
1,000 \\
\text { pounds }\end{array}$} \\
\hline & & & present $\dagger$ & potential $\ddagger$ & \\
\hline & & & dollars & dollars & dollars \\
\hline 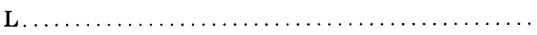 & 19.4 & 77 & 10.73 & 7.53 & 3.20 \\
\hline$\ldots \ldots$ & 24.8 & 54 & 6.45 & 6.24 & 0.21 \\
\hline N... & 39.4 & 87 & 9.76 & 7.21 & 2.55 \\
\hline $\mathrm{P}$. & 37.1 & 86 & 9.69 & 7.20 & 2.49 \\
\hline Q. & 30.0 & 97 & 10.58 & 7.85 & 2.73 \\
\hline R... & 46.3 & 54 & 7.03 & 5.75 & 1.28 \\
\hline S.... & 45.9 & 65 & 8.12 & 6.21 & 1.91 \\
\hline $\mathbf{T} \ldots$ & 46.4 & 37 & 6.07 & 5.03 & 1.04 \\
\hline $\mathrm{U} \ldots \ldots$ & 60.6 & 84 & 7.91 & 6.85 & 1.06 \\
\hline$\ldots \ldots \ldots \ldots \ldots \ldots \ldots \ldots$ & 68.4 & 66 & 6.81 & 6.03 & 0.78 \\
\hline$\ldots \ldots \ldots \ldots \ldots \ldots \ldots \ldots \ldots$ & 65.2 & 60 & 7.36 & 5.82 & 1.54 \\
\hline Average $\ldots \ldots \ldots \ldots \ldots$ & 44.0 & 70 & 8.23 & 6.52 & $1.56 \S$ \\
\hline
\end{tabular}

* Costs based on 1950 price and wage levels. Materials are omitted.

$\dagger$ These are the standardized costs given in tables 4 and 5 , reduced by 3 per cent to allow for certain items not included in the long-run cost curve. Costs are based on a 240 -hour season.

$\ddagger$ Calculated by substituting corresponding rates of output in the long-run cost function and based on a 240 hour season.

$\S$ Weighted by rates of total output.

It will be recalled that the costs for the sample plants were obtained by applying standardized wage rates and prices to the physical quantities of labor and durables noted in each plant. These prices and wages are the same as those used in developing the cost standards on which the long-run cost curve is based. The costs are appropriate for the specific rates of output given in the table, which are average rates with full utilization of the plant equipment and facilities. The costs are further standardized for a 240-hour season, which is slightly greater than the season average for the industry but probably is about the effective limit for most plants. Finally, the costs are reduced by about 3 per cent from those shown in tables 4 and 5 to allow for the omission of certain miscellaneous costs in the long-run cost functionunemployment insurance, land cost, and miscellaneous items that appear to be a part of distribution costs and which could not be properly separated in the plant records.

The fourth column of the table contains estimated average costs based on the long-run cost function for plants with rates of packed and cannery output 
corresponding to those in the sample plants and for the same length of season ( 240 hours). The last column shows the difference between these two estimates and constitutes the estimated long-run savings per 1,000 pounds that could be realized through the adoption of the most economical combinations of technologies. The average savings weighted by rates of total output amount to $\$ 1.56$ per 1,000 pounds. Applying this figure to the annual average 1950-1952 packing house volume for the industry-144,000 tonsthe average annual savings would amount to about $\$ 450,000$ in terms of 1950 prices. $^{\text {}}{ }^{4}$ Since our sample plants are not necessarily representative of the industry, this should be viewed as an indication of approximate magnitude rather than a precise industry estimate.

A part of these savings could be achieved in a relatively short time-for example, a conveyor might easily be substituted for hand trucks for packed fruit with little loss in investment. Most of the savings, however, are achievable only over a long period. They require substitution of important items of equipment and building construction and this will usually be profitable only as existing facilities are replaced. In most plants, the reductions in variable costs through changing to different technologies are not great enough to warrant scrapping existing equipment. To be profitable in the short run, the combined variable and fixed costs of the new equipment or technology, with allowance for the scrap value of old equipment, must be lower than the variable cost alone for the existing equipment.

One important qualification may be noted with regard to these estimates of potential savings. With as much uncertainty and variation concerning labor supplies and supplies of fruit as do in fact exist, most plants will find it difficult fully to achieve the adjustment of inputs and outputs indicated by the long-run cost function, although with efficient management the discrepancy should not be great. The costs for some of the sample plants also contain a minor amount of labor costs at overtime rates of pay-jobs such as car loaders and receiving truckers-not included in the long-run cost estimates. Allowing for these factors, the average savings would be reduced to about $\$ 1.25$ per 1,000 pounds or $\$ 360,000$ per year for the industry - still a substantial figure.

Further savings may be possible through increasing total volume per season by plant consolidation. A complete statement of such savings would require consideration of costs of assembly of the produce as well as in-plant costs, but some tentative conclusions are possible based on the long-run cost function alone.

Considering first the possibilities of expansion in the rate of operation, approximately 40 per cent of the existing pear plants in California are under 20,000 pounds per hour in total capacity. If these plants could be consolidated, in the long run, into plants with an average capacity of 35,000 to 40,000 pounds per hour, the average annual saving in in-plant costs would

${ }^{94}$ Total volume for the industry amounted to about 300,000 tons. A large portion of the pears went directly from orchards to canneries. The 144,000 tons is the estimated quantity through packing houses. Proportions of fruit packed for fresh shipment as reported by the sample plants in the various districts were applied to the total California Tree Fruit Agreement figures on fresh shipments to obtain estimates of total volume through packing houses. 
amount to approximately $\$ 1.20$ per 1,000 pounds of fruit handled, or roughly 15 per cent of the total costs excluding materials.

In most instances, the consolidation probably could be achieved without very large increases in assembly costs, as the absolute volume change suggested is not large and the production areas tend to be fairly concentrated in most districts. However, while such savings might be achieved by consolidating 40 per cent of the existing plants, these plants represent only about 20 per cent of the total industry output. In terms of 1950 prices and with average 1950-1952 volumes of production, the savings for the industry would thus amount to roughly $\$ 70,000$ per year. Another saving in in-plant costs of about 40 cents per 1,000 pounds might be achieved in the plants in the 20,000 to 40,000 group if they were consolidated into plants averaging 50,000 pounds per hour. These plants represent about a third of the total industry volume and the additional savings would amount to about $\$ 35,000$ per year. In terms of 1954 prices, these savings would be about 16 per cent higher.

Since the average length of season in California pear packing plants is only about 200 hours, there are still some economies that may be achieved through expanding hours of operation per season. If double-shift operation (and, consequently, further consolidation of plants) could increase the average length of season to 300 hours, the cost savings for plants of 50,000 pounds-per-hour capacity would amount to about $\$ 0.50$ per 1,000 pounds (see table 47). Higher savings would be possible for smaller plants and slightly lower savings for larger plants. Average annual savings to the industry could amount to over $\$ 140,000$.

The total of these potential savings amounts to roughly 20 per cent of the in-plant costs (excluding materials cost), although greater percentage savings would be possible in some individual plants. These savings could not be achieved at once, of course, particularly with regard to expansion in plant size. Reduction of variable cost generally is not great enough to warrant the immediate abandonment of existing facilities and consolidation with other plants or building new or larger plants. If there were profitable alternative uses for the present buildings and items of equipment, this step might be economical in the short run; otherwise consolidation would have to be achieved over time as the present plants wear out. And, of course, even in the long run, vested interests in jobs and property values and difficulties of agreement among merging parties would probably prevent a complete attainment of an optimum organization.

\section{SUMMARY AND CONCLUSIONS}

The analysis presented in this paper has had dual objectives : first, to develop and present a theoretical framework and methodological approach to cost studies and, second, to apply this approach in a study of the operations of pear packing plants. This leads to consideration of two sets of conclusions-conclusions on production efficiency in pear packing and conclusions on the advantages and limitations of the theoretical and methodological approach used. 


\section{Major Findings with Respect to Pear Packing}

Primary emphasis in this study has been on the synthesis of a long-run cost function for pear packing from elemental input-output data. This function represents the cost of production with least-cost combinations of technologies and with reasonably efficient management and worker performance. The function provides a basis for planning optimum plant size for any given season volume and length of harvest period and for evaluating the economies of large-scale production in both the rate and time dimensions. The technological details presented along with the function show the specific complexes of technologies and plant organizations that can be expected to give least total cost for any point on the curve, given the price and wage rates used. Each point on the curve represents a plant.

The detailed material concerning input-output and cost data for the various stages and cost components provides a basis for determining shortrun variable cost curves for each of these plants; three such curves were developed for purposes of illustration. When minor discontinuities are smoothed, marginal costs are constant up to plant capacity. Average variable costs decline up to capacity due to a spreading of the quasi-fixed labor elements over larger volumes. Marginal and average variable costs are slightly higher in the very small plants, leveling off at about the same magnitude for all plants over 25,000 pounds-per-hour capacity. Most of the technological adjustments have taken place by the time capacity reaches 25,000 pounds per hour, and expansion above this rate is obtained by increasing the number of units of equipment.

The long-run cost function is basically discontinuous, but since the discontinuities are relatively small and the exact points at which they occur not precisely calculated, a smooth function was used as a convenient and close approximation. The principal characteristic of this function is its linearity in both the rate and time dimensions. In the rate dimension, the impact on costs of shifts in technology is relatively minor and the major increases in rates of output are obtained by multiplication of similar types of operating units, thus leading to linear functions. In the time dimension, most changes in technology have taken place by the time a 100-hour season is reached and total costs vary linearly with hours of operation.

Since the total cost function is linear, economies of large-scale operation are associated primarily with a spreading of fixed elements over larger total volumes. The major advantages of increased size are about exhausted when rate of output reaches 50,000 to 60,000 pounds per hour, although some further reductions in average cost will continue as plant size increases. Eventually, increased difficulties of management and coördination presumably would cause average costs to turn up. Increasing costs of assembly of the raw material would also impose limits on economical plant size.

Inasmuch as any given season volume of fruit can be handled by many different combinations of hours and rates of output, the long-run function must be solved for the particular combinations that give minimum total costs. In this sense, the long-run cost function becomes a true planning curve. With no restrictions on hours of plant operation, optimum plant size 
for the largest season volume observed among the sample plants would be only about one third the size of the largest pear packing plant observed in this study, and operation would be for nearly 24 hours per day. But with institutional restrictions on hours of operation, the length of season, for all practical purposes, becomes predetermined. Expansion of total volume must then occur primarily through increased rate capacity.

Introduction of overtime pay requirements into the analysis tends to shift optimum hours and rates slightly in the direction of larger plants and shorter hours per season, due to the added costs of operation in excess of eight hours per day. For seasons of 25 days or more, the optimum plant would be of a size that could handle the required season volume with no overtime operation other than required to meet unexpected peak deliveries or special market situations. Under most circumstances, however, moderate deviations from the optimum size, particularly in the direction of smaller plants, do not impose very severe penalties since the added costs of overtime pay rates are partially balanced by reduced average fixed costs with increased hours of operation per season. For short seasons, plants of a size that would require some overtime operation may actually be the most economical.

Similarly, a plant that is ideally constructed for a given volume per season can handle moderate increases in volume with little change in average costs. The higher costs for the overtime operation necessary to handle the increased volume are almost exactly balanced by reduced average fixed costs due to spreading the costs over larger volumes. Of course, if the increased volume could be anticipated, a slightly larger plant would give somewhat lower average costs.

Another possible means of increasing hours per day is to operate two shifts per day. Cost reductions that may be achieved through working more hours per season must be balanced against the added costs associated with two-shift operation. Cost comparisons indicate that two-shift operation offers some major advantages for plants with short seasons-20 to 25 days or less. But as the length of season increases, the cost advantages are reduced and may actually become cost disadvantages for plants with very long seasons and relatively small total season volume.

The study also indicates that the organization and equipment specified for plants represented in the long-run cost curve inherently provide a considerable amount of flexibility. Major adjustments to changing total volumes are through variation in hours of operation. However, average variable costs increase only slightly in the rate dimension with operation at less than full capacity. Plants tend to be organized into a series of identical "lines" so that (say) half capacity requires little more than half the full labor crew. The equipment also can easily handle minor variations in proportions of packed fruit, but with large fluctuations it may be necessary to build excess capacity in some stages to prevent large reductions in rates of output in others. The elemental input-output and cost data that are presented provide a basis for estimating costs and plant organizations for plants operating under such conditions.

Since the cost estimates are built up from elemental input-output rela- 
tions, the findings can be adapted to the conditions in individual plants (where different than specified in our general model) and can also be adjusted to changing levels of prices and wages. The original estimates were based on 1950 wages and prices. Use of more recent (1954) data would not greatly alter the efficient complexes of technologies, for both wage rates and equipment costs increased in about the same proportion. Prices for 1954, however, would raise the level of the long-run cost curve about 16 per cent. ${ }^{95}$

Although most pear packing plants have achieved a relatively high degree of efficiency, there are two major types of adjustments, aside from any possible innovations, which may lead to further cost reduction. These are: (1) selection of efficient technologies which would bring individual plant costs down to the level of the long-run cost curve; and (2) movement along the curve in terms of both increased hours and larger plants (and, consequently, fewer plants). Potential long-run industry savings are estimated to be about $\$ 360,000$ per year for the first step, and $\$ 245,000$ per year for the second step. This amounts to about 20 per cent of the in-plant costs (excluding materials). A full evaluation of these savings would require consideration of costs of assembly and distribution as well. However, since plants tend to be closely located within producing districts, a considerable amount of consolidation presumably could be accomplished without materially increasing assembly costs.

While some of the potential savings could be achieved in the short run, most of the cost reduction possibilities involve changes in durable facilities which would be economical only as existing facilities are worn out. With technology changing over time and with many institutional barriers to change suggested here, it is doubtful that more than a part of these savings can actually be attained. However, the material that has been presented should provide useful guides for packing plant operators interested in planning new facilities and for groups of plants contemplating reorganization and consolidation.

\section{Theoretical and Methodological Approach}

The theoretical framework for the empirical study consists mainly of elaborations and modifications of the conventional theory of the firm. These modifications stress five important points: First, total plant output for any demand or sale period is commonly varied by holding rates of output constant and changing the number of hours operated as well as by varying rates of output. Instantaneous rates of production do not correspond directly to rates of consumption. Variation in output through changing hours of plant operation results in linear input-output functions. Failure to distinguish clearly between rate and time variation has been a source of a good deal of controversy concerning the nature of plant cost curves and the applicability of the "law of diminishing returns." Second, in the rate dimension, output is often varied through multiplication of identical units of equip-

\footnotetext{
${ }^{95}$ Adjustment of the costs given in this report to the 1954 price level has been made in a publication by B. C. French, L. L. Sammet, and R. G. Bressler, Efficiency in Fruit Marketing, Economies of Scale in Pear Packing, Giannini Foundation of Agricultural Economies, Mimeographed Report No. 181, 1955.
} 
ment-plant "segmentation." This also leads to linear, although discontinuous, functions. Third, plants are usually composed of an integration and aggregation of many stages or operations with a resulting compounding of the usual theory and with problems of "harmonious" combinations of stages. Fourth, most cost functions are discontinuous, rather than continuous as assumed by conventional theory. This condition arises in part from combining the operations for various stages and in part from the discrete nature of many inputs. For any given plant, machines are commonly available only in selected sizes while men are hired and used in whole units. Discontinuities in the cost functions lead to contradictions of the profit-maximizing conditions (marginal cost equals marginal revenue) of the conventional theory. Fifth, some inputs consist of durable goods that are only partially consumed in any short period. This leads to difficulties in determining the nature of real inputs and of costs for durable factors.

Data for the study have been obtained through use of a set of research tools that appear appropriate for approximating empirically the kinds of relations postulated by the theory of the firm as reformulated here. Stress has been heavy on engineering studies as a means of obtaining detailed basic data. In many cases the detail required to conform to the theoretical framework can be obtained only through engineering studies. Data on some other aspects of the plant operation are obtainable mainly from plant records or from manufacturers of equipment. The three sources of data have been blended together to estimate the detailed input and cost relations for the various segments of the plant operation. Once the basic measurements are obtained, the process of selecting efficient technologies and integrating or synthesizing the separate cost functions into an over-all equation is conceptually simple.

It should be emphasized that although the input-ouput functions derived in this study have been predominantly linear, the economic-engineering approach used does not by its nature necessarily produce functions in this form. The forms of the empirical functions presented were determined by the basic characteristics of the packing plant process, and not by the research method. Of course, the method can be misused. But if carefully applied with a sound theoretical framework and understanding of the details of the plant processes, the economic-engineering approach can be used to measure almost any form of input-output relation. In fact, in many cases it may be the only method that can measure or disclose such relationships.

The theory that has been suggested as a framework for studies of cost and efficiency, if valid at all, is valid regardless of the procedures used to obtain the empirical estimates of cost relationships. The approach to the study of cost and efficiency that is used here is certainly not the only or necessarily the best approach to this problem. The methodology used must be evaluated in terms of the specific objectives of the research and the particular nature of the productive activity to be studied.

If one of the objectives of the cost study is to compare the costs of alternative methods of performing a specific operation or to devise improved methods of operation, the detailed engineering-accounting record approach may be the best and perhaps the only way to obtain the necessary cost data. The 
detailed cost estimates may then be integrated or synthesized into estimates of total costs which can be used to achieve broader objectives, such as determining the economies of scale and possible advantages of industry reorganization.

Another advantage of this approach is that, as the cost estimates are built up from elemental physical input-output data, they may be adjusted for varying conditions in individual plants and for variations in prices of inputs. As a practical matter, however, only a few variations have been considered for they involve rather laborious, although simple, calculations.

A disadvantage of this approach is that it is costly in terms of man-hours of research labor. If the objectives of a study of cost are fairly broad-i.e., to compare total costs or to determine only the general economies of scale-a less costly approach might be used which would give somewhat less refined results but nevertheless adequate approximations. For example, a combination of total cost data and rather broad engineering observation should result in satisfactory approximations to the economies of scale curve.

An important factor tending to offset the cost disadvantage of the detailed studies is the accumulation over a period of time of estimates of standard labor requirements for performing many different operations and, to a lesser extent, standard requirements for certain types of buildings and for some nonlabor variable costs. As different types of plants are studied, it will be found that some of the operations are quite similar to those in plants studied previously. The standards already developed may then be used to estimate costs for these operations, thus eliminating the need for some additional measurements. ${ }^{\circ}$ Moreover, the measurement procedures developed have been and are being continually improved so that a given amount of data may be obtained with continually improving research efficiency.

It may be noted, finally, that although a considerable amount of empirical data has been presented, primary emphasis has been on the further development of basic theory and methodological procedures which may serve as a point of departure for further studies in this area. As in all empirical studies, the procedures outlined give only approximations to the actual cost relations, but if carefully carried out and with proper theoretical-empirical models, the approximations may be fairly close and thus provide a useful tool for managerial decision.

\section{ACKNOWLEDGMENTS}

Many individuals participated in and contributed to the project. Barton DeLoach of the Agricultural Marketing Service, United States Department of Agriculture, was instrumental in the inauguration of the work, supported it throughout its duration, and contributed in many ways to its progress. J. B. Hassler of the Giannini Foundation assisted on mathematical and statistical formulations, and D. G. Malcolm and B. G. McCauley of the College of Engineering aided in the development of appropriate research

${ }^{9}$ For example, a considerable amount of the basic material for the present study was also used in a study of olive processing plants by G. R. Sitton and L. L. Sammet, Economic Factors in Picking, Assembling and Grading Sevillano Olives, Giannini Foundation of Agricultural Economics, Mimeographed Report No. 155, June 1953. 
techniques and assisted in field studies. I. F. Davis and Eric Thor participated in field work as graduate research assistants of the Giannini Foundation. Mrs. Betty Wentworth and other members of the Statistical Pool of the Giannini Foundation carried much of the work of the computations, while Mrs. Viola Jank and her coworkers in the Secretarial Pool were responsible for the preparation of the several versions of the manuscript. The excellent charts are the work of Mrs. Katherine Eardley. To these and other colleagues, the authors are indebted and acknowledge their many contributions with real gratitude.

Detailed studies of plant costs and efficiency are impossible without important coöperation from the industry, and the authors believe that such cooperation has been excellent. While it is difficult to single out particular individuals in this connection, the authors wish to express their particular thanks to the following men and organizations: Harold Angier, California Grape and Tree Fruit League; D. O. Nathan, Pacific Fruit Exchange ; Grove Dye, California Fruit Exchange; R. K. Sanderson, Lake County Fruit Exchange; Wendell Henderson, Kelseyville Packing Company ; D. J. Elliot, Stillwater Orchards Company ; J. P. Sotter, Ukiah Fruit Growers Exchange; Dean Morrison and E. L. Fraser, Lake Cove Growers; Alex R. Thomas of Alex R. Thomas and Company, Ukiah; and the late V. J. DeCampos, Newcastle Fruit Growers Asosciation.

This report is based on research carried on coöperatively by the Giannini Foundation of Agricultural Economics, California Agricultural Experiment Station, and the Agricultural Marketing Service (formerly the Bureau of Agricultural Economics), United States Department of Agriculture. The studies were made under the authority of the Research and Marketing Act of 1946 .

ABRUZzi, AdaM

\section{BIBLIOGRAPHY}

1952. Developing standard data for predictive purposes. Proceedings, Fourth Annual Industrial Engineering Institute. Berkeley and Los Angeles, University of California, pp. 24-28.

BARNES, RALPH M.

1949. Motion and time study. John Wiley and Sons, New York.

Boulding, K. E.

1948. Economic analysis. Harper and Bros., New York.

BREMS, HANS

1952. A discontinuous cost function. Amer. Econ. Rev. 42:577-86.

BressleR, R. G.

1945. Research determination of economies of scale. Jour. Farm Econ. 27:526-39.

1950. Efficiency in the production of marketing services. Social Science Research Council Project in Agricultural Economies, Economic Efficiency Series Paper No. 6, University of Chicago, Chicago.

1952a. City milk distribution. Harvard Univ. Press. Cambridge.

1952b. Efficiency in fruit marketing: Marketing costs for deciduous fruits. Berkeley, Giannini Found. Agr. Econ., Mimeo. Rpt. No. 127.

Bressler, R. G., and B. C. FrenCH

1952. Efficiency in fruit marketing: Grading costs for apples and pears. Berkeley, Giannini Found. Agr. Econ., Mimeo. Rpt. No. 128.

Bressler, R. G., and D. O. HAMmerberg

1942. Efficiency of milk marketing in Connecticut: 3. Economics of the assembly of milk. [Storrs, Conn.7 Agr. Exp. Sta. Bul. 239. 
California Crop and Livestock Reporting Service

1932-1952. California fruit and nut crop annual summary. Annual issues. Sacramento. California Department of Agriculture

1952. 1952 grade regulations for canning Bartlett pears produced in California. Sacramento.

California Laws, Statutes, et cetera.

1951. Agricultural code, 1951. Sacramento, California State Print. Off.

California Tree Fruit Agreement

1946-52. Annual report. Sacramento, 1946-1952.

1939-52. Bartlett pear bulletin. Sacramento. Periodic Reports, June, 1939-June, 1952.

1946-52. Bartlett pear packout. Sacramento. Daily reports, 1946-1952.

CARLSON, SUne

1939. A study on the pure theory of production. P. S. King and Son, Ltd., London.

Chamberlin, E. H.

1947. Theory of monopolistic competition. Harvard Univ. Press, Cambridge.

Chenery, H. B.

1953. Process and production functions from engineering data. In Studies in the structure of the American economy, by W. Leonteif et al. Oxford Univ. Press, New York. Chapter 8.

Clark, J. M.

1923. The economies of overhead costs. University of Chicago Press, Chicago.

1940. Toward a concept of workable competition. Amer. Econ. Rev. 30:241-56.

Clarke, D. A.

1952. Pricing milk in relation to delivery volume. A statement prepared for presentation at the public hearing conducted by the Bureau of Milk Control, California Dept. Agr., Los Angeles, Oct. 16.

CONFERENCE ON PRICE RESEARCH

1943. Cost behavior and price policy. Nat'l Bur. Econ. Res., New York.

COOPER, Martin R.

1953. That extra machine may pay in the long-run. In The Agricultural Situation.

DeAN, JoEt U. S. Dept. Agr., Bur. Agr. Econ., Washington, D.C., April.

1941a. The relation of cost to output for a leather belt shop. Nat'l Bur. Econ. Res., New York.

1941b. Statistical cost functions of a hosiery mill. University of Chicago Press, Chicago. DORFMAN, ROBERT

1951. Applications of linear programming to the theory of the firm. Berkeley and Los Angeles, Univeristy of California Press.

EITEMan, W. J.

1949. Price determination: Business practice versus economic theory. University of Michigan, School of Business Administration, Ann Arbor.

Ezekiel, M., and K. H. WruIE

1941. Cost functions for the steel industry. Jour. Amer. Stat. Assoc. 36:91-99.

Ferguson, A. R.

1950. Empirical determination of a multidimensional marginal cost function. Econometrica $18: 217-35$.

French, B. C.

1952. Packing costs for California apples and pears. Berkeley, Giannini Found. Agr. Econ., Mimeo. Rpt. No. 138.

1953. Efficiency in fruit marketing: Costs of lidding packed fruit boxes influenced by type of equipment, size of plant, length of season. California Agriculture 7(1): 10-12, January.

French, B. C., and R. G. BREsSler

1953. Economy and accuracy in accounting to growers for fruit received at the packing house. Berkeley, Giannini Found. Agr. Econ., Mimeo. Rpt. No. 149.

French, B. C., and L. L. SAMmeT

1954. Efficiency in fruit marketing: Wage plans and efficiency in grape packing. Berkeley, Giannini Found. Agr. Econ., Mimeo. Rpt. No. 173. 
GORDON, R. A.

1948. Short period price determination. Amer. Econ. Rev. 38:265-88.

Grosse, ANNE P.

1953. The technological structure of the cotton textile industry. In Studies in the structure of the American economy, by W. Leonteif et al. Oxford University Press, New York. Chapter 10.

HALL, R. L., and C. J. HITCH

1939. Price theory and business behavior. Oxford Econ. Papers, May, pp. 12-45.

HART, A. G.

1942. Risk, uncertainty, and the unprofitability of compounding probabilities. In Studies in mathematical economies and econometries. University of Chicago Press, Chicago.

Henderson, JoHN S.

1953. Marginal productivity analysis-a defect and a remedy. Econometrica $21: 155-68$.

Hicks, J. R.

1946. Value and capital. Oxford Univ. Press, New York, 1939. (2d ed., 1946.)

JANTZEN, IVAR

1924. Voxende Udbytte i Industeien. Nationalökonomisk Tidsskrift Vol. 62.

JUDGE, G. G., and R. L. BAKER

1952. Time and cost functions for egg routes. Poultry Sci., Vol. 31, July.

KeYNes, J. M.

1935. The general theory of employment, interest, and money. Harcourt, Brace and Company, New York. (Appendix on User Costs.)

LESTER, R. A.

1946. Shorteomings of marginal analysis for wage-employment problems. Amer. Econ. Rev. $36: 63-82$.

Lutz, Fredrich and Vera

1951. The theory of investment of the firm. Princeton Univ. Press, Princeton.

Malcolm, D. G., and L. L. SAMmeT

1954. Work sampling applications. Jour. Ind. Engin., Vol. 3, May.

MCCAUley, BRUCE G.

1954. Box making methods and costs. California Agriculture 8 (2): 2, February.

MORROW, R. L.

1946. Time study and motion economy. Ronald Press, New York.

Paulson, W. E.

1942. Cost and profit of ginning cotton in Texas. Texas Agr. Exp. Sta. Bul. 606. College Station.

Pulver, H. E.

1947. Construction estimates and costs. McGraw Hill Book Company, Inc., New York. RUGGLES, RICHARD

1941. The concept of linear total cost-output regressions. Amer. Econ. Rev. 31:332-35.

SAMMET, L. L.

1953a. In-plant transportation costs as related to materials handling methods-apple and pear packing. Berkeley, Giannini Found. Agr. Econ., Mimeo. Rpt. No. 142.

$1953 \mathrm{~b}$. Costs of dumping incoming fruit as related to work methods-apple pear packing. Berkeley, Giannini Found. Agr. Econ., Mimeo. Rpt. No. 153.

1955. Packing box distribution costs. California Agriculture 9(4), April.

SAMMET, L. L. and I. F. DAvis

1952. Building and equipment costs, apple and pear packing. Berkeley, Giannini Found. Agr. Econ., Mimeo. Rpt. No. 141.

SAMMET, L. L. and J. B. HASSLER

1951. Use of the ratio-delay method in processing plant operations. Agr. Econ. Res. $3: 124-34$

SAMMET, L. L., and D. G. MALCOLM

1954. Work sampling studies: Guides to analysis and accuracy eriteria. Jour. Ind. Engin., Vol. 4, July.

SAMUelson, P. A.

1947. Foundations of economic analysis. Harvard Univ. Press, Cambridge. 
Santa Clara Country, California, Agricultural Commissioner 1950-52. Crop report. Santa Clara, Annual Issues, 1950-1952.

SCHNEIDER, ERICH 1951. Pricing and equilibrium. The Macmillan Company, New York.

SiTTON, G. R., and L. L. SAMMET

1953. Economic factors in picking, assembling and grading Sevillano olives. Berkeley, Giannini Found. Agr. Econ., Mimeo. Rpt. No. 155.

SмIтH, C. A.

1942. The cost-output relation for the U. S. Steel Corporation. Rev. Econ. Stat. 24: $166-76$.

Staehle, Hans

1942. The measurement of statistical cost functions: An appraisal of some recent contributions. Amer. Econ. Rev. 32:321-34.

STIGLER, GEORGE

1939. Production and distribution in the short-run. Jour. Pol. Econ. 47:305-27.

WYLIE, K. H., and M. EzEKIEL

1940. The cost curve for steel production. Jour. Pol. Econ. 48:777-821.

YNTEMA, T. O.

1940. Analysis of steel prices, volume and costs. Pamphlet No. 6 in United States Steel Corporation T.N.E.C. Papers published by United States Steel Corporation, Vol. $1: 223-302$.

\section{APPENDIX A}

The following tables and diagram summarize the total season costs in relation to rates of output for each of the technologies used in the several stages for which alternative technologies are available. Costs are shown for four lengths of season-100, 200, 300, and 400 hours. Season costs for the dumping-grading operation are given only for a situation where 80 per cent of the fruit is first grade. Relative costs among the various technologies are about the same for other proportions. (See Appendix figure 1.)

Similarly, costs of transporting incoming, cannery, and cull fruit are shown only for one proportion and for a situation where the dumper has conveyor aids. Relative costs among the transportation technologies are about the same with other proportions and in cases where the dumper has no conveyor aids. 


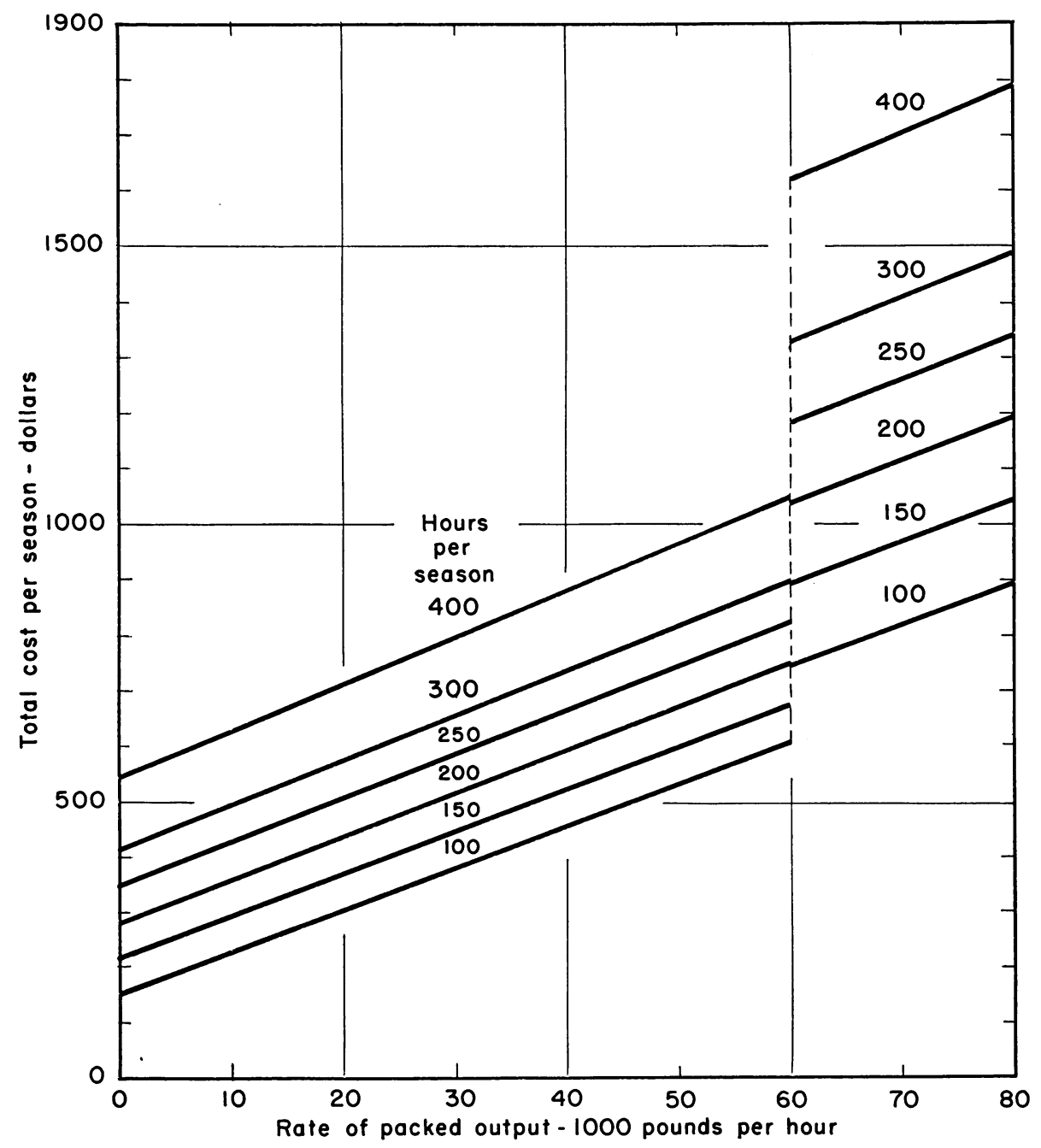

Appendix fig. 1. Total season costs of transporting packed fruit to cars by conveyor in relation to capacity rates of packed output. 


\section{APPENDix TABle 1}

TOTAL SEASON COSTS FOR SIX METHODS OF DUMPING AND GRADING PEARS (ASSUMES THAT 80 PER CENT OF THE FRUIT IS FIRST

GRADE; 1950 WAGES AND PRICES)

\begin{tabular}{|c|c|c|c|c|c|c|c|c|}
\hline \multirow{3}{*}{$\begin{array}{c}\text { Rate of } \\
\text { total output }\end{array}$} & \multicolumn{8}{|c|}{ Total cost per season-dollars } \\
\hline & \multicolumn{8}{|c|}{ Method } \\
\hline & $1 \mathrm{~A}-2 \mathrm{~A}$ & $1 \mathrm{~A}-2 \mathrm{C}$ & $\begin{array}{l}1 \mathrm{E}-2 \mathrm{D} \\
\text { Hand } \\
\text { truck }\end{array}$ & $\begin{array}{c}\text { 1E-2D } \\
\text { Fork } \\
\text { truck }\end{array}$ & $\begin{array}{l}1 \mathrm{E}-2 \mathrm{C} \\
\text { Hand } \\
\text { truck }\end{array}$ & $\begin{array}{c}\text { 1E-2C } \\
\text { Fork } \\
\text { truck }\end{array}$ & 1D-2D & 1A-2B \\
\hline 1,000 pounds & \multicolumn{8}{|c|}{100 hours per season } \\
\hline $10 \ldots \ldots \ldots$ & 1,150 & 1,291 & 1,917 & 2,051 & 1,757 & 1,891 & 1,898 & 1,174 \\
\hline $15 \ldots$ & 2,089 & 1,296 & 2,022 & 2,156 & 1,862 & 1,996 & 2,003 & 1,279 \\
\hline 20. & 2,194 & 1,707 & 2,127 & 2,261 & 1,967 & 2,101 & 2,108 & 1,700 \\
\hline $25 .$. & 2,299 & 1,817 & 2,232 & 2,366 & 2,075 & 2,209 & 2,349 & 2,457 \\
\hline $30 \ldots$ & $\ldots \ldots$ & 2,580 & 2,552 & 2,686 & 2,287 & 3,737 & 2,670 & 2,562 \\
\hline $35 \ldots \ldots \ldots \ldots$ & $\ldots \ldots$ & 3,002 & 2,762 & 3,021 & 3,700 & 3,967 & 2,880 & $\ldots \ldots$ \\
\hline $40 \ldots \ldots \ldots \ldots \ldots$ & $\ldots \ldots$ & 3,212 & 2,867 & 3,126 & 3,910 & 4,177 & 2,985 & $\ldots \ldots$ \\
\hline $45 \ldots \ldots \ldots \ldots \ldots$ & $\ldots \ldots$ & 3,317 & 4,335 & 4,602 & 4,015 & 4,282 & 4,436 & $\ldots \ldots$ \\
\hline $50 \ldots \ldots \ldots \ldots \ldots$ & $\ldots \ldots$ & 3,628 & 4,440 & 4,818 & 4,120 & 4,498 & 4,541 & $\ldots \ldots$ \\
\hline $55 \ldots \ldots \ldots \ldots$ & $\ldots \ldots$ & 3,838 & 4,760 & 5,028 & 4,440 & 4,708 & 4,861 & $\cdots$ \\
\hline $60 \ldots$ & $\cdots$ & 4,915 & 4,865 & 5,133 & 5,852 & 6,128 & $\begin{array}{l}4,001 \\
4,966\end{array}$ & $\cdots$ \\
\hline $65 \ldots$ & $\ldots \ldots$ & 5,026 & 5,075 & 5,343 & 5,957 & 6,233 & 5,311 & $\ldots \ldots$ \\
\hline $70 \ldots$ & $\ldots$ & 5,131 & 5,180 & 5,573 & 6,062 & 6,435 & 5,416 & $\cdots$ \\
\hline 75. & $\ldots \ldots$ & 5,236 & 5,390 & 5,893 & 6,167 & 6,679 & 5,626 & $\ldots \ldots$ \\
\hline $80 .$. & $\ldots \ldots$ & 5,652 & 5,605 & 5,998 & 6,488 & 6,889 & 5,841 & $\ldots \ldots$ \\
\hline $90 \ldots$ & .. & 6,830 & 7,283 & 7,684 & 8,003 & 8,438 & 7,501 & $\ldots$ \\
\hline \multirow[t]{2}{*}{$100 \ldots \ldots \ldots \ldots \ldots \ldots$} & $\ldots \ldots$ & 7,040 & 7,598 & 7,999 & 8,213 & 8,648 & 7,816 & $\ldots \ldots$ \\
\hline & \multicolumn{8}{|c|}{200 hours per season } \\
\hline $10 \ldots \ldots \ldots \ldots \ldots$ & 2,134 & 2,287 & 2,913 & 3,172 & 2,746 & 3,005 & 3,022 & 2,160 \\
\hline $15 \ldots \ldots \ldots \ldots \ldots$ & 3,847 & 2,377 & 3,123 & 3,382 & 2,956 & 3,215 & 3,232 & 2,370 \\
\hline $20 \ldots \ldots \ldots \ldots \ldots \ldots$ & 4,057 & 3,052 & 3,333 & 3,592 & 3,166 & 3,425 & 3,442 & 3,045 \\
\hline $25 \ldots \ldots \ldots \ldots \ldots \ldots$ & 4,267 & 3,272 & 3,543 & 3,802 & 3,382 & 3,641 & 3,924 & 3,439 \\
\hline $30 \ldots \ldots \ldots \ldots$ & $\ldots \ldots$ & 4,671 & 4,183 & 4,442 & 5,677 & 5,943 & 4,566 & 4,649 \\
\hline $35 \ldots \ldots \ldots \ldots \ldots$ & $\cdots$ & 5,347 & 4,603 & 5,112 & 5,887 & 6,403 & 4,986 & $\ldots \ldots$ \\
\hline 40. & $\ldots \ldots$ & 5,767 & 4,813 & 5,322 & 6,307 & 6,823 & 5,196 & $\cdots \cdots$ \\
\hline $45 \ldots$ & $\ldots \ldots$ & 5,977 & 6,851 & 7,367 & 6,517 & 7,033 & 7,347 & $\ldots \ldots$ \\
\hline $50 \ldots$ & $\cdots$ & 6,532 & 7,061 & 7,799 & 6,727 & 7,465 & 7,557 & $\cdots$ \\
\hline $55 \ldots \ldots \ldots \ldots$ & $\ldots$. & 6,952 & 7,701 & 8,219 & 7,367 & 7,885 & 8,197 & $\ldots \ldots$ \\
\hline $60 \ldots \ldots \ldots$ & & 8,811 & 7,911 & 8,429 & 9,446 & 9,972 & 8,407 & $\ldots \ldots$ \\
\hline $65 \ldots \ldots \ldots$ & $\ldots$ & 9,033 & 8,331 & 8,849 & 9,656 & 10,182 & 9,097 & $\cdots$ \\
\hline $70 \ldots \ldots$ & & 9,243 & 8,541 & 9,309 & 9,866 & 10,586 & 9,307 & $\ldots$ \\
\hline $75 \ldots \ldots \ldots$ & & 9,453 & 8,961 & 9,949 & 10,076 & 11,074 & 9,727 & $\ldots \ldots$ \\
\hline $80 \ldots \ldots \ldots$ & & 10,218 & 9,391 & 10,159 & 10,718 & 11,494 & 10,157 & $\ldots \ldots$ \\
\hline $90 \ldots \ldots \ldots$ & & 12,279 & 11,849 & 12,625 & 13,004 & 13,815 & 12,727 & $\ldots \ldots$ \\
\hline $100 \ldots \ldots \ldots \ldots \ldots$ & $\cdots$ & 12,699 & 12,479 & 13,255 & 13,424 & 14,235 & 13,357 & $\cdots$ \\
\hline
\end{tabular}


APPENDIX TABLE 1 (continued)

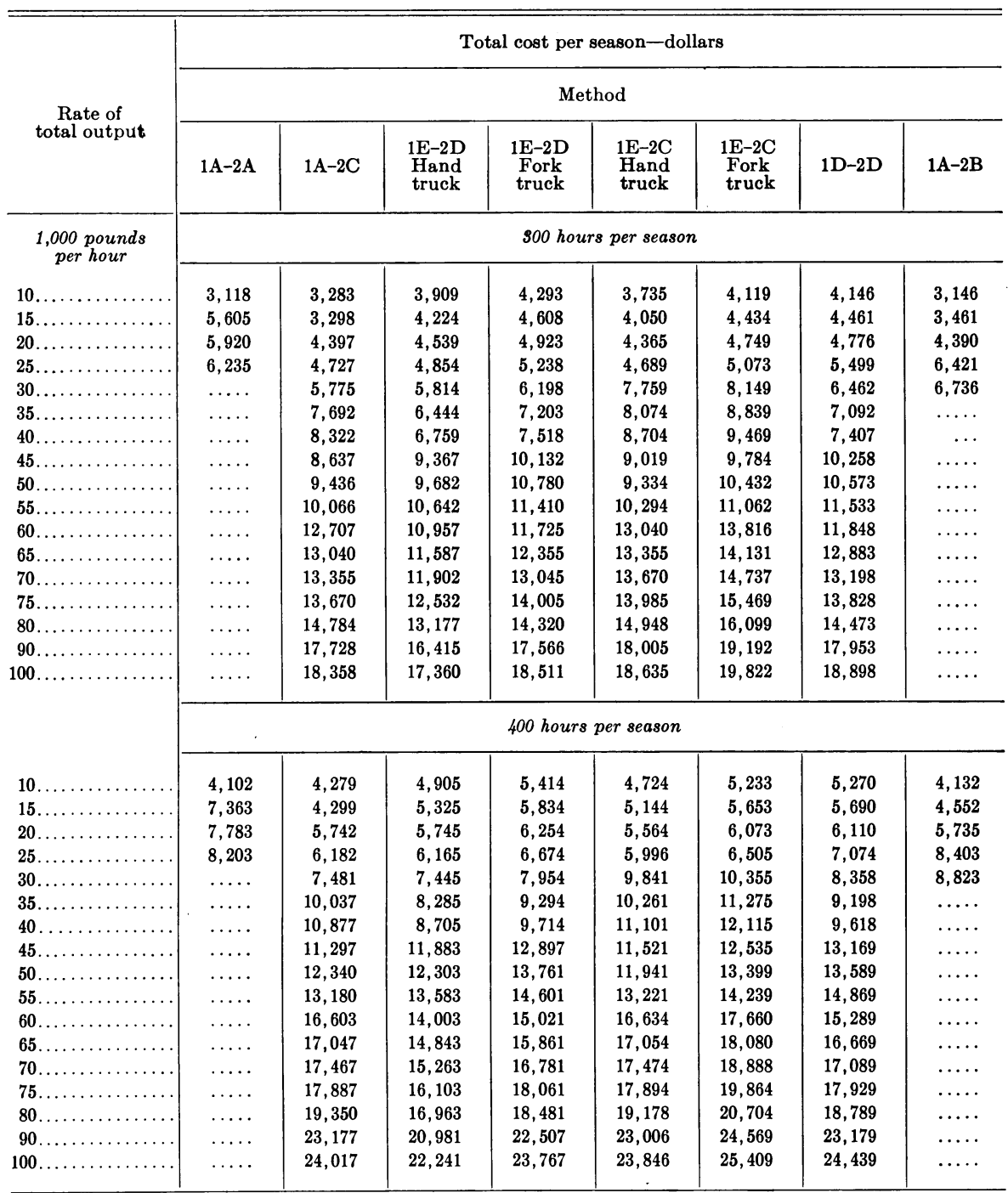




\section{APPENDIX TABLE 2}

TOTAL SEASON COSTS OF TRANSPORTING INCOMING CANNERY AND CULL FRUIT WITH HAND TRUCKS AND FORK TRUCKS (DUMPER HAS CONVEYOR AIDS; 1950 WAGES AND PRICES)

\begin{tabular}{|c|c|c|c|c|c|c|c|c|}
\hline \multirow{3}{*}{$\begin{array}{c}\text { Rate of } \\
\text { total output }\end{array}$} & \multicolumn{8}{|c|}{ Total cost per season-dollars } \\
\hline & \multicolumn{2}{|c|}{100 hours per season } & \multicolumn{2}{|c|}{200 hours per season } & \multicolumn{2}{|c|}{300 hours per season } & \multicolumn{2}{|c|}{400 hours per season } \\
\hline & $\underset{\text { truck }}{\text { Hand }}$ & $\underset{\text { Fork }}{\text { Bruck }}$ & $\underset{\text { truck }}{\text { Hand }}$ & $\underset{\text { Fork }}{\text { Bruck }}$ & $\underset{\text { Hand }}{\mathrm{A}}$ & $\underset{\text { Fork }}{\mathrm{B}}$ & $\underset{\text { Hand }}{\mathrm{A}}$ & $\underset{\text { Fork }}{\text { Bruck }}$ \\
\hline 1,000 pounds & \multicolumn{8}{|c|}{70 per cent packed } \\
\hline $10 \ldots$ & 403 & 783 & 779 & 949 & 1,155 & 1,114 & 1,531 & 1,279 \\
\hline $15 \ldots$ & 537 & 1,567 & 1,038 & 1,897 & 1,540 & 2,228 & 2,041 & 2,558 \\
\hline $20 \ldots$ & 672 & 1,567 & 1,289 & 1,897 & 1,924 & 2,228 & 2,551 & 2,558 \\
\hline $25 \ldots$ & 806 & 1,567 & 1,558 & 1,897 & 2,309 & 2,228 & 3,061 & 2,558 \\
\hline $30 \ldots \ldots \ldots \ldots$ & 940 & 2,350 & 1,817 & 2,846 & 2,694 & 3,342 & 3,571 & 3,838 \\
\hline $35 \ldots \ldots \ldots \ldots$ & 1,209 & 2,350 & 2,336 & 2,846 & 3,464 & 3,342 & 4,592 & 3,838 \\
\hline $40 \ldots \ldots \ldots$ & 1,343 & 3,133 & 2,596 & 3,794 & 3,849 & 4,456 & 5,102 & 5,117 \\
\hline 45. & 1,477 & 3,133 & 2,856 & 3,794 & 4,234 & 4,456 & 5,612 & 5,117 \\
\hline $50 \ldots$ & 1,612 & 3,133 & 3,115 & 3,794 & 4,619 & 4,456 & 6,122 & 5,117 \\
\hline 55. & 1,746 & 3,916 & 3,375 & 4,743 & 5,004 & 5,570 & 6,633 & 6,396 \\
\hline 60. & 1,880 & 3,916 & 3,634 & 4,743 & 5,389 & 5,570 & 7,143 & 6,396 \\
\hline 65. & 2,014 & 3,916 & 3,894 & 4,743 & 5,774 & 5,570 & 7,653 & 6,396 \\
\hline $70 \ldots$ & 2,283 & 4,700 & 4,413 & 5,692 & 6,543 & 6,683 & 8,673 & 7,675 \\
\hline $75 \ldots$ & 2,417 & 4,700 & 4,673 & 5,692 & 6,928 & 6,683 & 9,184 & 7,675 \\
\hline 80. & 2,552 & 5,483 & 4,932 & 6,640 & 7,313 & 7,797 & 9,694 & 8,954 \\
\hline 90. & 2,820 & 5,483 & 5,452 & 6,640 & 8,083 & 7,797 & 10,714 & 8,954 \\
\hline $100 \ldots \ldots$ & 3,089 & 6,266 & 5,971 & 7,589 & 8,853 & 8,911 & 11,735 & 10,234 \\
\hline
\end{tabular}


APPENDix TABLe 3

TOTAL SEASON COSTS OF TRANSPORTING PACKED FRUIT FROM THE LIDDER TO THE CAR WITH HAND TRUCKS AND FORK TRUCKS (1950 WAGES AND PRICES)

\begin{tabular}{|c|c|c|c|c|c|c|c|c|}
\hline \multirow{3}{*}{$\begin{array}{c}\text { Rate of } \\
\text { packed output }\end{array}$} & \multicolumn{8}{|c|}{ Total cost per season-dollars } \\
\hline & \multicolumn{2}{|c|}{100 hours per season } & \multicolumn{2}{|c|}{200 hours per season } & \multicolumn{2}{|c|}{300 hours per season } & \multicolumn{2}{|c|}{400 hours per season } \\
\hline & $\underset{\text { Hand }}{A}$ & $\underset{\text { Fork }}{\mathrm{B}}$ & $\underset{\text { Hand }}{\mathrm{A}}$ & $\underset{\text { Fork }}{\text { B }}$ & 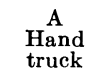 & $\underset{\text { truck }}{\mathrm{B}}$ & $\underset{\text { truck }}{\mathrm{A}}$ & $\underset{\text { Fork }}{\mathrm{B}}$ \\
\hline \multicolumn{9}{|l|}{$\begin{array}{c}1,000 \text { pounds } \\
\text { per hour }\end{array}$} \\
\hline $0-7.0$. & 134 & 783 & 260 & 949 & 385 & 1,114 & 510 & 1,279 \\
\hline $7.1-14.0$ & 160 & 783 & 310 & 949 & 461 & 1,114 & 611 & 1,279 \\
\hline $14.1-15.0$. & 294 & 783 & 569 & 949 & 845 & 1,114 & 1,120 & 1,279 \\
\hline $15.1-20.0 \ldots$ & 294 & 908 & 569 & 1,199 & 845 & 1,489 & 1,120 & 1,779 \\
\hline $20.1-24.0 \ldots$ & 528 & 908 & 1,029 & 1,199 & 1,530 & 1,489 & 2,031 & 1,779 \\
\hline $24.1-30.0 \ldots$ & 653 & 1,033 & 1,279 & 1,449 & 1,905 & 1,864 & 2,531 & 2,279 \\
\hline $30.1-40.0 \ldots$ & 787 & 1,033 & 1,538 & 1,449 & 2,290 & 1,864 & 3,041 & 2,279 \\
\hline $40.1-46.0 \ldots$ & 922 & 1,033 & 1,798 & 1,449 & 2,675 & 1,864 & 3,551 & 2,279 \\
\hline $46.1-48.0 \ldots \ldots$ & 922 & 1,817 & 1,798 & 2,397 & 2,675 & 2,978 & 3,551 & 3,558 \\
\hline $48.1-50.0 \ldots$ & 1,046 & 1,942 & 2,048 & 2,647 & 3,050 & 3,353 & 4,051 & 4,058 \\
\hline $50.1-60.0 \ldots$ & 1,181 & 1,942 & 2,308 & 2,647 & 3,434 & 3,353 & 4,561 & 4,058 \\
\hline $60.1-70.0 \ldots$ & 1,315 & 1,942 & 2,567 & 2,647 & 3,819 & 3,353 & 5,071 & 4,058 \\
\hline $70.1-72.0 \ldots \ldots \ldots$ & 1,449 & 1,942 & 2,827 & 2,647 & 4,204 & 3,353 & 5,582 & 4,058 \\
\hline $72.1-80.0 \ldots \ldots \ldots$ & 1,574 & 2,067 & 3,077 & 2,897 & 4,579 & 3,728 & 6,082 & 4,558 \\
\hline
\end{tabular}




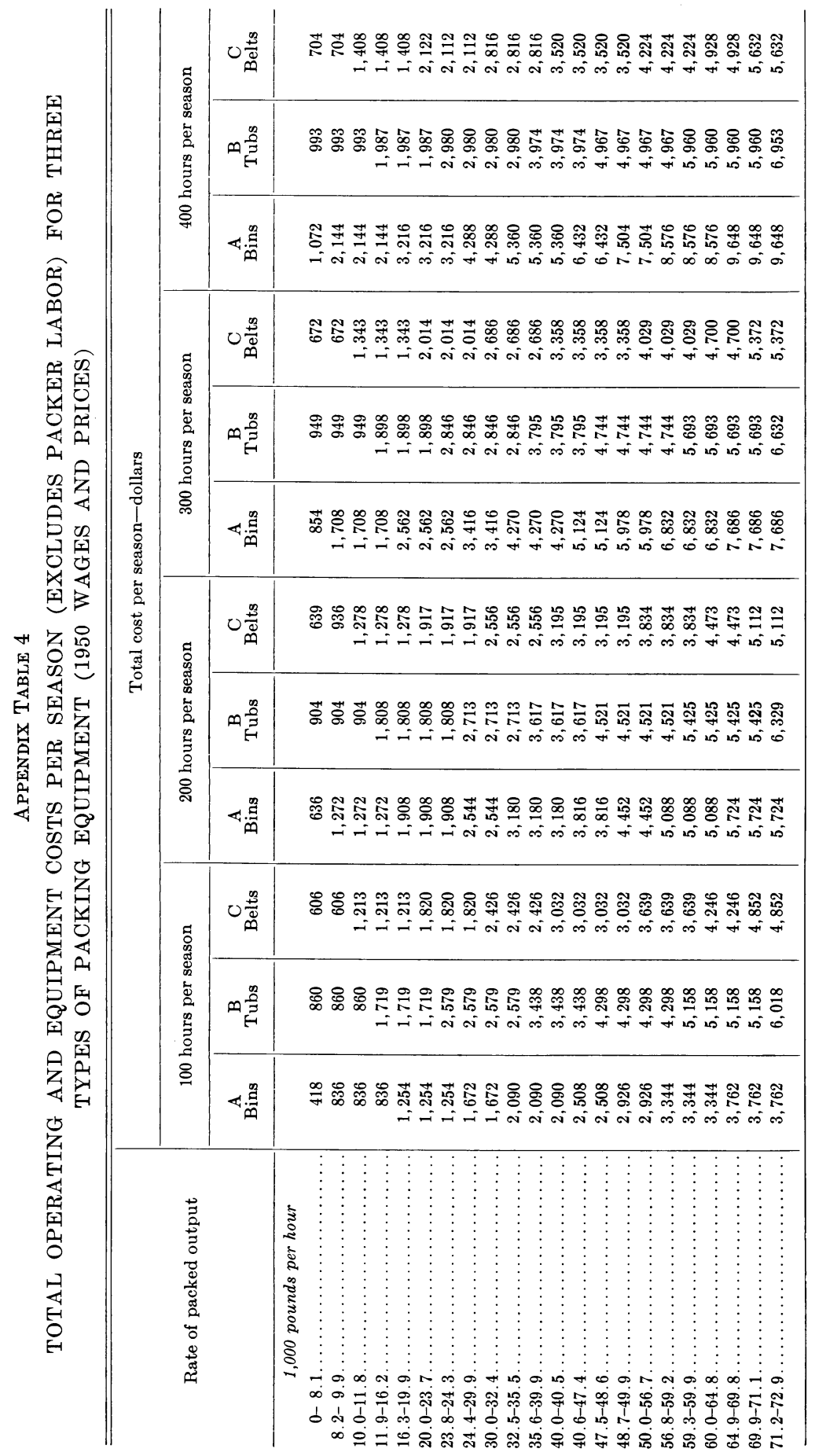


APPENDIX TABLE 5

TOTAL SEASON COSTS FOR 5 METHODS OF SUPPLYING EMPTY BOXES TO PACKERS (1950 WAGES AND PRICES)

\begin{tabular}{|c|c|c|c|c|c|c|c|c|c|c|}
\hline \multirow{3}{*}{$\begin{array}{c}\text { Rate of } \\
\text { total output }\end{array}$} & \multicolumn{10}{|c|}{ Total cost per season-dollars } \\
\hline & \multicolumn{5}{|c|}{100 hours per season } & \multicolumn{5}{|c|}{200 hours per season } \\
\hline & A & B & $\mathrm{C}$ & $\mathrm{D}$ & $\mathrm{E}$ & A & B & $\mathrm{C}$ & $\mathbf{D}$ & $\mathrm{E}$ \\
\hline $\begin{array}{c}1,000 \text { pounds } \\
\text { per hour }\end{array}$ & & & & & & & & & & \\
\hline $0-9.1 \ldots$ & 345 & 396 & 251 & 304 & 157 & 560 & 612 & 462 & 418 & 264 \\
\hline $9.2-10.8$ & 470 & 396 & 251 & 304 & 157 & 790 & 612 & 462 & 418 & 264 \\
\hline $10.9-11.7$. & 470 & 396 & 398 & 304 & 157 & 790 & 612 & 716 & 418 & 264 \\
\hline $11.8-17.0$ & 667 & 396 & 398 & 304 & 314 & 1,094 & 612 & 716 & 418 & 528 \\
\hline $17.1-21.3$. & 667 & 603 & 398 & 544 & 314 & 1,094 & 926 & 716 & 768 & 528 \\
\hline 21.4-23.5. & 667 & 603 & 534 & 544 & 314 & 1,094 & 926 & 958 & 768 & 528 \\
\hline $23.6-30.0$. & 864 & 603 & 534 & 544 & 471 & 1,398 & 926 & 958 & 768 & 792 \\
\hline $30.1-31.6$. & 864 & 749 & 534 & 671 & 471 & 1,398 & 1,178 & 958 & 1,002 & 792 \\
\hline $31.7-35.0 \ldots$ & 864 & 749 & 681 & 671 & 471 & 1,398 & 1,178 & 1,212 & 1,002 & 792 \\
\hline $35.1-35.2$. & 864 & 895 & 681 & 671 & 471 & 1,398 & 1,430 & 1,212 & 1,002 & 792 \\
\hline $35.3-37.9 \ldots$ & 989 & 895 & 681 & 671 & 628 & 1,628 & 1,430 & 1,212 & 1,002 & 1,056 \\
\hline $38.0-39.3 \ldots$ & 1,105 & 895 & 681 & 671 & 628 & 1,850 & 1,430 & 1,212 & 1,002 & 1,056 \\
\hline $39.4-41.7 \ldots$ & 1,281 & 1,163 & 681 & 931 & 628 & 2,132 & 1,806 & 1,212 & 1,372 & 1,056 \\
\hline $41.8-47.0 \ldots$ & 1,281 & 1,163 & 817 & 931 & 628 & 2,132 & 1,806 & 1,454 & 1,372 & 1,056 \\
\hline $47.1-51.6$. & 1,478 & 1,163 & 817 & 931 & 785 & 2,436 & 1,806 & 1,454 & 1,372 & 1,320 \\
\hline $51.7-54.2 \ldots$ & 1,478 & 1,163 & 943 & 931 & 785 & 2,436 & 1,806 & 1,686 & 1,372 & 1,320 \\
\hline 54.3-58.8. . & 1,478 & 1,163 & 1,068 & 931 & 785 & 2,436 & 1,806 & 1,916 & 1,372 & 1,320 \\
\hline $58.9-60.0 \ldots$ & 1,675 & 1,163 & 1,068 & 931 & 942 & 2,740 & 1,806 & 1,916 & 1,372 & 1,584 \\
\hline $60.1-61.9 \ldots$ & 1,675 & 1,340 & 1,068 & 1,192 & 942 & 2,740 & 2,090 & 1,916 & 1,744 & 1,584 \\
\hline $62.0-70.0 \ldots$ & 1,675 & 1,340 & 1,215 & 1,192 & 942 & 2,740 & 2,090 & 2,170 & 1,744 & 1,584 \\
\hline $70.1-70.5$ & 1,675 & 1,516 & 1,215 & 1,192 & 942 & 2,740 & 2,372 & 2,170 & 1,744 & 1,584 \\
\hline $70.6-72.2$. & 1,831 & 1,516 & 1,215 & 1,192 & 1,099 & 3,002 & 2,372 & 2,170 & 1,744 & 1,848 \\
\hline $72.3-75.8 \ldots$ & 1,831 & 1,516 & 1,362 & 1,192 & 1,099 & 3,002 & 2,372 & 2,424 & 1,744 & 1,848 \\
\hline $75.9-78.7 \ldots$ & 1,966 & 1,516 & 1,362 & 1,192 & 1,099 & 3,342 & 2,372 & 2,424 & 1,744 & 1,848 \\
\hline
\end{tabular}


APPENDix TABLE 5 (continued)

\begin{tabular}{|c|c|c|c|c|c|c|c|c|c|c|}
\hline \multirow{3}{*}{$\begin{array}{c}\text { Rate of } \\
\text { total output }\end{array}$} & \multicolumn{10}{|c|}{ Total cost per season-dollars } \\
\hline & \multicolumn{5}{|c|}{300 hours per season } & \multicolumn{5}{|c|}{400 hours per season } \\
\hline & $\mathbf{A}$ & B & $\mathrm{C}$ & $\mathrm{D}$ & $\mathbf{E}$ & $\mathbf{A}$ & B & C & D & $\mathbf{E}$ \\
\hline \multicolumn{11}{|l|}{$\begin{array}{l}1,000 \text { pounds } \\
\text { per hour }\end{array}$} \\
\hline $0-9.1 \ldots$ & 775 & 828 & 673 & 532 & 371 & 990 & 1,044 & 884 & 646 & 478 \\
\hline $9.2-10.8$ & 1,110 & 828 & 673 & 532 & 371 & 1,430 & 1,044 & 884 & 646 & 478 \\
\hline $10.9-11.7$. & 1,110 & 828 & 1,034 & 532 & 371 & 1,430 & 1,044 & 1,352 & 646 & 478 \\
\hline $11.8-17.0 \ldots$ & 1,521 & 828 & 1,034 & 532 & 742 & 1,948 & 1,044 & 1,352 & 646 & 956 \\
\hline $17.1-21.3$. & 1,521 & 1,249 & 1,034 & 992 & 742 & 1,948 & 1,572 & 1,352 & 1,216 & 956 \\
\hline $21.4-23.5$. & 1,521 & 1,249 & 1,382 & 992 & 742 & 1,948 & 1,572 & 1,806 & 1,216 & 956 \\
\hline $23.6-30.0$. & 1,932 & 1,249 & 1,382 & 992 & 1,113 & 2,466 & 1,572 & 1,806 & 1,216 & 1,434 \\
\hline $30.1-31.6 \ldots$ & 1,932 & 1,607 & 1,382 & 1,333 & 1,113 & 2,466 & 2,036 & 1,806 & 1,664 & 1,434 \\
\hline $31.7-35.0 \ldots$ & 1,932 & 1,607 & 1,743 & 1,333 & 1,113 & 2,466 & 2,036 & 2,274 & 1,664 & 1,434 \\
\hline $35.1-35.2$. & 1,932 & 1,965 & 1,743 & 1,333 & 1,113 & 2,466 & 2,500 & 2,274 & 1,664 & 1,434 \\
\hline 35.3-37.9. & 2,267 & 1,965 & 1,743 & 1,333 & 1,484 & 2,906 & 2,500 & 2,274 & 1,664 & 1,912 \\
\hline $38.0-39.3$. & 2,595 & 1,965 & 1,743 & 1,333 & 1,484 & 3,340 & 2,500 & 2,274 & 1,664 & 1,912 \\
\hline $39.4-41.7$. & 2,983 & 2,449 & 1,743 & 1,813 & 1,484 & 3,834 & 3,092 & 2,274 & 2,254 & 1,912 \\
\hline $41.8-47.0$. & 2,983 & 2,449 & 2,091 & 1,813 & 1,484 & 3,834 & 3,092 & 2,728 & 2,254 & 1,912 \\
\hline $47.1-51.6$. & 3,394 & 2,449 & 2,091 & 1,813 & 1,855 & 4,352 & 3,092 & 2,728 & 2,254 & 2,390 \\
\hline $51.7-54.2$. & 3,394 & 2,449 & 2,429 & 1,813 & 1,855 & 4,352 & 3,092 & 3,172 & 2,254 & 2,390 \\
\hline $54.3-58.8$. & 3,394 & 2,449 & 2,764 & 1,813 & 1,855 & 4,352 & 3,092 & 3,612 & 2,254 & 2,390 \\
\hline $58.9-60.0$. & 3,805 & 2,449 & 2,764 & 1,813 & 2,226 & 4,870 & 3,092 & 3,612 & 2,254 & 2,868 \\
\hline $60.1-61.9$. & 3,805 & 2,840 & 2,764 & 2,296 & 2,226 & 4,870 & 3,590 & 3,612 & 2,848 & 2,868 \\
\hline $62.0-70.0$. & 3,805 & 2,840 & 3,125 & 2,296 & 2,226 & 4,870 & 3,590 & 4,080 & 2,848 & 2,868 \\
\hline $70.1-70.5$. & 3,805 & 3,228 & 3,125 & 2,296 & 2,226 & 4,870 & 4,084 & 4,080 & 2,848 & 2,868 \\
\hline $70.6-72.2$. & 4,173 & 3,228 & 3,125 & 2,296 & 2,597 & 5,344 & 4,084 & 4,080 & 2,848 & 3,346 \\
\hline 72.3-75.8. & 4,173 & 3,228 & 3,486 & 2,296 & 2,597 & 5,344 & 4,084 & 4,548 & 2,848 & 3,346 \\
\hline $75.9-78.7$. & 4,518 & 3,228 & 3,486 & 2,296 & 2,597 & 5,794 & 4,084 & 4,548 & 2,848 & 3,346 \\
\hline
\end{tabular}



The journal Hilgardia is published at irregular intervals, in volumes of about 600 pages. The number of issues per volume varies.

Subscriptions are not sold. The periodical is sent as published only to libraries, or to institutions in foreign countries having publications to offer in exchange.

You may obtain a single copy of any issue free, as long as the supply lasts; please request by volume and issue number from:

\section{Agricultural Publications \\ Room 22, Giannini Hall \\ University of California \\ Berkeley 4, California}

The limit to nonresidents of California is 10 separate issues on a single order. $A$ list of the issues still available will be sent on request.

In our publications it is sometimes convenient to use trade names of products or equipment rather than scientific identifications. In so doing it is unavoidable in some cases that similar products which are on the market under other tracie names may not be cited. No endorsement of named products is intended nor is criticism implied of similar products which are not mentioned. 